\title{
North by north-west : climate change and directions of density shifts in birds
}

\section{Lehikoinen, Aleksi}

2016-03

Lehikoinen, A \& Virkkala , R 2016 , ' North by north-west : climate change and directions of density shifts in birds ' , Global Change Biology , vol. 22 , no. 3 , pp. 1121-1129 . https://doi.org/10.1111/gcb.13150

http://hdl.handle.net/10138/308648

https://doi.org/10.1111/gcb.13150

acceptedVersion

Downloaded from Helda, University of Helsinki institutional repository.

This is an electronic reprint of the original article.

This reprint may differ from the original in pagination and typographic detail.

Please cite the original version. 
1 North by northwest: climate change and directions of density shifts in birds

3 Running head: Climate change and direction of density shift

5 Aleksi Lehikoinen ${ }^{1 *} \&$ Raimo Virkkala ${ }^{2}$

6

$7{ }^{1}$ The Helsinki Lab of Ornithology, Finnish Museum of Natural History, University of

8 Helsinki, P. O. Box 17, FI-00014 University of Helsinki, Finland.

$9{ }^{2}$ Finnish Environment Institute, Natural Environment Centre, Mechelininkatu 34 a,

10 P.O. Box 140, FI-00251 Helsinki, Finland.

$11 *$ corresponding author: email-address: aleksi.lehikoinen@helsinki.fi, Tel.

$12+358451375732$.

14 Abstract

16 There is increasing evidence that climate change shifts species distributions towards

17 poles and mountain tops. However, most studies are based on presence-absence data,

18 and either abundance or the observation effort have rarely been measured. In addition,

19 hardly any studies have investigated the direction of shifts and factors affecting them.

20 Here we show using count data on a $1000 \mathrm{~km}$ south-north gradient in Finland, that

21 between 1970-1989 and 2000-2012, 128 bird species shifted their densities, on

22 average, 37 kilometres towards the north northeast. The species-specific directions of

23 the shifts in density were significantly explained by migration behaviour and habitat

24 type. Although the temperatures have also moved on average towards the north

25 northeast (186 kilometres), the species-specific directions of the shifts in density and 
26 temperature did not correlate due to high variation in density shifts. Findings highlight

27 that climate change is unlikely the only driver of the direction of species density

28 shifts, but species-specific characteristics and human land use practices are also

29 influencing the direction. Furthermore, the alarming results show that former climatic

30 conditions in the northwest corner of Finland have already moved out of the country.

31 This highlights the need for an international approach in research and conservation

32 actions to mitigate the impacts of climate change.

33

34 Keywords: distribution changes, ecological traits, global warming, habitat selection,

35 monitoring censuses, species distribution models.

36 
Introduction

40 Understanding the impact of climate change on species populations is a fundamental

41 question to mitigate the effects of changing climate. There is an increasing body of

42 literature showing that species of various taxonomic groups including plants,

43 invertebrates and vertebrates in both northern and southern hemisphere of the globe

44 have shifted their distribution during both summer and winter season likely due to

45 climate change (Parmesan et al., 1999; Parmesan \& Yohe, 2003; Hickling, et al.,

46 2006; Kelly \& Goulden, 2008; Zuckerberg et al., 2009; Booth et al., 2011; Chen et

47 al., 2011; La Sorte \& Jetz, 2012; Breed et al., 2013; Pearce-Higgins \& Green, 2014).

48 Although there is some evidence that species-specific characteristics, such as habitat

49 preferences, affect how species are responding to climate change (Pöyry et al., 2009)

50 it is still largely poorly known what factors drive the variation in species-specific

51 responses.

52 Distribution changes are typically examined at the edges of the distribution

53 using presence-absence data often ignoring the importance of survey effort (Kujala et

54 al., 2013), whereas changes in the central gravity of the populations using abundance

55 data has much less frequently been examined (Maclean et al., 2008; Lehikoinen et al.,

56 2013; Virkkala \& Lehikoinen, 2014). Furthermore, majority of the studies have only

57 investigated shifts directly towards the poles despite the fact that isotherms are rarely

58 placed linearly along latitudes in nature (Huntley et al., 2007, see also Fig. 1).

59 Therefore, predicted distribution changes of species have also been suggested to occur

60 nonlinearly towards the poles (Huntley et al., 2007; Burrows et al., 2013).

61 Interestingly, the direction of the distribution changes has often been neglected

62 (Gillings et al., 2015). This could underestimate the distance in species distribution 
63 changes (Gillings et al., 2015) as most of the earlier studies have often looked at only

64 on one dimension of the shift (e.g. Thomas \& Lennon, 1999; Thomas, 2010).

Hockey et al. (2011) studied the direction of the species distribution changes in

66 South Africa using only cardinal directions. On the other hand, Gillings et al. (2015)

67 investigated the actual direction of the shift using presence-absence data from UK. In

68 view of conservation, it is more important to investigate the changes in species

69 abundance than occurrence only, as presence-absence data can mask changes in

70 species abundance (Virkkala \& Lehikoinen, 2014). To our knowledge, the directions

71 of the species' density shifts using long-term abundance data over decades have not

72 been investigated before. However, Tayleur et al. (2015) investigated directions of

73 density shifts of Swedish birds in $21^{\text {st }}$ century and found that shifts were poorly

74 connected with climatic variables. Furthermore, the impact of potential other

75 ecological factors than climate on the species-specific variation in the direction of the

76 density shifts have not been examined.

77 Here we investigate, based on 128 Finnish birds species, the general direction in

78 shifts of species' central gravity of abundance (hereafter density shift), and whether it

79 is linked with the direction of the temperature change. Our hypothesis is that

80 directions of the species-specific temperature and density changes would correlate to

81 support the impact of climate change as the key driver of distribution changes.

82 Furthermore, we investigate whether the direction of the shift differs between

83 functional ecological species groups. We compare density shifts in $14750-\mathrm{km}$ grid

84 cells between two periods: $1970-1989$ and 2000-2012.

85 We used three different categorizations of species: (i) distribution type, (ii)

86 habitat type and (iii) migration strategy. We used these groups, because (i) northern

87 species have shifted their densities toward the north at a faster rate than southern 
88 species (Virkkala \& Lehikoinen, 2014). We therefore predict that northern species

89 would show density shifts towards more northerly directions than southern ones, and

90 the more diverse distribution of directions among southern species would thus explain

91 the slower speed of density shifts. (ii) Potential habitats for farmland, urban and

92 montane species are highly restricted, and the first two ones are highly influenced by

93 human activities, as e.g. farmland practices have strongly affected farmland bird

94 population trends in Europe including Finland in recent decades (Donald et al., 2001;

95 Laaksonen \& Lehikoinen, 2013). Our hypothesis is that forest species would show

96 density shifts to more northerly directions than farmland and urban species. Arable

97 land in Central Finland is concentrated especially on western part of the country

98 (Ostrobothnia area), which could cause a more western direction of density shifts in

99 farmland species compared to other species groups. (iii) In residents and partial

100 migrants a substantial proportion of the individuals remain in the breeding areas and

101 can thus better track directly changes in their breeding environment compared to

102 migratory birds, which are also affected by changes on their migratory route and

103 wintering grounds. European long-distance migrants especially have declined

104 substantially in recent decades (Sanderson et al., 2006; Laaksonen \& Lehikoinen,

105 2013). In addition to migration distance, the migration direction may affect the

106 direction of the density shift. Finnish birds have several migration directions from

107 West Africa to East Asia, and since species are migrating from different directions,

108 this can affect their direction of the density shift. We predict that southwest, south and

109 southeast migrants would show density shifts towards northeast, north and northwest,

110 respectively. 
113 Materials and methods

115 Census data and calculation of relative densities

117 Line transects have been conducted in Finland regularly since the 1970's (Virkkala \&

118 Lehikoinen, 2014). The line transects are one-visit censuses in which birds are

119 counted along a transect with a length typically $3-6 \mathrm{~km}$, and the locations of the

120 transects have been placed on a map in advance (Lehikoinen et al, 2014; Virkkala \&

121 Lehikoinen, 2014). The methodology is suitable for counting birds over large areas,

122 and the line transect census can be used to investigate relative densities of species

123 (Järvinen \& Väisänen, 1975, 1981). The census period is June and the counts are

124 carried out earlier in southern Finland (between June 1-20) compared to northern

125 Finland (between June 10-30) due to later breeding phenology in northern latitudes.

126 Transects were censused during early morning, when the singing activity of birds is

127 highest in dry weather conditions. The observer walks alone at a speed of 45-60

$128 \mathrm{~min} / \mathrm{km}$ depending on the density of birds along the route using a map, compass or

129 GPS. Each observation is classified as one of the five following categories: (i) singing

130 or displaying, (ii) other calls, (iii) sightings (male, female, pair, brood or nest), (iv)

131 flying bird and (v) flying flock. Flocks are transformed into pairs, normally by

132 dividing by two (male and female) plus the mean species-specific brood size in case

133 of brood flocks. The census unit is a pair of birds, not an individual; thus a male and a

134 female seen separately or together, or a parent with offspring, is transformed into one

135 pair (see Järvinen et al., 1991). The line transect is divided into a main belt and a

136 supplementary belt. The main belt is $50 \mathrm{~m}$ wide $(25 \mathrm{~m}$ on both sides of the transect

137 line) and the supplementary belt is beyond the main belt as far as birds can be 
138 detected. Every observation is placed either on the main belt or on the supplementary

139 belt. Birds crossing the main belt belong to the supplementary belt even if first

140 observed above the main belt. Together, the main belt and the supplementary belt

141 form the survey belt. An earlier study showed that species-specific annual proportions

142 of displaying birds and birds in the main belt were stable during 1987-2010, which

143 indicates that there are no major changes in species detectability (Lehikoinen, 2013).

144 We divided Finland into 50-km grids and calculated how many kilometres of

145 line transects have been conducted in each grid during the two different periods,

$146 \quad 1970-1989$ and 2000-2012 (on average 25 years apart). We omitted the 1990s, since

147 this period has slightly poorer coverage than other decades in some parts of the

148 country. Nevertheless, the decadal data has shown that abundances of the 94 most

149 common species shifted progressively toward higher latitudes (Virkkala \&

150 Lehikoinen, 2014). Altogether 147 grid cells, covering most parts of the country,

151 included at least 10 kilometres of line transects during both the periods (see Fig. 1a).

152 During our study periods of 1970-1989 and 2000-2012, altogether 303,647 and

153490,474 pairs of birds were observed, respectively. 128 species having at least 20

154 observations during both periods were included in the analyses (Supplementary

155 Table 1).

156 We calculated species-specific densities for each grid, based on the number of

157 pair observations and the length of the line transects in each block and species-

158 specific correction coefficients (Järvinen \& Väisänen, 1983). The relative density of a

159 species (D, pairs $/ \mathrm{km}^{2}$, hereafter density) based on the Finnish line transect census was

160 calculated as:

$161 \quad \mathrm{D}=\mathrm{K} \times \mathrm{N} / \mathrm{L}$, 
162 where $\mathrm{K}=$ species-specific correction coefficient, $\mathrm{N}=$ numbers of pair observations

163 of a species on the whole survey belt, and $\mathrm{L}=$ transect length (in $\mathrm{km}$ ). Species-

164 specific correction coefficients are based on distance sampling, where ratios of bird

165 observations on the main belt to those on the supplementary belt are used to calculate

166 densities of species in a larger (survey belt) line transect (Järvinen \& Väisänen, 1983).

167 We used the earlier published correction coefficients (Virkkala \& Lehikoinen, 2014,

168 Supplementary Table 1) and, using the same data, calculated correction coefficients

169 for the additional 34 species that were not included in the earlier study

170 (Supplementary Table 1).

171 Järvinen \& Väisänen (1983) have presented correction coefficients based on

172 data prior to the 1980s. However, since then a lot of new data have been gathered, so

173 we have revised the coefficients. We calculated species-specific correction

174 coefficients for southern and northern Finland (divided by the 710 latitude in the

175 Finnish coordinate system) and for the whole country based on the whole of the

176 Finnish monitoring data since the 1970s, when both the main belt and the

177 supplementary belt had been used. The species-specific correction coefficient (K) was 178 calculated as (Järvinen \& Väisänen, 1983):

$179 \mathrm{~K}=40-40 \sqrt{ }(1-\mathrm{p})$,

180 where $\mathrm{p}=$ proportion of main belt observations (range $0-1$ ); for details of the

181 calculations, see Järvinen (1976) and Järvinen \& Väisänen (1975, 1976a, 1983).

182 Observability of species is also affected by the overall density of bird specimens. The 183 higher the total bird density, the lower the observability on the supplementary belt

184 (see Järvinen \& Väisänen, 1976b). This can be corrected by studying the number of 185 observations on the main belt. Therefore we also used density dependent correction 186 coefficient (y) calculated as (see Järvinen \& Väisänen, 1983): 
188 where $\mathrm{x}$ is the number of main belt observations of all species per $\mathrm{km}$. The correction

189 coefficient (y) receives values above one in regions of high main belt density and

190 below one in regions of low density. Thus, the density values calculated (equation 1)

191 were multiplied by the density dependent correction coefficient (y) (Järvinen \&

192 Väisänen, 1983). The density dependent correction coefficient was calculated

193 separately for each 50-km square for both periods.

194 We used these grid-specific densities to calculate arithmetic central gravity of

195 densities for each species during both the periods. This was done by first calculating

196 the northern latitude using mean densities per each latitude grid row (Virkkala \&

197 Lehikoinen, 2014) and then calculating the longitude using mean densities per each

198 grid column (species-specific density maps and central gravity of densities are shown

199 in Supplementary Figs 1-128). In addition, gravity of densities was affected by the

200 location of censuses inside each grid. The point of each grid cell used in the analyses

201 was calculated based on mean coordinates of all line transects conducted in the grid

202 during that particular period. We preferred arithmetic mean instead of median or

203 geometric mean, since using median the shift would be occurring mainly on grid level

204 in compass points and intercardinal directions, whereas arithmetic mean allows higher

205 resolution in direction of the shifts. We declined to use geometric mean, since many

206 grid cells have zero values which complicates the calculation of geometric mean.

207 Based on latitude and longitude it was possible to calculate direction and

208 distance of the density shift of species between the two periods. Direction in degrees

209 could be calculated using inverse hyperbolic tangent and distance using Pythagoras'

210 Theorem. 
212 (Supplementary Table 1). First, we divided species into groups based on their general

213 distribution (southern edge and northern edge species and species which occur in the

214 larger part of country). This was done using the bird atlas data from Finland from

215 2006-2010 (see Valkama et al., 2011). Southern and northern species, which had

216 been observed in less than $20 \%$ of the grid cells in Finland during this atlas period,

217 were classified as edge species. Rest were classified into one group that inhabit larger

218 geographic areas. Second, we divided species into four categories based on their

219 habitat use: farmland-urban, forest, wetlands (including rocky outcrops) and montane

220 (Virkkala et al., 1994; Väisänen et al., 1998; Laaksonen \& Lehikoinen, 2013). Third,

221 species were classified into four groups based on their migration distance (residents,

222 partial migrants, short- and long-distance migrants (Cramp et al., 1977-1994;

223 Valkama et al., 2014). We first divided species into two groups, residents-partial

224 migrants and true migrants (short- and long-distance migrants) and later performed a

225 more detailed analysis where all four groups were included. Last, we divided species

226 into three groups based on their main migration direction: southwest (wintering in

227 West Europe and West Africa), south (South and Central Europe, South and East

228 Africa) and southeast (Southeast Europe and Asia (Cramp et al., 1977-1994, Valkama

229 et al., 2014). There was no strong collinearity between groups (all $|\mathbf{r}|<0.27$ ).

230 The general direction of density shifts could also be caused by the geographical

231 shape of Finland, since the shape of the country is not a rectangle. We investigated

232 how this could affect the direction of the density shifts by moving densities of the grid

233 cells directly towards north. We moved the densities of the first period one grid

234 northwards (except the most southernmost grids which remained similar) to mimic the

235 northwards density shifts. In cases where the grid did not have density value on the 
southern side, we used mean density values of the nearest southwest and southeast

237 side of the grid (Supplementary Fig. 129). We did these movements of densities for

238 each species and calculated the direction of density shifts similarly as in the observed

239 density shifts of species, and thus calculated the hypothetical density shift of each

240 species.

241 The temperature data originates from the Finnish Meteorological Institute and

242 included daily values in 10-km grid cells (Fig. 1b). We calculated mean temperatures

243 for $50-\mathrm{km}$ grids used in the analyses of bird data during the two study periods.

244 Furthermore, we searched, using temperature of the first period for each 50-km grid,

245 where the nearest as cold grid cell within Finland was located during the second

246 period. Based on this information we could calculate which direction the climate has

247 shifted regionally (Fig. 1c), and thus what would be the direction that species should

248 have shifted to remain in the same climatic conditions. Last, for each species we

249 calculated the mean direction and distance of the temperature change from the grid

250 cells where the species had been observed in the first study period.

252 Statistical analyses

254 All the statistical analyses were conducted in Matlab R2014a. Significance of the

255 species-specific density shifts along compass directions and impact of sampling effort

256 and temperature were tested using log-linear Poisson regression model

$257 \mathrm{~N}=\mathrm{L}+$ Temp + Latitude + Longitude

258 where the grid specific change in the number of observed pairs in grid cell $(\mathrm{N})$ is

259 explained by corresponding change in the length of the line transect (L), temperature

260 (Temp), latitude and longitude of the same grid cell. 
The species-specific directions of the density shifts were calculated by using

262 inverse tangent (Matlab function atand) and by using the values of the Finnish

263 uniform coordinate system, where a change of one unit corresponds distance of 10

264 kilometres (see Fig. 1). For circular analyses, Circular Statistics Toolbox was used.

265 All the functions of the toolbox and their codes are freely available on the web

266 (Berens, 2009). The mean direction was calculated using the function circ_mean and

267 the $95 \%$ confidence intervals were calculated using the function circ_confmean.

268 Rayleigh's test (function circ_rtest; test for the significance of the mean direction in

269 the cycle histogram) was used to test whether the directions differ from an even

270 distribution. Furthermore, the Harrison-Kanji test (function circ_hktest; circular

271 analog of two-factor ANOVA) was used to analyse whether the direction of different

272 groups differed. The Watson-Williams test (function circ_wwtest; circular analog of

273 the one-factor ANOVA) was used to test whether the direction of temperature and

274 density shifts differed, and the function circ_corrcc was used to test whether the

275 species-specific directions in temperature and density correlate. Last, because closely

276 related species may show similar type of responses, we investigated whether the

277 findings were linked to the phylogeny of the species. We tested whether the residuals

278 of results were correlated with the relative phylogenetic distance on the order and

279 family level. We did this by correlating the differences in residuals of a pair of species

280 with the corresponding relative phylogenetic distance between the species. The

281 phylogeny was based on the taxonomy of AERC TAC (http://www.aerc.eu/tac.html).

282 Function circ_corrcl was used to test the potential influence of phylogeny by

283 correlating the differences in residuals of each pair of species with the corresponding

284 relative phylogenetic distance between the species. In addition, the average direction 
285 and distance of shifts (vector) was calculated by using the arithmetic mean of a 286 species' latitude and longitude change.

287 Since the analyses of the significance of the density shifts (128 tests per

288 variable) and the investigation of impacts of different groups required multiple testing

289 (5 tests) we used a sequential Bonferroni correction to adjust the P-values (Rice,

290 1989).

291

292 
295 The findings show that the mean direction of the density shift was on average towards 296 the north northeast $\left(\alpha=12^{\circ}, 0^{\circ}\right.$ is north with rotation clockwise). The distribution of 297 directions differed significantly from an even distribution (Rayleigh's test, $\mathrm{z}=17.7$, $298 \mathrm{n}=128, \mathrm{P}<0.001$ ), but not from the direct north direction (Fig. 2a). On average, 299 species densities shifted 35.9 kilometres towards the north and 7.0 kilometres toward 300 the east in 25 years $(36.6 \mathrm{~km}$ in total, $1.5 \mathrm{~km} /$ year $)$. However, there was a large 301 variation in the density shift between species. Among the 128 study species, 96 302 species shifted their densities northward (mean $\alpha=17^{\circ}$, north northeast, c.i. $7-27^{\circ}$ ) 303 with an average of 60.2 kilometres shift north and $18.9 \mathrm{~km}$ shift east (mean average 304 total length of density shift of $82.1 \mathrm{~km}, 3.3 \mathrm{~km} /$ year). About half of these species, 49 305 species, shifted their densities northward more than 50 kilometres, and for only 25 306 species the shift towards north was less than 20 kilometres (Supplementary Table 1). 307 Correspondingly, 32 species shifted their densities in the southern directions 308 (mean $\alpha=216^{\circ}$, c.i. $197-235^{\circ}$ ) with an average of $33.8 \mathrm{~km}$ shift south and of $34.7 \mathrm{~km}$ 309 shift west (mean average total length of density shift of $72.7 \mathrm{~km}, 2.9 \mathrm{~km} /$ year). Half 310 of these species (16) shifted their densities less than 20 kilometres towards south and 311 only seven species shifted their densities more than 50 kilometres southwards

312 (Supplementary Table 1). The glm test revealed that 63 of the species shifted their

313 densities significantly towards north and 17 significantly towards south

314 (Supplementary Table 1). Correspondingly 11 species shifted their densities

315 significantly towards east and ten towards west. Grid-specific changes in temperature 316 explained only shifts of four species, and changes in length of line transects did not 317 showed significant results. 
319 average density shift towards the north $\left(\alpha=9^{\circ}\right.$, c.i. $\left.358-20^{\circ}\right)$, which did not differ

320 either from the direct north or the corresponding observed density shift of species $(\alpha$

$321=12^{\circ}$.

322 The mean direction of the temperature shift was north northeast $\left(\alpha=13^{\circ}\right.$, Fig.

323 2a) and did not differ from mean direction of the species' density shift (Watson-

324 Williams test, $\left.\mathrm{F}_{1,254}=0.02, \mathrm{P}=0.90\right)$. There was however a clear geographical pattern

325 in the direction of the temperate shift. In the southern half of Finland, the direction

326 was on average toward the northeast, whereas in the northern part of the country the

327 temperatures shifted westward toward the mountainous region in the northwest (Fig.

328 1c). In the northwest corner, the climatic conditions of the 1970's and 1980's, in the

329 resolution of 50-km grids, have already moved outside the borders of Finland (Fig.

330 1c). Despite the similar mean direction of both the temperature and density shifts of

331 species, the species-specific directions did not correlate significantly (rho $=-0.03, \mathrm{n}=$

$332128, \mathrm{P}=0.71)$. Furthermore, the distance of the temperature change was on average

$333186 \mathrm{~km}$ (min-max 143-301 km), which is more than five times the mean distance that

334 all species have shifted toward the north.

335 Habitat type and migration distance significantly explained the difference in

336 distribution of directions (Harrison-Kanji test, $\chi_{2}^{2}=17.92, \mathrm{P}=0.0064, \chi_{6}^{2}=8.84$,

$337 \mathrm{P}=0.012$, respectively, Fig. 2b-c). Despite the high variation in the directions,

338 farmland-urban, wetland and montane species shifted their densities towards the north

339 northwest $\left(\alpha=335^{\circ}, \alpha=339^{\circ}\right.$, and $\alpha=350$, respectively; Fig. $\left.2 b-c\right)$, whereas forest

340 species moved towards the north northeast ( $\alpha=32^{\circ}$, Fig. 2b, Supplementary Fig.

341 130). For instance typical farmland species like Lapwing Vanellus vanellus, Skylark

342 Alauda arvensis, Barn Swallow Hirundo rustica and Eurasian Starling Sturnus 
343 vulgaris shifted their densities more than $40 \mathrm{~km}$ westward. In contrast, Eurasian

344 Sparrowhawk Accipiter nisus, Osprey Pandion haliaetus, Merlin Falco columbarius,

345 Red-breasted Flycatcher Ficedula parva, Willow Tit Poecile montanus, Coal Tit

346 Periparus ater and Common Crossbill Loxia curvirostra showed the strongest shifts

347 among forest birds towards north and east (all shifted more than $150 \mathrm{~km}$,

348 Supplementary Table 1). Among montane birds, the strongest shifts were observed in

349 Long-tailed Skua Stercorarius longicaudus and Lapland Longspur Calcarius

350 lapponicus which shifted towards northeast more than 100 kilometres and Snow

351 Bunting Plectrophenax nivalis whose densities shifted towards the highest mountains

352 in the northwest more than 80 kilometres.

353 Furthermore, when grouping species into residents-partial migrants and true

354 migrants, there was a significant difference in the directions between groups (Fig. 2d).

355 Almost all resident and partial migratory species shifted their densities towards the

356 northeast ( $\alpha=39^{\circ}$, Fig. $2 d$ ), whereas many migratory species showed density shifts

357 towards the west and southwest ( $\alpha=358^{\circ}$, Fig. 2d, Supplementary Fig. 131).

358 However, a more complicated model with the four migration type categories did not

359 explain species-specific variation in the shift of the densities $\left(\mathrm{H}-\mathrm{K}\right.$ test, $\chi^{2}{ }_{6}=9.54$,

$360 \mathrm{P}=0.15$ ). This was likely because both residents and partial migrants moved towards

361 the northeast and short- and long-distance migrants towards the north (Supplementary

362 Fig. 132a-d). In the case of either habitat type or the migration distance the residuals

363 of the models were not correlated with the phylogeny either at the order or family

364 level (all P's > 0.26).

365 There was some evidence that migration direction explains part of the variation

366 in density shifts $\left(\mathrm{H}-\mathrm{K}\right.$ test, $\left.\chi_{4}^{2}=11.1, \mathrm{P}=0.086\right)$. Species wintering in the southwest

367 shifted their densities on average towards the north northeast direction $\left(\alpha=13^{\circ}\right)$, 
368 whereas species wintering in the south and southeast shifted their densities towards

369 north northwest ( $\alpha=339^{\circ}$ and $\alpha=335^{\circ}$, respectively, Fig. $2 \mathrm{e}$ ), as would have been

370 expected based on their migration routes. The distribution of the directions did not

371 differ between southern edge $\left(\alpha=323^{\circ}\right)$ or northern edge $\left(\alpha=72^{\circ}\right)$ species or species

372 that occur in the large part of the country $\left(\alpha=8^{\circ}, \mathrm{H}-\mathrm{K}\right.$ test, $\chi^{2}{ }_{4}=7.12, \mathrm{P}=0.13$;

373 Fig. 2f). In general, the group of species that shifted their densities westwards

374 included several types of species, such as migrants wintering in Asia (e.g. Blyth's

375 Reed Warbler Acrocephalus dumetorum and Greenish Warbler Phylloscopus

376 trochiloides), farmland species (mentioned above), and other species with declining

377 population dynamics (e.g. Common Buzzard Buteo buteo, Honey Buzzard Pernis

378 apivorus, Hen Harrier Circus cyaneus and Sedge Warbler Acrocephalus

379 schoenobaenus) (see Supplementary Table 1).

380

381 
Discussion

385 The findings reveal that directions of species' density and temperature shifts are not

386 directly towards the north, but most often towards the north northeast and north

387 northwest. Although these directions can partly be driven by the geographical shape

388 of the country, this underlines that the rate of species density shifts are

389 underestimated, if the shift is only measured using one north-south dimension.

390 However, the speed of the temperature change has been much faster than

391 corresponding speed in the change of bird species densities, which has also been

392 found in some earlier studies both in Europe and North America (Devictor et al.,

393 2008, 2012; La Sorte \& Jetz, 2012). Importantly, although the species and

394 temperature had on average the same direction, the species-specific values were not

395 significantly correlated as we predicted. This is probably due to the large variation in

396 the species density shifts, since $25 \%$ of the species show a move towards southern

397 directions. In a recent work, Tayleur et al. (2015) showed that only $20 \%$ of the

398 Swedish bird species had shifted their densities towards the expected direction during

$39921^{\text {th }}$ century according to the temperature change and changes in rainfall had hardly

400 any impact on density changes. On the other hand, Virkkala et al. (2014) showed that

401 observed changes in Finnish bird distributions between 1974-89 and 2006-2010 were

402 largely in the same direction as predicted range shifts by 2051-2080 based on

403 bioclimatic envelope models. Understanding causes of the variation in species-

404 specific directions and the speed of change is crucial for making predictions in species

405 distributions and for conservation actions.

406 This study shows that forest bird species have on average shifted towards a

407 northeastern direction, whereas species of other habitats have on average shifted their 
408 densities towards northwestern directions. Finland is situated on the western edge of

409 the Eurasian boreal forest zone (see e.g. Huntley et al., 2007; Virkkala et al., 2008),

410 which is why it is logical that forest species show density shift towards the northeast.

411 Nevertheless, management of forest can also affect species ability to move their

412 distributions (Felton et al., 2014). On the other hand, declining montane species

413 (Lehikoinen et al., 2014) were moving on average towards the north northwest, where

414 the highest and coldest montane areas are situated in Finland. Thus, the physiography

415 of Finland explains some of the shifts. Northwards density shifts of bird species have

416 also been observed in Finnish protected areas, where human-caused land use is

417 prohibited, suggesting that climate change was the main cause for species density

418 shifts in natural habitats (forests, wetlands and montane habitats) (Virkkala \&

419 Rajasärkkä, 2011). In addition, land use changes also influence our results. Farmland

420 birds have generally declined in Finland since the 1970's, mainly due to changes in

421 farmland practices (Rintala \& Tiainen, 2007; Laaksonen \& Lehikoinen, 2013). Mean

422 density shifts of farmland species towards a northwestern direction is supported by

423 our predictions, as the largest arable land areas in the northern and central part of the

424 country are situated on the western side. Moreover, densities of several farmland

425 species have shifted towards the southwest indicating that these species have retracted

426 towards their core breeding areas. In the UK, land use changes have been shown to be

427 more important drivers of the farmland bird species than climatic factors (Eglington \&

428 Pearce-Higgins, 2012).

429 Furthermore, migration behaviour, especially the comparison between residents

430 (including partial migrants) and true migrants explained the differences in species-

431 specific variation in the shift direction. Residents and partial migrants shifted their

432 densities very strongly toward the northeast, whereas among migrants, many species 
433 showed western or southwestern density shifts. This could indicate that residents and

434 partial migrants could better track climatic changes than migratory species, which are 435 away for the winter (Pearce-Higgins \& Green, 2014).

436 Many south-eastern and southern migrants tend to spread in western directions,

437 whereas southwestern migrants tend to spread towards the north northeast. Although

438 these groups did not differ between each other significantly, this kind of pattern would

439 make sense as species migration direction classifies the angle along which birds tend

440 to move most during their life cycle. One of the widely known impact of climate

441 change is advanced spring arrival dates of many bird species (Jonzén et al., 2006;

442 Lehikoinen \& Sparks, 2010, Vaitkuviene et al. 2015). The advanced spring migration

443 potentially together with more favourable migration conditions could be one of the

444 mechanisms behind climate induced distribution shifts due prolonged to migration

445 distances (Otterlind, 1954; Berthold, 2001). This emphasizes that the migration

446 direction and route of dispersal should be investigated in more detail. However, since

447 our study showed that residents and partial migrants shifted more towards northeast

448 than true migrants other mechanisms are also acting here.

449 Although this study is based on large-scale data covering over $1000 \mathrm{~km}$ in a

450 north-south direction through the boreal zone and over 600 kilometres in a west-east

451 direction, it is still conducted within one country and does not cover the whole

452 population of any of the study species. Such analyses dealing with abundance shifts at

453 a whole population level are very rare (see, however, Lehikoinen et al., 2013: Pavón-

454 Jordan et al., 2015), and require harmonious monitoring schemes. Furthermore, the

455 conservation decisions and management actions are typically done on a national level,

456 which is why these borders need to be taken into account although species do not

457 recognize border lines (Pouzols et al., 2014). 
Unfortunately corresponding long-term census data from the border countries, especially from the Russian side, are lacking. Furthermore, the alarming results show

460 that the former climatic conditions in the northwest corner of Finland have already

461 moved out of Finland at least on the 50-km grid scale. Although in this mountainous

462 region, in the short-term species could cope with climate change by shifting their

463 densities uphill, in the long-term their currently declining populations (Lehikoinen et

464 al., 2014) may become extirpated from northwestern Europe (Huntley et al., 2007;

465 Virkkala et al., 2008). This underlines that international collaboration should be

466 increased to improve our understanding of species abundance and distribution

467 changes (Jiguet et al., 2010; Lehikoinen et al., 2014) and to design management

468 actions to conserve biodiversity in the face of changing climate (Pearce-Higgins \&

469 Green, 2014; Pouzols et al., 2014).

471 Acknowledgements

473 We thank the hundreds of birdwatchers who participated in the data collection. Risto

474 A. Väisänen coordinated the censuses at the Finnish Museum of Natural History for

475 decades. The Ministry of the Environment provided financial support for the counts

476 and A.L. received financial support from the Academy of Finland (project 275606).

477 The detailed comments by three anonymous reviewers are greatly acknowledged.

478 Benjamin Steele kindly checked the language. 
Berens P (2009) CircStat: A Matlab Toolbox for Circular Statistics. Journal of Statistica Software, 31, 10. (available at www.jstatsoft.org/v31/i10)

Berthold P (2001) Bird migration. Oxford University Press, Oxford.

Booth DJ, Bond N, Maccreadie P (2011) Detecting range shifts among Australian fishes in response to climate change. Marine and Freshwater Research, 62, 1027-1042.

Breed GA, Stichter S, Crone EE (2013) Climate-driven changes in northeastern US butterfly communities. Nature Climate Change, 3, 142-145.

Burrows, MT, Schoeman DS, Richardson AJ et al. (2014) Geographical limits to species-range shifts are suggested by climate velocity. Nature, 507, 492-495.

Chen I-C, Hill JK, Ohlemüller R, Roy DB, Thomas CD (2011) Rapid range shifts of species associated with high levels of climate warming. Science, 333, 1024 1026.

Cramp S, Simmons KEL, Perrins CM (1977-1994) Handbook of the birds of Europe, Middle East and North America: Birds of the Western Palaearctic. Oxford University Press.

Devictor V, Julliard R, Couvet D, Jiguet F (2008) Birds are tracking climate change, but not fast enough. Proceedings of the Royal Society B-Biological Sciences, 254, 2743-2748.

Devictor V, van Swaay C, Brereton T et al. (2012). Differences in the climate debt of birds and butterflies at a continental scale. Nature Climate Change, 2, 121-124.

Donald PF, Green RE, Heath MF (2001) Agricultural intensification and the collapse of Europe's farmland bird populations. Proceedings of the Royal Society BBiological Sciences, 268, 25-29. 
506 Eglington SM, Pearce-Higgins JW (2012) Disentangling the relative importance of

$507 \quad$ changes in climate and land-use intensity in driving recent bird population

$508 \quad$ trends. PLoS One, 7, e30407.

509 Felton A, Lindbladh M, Elmberg J, Felton AM, Andersson E, Sekercioglu CH,

510 Collingham Y, Huntley B (2014) Projecting impacts of anthropogenic climatic

511 change on the bird communities of southern Swedish spruce monocultures: will

512 the species poor get poorer? Ornis Fennica 91, 1-13.

513 Gillings S, Balmer DE, Fuller RJ (2015) Directionality of recent bird distribution

$514 \quad$ shifts and climate change in Great Britain. Global Change Biology 21, 2155-

$515 \quad 2168$.

516 Hickling R, Roy DB, Hill JK, Fox R, Thomas CD (2006) The distributions of a wide range of taxonomic groups are expanding polewards. Global Change Biology,

$518 \quad \mathbf{1 2}, 450-455$.

519 Hockey PAR, Sirami C, Ridley AR ,Midgley GF, Babiker HA (2011) Interrogating 520 recent range change in South African birds: confounding signals from land use and climate change present a challenge for attribution. Diversity and

523 Huntley B, Green RE, Collingham YC, Willis SG (2007) A climatic atlas of European 524 breeding birds. Durham University, The RSPB and Lynx Edicions, Barcelona. 525 Järvinen O (1976) Estimating relative densities of breeding birds by the line transect 526 method. II. Comparison between two methods. Ornis Scandinavica, 7, 43-48.

527 Järvinen O,Väisänen, RA (1975) Estimating relative densities of breeding birds by the $528 \quad$ line transect method. Oikos, 26, 316-322.

529 Järvinen O,Väisänen, RA (1976a) Finnish line transect censuses. Ornis Fennica, 53, $530 \quad 115-118$. 
531 Järvinen O,Väisänen, RA (1976b) Estimating relative densities of breeding birds by 532 the line transect method. IV. Geographical constancy of the proportion of main 533 belt observations. Ornis Fennica, 53, 87-91.

534 Järvinen O,Väisänen, RA (1981) Methodology for censusing land bird faunas in large $535 \quad$ regions. Studies in Avian Biology, 6, 146-151.

536 Järvinen O, Väisänen RA (1983) Correction coefficients for line transect censuses of 537 breeding birds. Ornis Fennica, 60, 97-104.

538 Järvinen O, Koskimies P, Väisänen RA (1991) Line transect census of breeding land 539 birds. In: Monitoring bird populations: a manual of methods applied in Finland 540 (eds Koskimies P, Väisänen RA). Zoological Museum, Finnish Museum of $541 \quad$ Natural History, pp. 33-40.

542 Jiguet F, Devictor V, Ottvall R, Van Turnhout C, Van der Jeugd H, Lindström, A 543 (2010) Bird population trends are linearly affected by climate change along 544 species thermal ranges. Proceedings of the Royal Society B-Biological Sciences, $545 \quad 277,3601-3618$.

546 Jonzén N, Lindén A, Ergon, T et al. (2006) Rapid advance of spring arrival dates in 547 long-distance migratory birds. Science, 312, 1959-1961

548 Kelly AE, Goulden ML (2008) Rapid shifts in plant distribution with recent climate 549 change. Proceedings of the National Academy of Sciences of the United States $550 \quad$ of America, 105, 11823-11826.

551 Kujala H, Vepsäläinen V, Zuckerberg B, Brommer JE (2013) Range margin shifts of 552 birds revisited - the role of spatiotemporally varying survey effort. Global 553 Change Biology, 19, 420-430. 
554 Laaksonen T, Lehikoinen A (2013) Population trends in boreal birds: Continuing 555 declines in agricultural, northern, and long-distance migrant species. Biological $556 \quad$ Conservation, 168, 99-107.

557 La Sorte FA, Jetz W (2012) Tracking of climatic niche boundaries under recent 558 climate change. Journal of Animal Ecology, 81, 914-925.

559 Lehikoinen A (2013) Climate change, phenology and species detectability in a 560 monitoring scheme. Population Ecology, 55, 315-323.

561 Lehikoinen A, Green M, Husby M, Kålås JA, Lindtröm, Å (2014). Common montane 562 birds are declining in northern Europe. Journal of Avian Biology, 45, 3-14.

563 Lehikoinen A, Jaatinen K, Vähätalo AV et al. (2013) Rapid climate-driven shifts in 564 wintering distributions of three common waterbird species. Global Change $565 \quad$ Biology, 19, 2071-2081.

566 Lehikoinen E, Sparks TH (2010) Changes in migration. In Effects of climate change 567 on birds (A. Møller, W. Fiedler, \& P. Berthold, eds), Oxford Univ. Press, $568 \quad$ Oxford, UK, pp. 89-112.

569 Maclean IMD, Austin GE, Rehfisch MM et al. (2008) Climate change causes rapid 570 changes in the distribution and site abundance of birds in winter. Global Change $571 \quad$ Biology, 14, 2489-2500.

572 Otterlind G (1954) Flyttning och utbredning. Vår Fågelvärld, 13, 1-261.

573 Parmesan C, Ryrholm N, Stefanescu C, et al. (1999) Poleward shifts in geographical $574 \quad$ ranges of butterfly species associated with regional warming. Nature, 399, 579$575 \quad 583$.

576 Parmesan C, Yohe G (2003) A globally coherent fingerprint of climate change 577 impacts across natural systems. Nature, 421, 37-42. 
578 Pavón-Jordán D, Fox AD, Clausen P et al. (2015). Climate driven changes in winter

579 abundance of a migratory waterbird in relation to EU protected areas. Diversity and Distributions, 21, 571-582

581 Pearce-Higgins J, Green, RE (2014) Birds and Climate Change: impacts and conservation responses. University of Cambride.

583 Pouzols FM, Toivonen T, Di Minin E et al. (2014) Global protected area expansion is compromised by protected land-use and parochialism. Nature, 516, 383-386.

Pöyry J, Luoto M, Heikkinen RK, Kuussaari M, Saarinen K (2009) Species traits explain recent range shifts of Finnish butterflies. Global Change Biology, 15, $732-743$.

Rice WR (1989) Analyzing tables of statistical tests. Evolution, 43, 223-225.

Rintala J, Tiainen J (2007) A model incorporating a reduction in carrying capacity translates brood size trends into a population decline: the case of Finnish starlings, 1951-2005. Oikos, 117, 47-59.

592 Sanderson FJ, Donald PF, Pain DJ, Burfield, IJ, van Bommel FPJ (2006) Long-term population declines in Afro-Palearctic migrant birds. Biological Conservation,

595 Tayleur C, Caplat P, Massinino D, Johnston A, Jonzén N, Smith HG, Lindström A (2015) Swedish birds are tracking temperature but not rainfall: evidence from a decade of abundance changes. Global Ecology and Biogeography, 24, 859-872.

598 Thomas CD (2010) Climate, climate change and range boundaries. Diversity and Distributions, 16, 488-495.

600 Thomas CD, Lennon JJ (1999) Birds extend their ranges northwards. Nature, 399, 601 213-213. 
Väisänen RA, Lammi E, Koskimies P (1998) Distribution, numbers and population changes of Finnish breeding birds. Otava.

604 Vaitkuviene D, Gagys M, Bartkeviciene G, Romanovskaja D (2015) The effect of

605 weather variables on the White Stork (Ciconia ciconia) spring migration

606 phenology. Ornis Fennica 92, 43-52.

607 Valkama J, Vepsäläinen V, Lehikoinen A (2011) The Third Finnish Breeding Bird 608 Atlas. Finnish Museum of Natural History and Ministry of Environment 609 (http://atlas3.lintuatlas.fi/english), Helsinki.

610 Valkama J, Saurola P, Lehikoinen A, Lehikoinen, E, Piha, M, Sola, P, Velmala, W 611 (2014) The Finnish Bird Ringing Atlas. Vol. II. Finnish Museum of Natural 612 History and Ministry of Environment.

613 Virkkala R, Heikkinen RK, Leikola N, Luoto M (2008) Projected large-scale range 614 reductions of northern-boreal land bird species due to climate change.

615 Biological Conservation, 141, 1343-1353.

616 Virkkala R, Lehikoinen A (2014) Patterns of climate-induced density shifts of 617 species: poleward shifts faster in northern boreal birds than in southern birds. $618 \quad$ Global Change Biology, 20, 2995-3003.

619 Virkkala R, Pöyry J, Heikkinen RK, Lehikoinen A, Valkama J (2014) Protected areas 620 alleviate climate change effects on northern bird species of conservation $621 \quad$ concern. Ecology and Evolution, 4, 2991-3003.

622 Virkkala R, Rajasärkkä A (2011) Northward density shift of bird species in boreal 623 protected areas due to climate change. Boreal Environment Research, 16 (suppl. $624 \quad$ B), 2-13. 
625 Virkkala R, Rajasärkkä A, Väisänen RA, Vickholm M, Virolainen E (1994) The 626 significance of protected areas for the land birds of southern Finland.

627 Conservation Biology, 8, 532-544

628 Zuckerberg B, Woods AM, Porter WF (2009) Poleward shifts in breeding bird 629 distributions in New York State. Global Change Biology, 15, 1866-1883.

630

631

632

633 

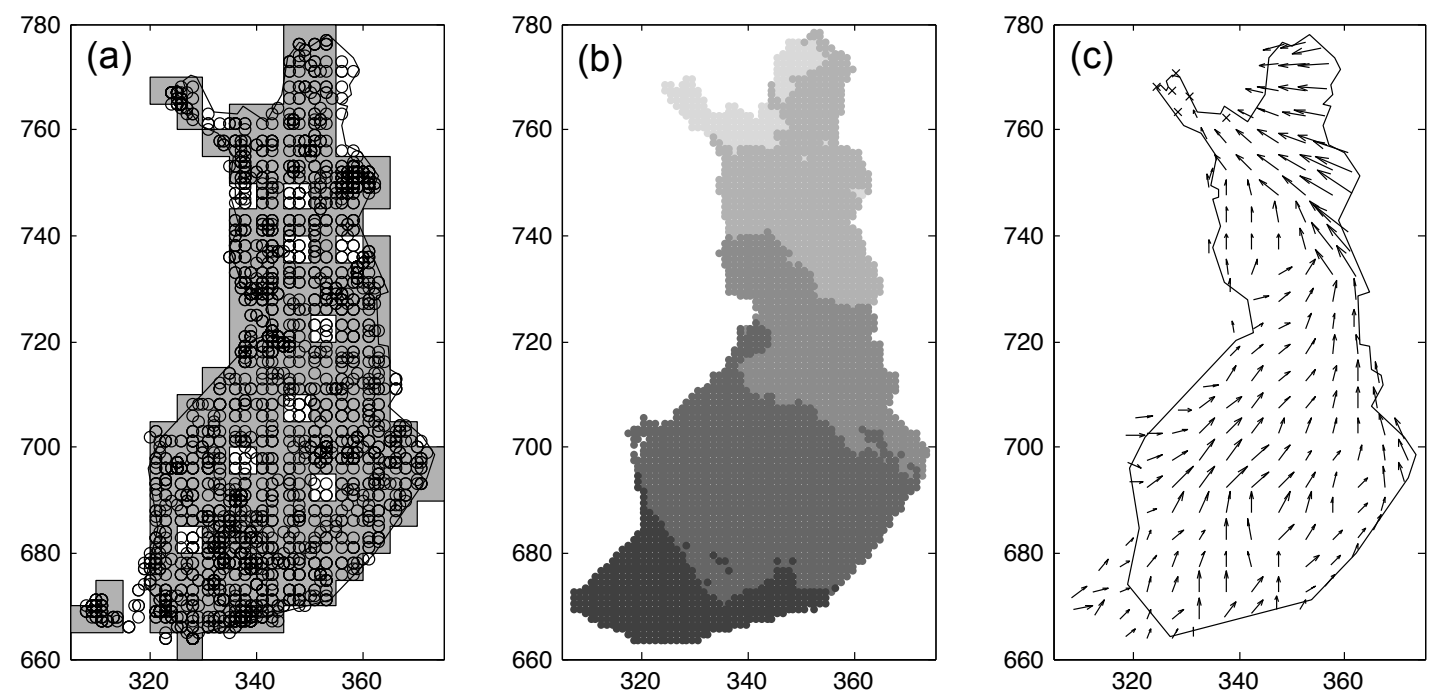

636 Fig. 1. Map of Finland showing a) 50-km grid cells in grey and individual census sites

637 in circles in the 1970s, 1980s and 2000s, b) isoterms in annual temperature during

638 1970-1989 (darker colour indicate warmer tempeature) and c) directions that 
640 arrows indicate stronger temperature shifts. ' $\mathrm{x}$ '-marks show grids where climate in the

641 1970s and 1980s no longer exists in Finland during the second study period.

642
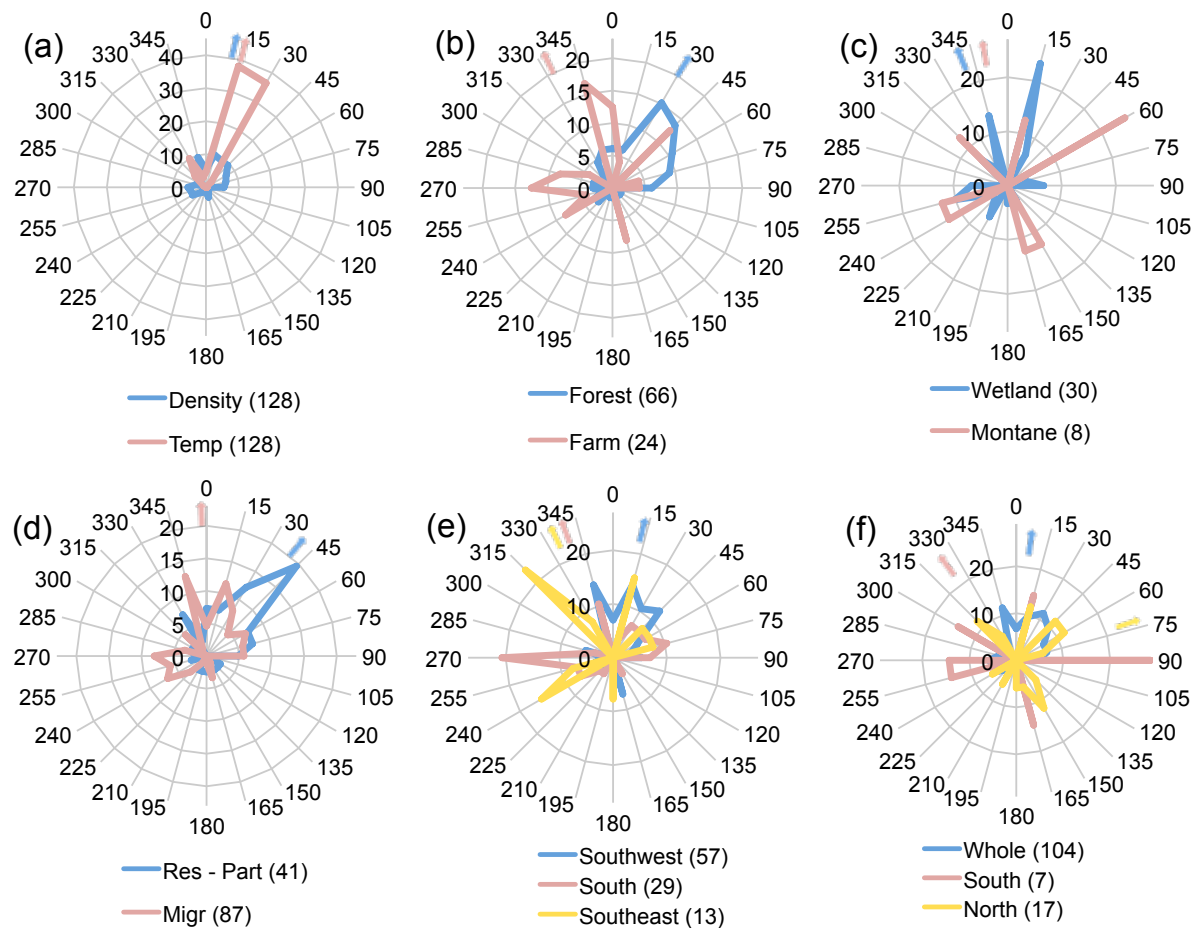

644 Fig. 2. Distribution of directions of density shifts. (a) Densities of all species $(95 \% \mathrm{c}$.

645 i. of the mean direction $\left.358-30^{\circ}\right)$ and corresponding temperature $\left(95 \%\right.$ c. i. $\left.8-17^{\circ}\right)$ in 646 their same breeding range from 1970-1989 to 2000-2012. Distribution of directions

647 of density shifts according to main habitat type of the species [b) farmland and forest

648 species and c) wetland and montane species], migration behaviour [d) residents -

649 partial migrants and fully migratory species], spring migration direction [e) southwest, 650 south or southeast] and general distribution of the species [f) southern edge, large part 651 of the country and northern edge]. The colour lines show the distribution of directions 652 in $15^{\circ}$ intervals and the colour arrows next to the degrees show the mean direction of 653 the particular distribution. 
Supporting information

656

657 Supplementary Table 1. Species-specific data with sample sizes, habitat, migration 658 and distribution classifications, central gravity of density expressed as latitudes and

659 longitudes during both study periods, direction of the density shift, total distance of

660 shift density shift along latitude and longitude directions and direction of the species-

661 specific temperature shift.

662

663 Supplementary Figs. 1-128. Species-specific density maps during the first (1970-

664 1989, left panel) and second (2000-2012, right panel) study period.

665

666 Supplementary Fig. 129. Illustration of moved densities of species to estimate the

667 potential effect of shape of the country on the direction of density shifts.

668

669 Supplementary Fig. 130. Grid specific changes of relative densities of groups of

670 species classified based on their main habitat type.

671

672 Supplementary Fig. 131. Grid specific changes of relative densities of groups of

673 species classified based on their migration type.

674

675 Supplementary Fig. 132. Distribution of directions of changes in densities based on

676 four migration groups.

677 
Supplementary figs 1-128. Species-specific density maps during the first (1970-1989, left panel) and second (2000-2012, right panel) study period. The 50-km grid-specific densities are shown in grey scale illustrated by three values on the up left corned or each panel. Large asterisk shows the central gravity of the densities and small black crosses are grids that did not have enough data (excluded from the analyses).
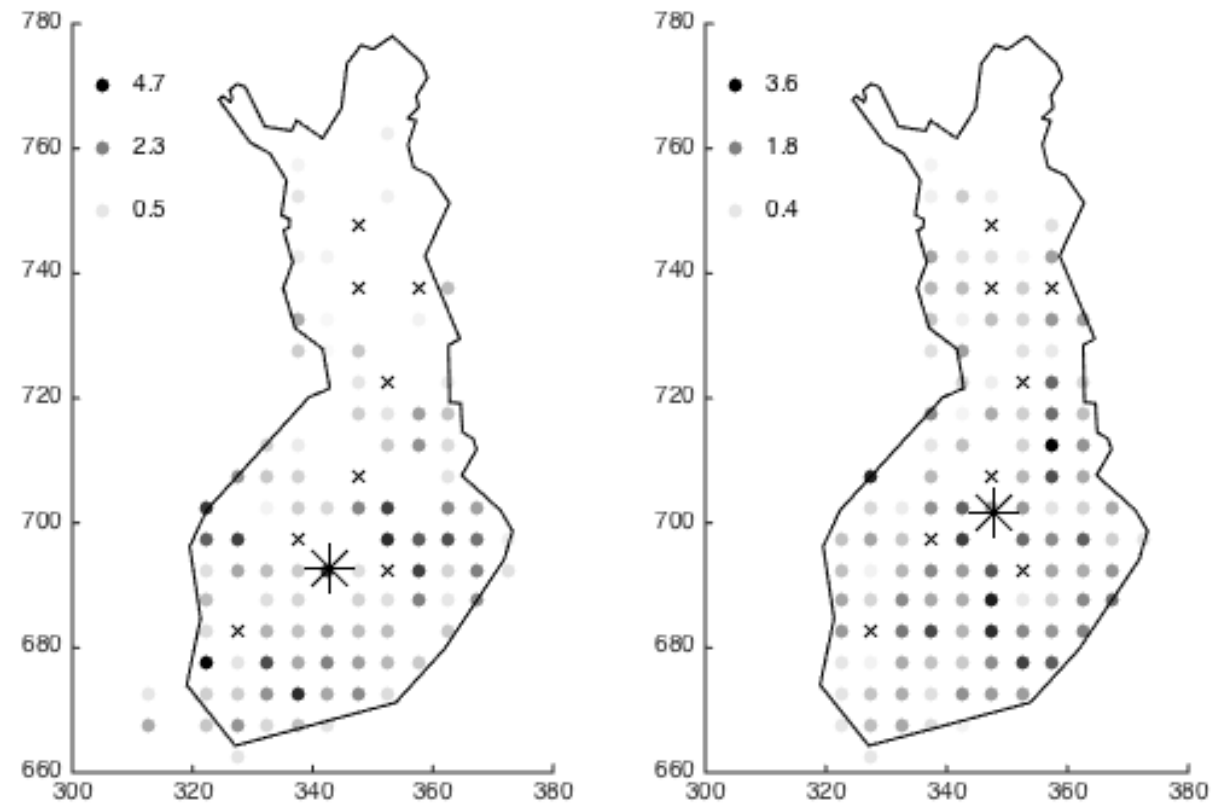

Supplementary fig. 1. Tetrastes bonasia
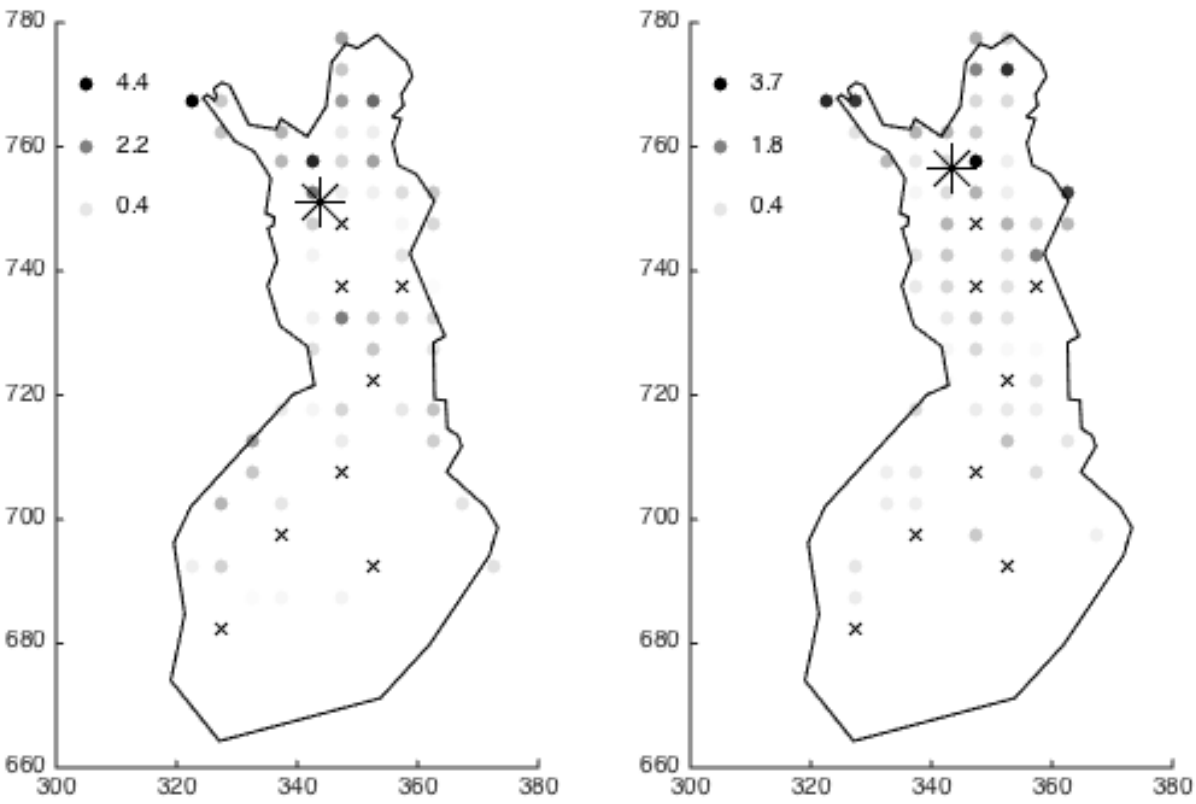

Supplementary fig. 2. Lagopus lagopus 

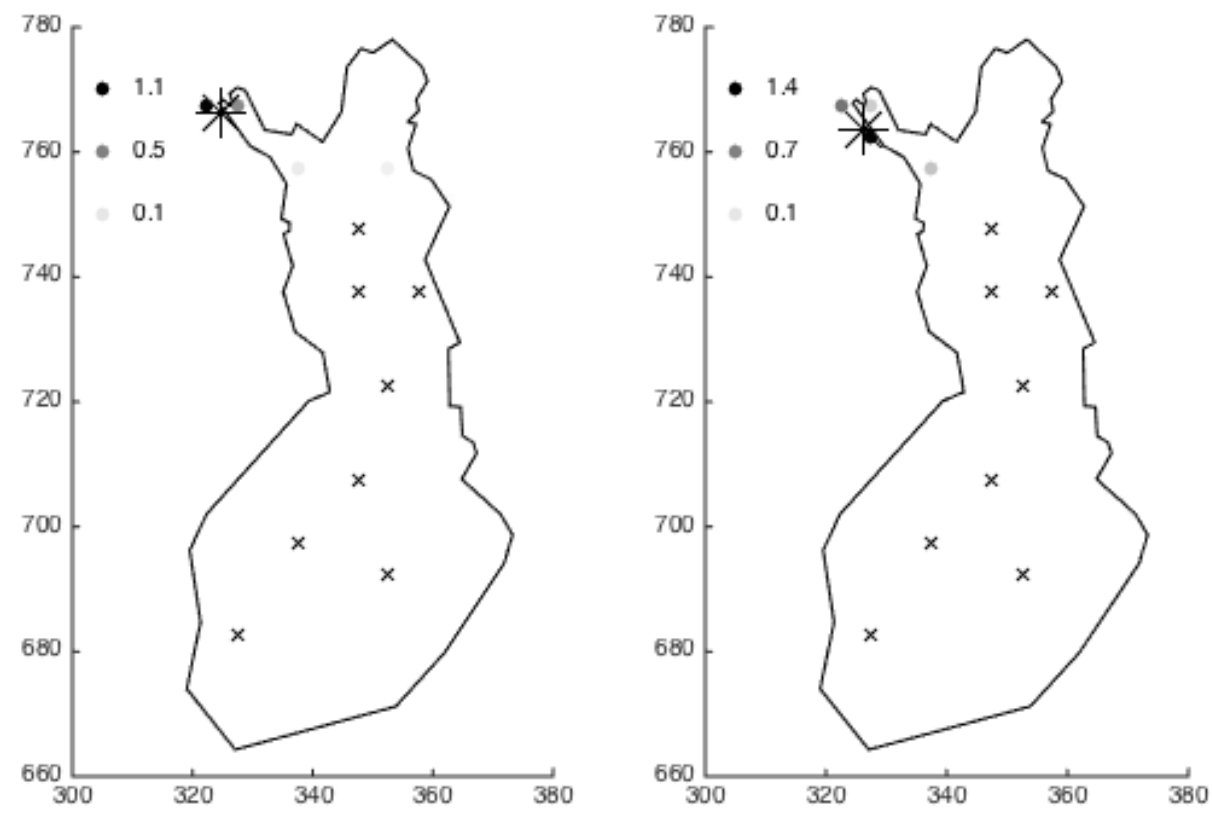

Supplementary fig. 3. Lagopus muta
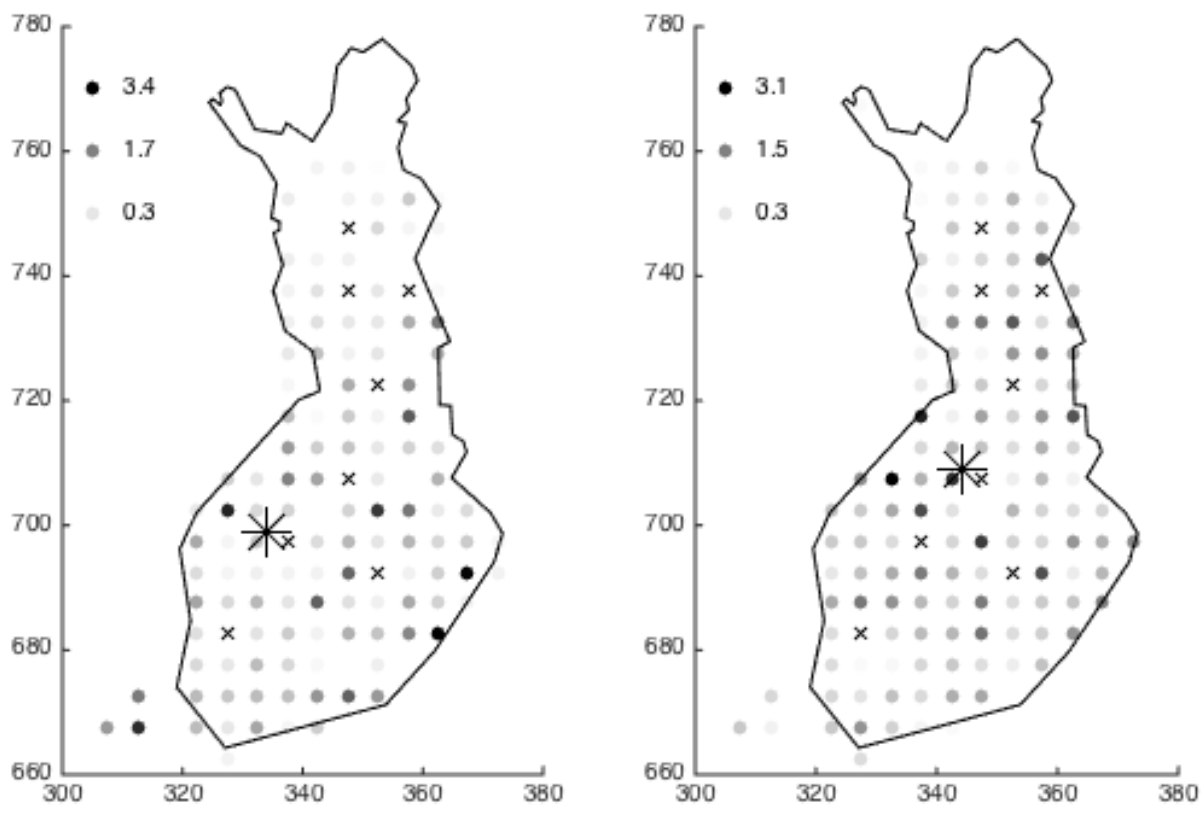

Supplementary fig. 4. Tetrao tetrix 

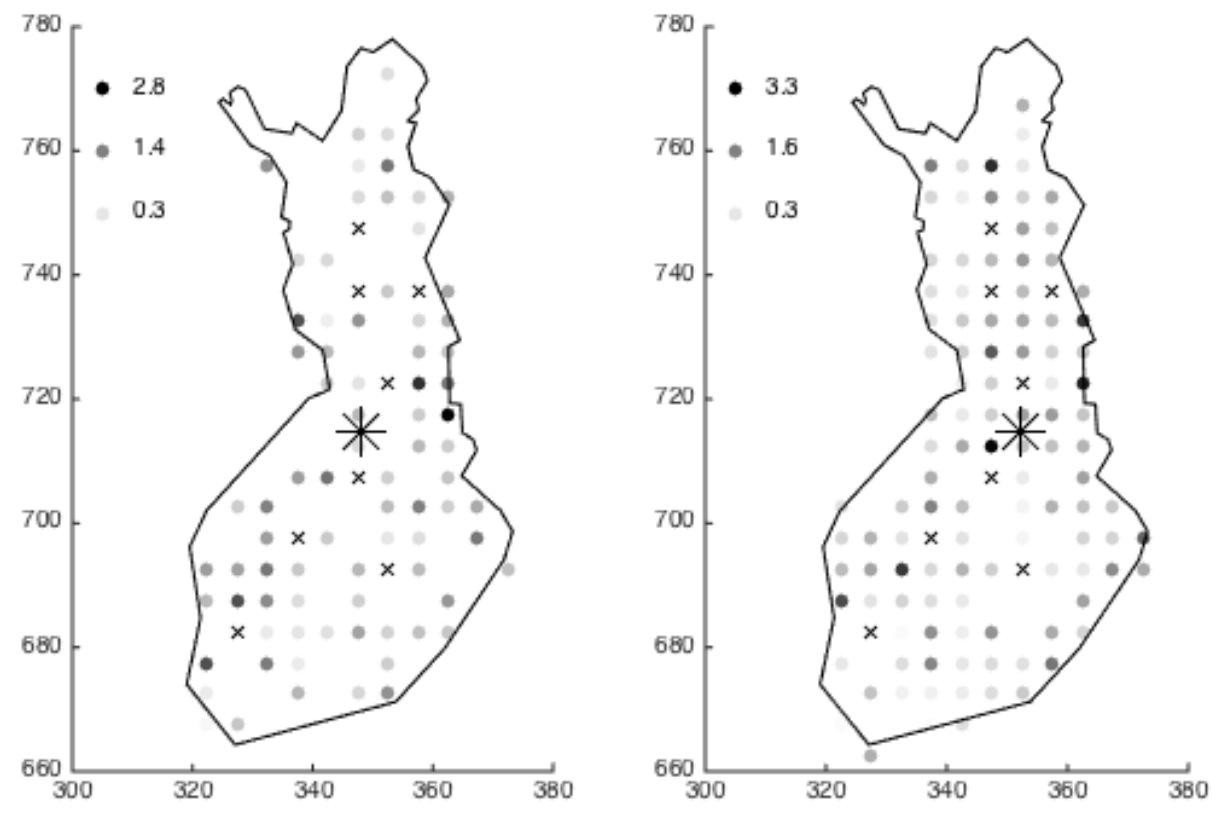

Supplementary fig. 5. Tetrao urogallus
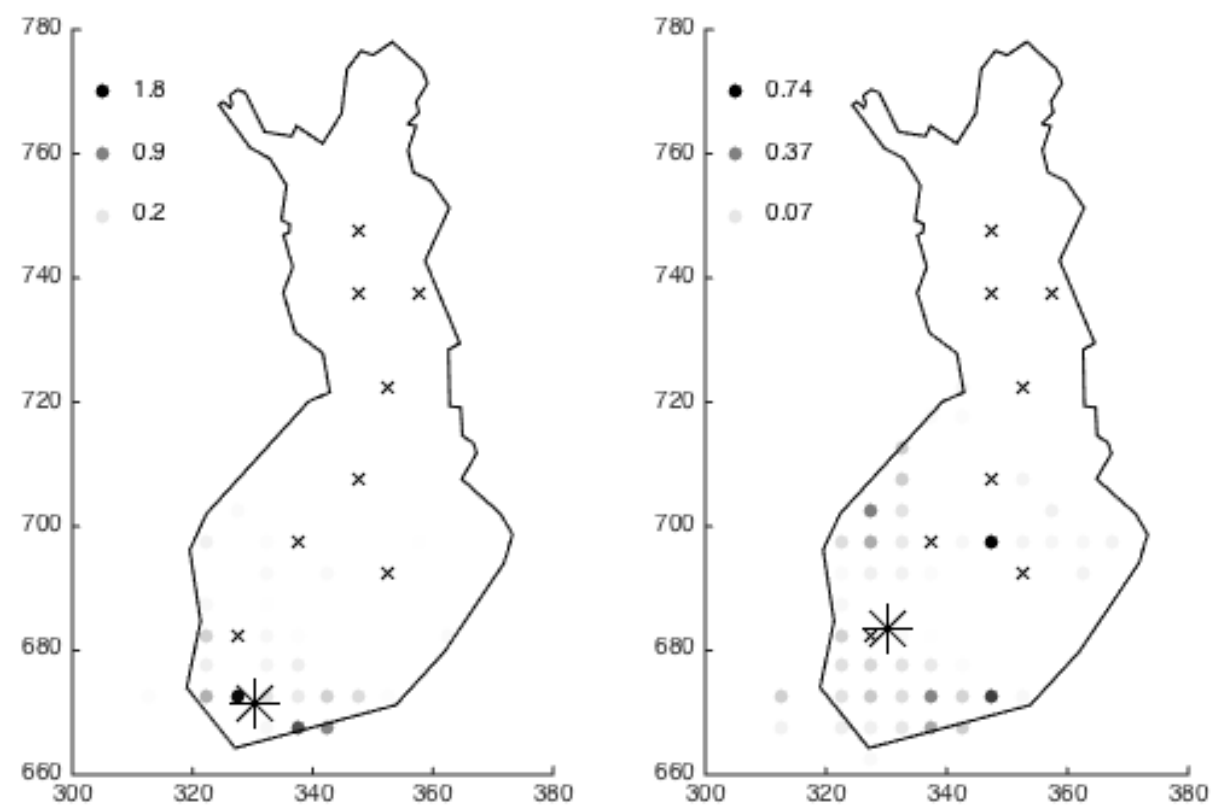

Supplementary fig. 6. Phasianus colchicus 

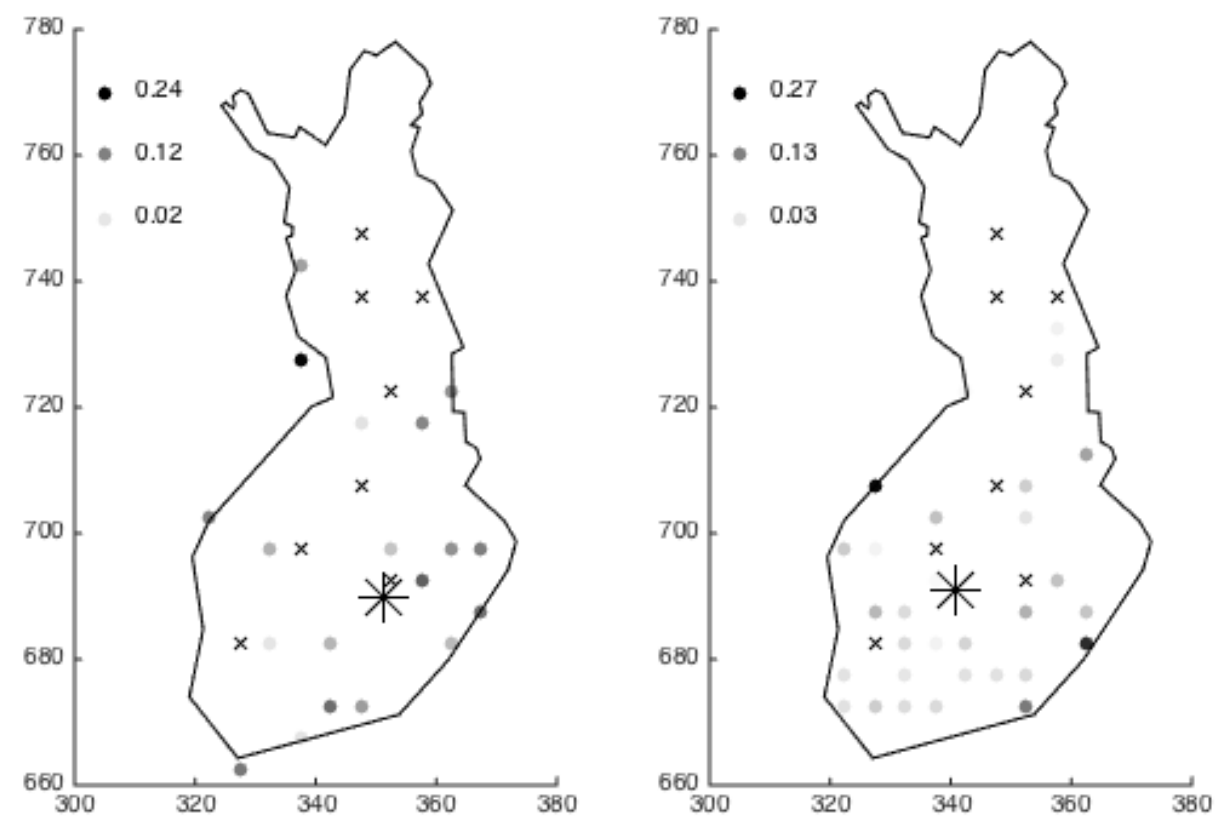

Supplementary fig. 7. Pernis apivorus
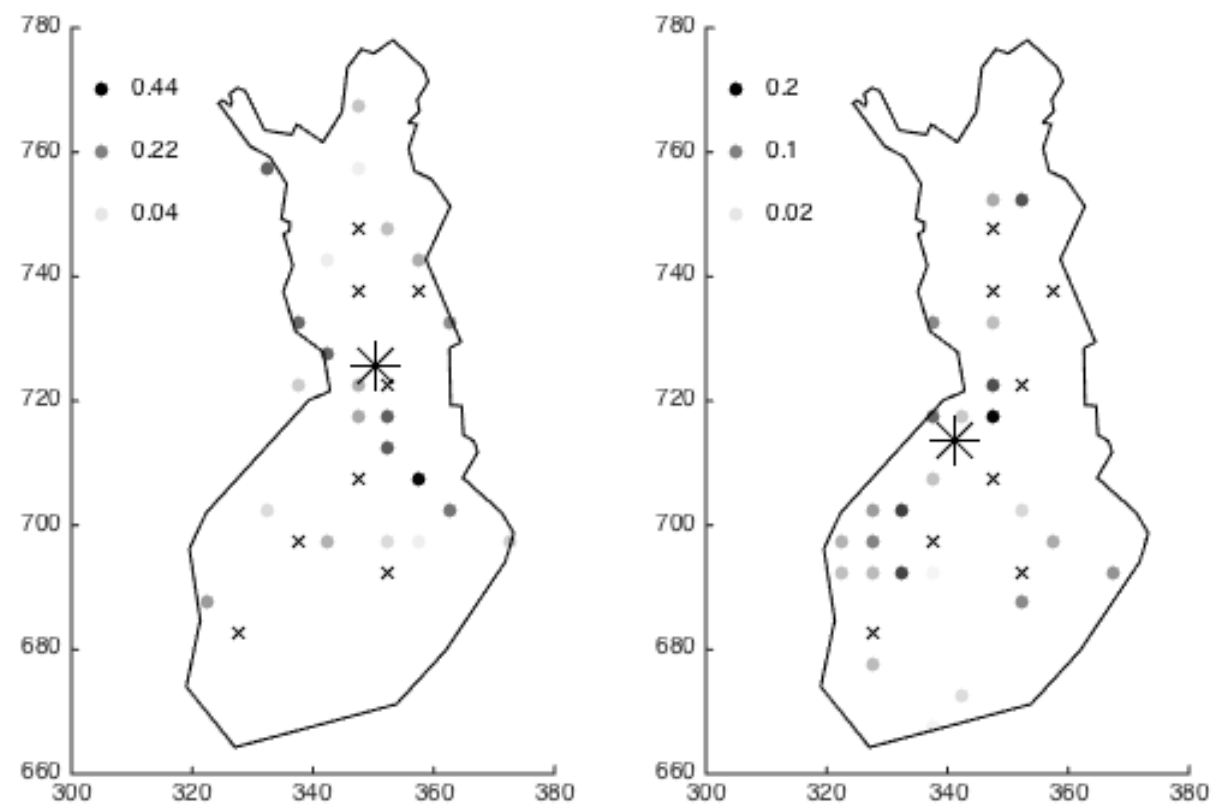

Supplementary fig. 8. Circus cyaneus 

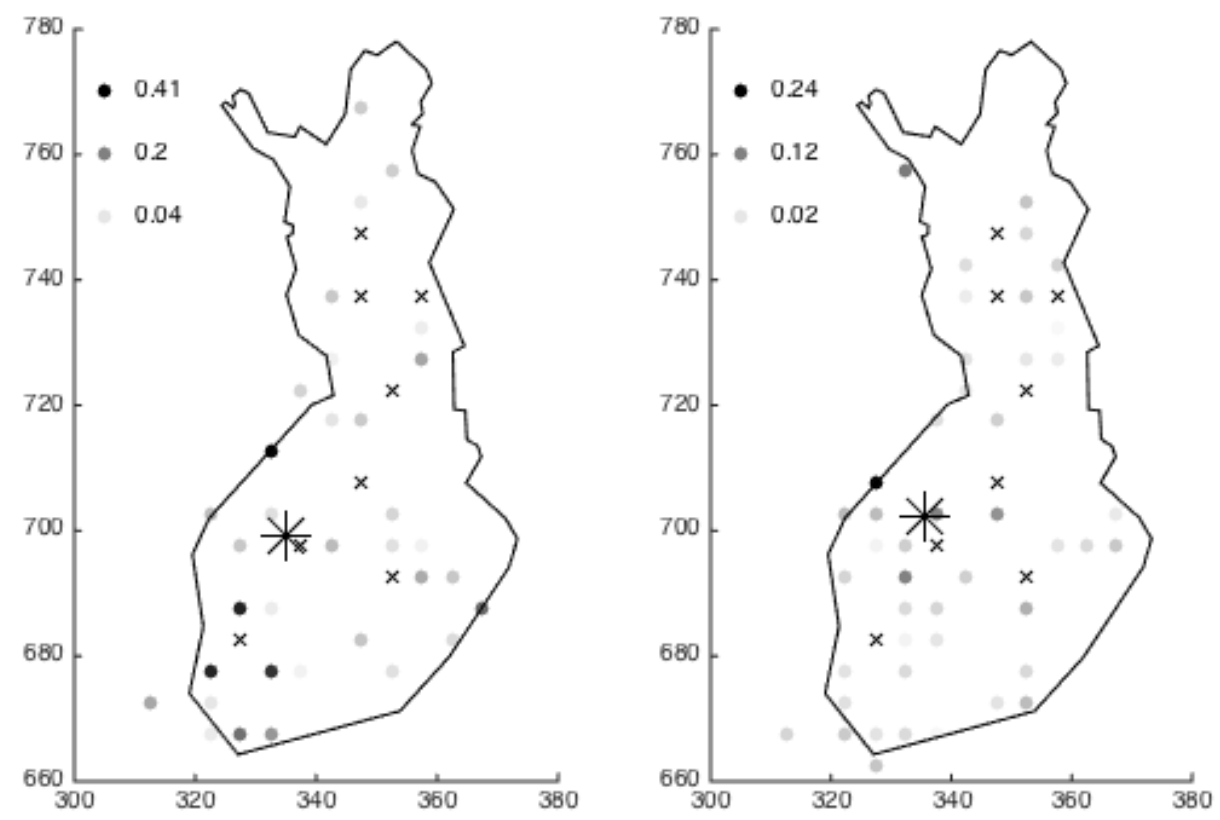

Supplementary fig. 9. Accipiter gentilis
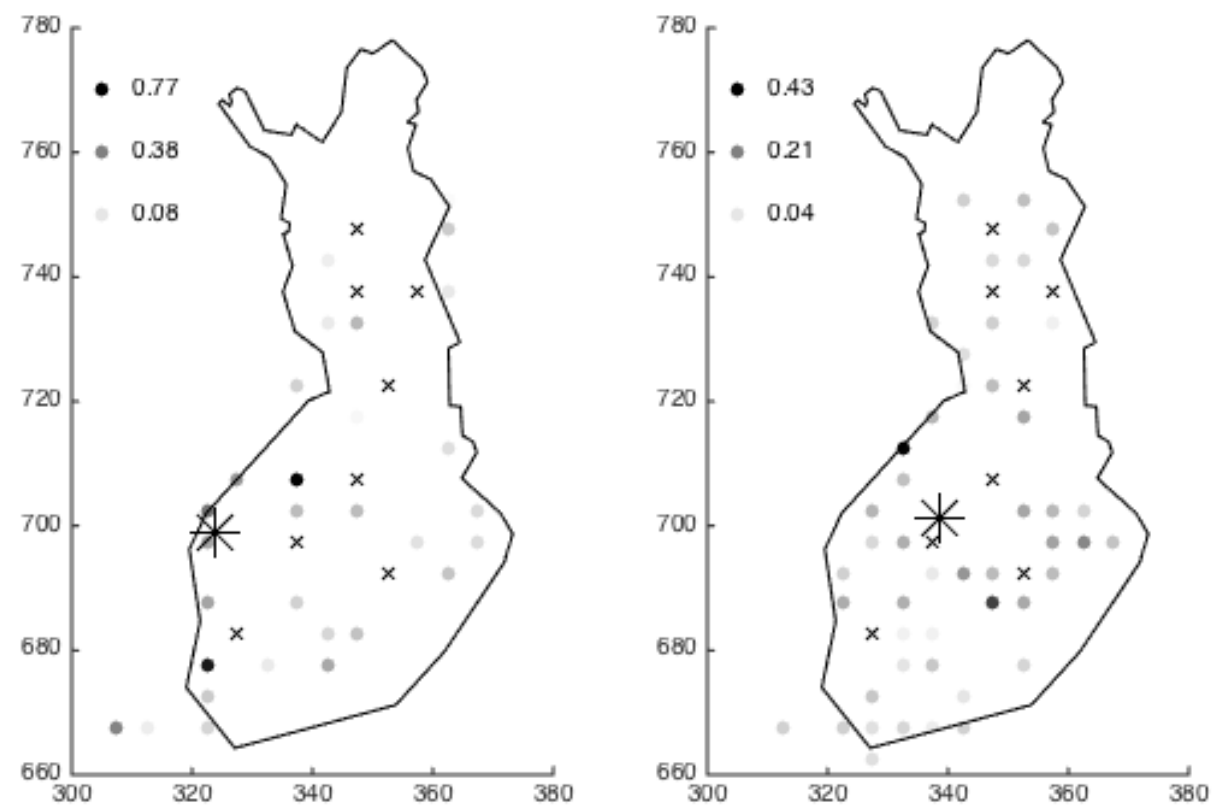

Supplementary fig. 10. Accipiter nisus 

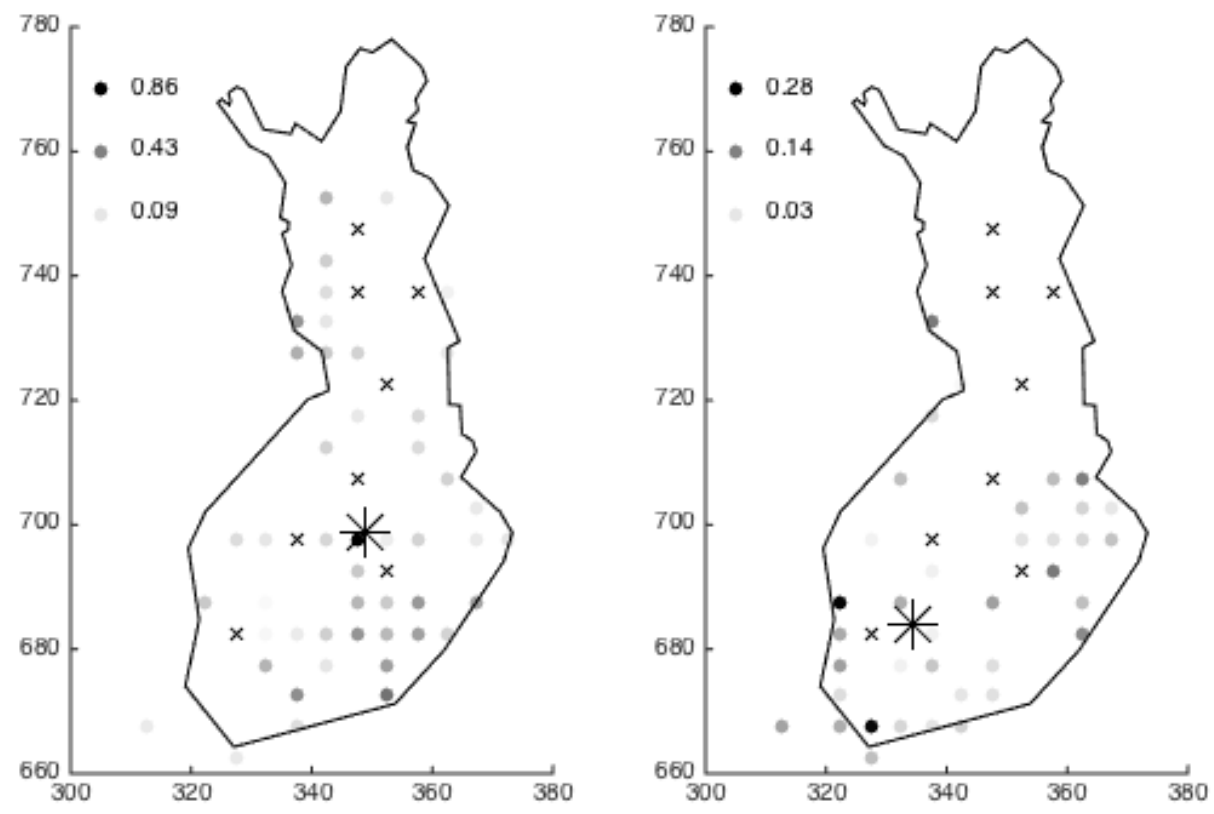

Supplementary fig. 11. Buteo buteo
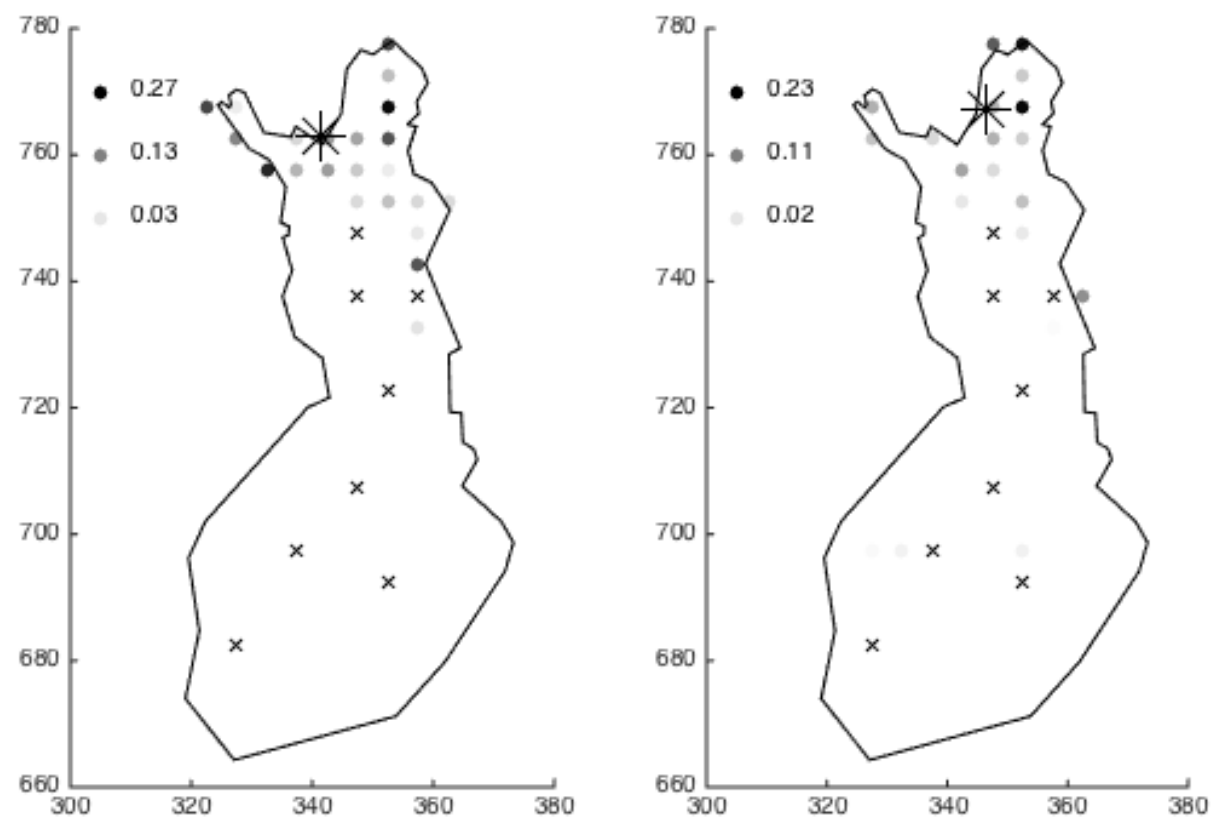

Supplementary fig. 12. Buteo lagopus 

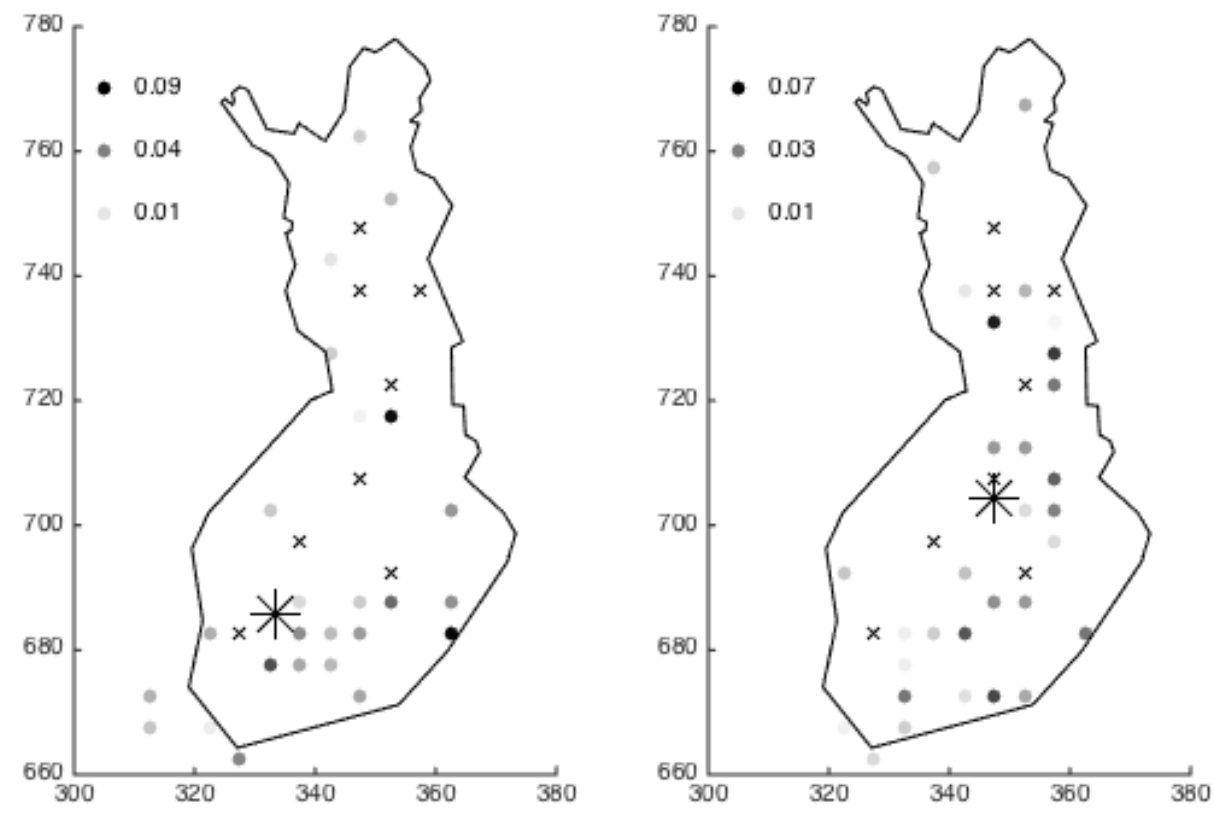

Supplementary fig. 13. Pandion haliaetus
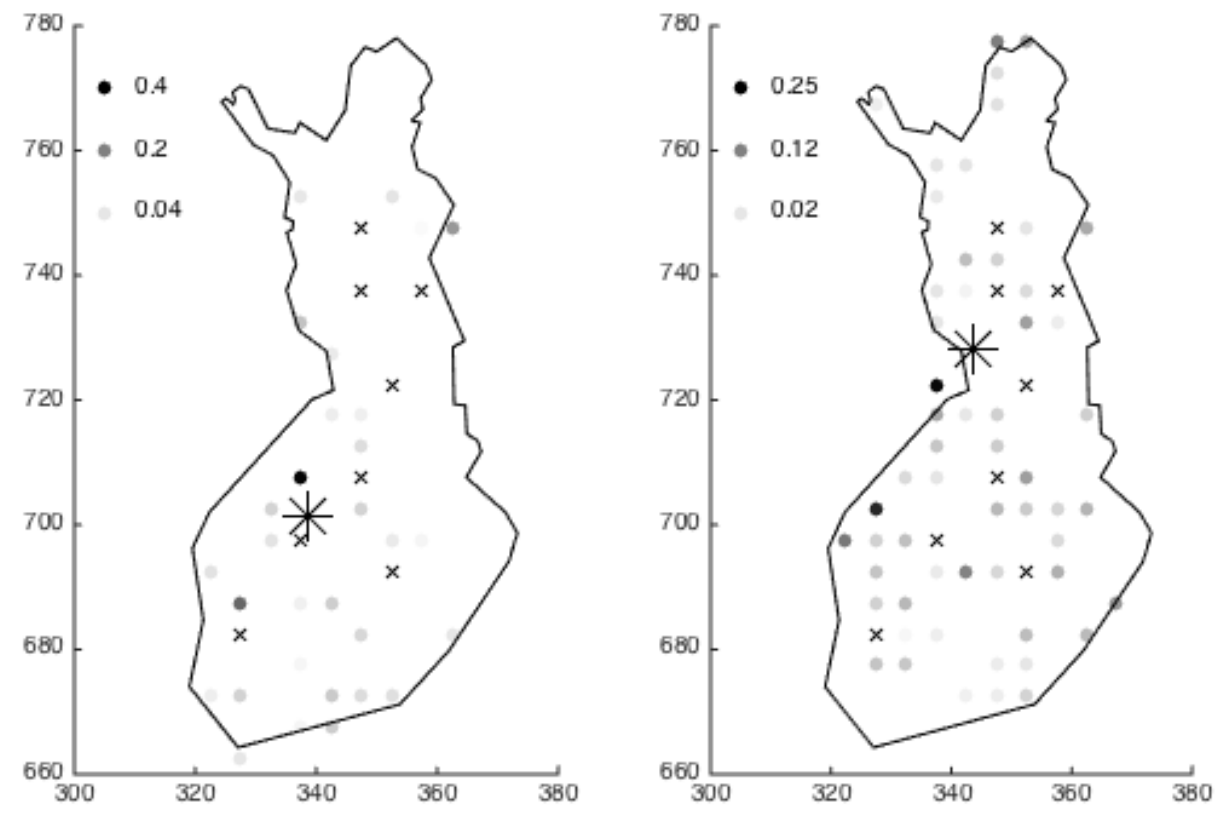

Supplementary fig. 14. Falco tinnunculus 

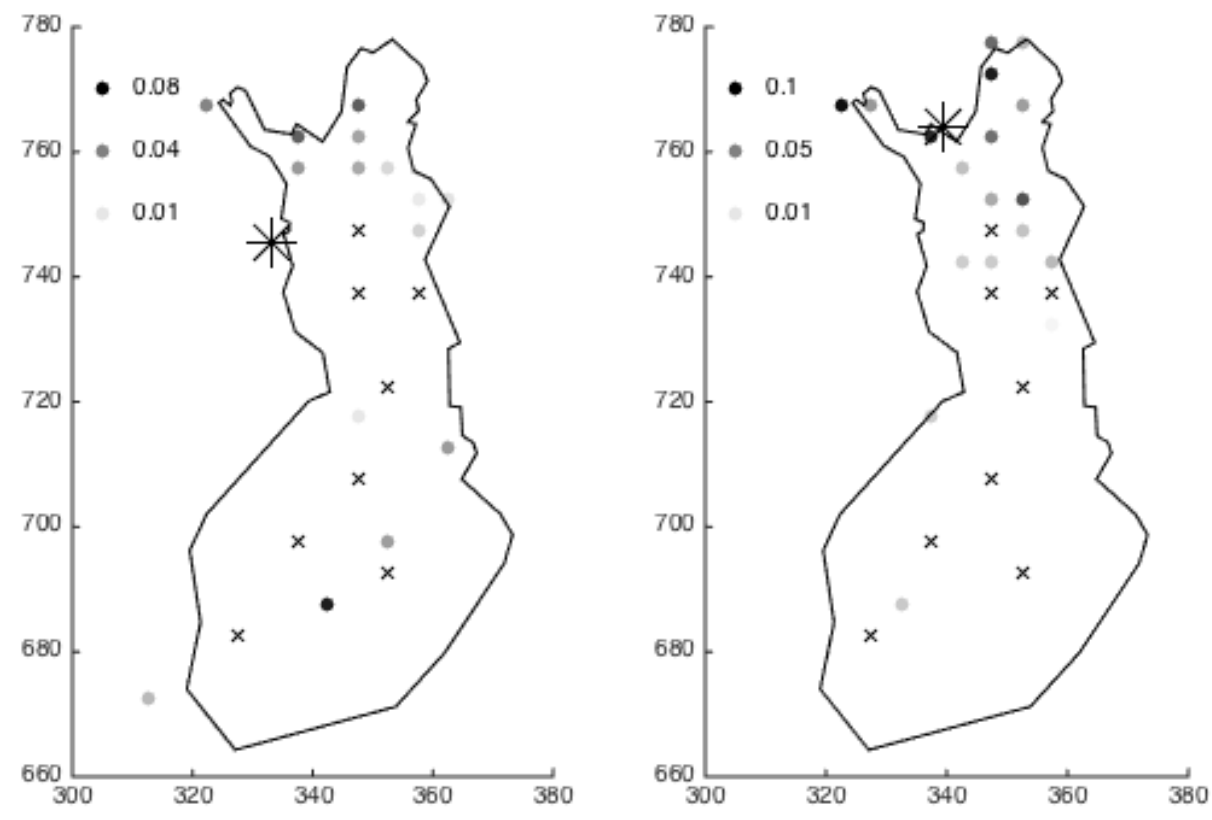

Supplementary fig. 15. Falco columbarius
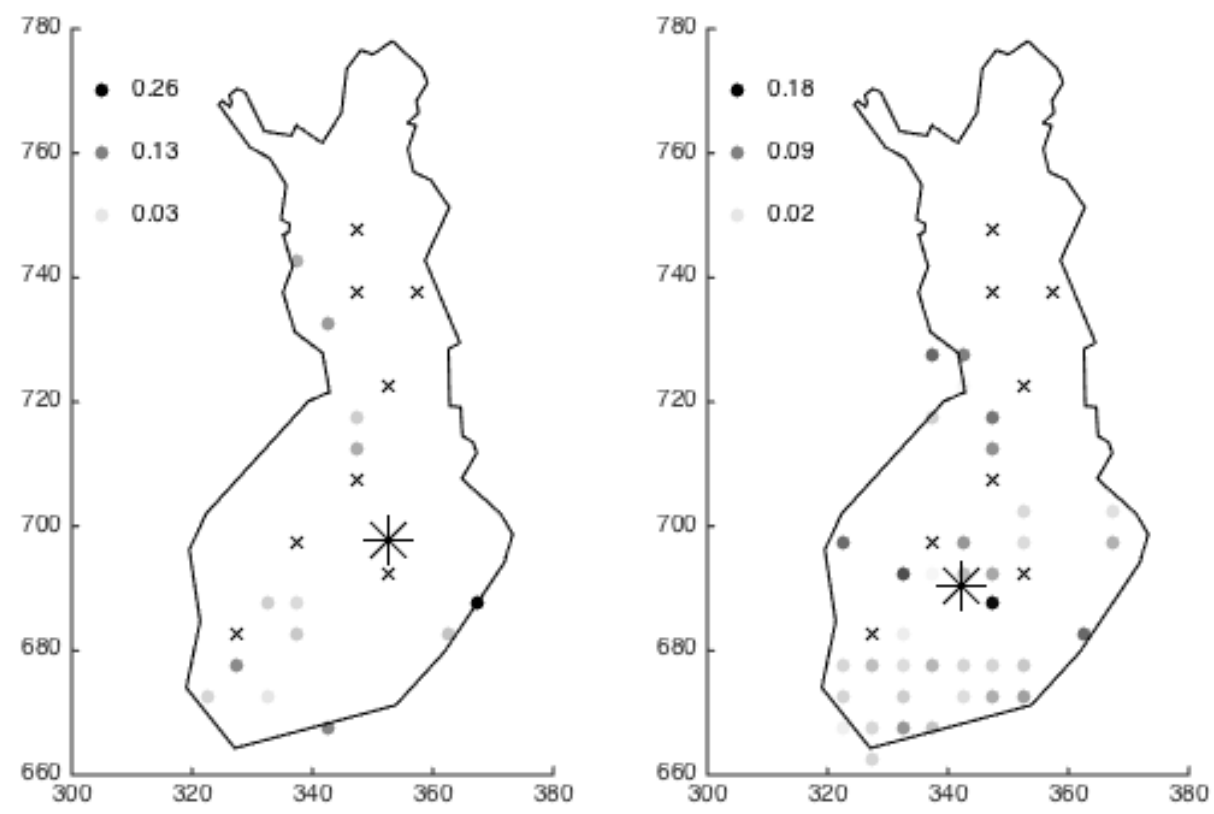

Supplementary fig. 16. Falco subbuteo 

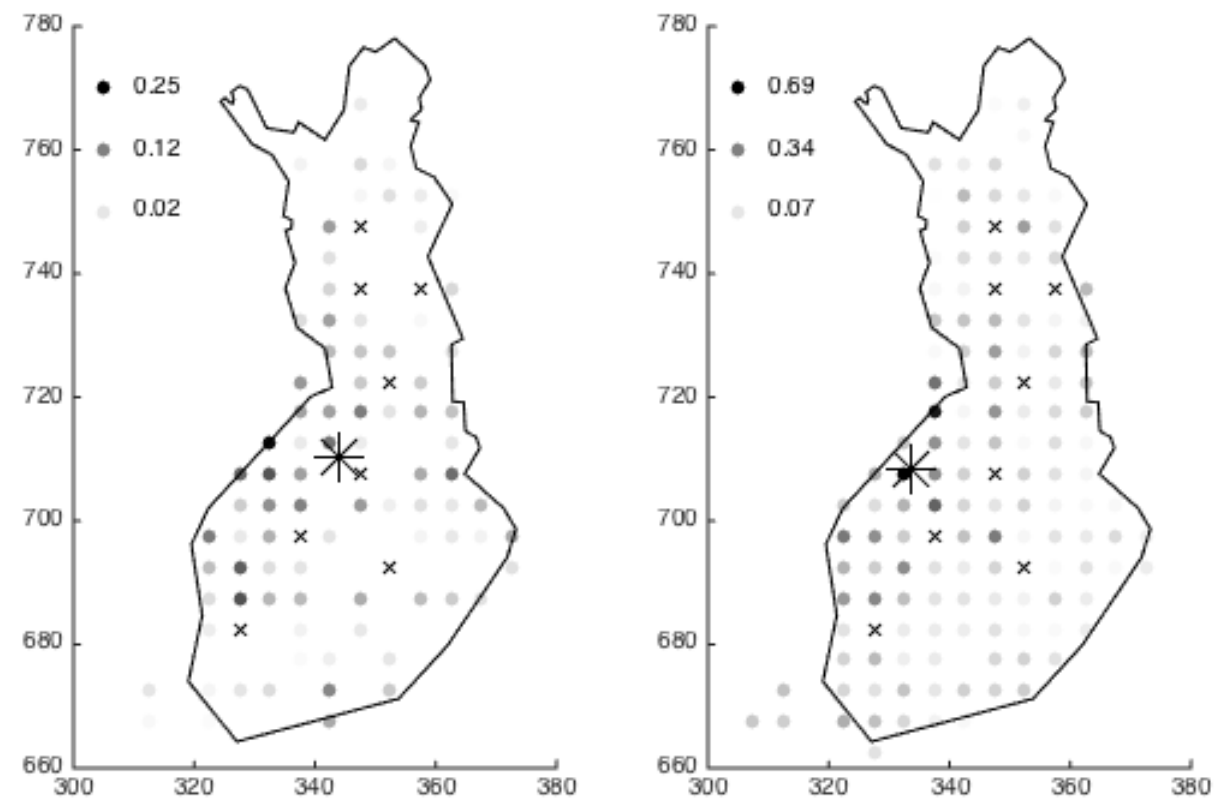

Supplementary fig. 17. Grus grus
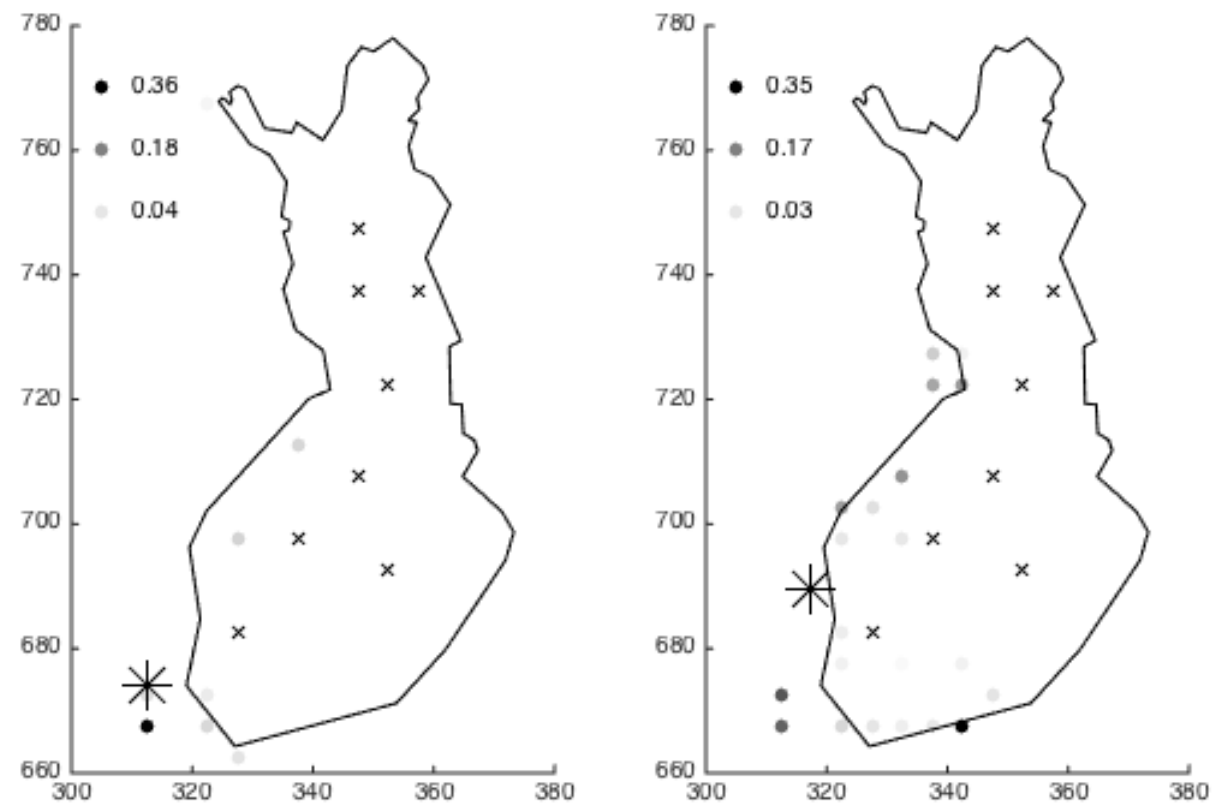

Supplementary fig. 18. Haematopus ostralegus 

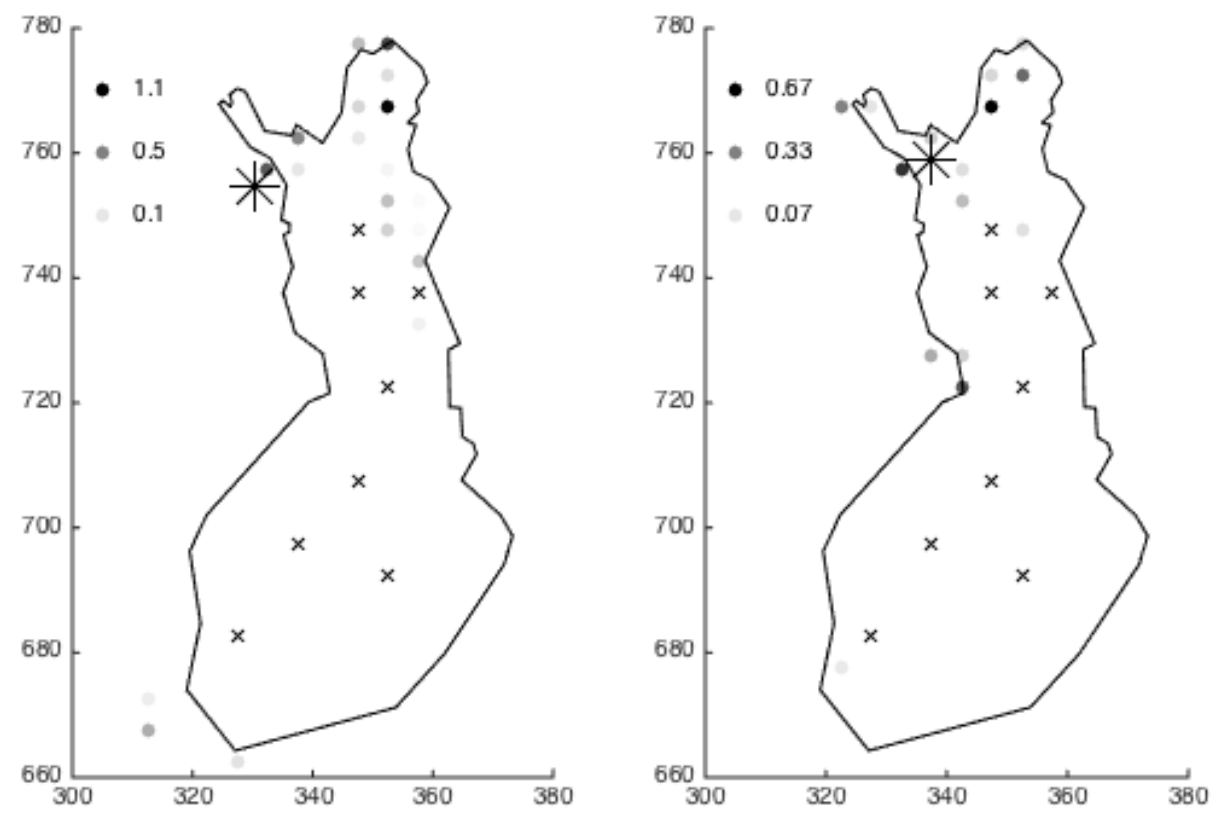

Supplementary fig. 19. Charadrius hiaticula
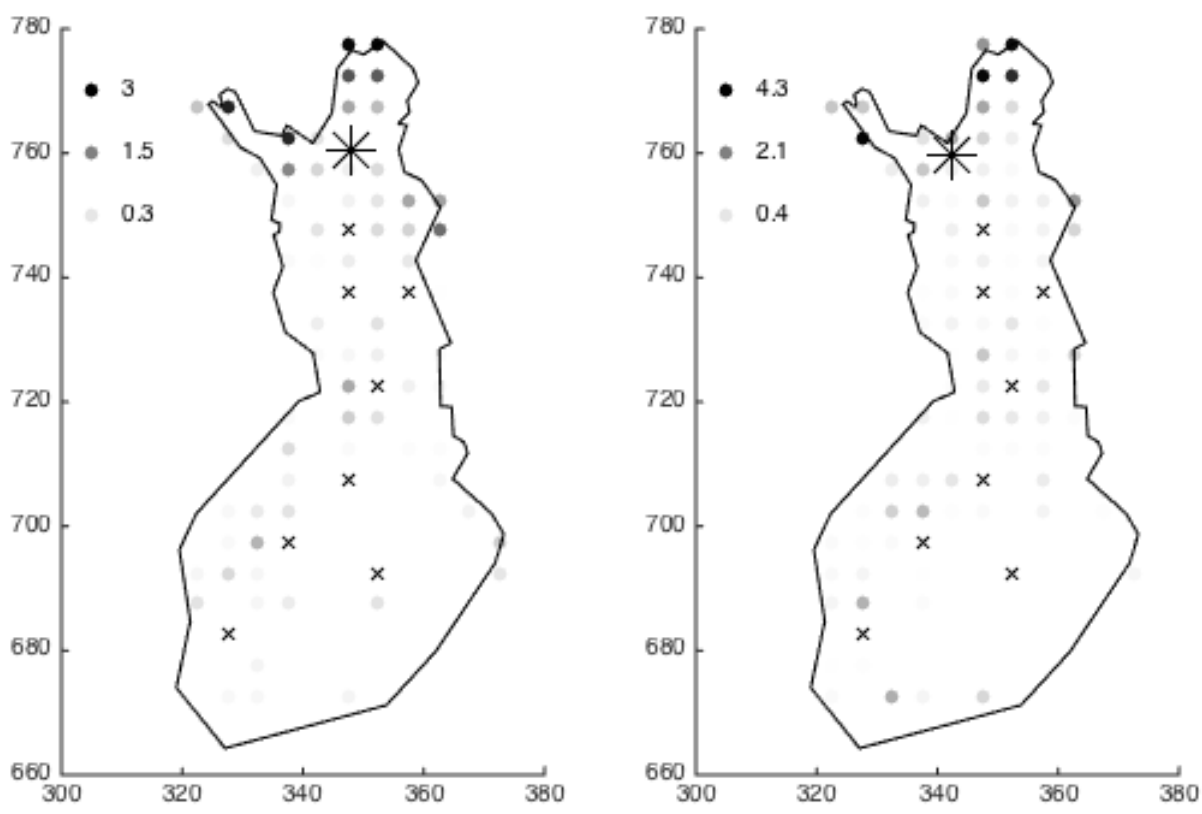

Supplementary fig. 20. Pluvialis apricaria 

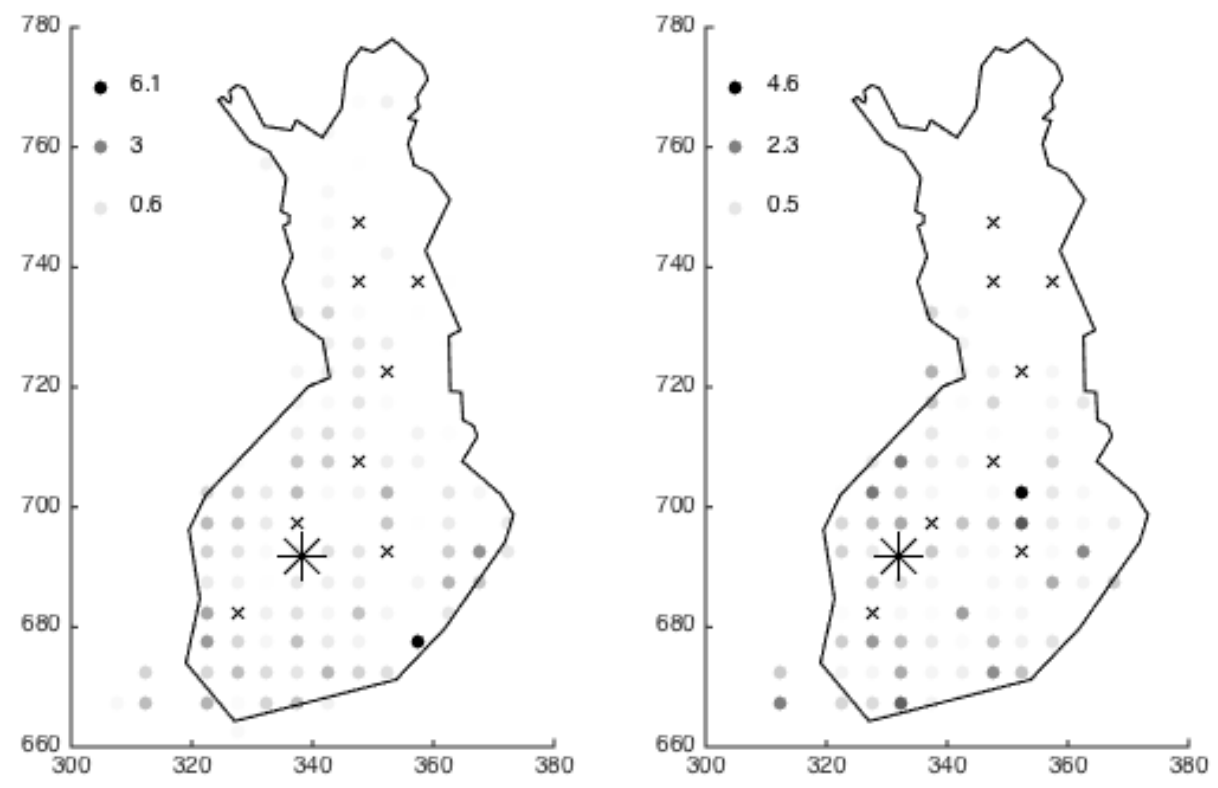

Supplementary fig. 21. Vanellus vanellus
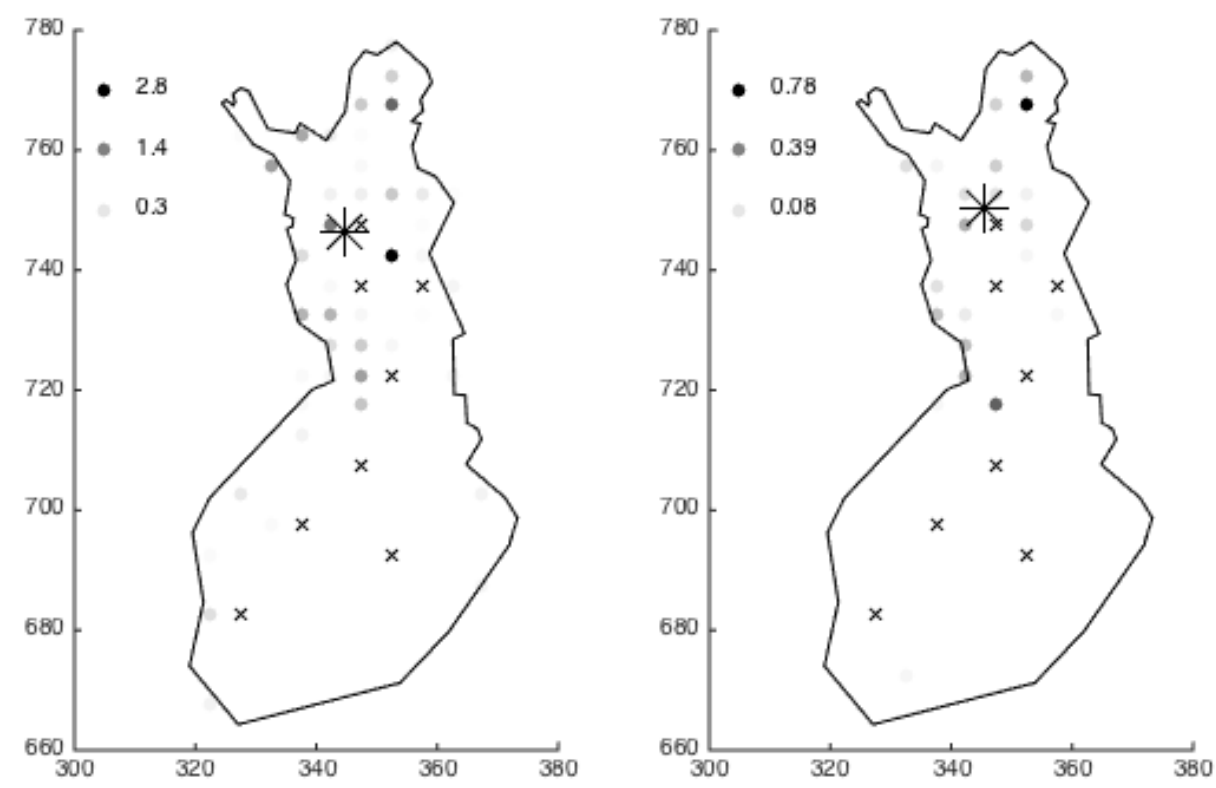

Supplementary fig. 22. Calidris pugnax 

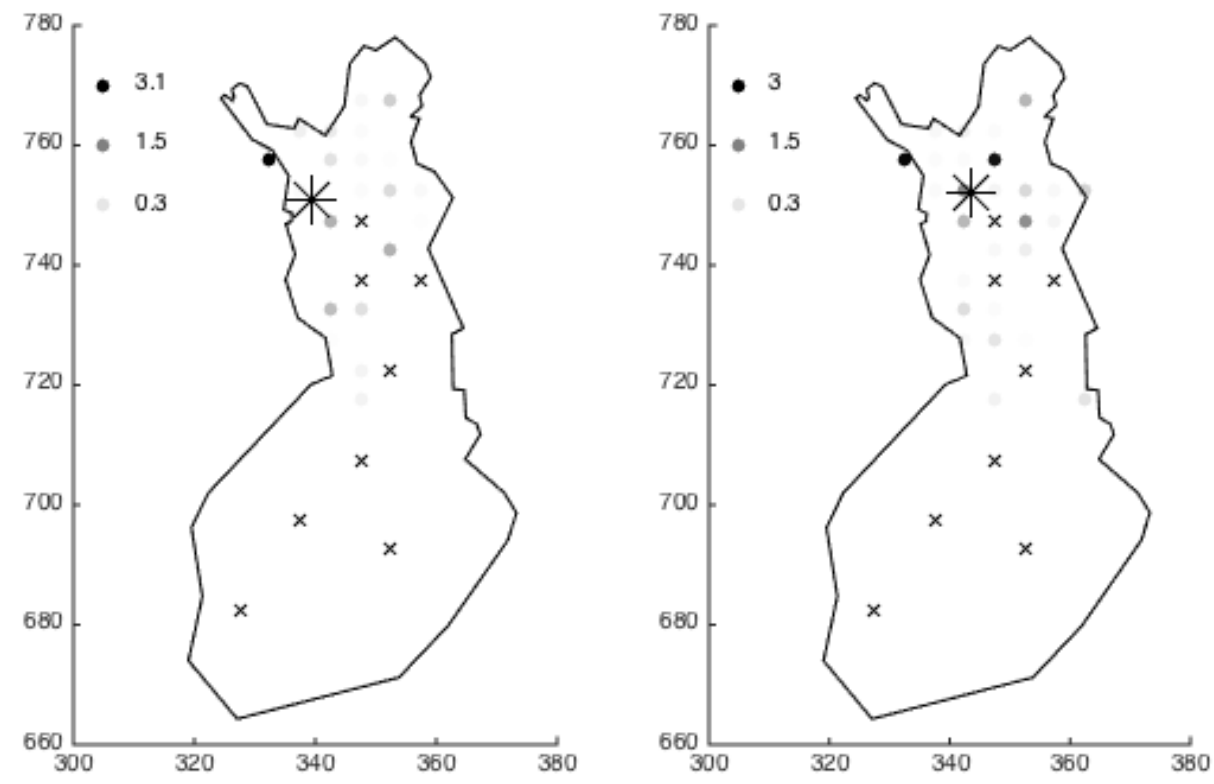

Supplementary fig. 23. Calidris falcinellus
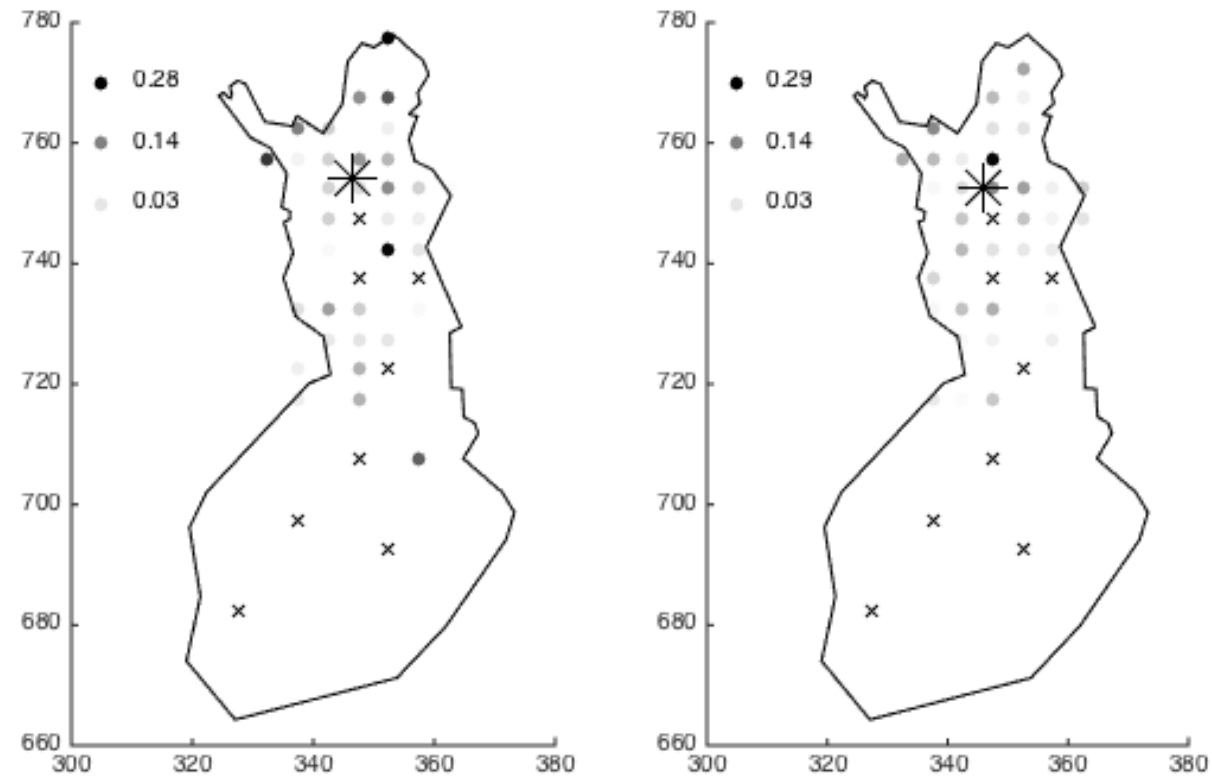

Supplementary fig. 24. Lymnocryptes minumus 

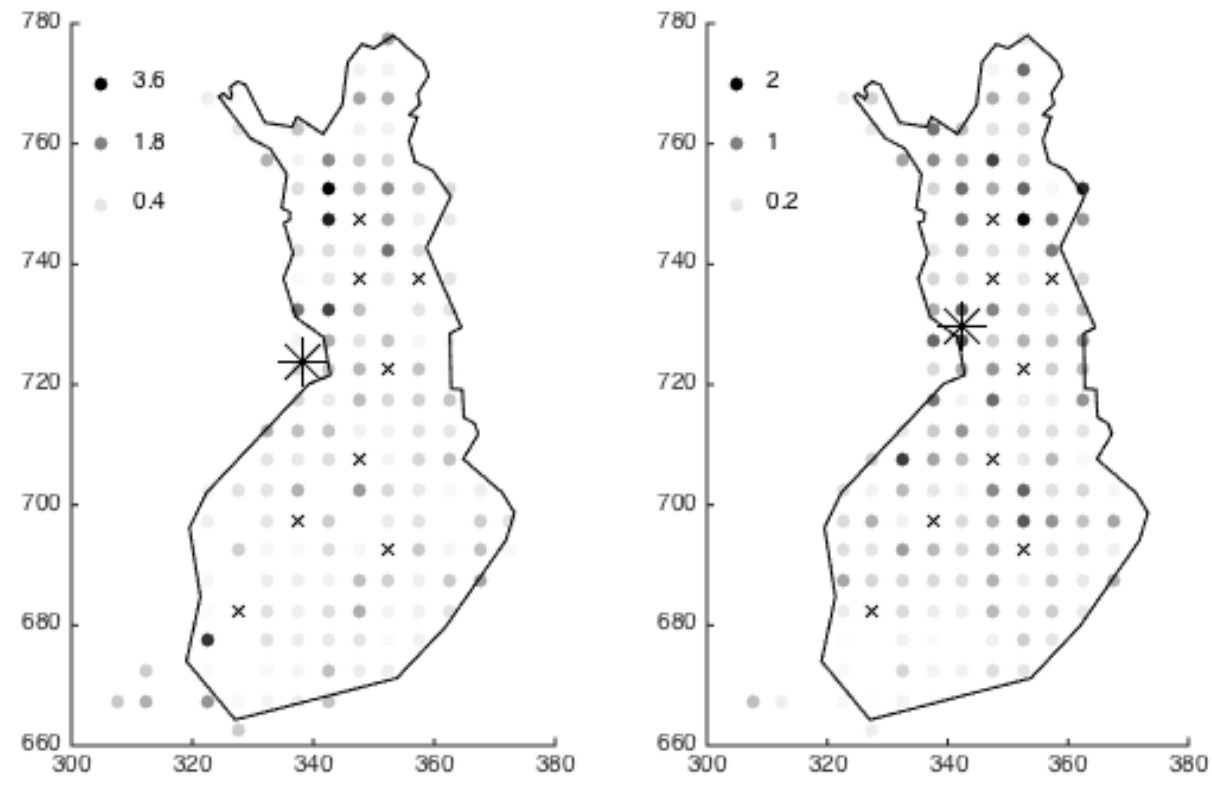

Supplementary fig. 25. Gallinago gallinago
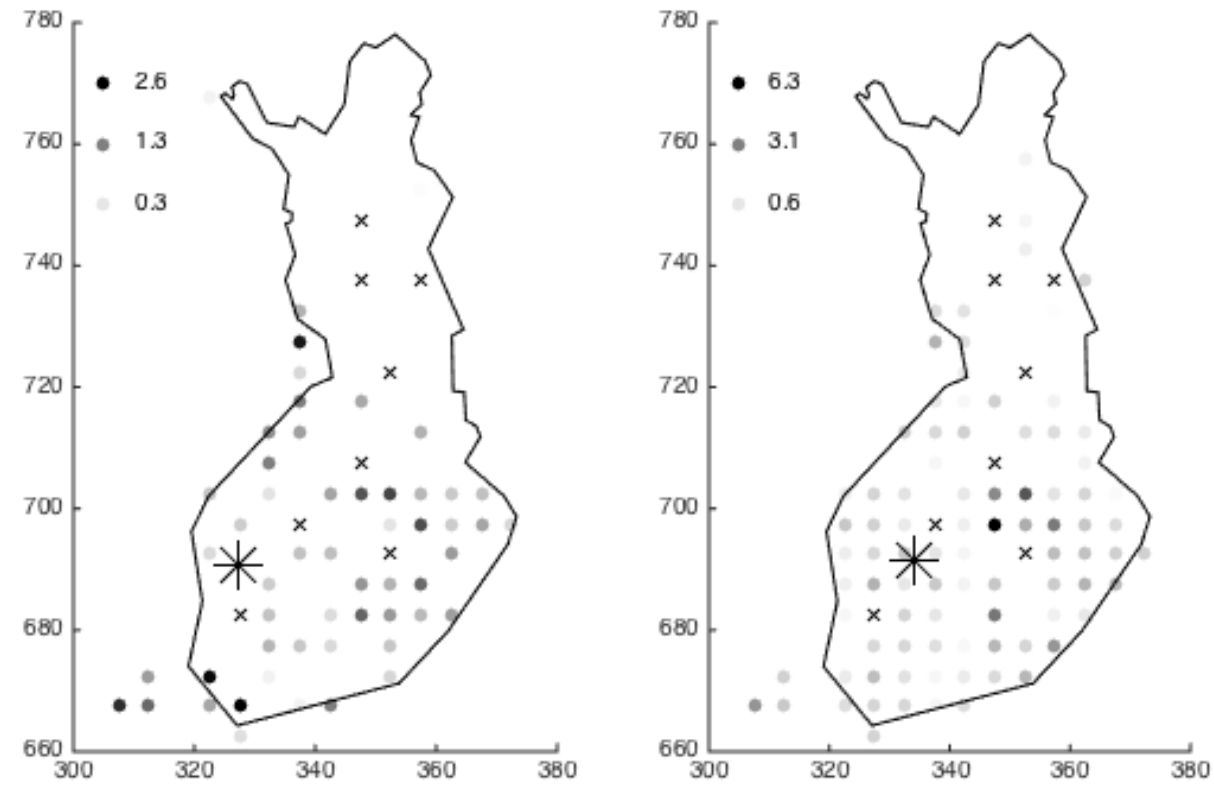

Supplementary fig. 26. Scolopax rusticola 

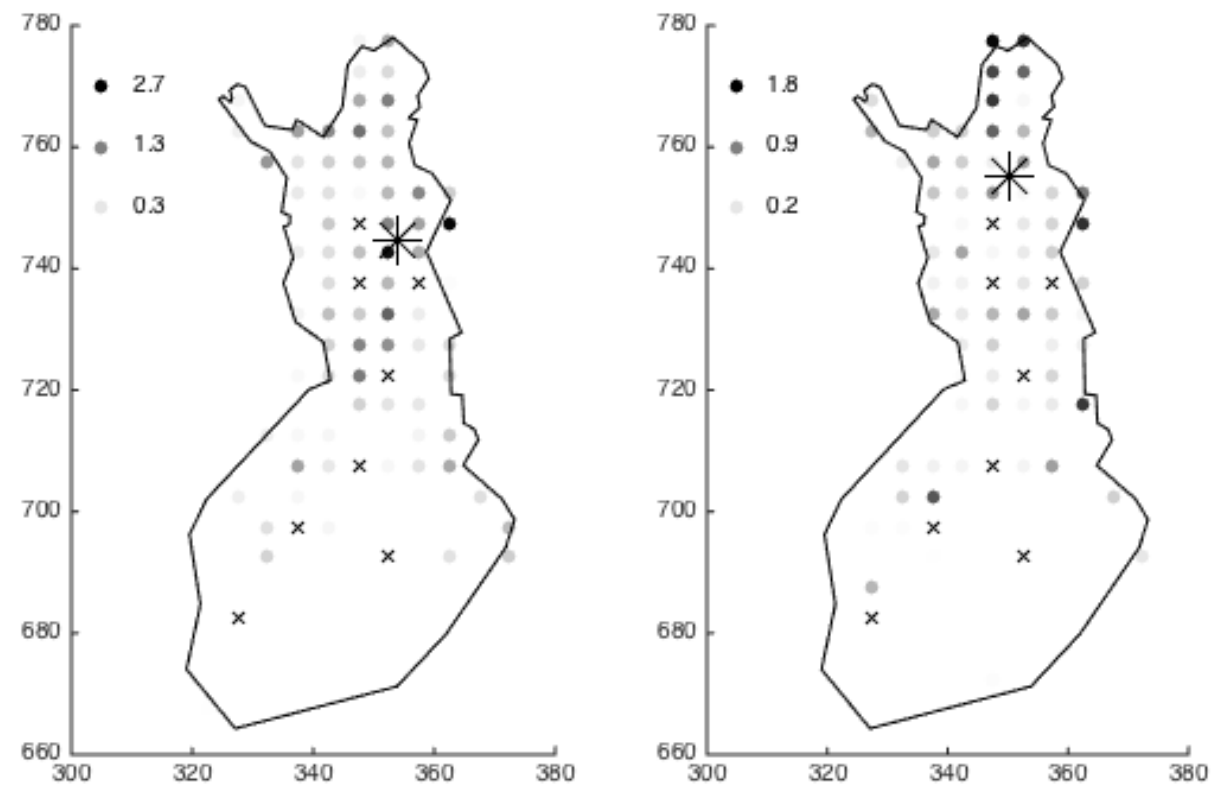

Supplementary fig. 27. Numenius phaeopus
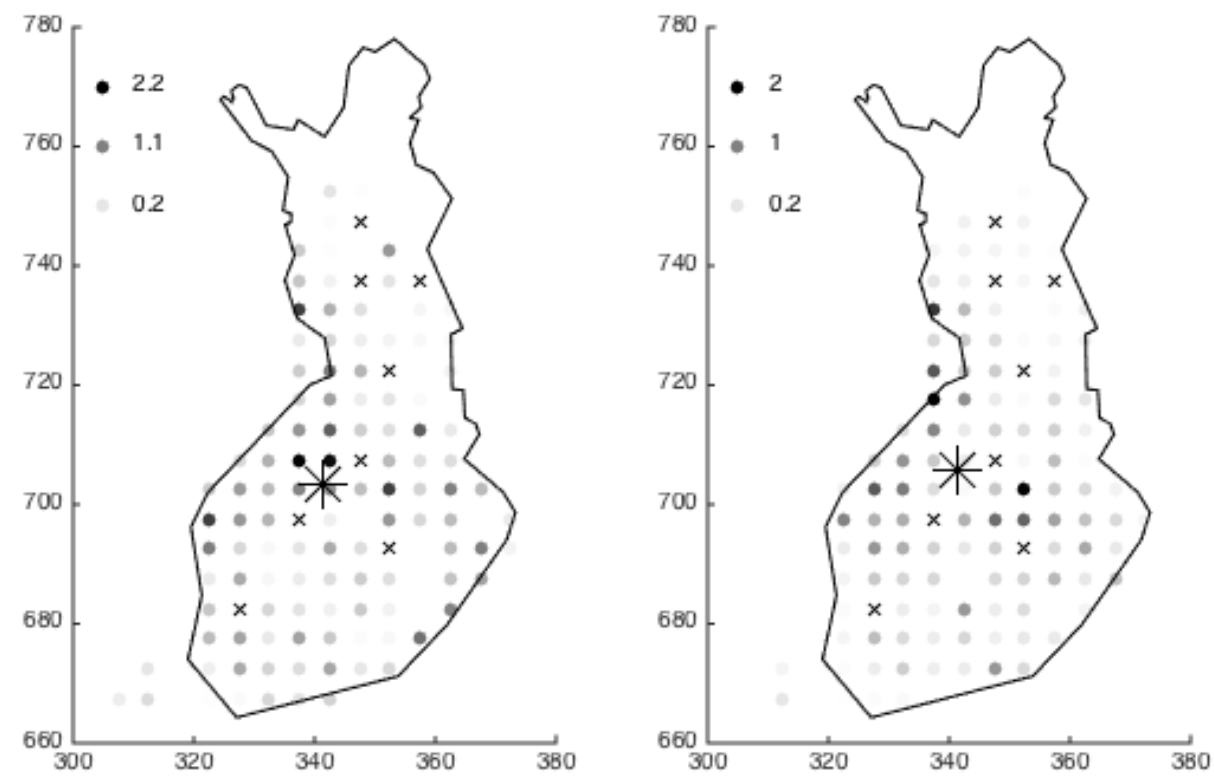

Supplementary fig. 28. Numenius arquata 

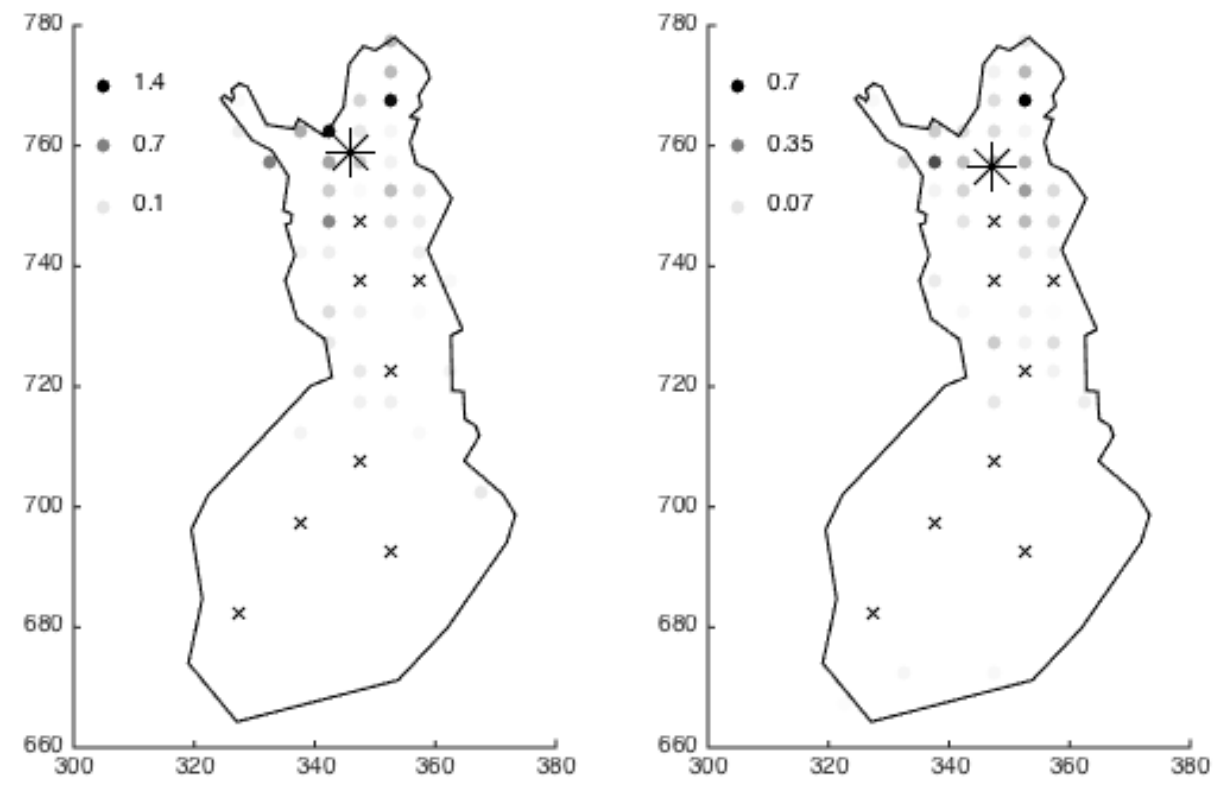

Supplementary fig. 29. Tringa erythropus
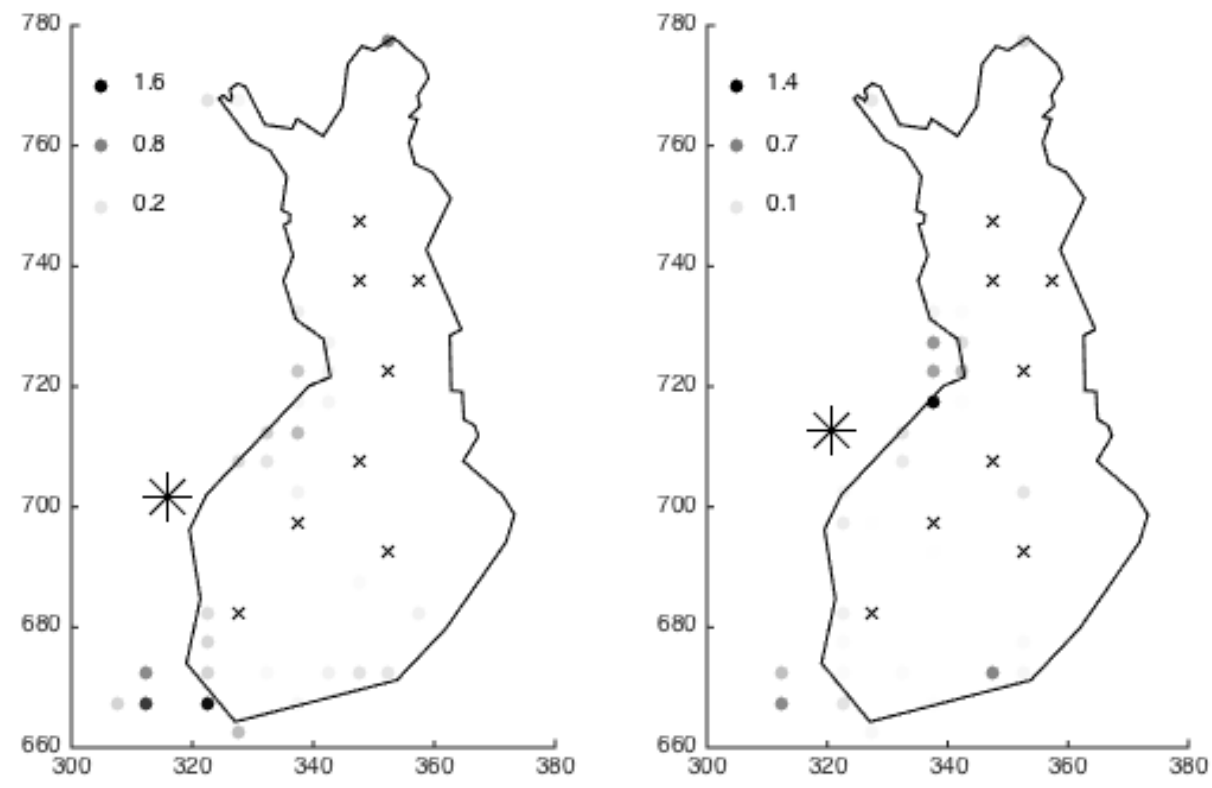

Supplementary fig. 30. Tringa totanus 

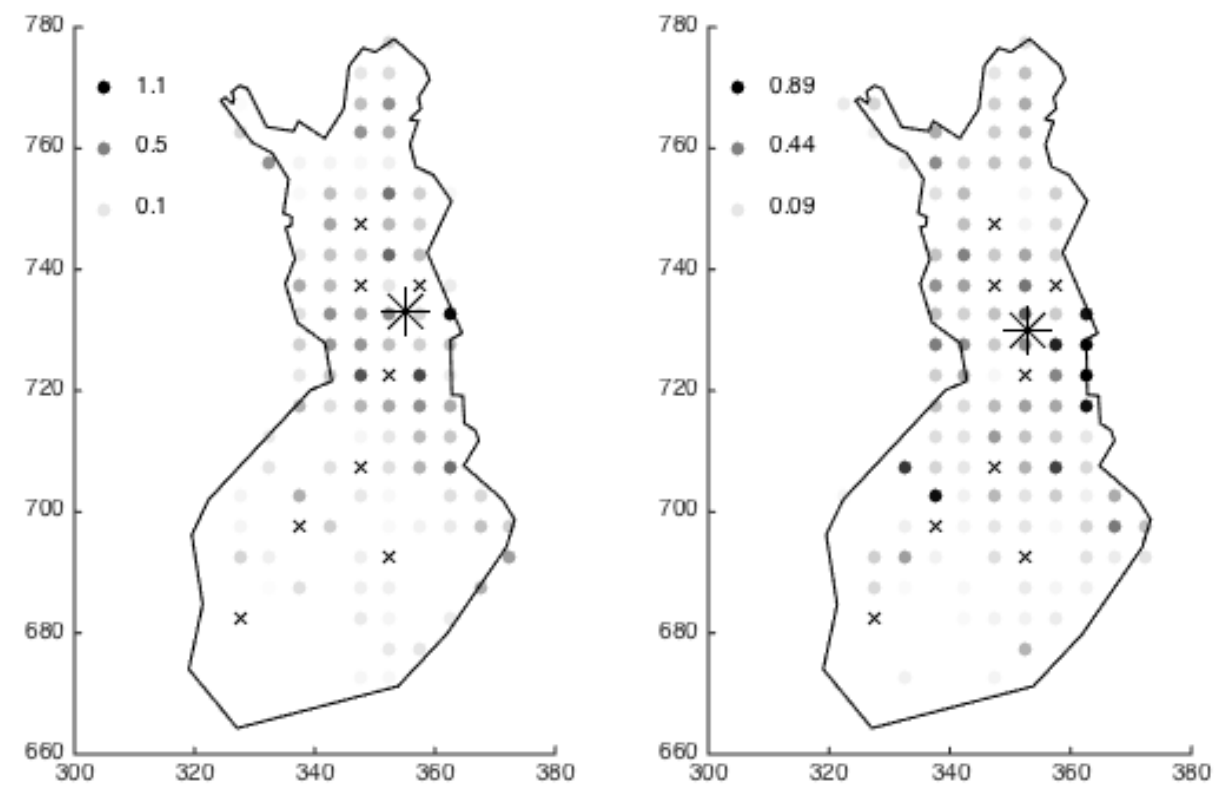

Supplementary fig. 31. Tringa nebularia
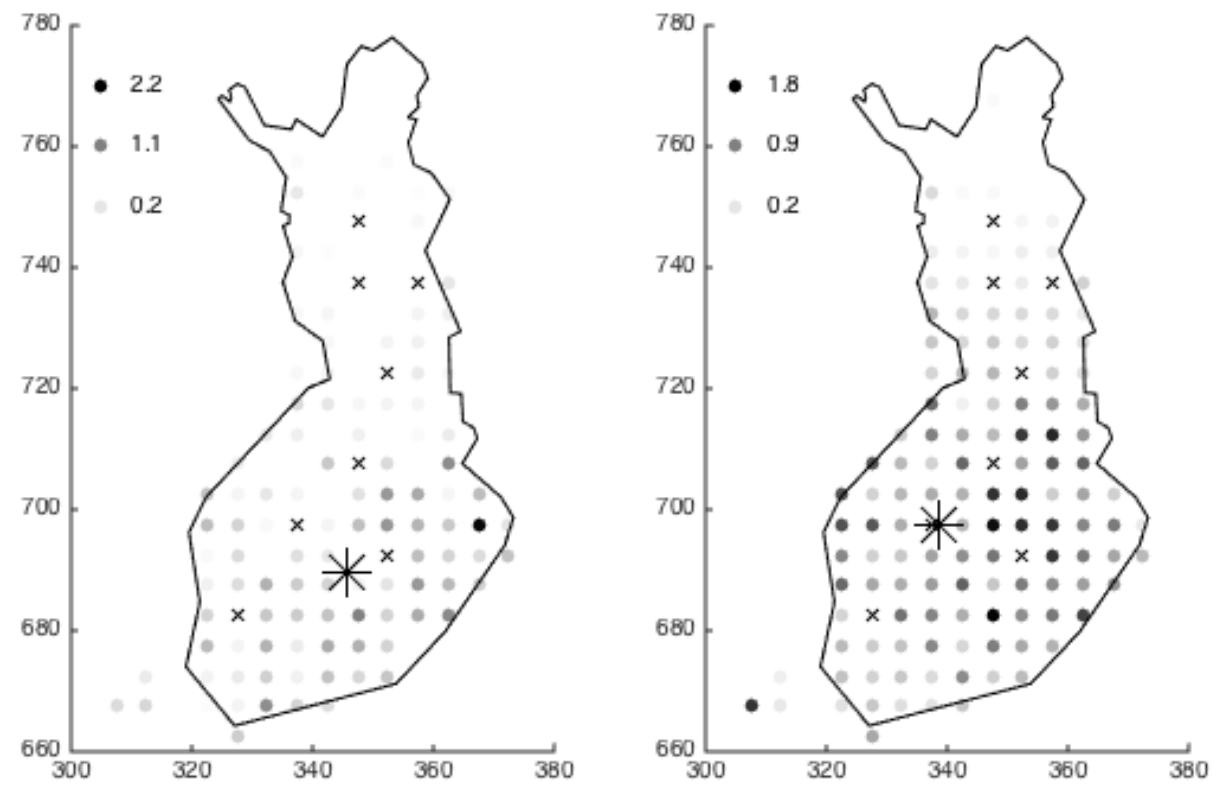

Supplementary fig. 32. Tringa ochropus 

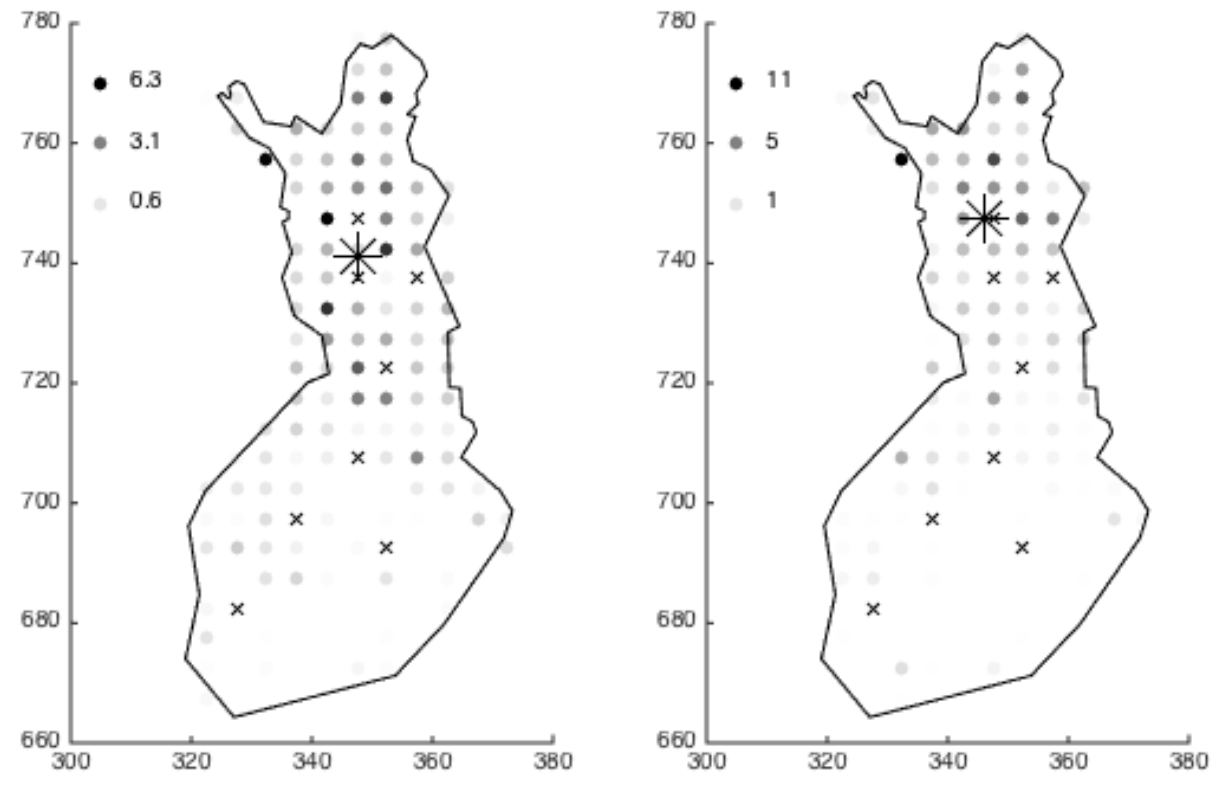

Supplementary fig. 33. Tringa glareola
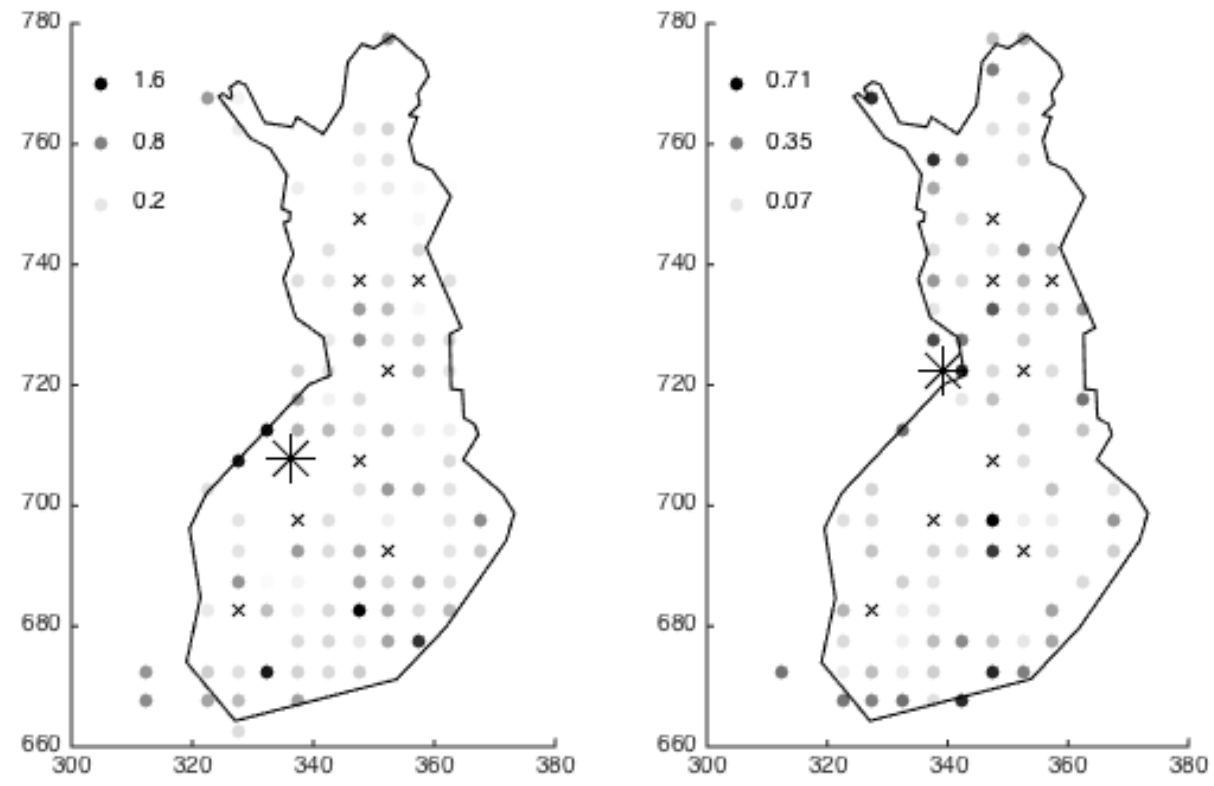

Supplementary fig. 34. Actitis hypoleucos 

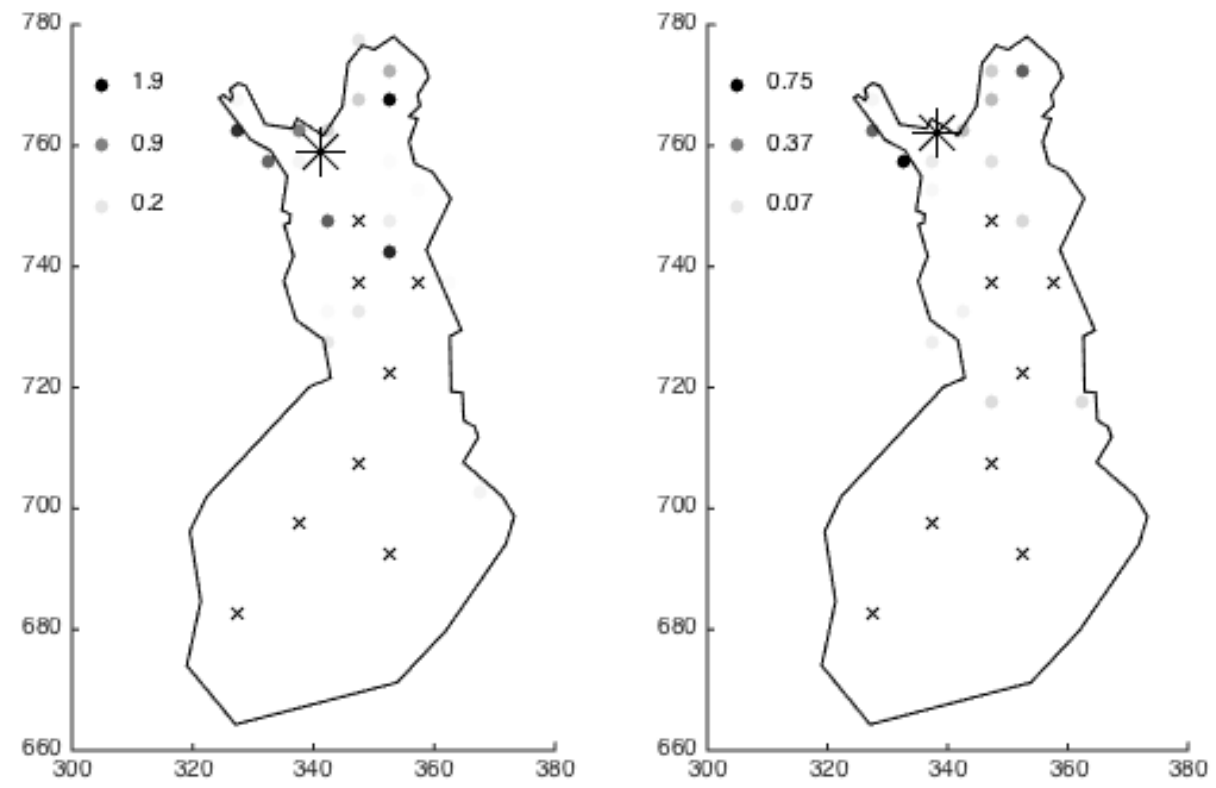

Supplementary fig. 35. Phalaropus lobatus
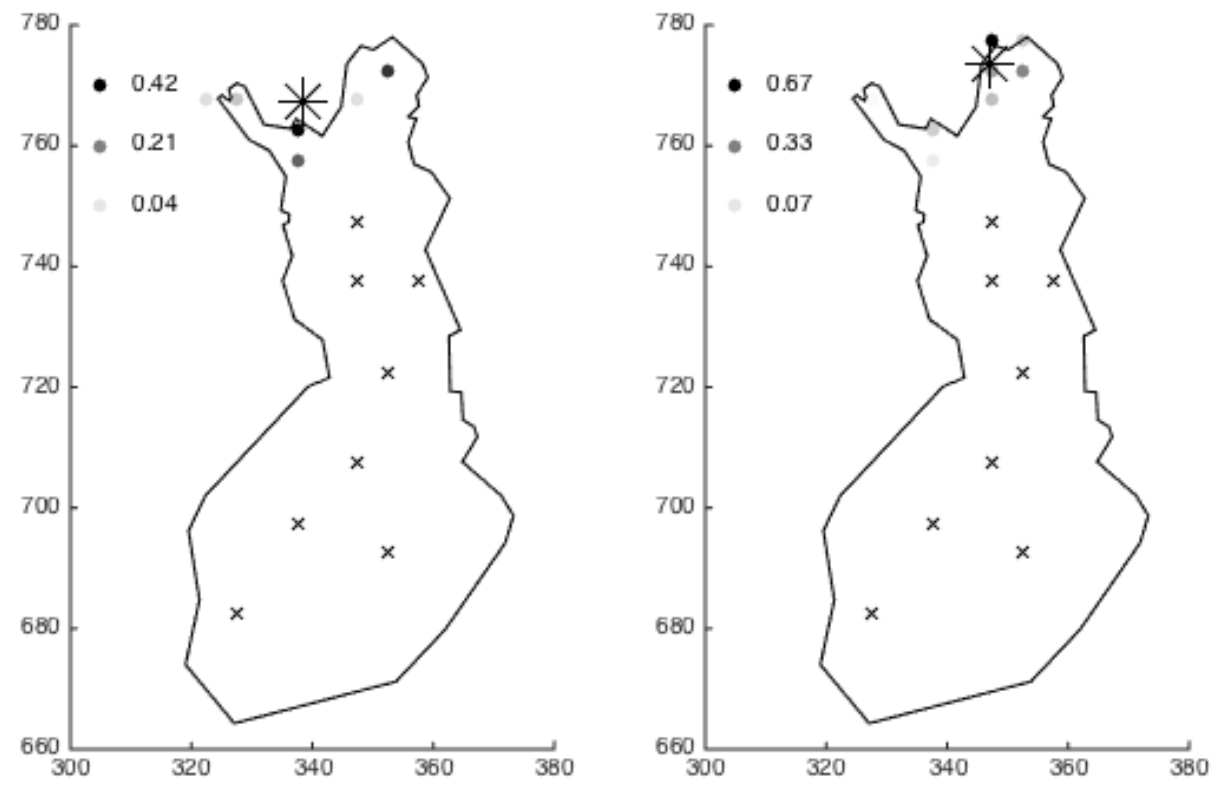

Supplementary fig. 36. Stercorarius longicaudus 

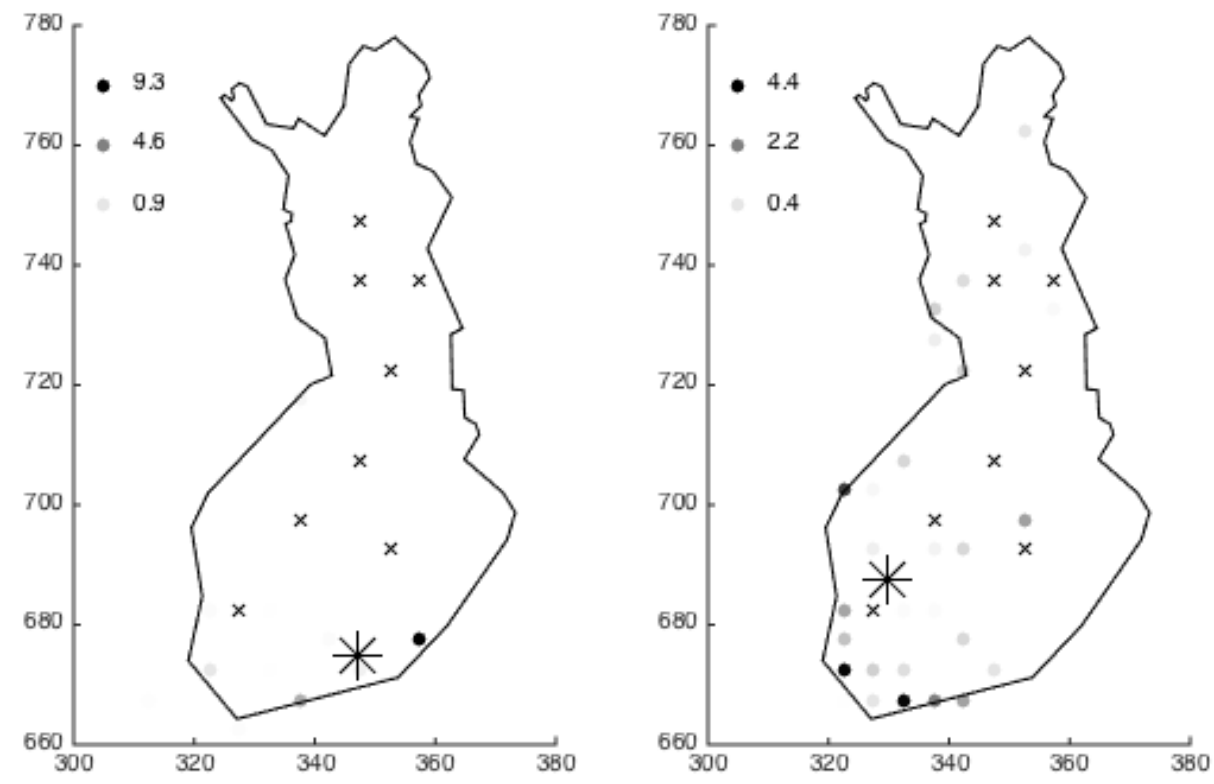

Supplementary fig. 37. Columba livia
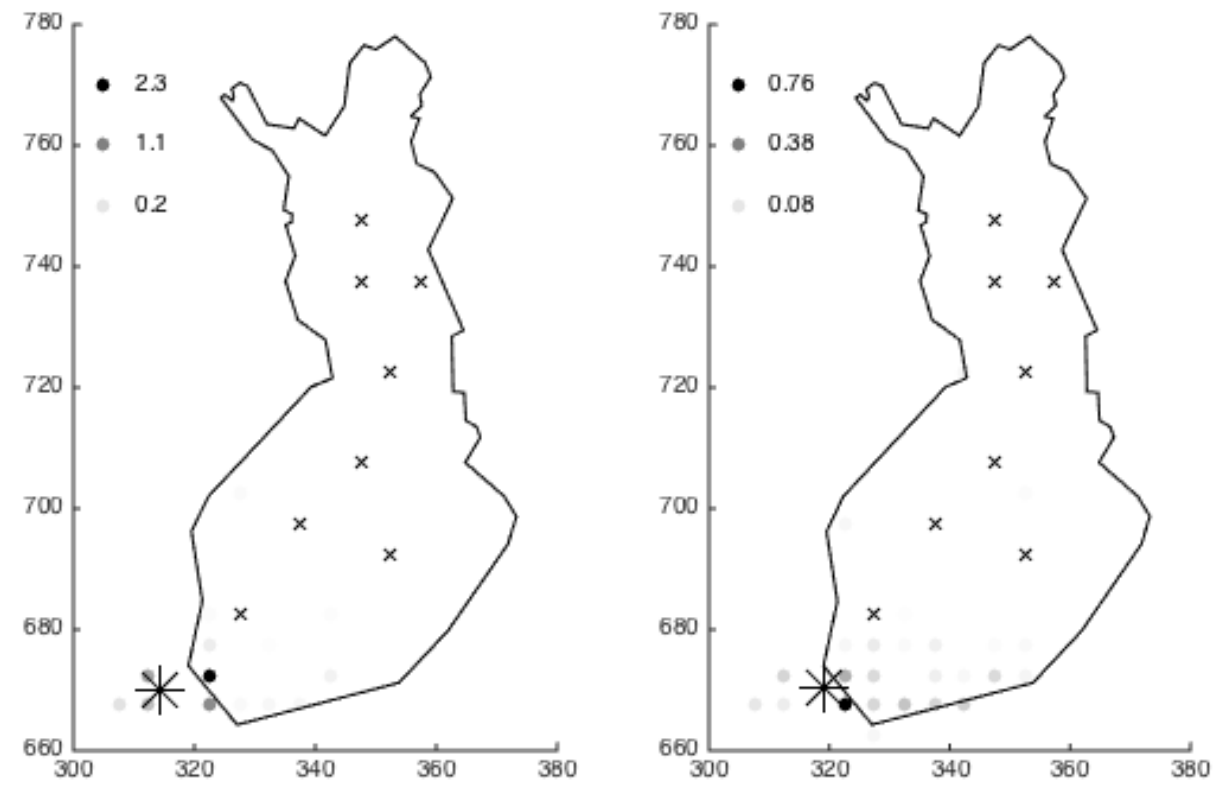

Supplementary fig. 38. Columba oenas 

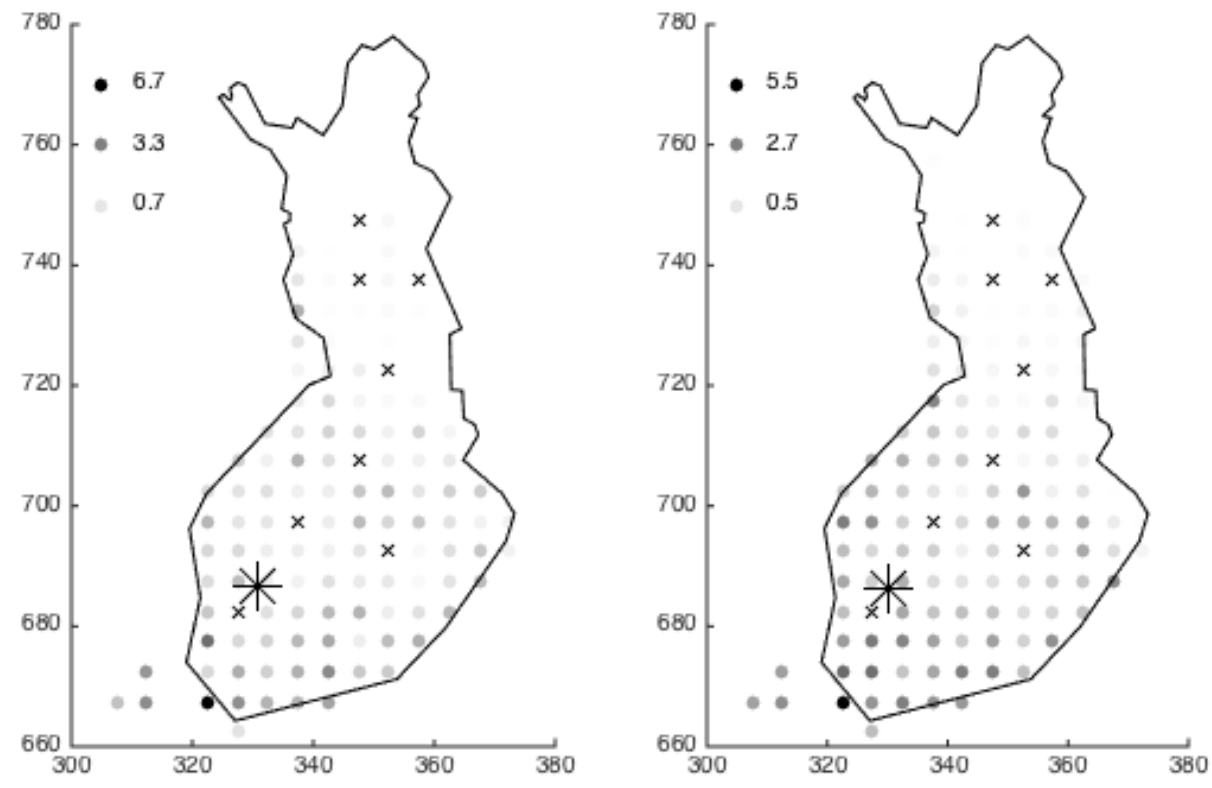

Supplementary fig. 39. Columba palumbus
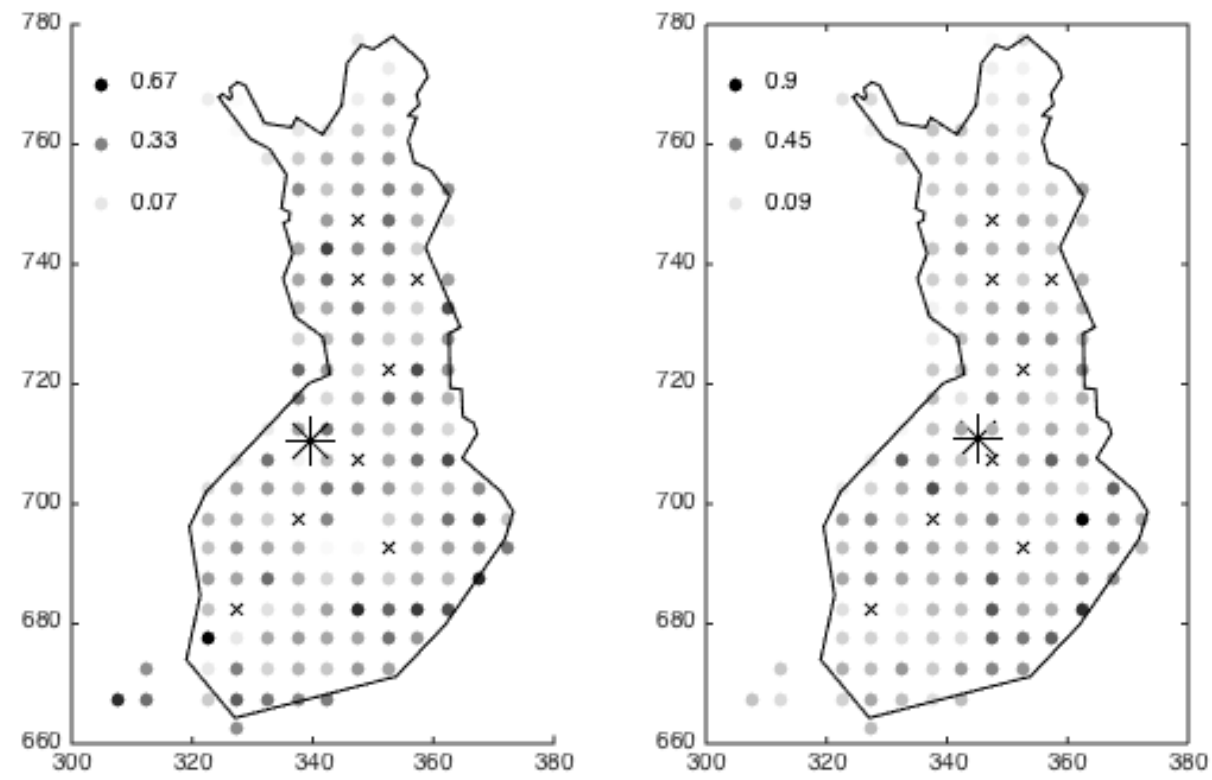

Supplementary fig. 40. Cuculus canorus 

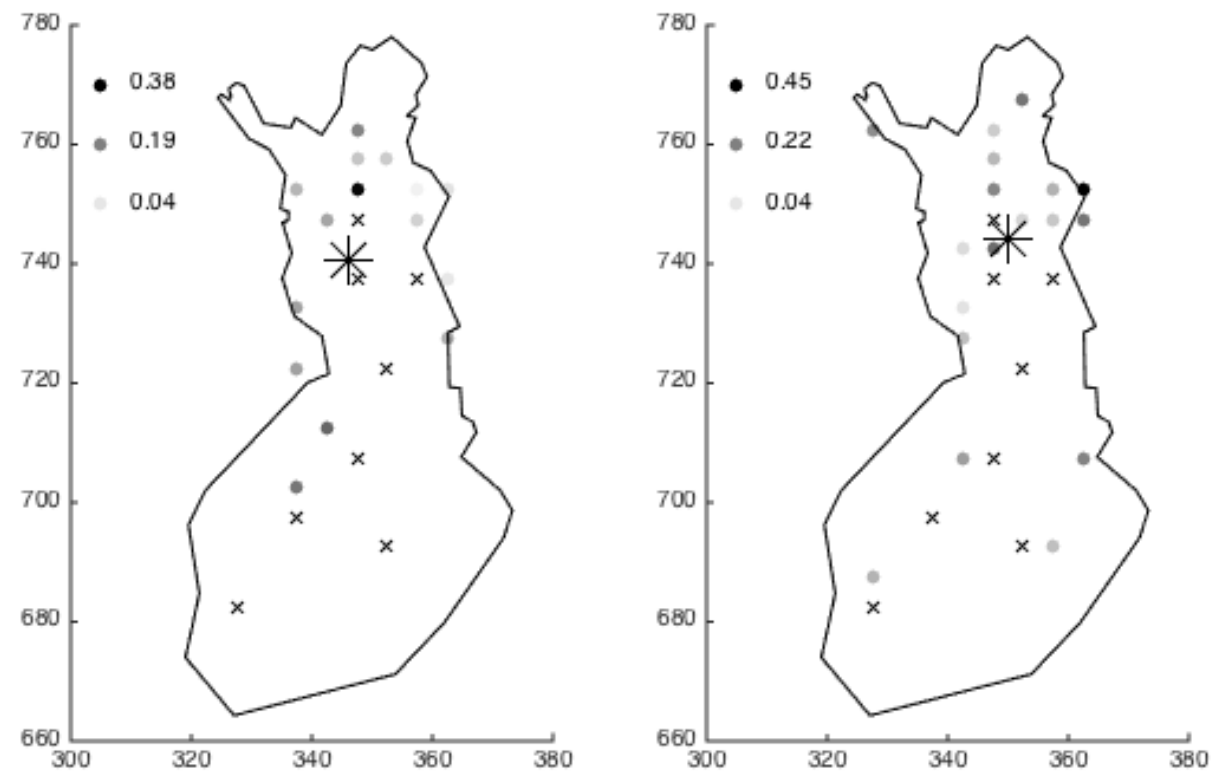

Supplementary fig. 41. Surnia ulula
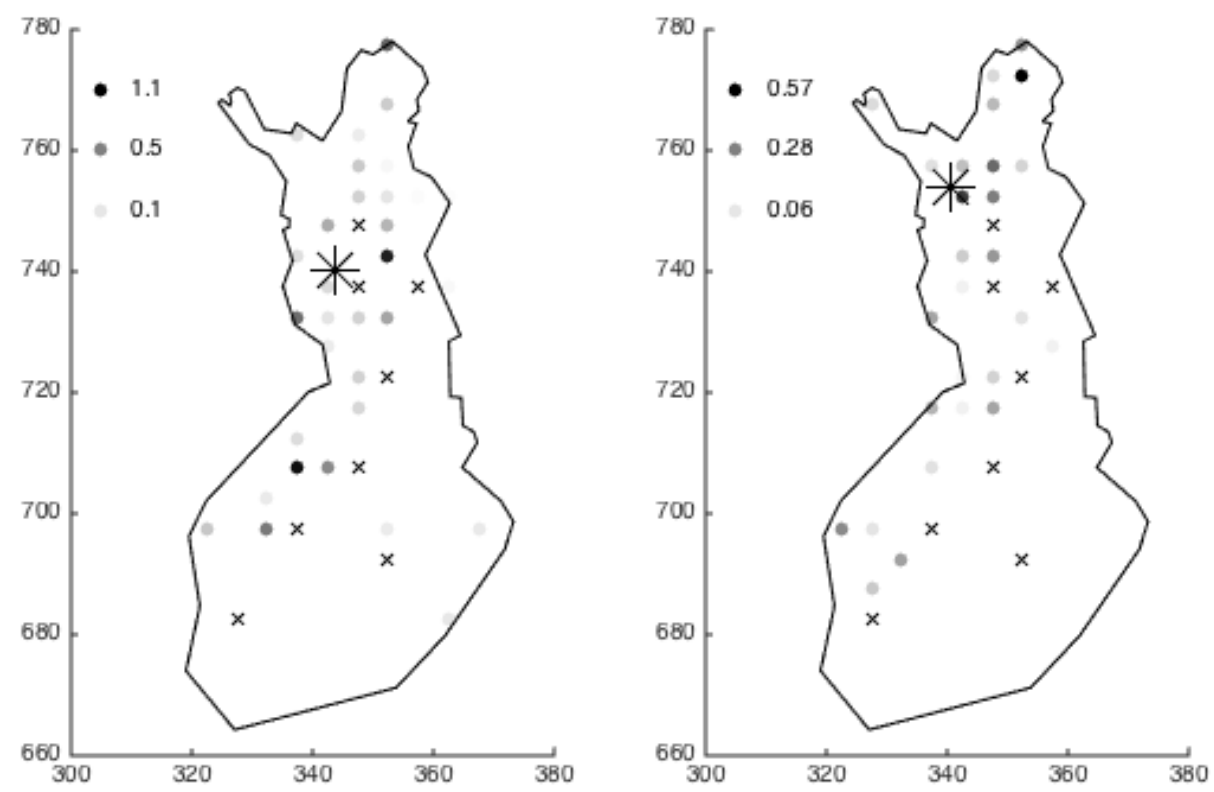

Supplementary fig. 42. Asio flammeus 

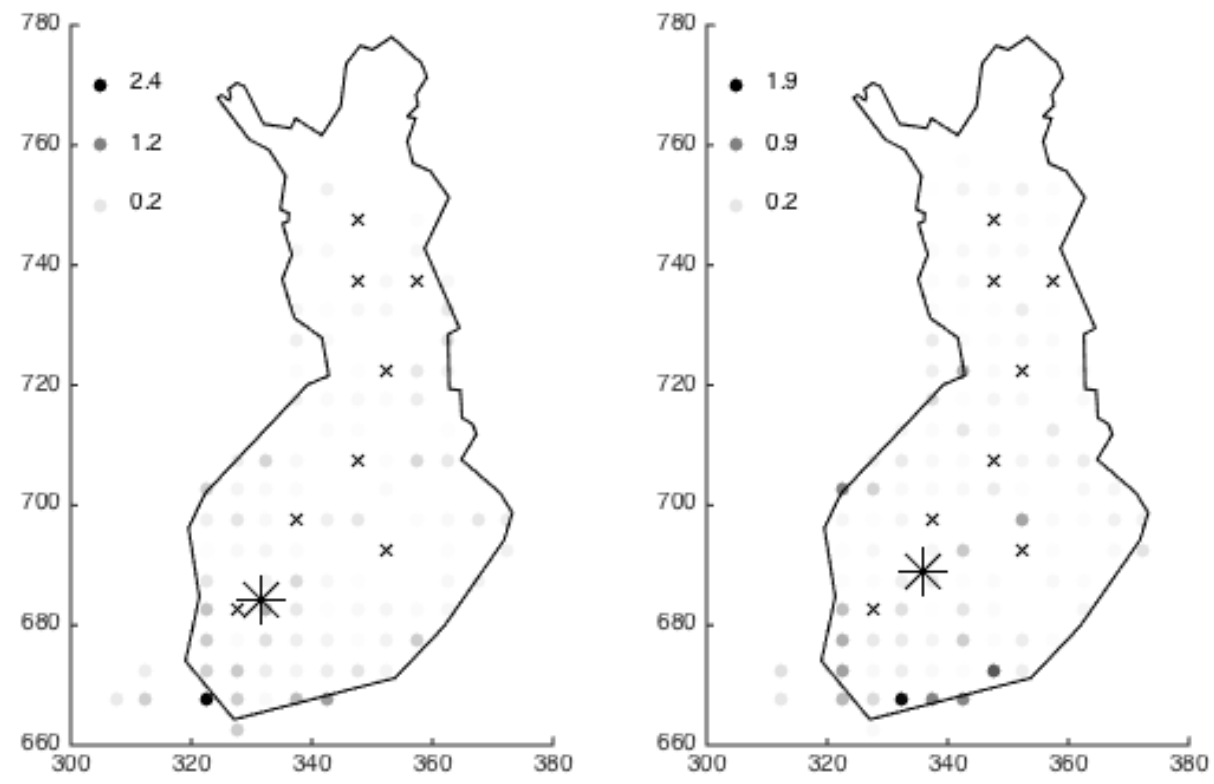

Supplementary fig. 43. Apus apus
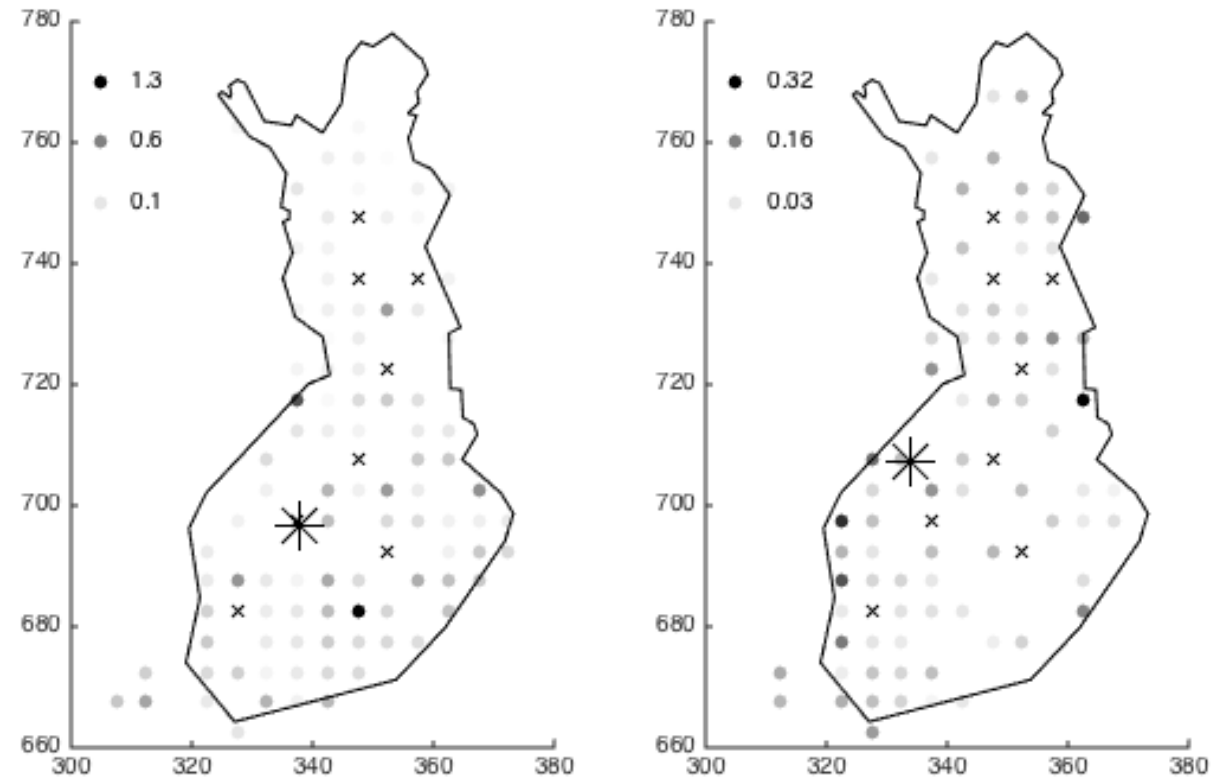

Supplementary fig. 44. Jynx torquilla 

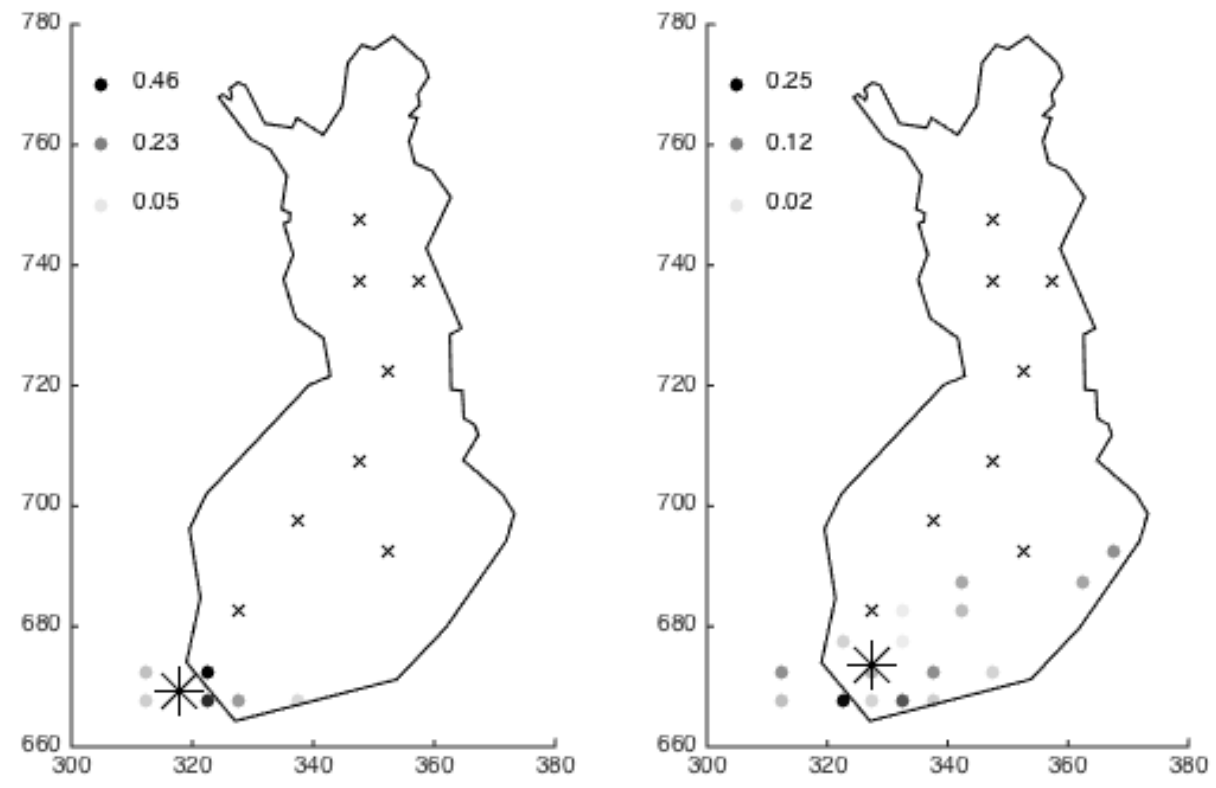

Supplementary fig. 45. Picus canus
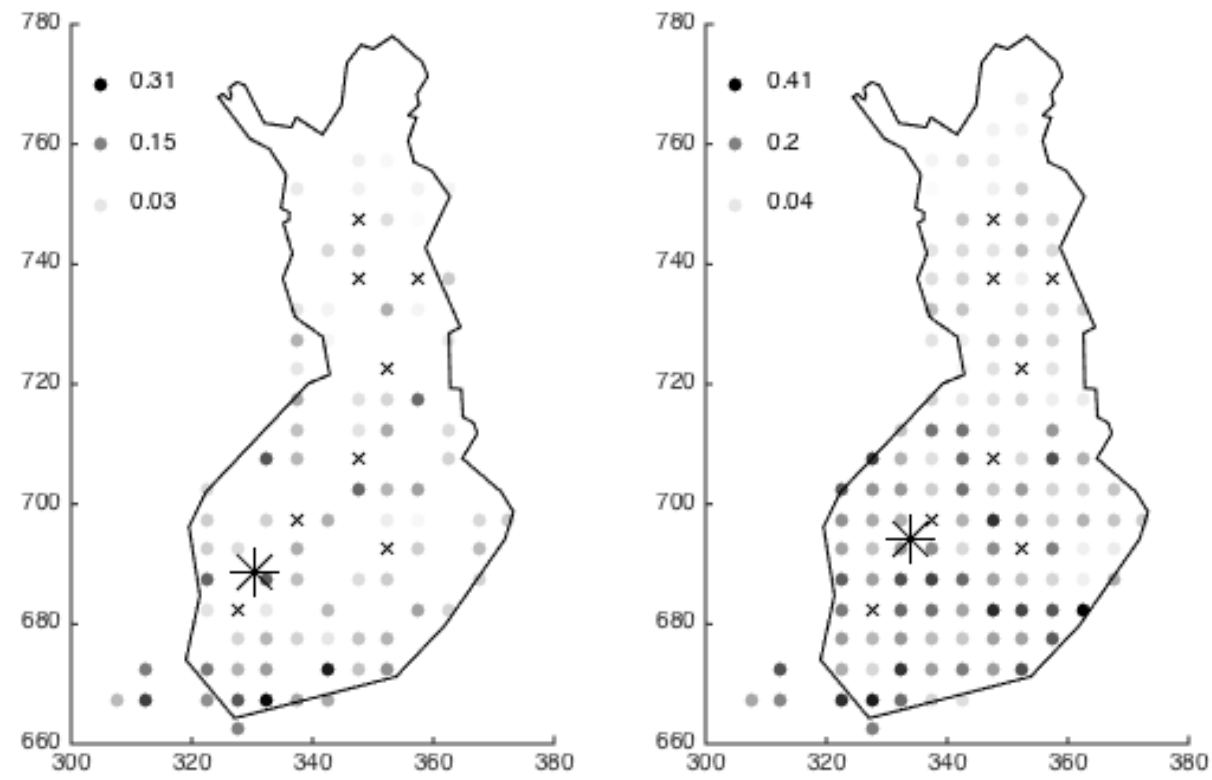

Supplementary fig. 46. Dryocopus martius 

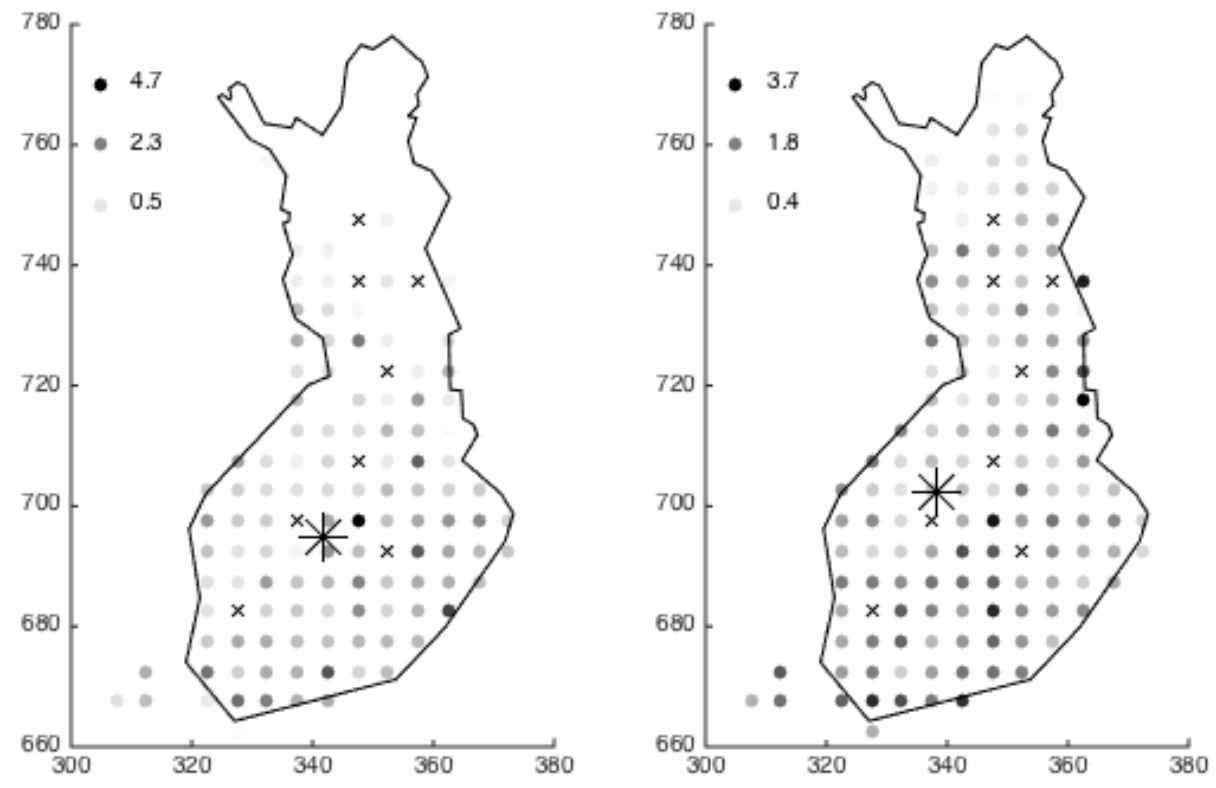

Supplementary fig. 47. Dendrocopos major
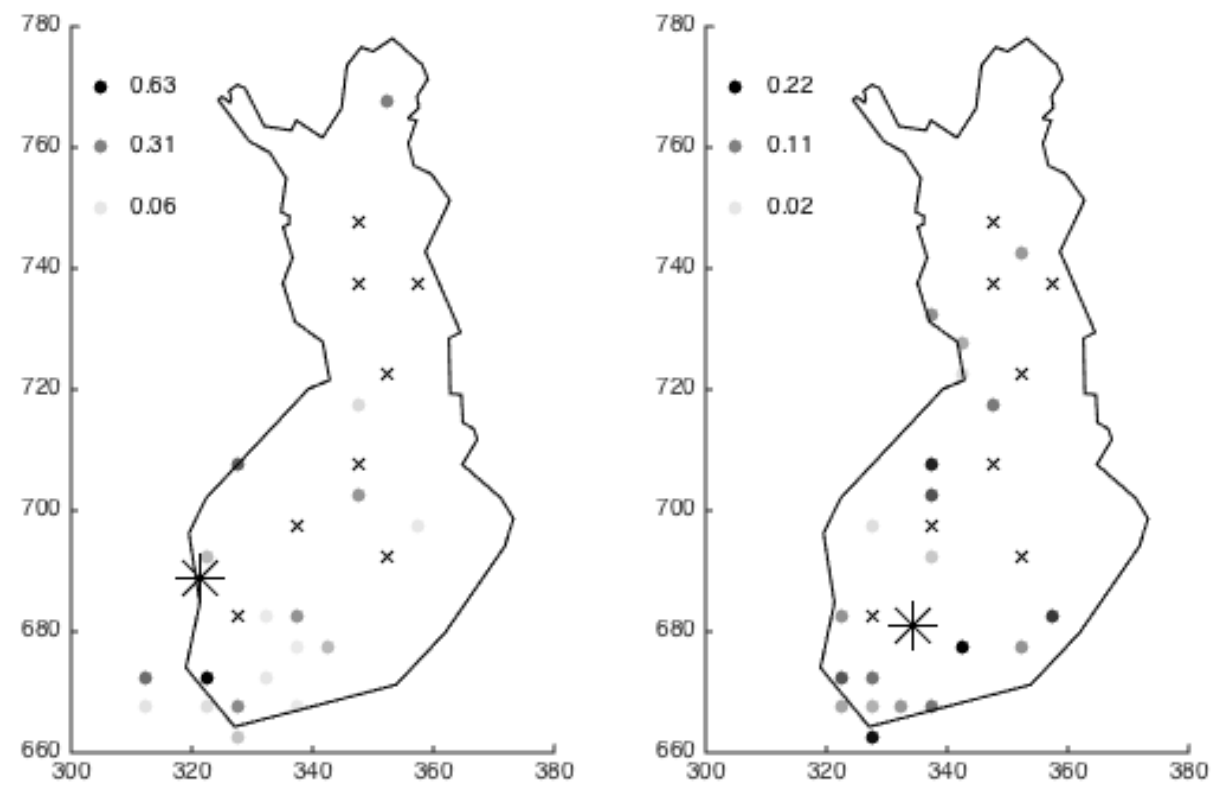

Supplementary fig. 48. Dendrocopos minor 

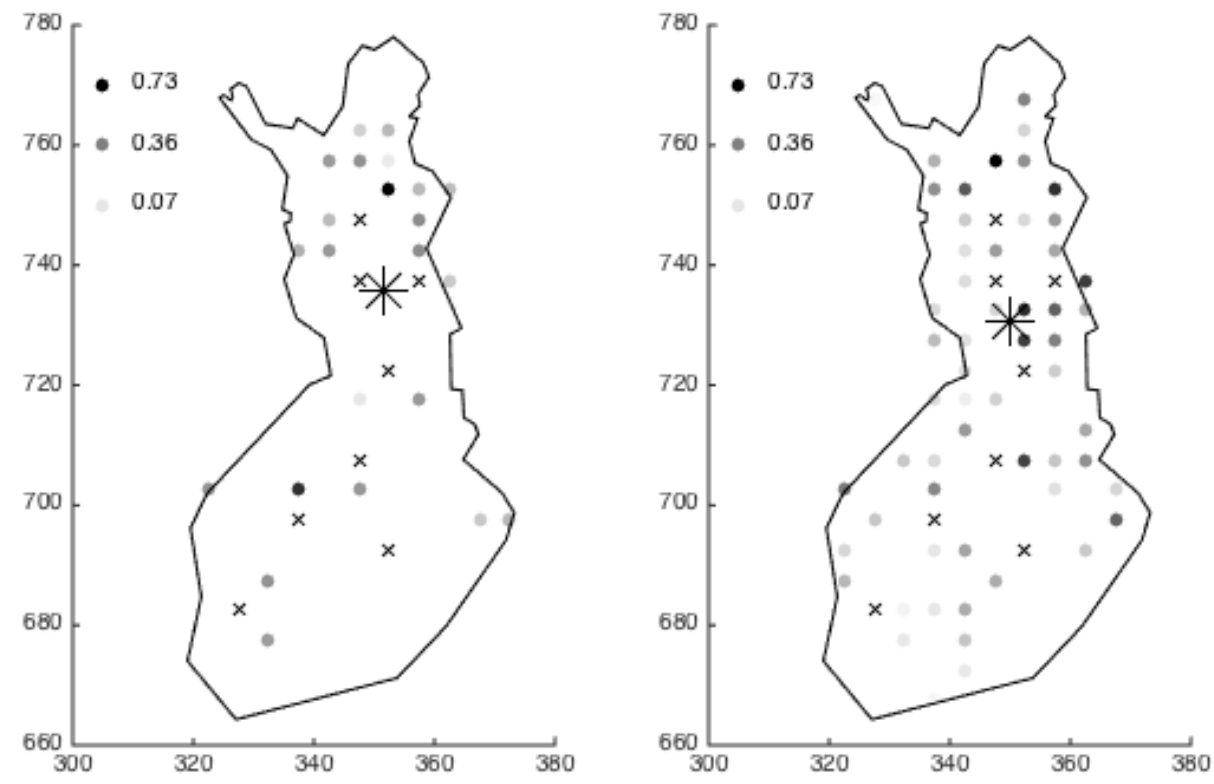

Supplementary fig. 49. Picoides tridactylus
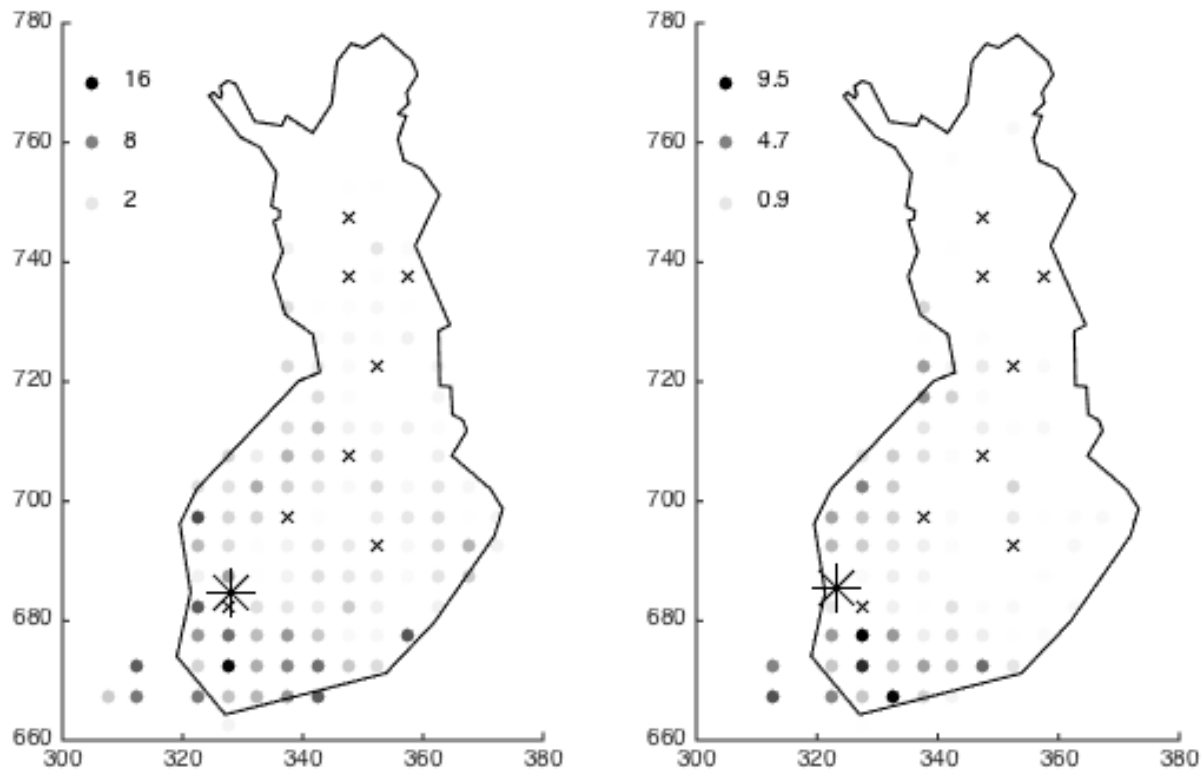

Supplementary fig. 50. Lullula arborea 

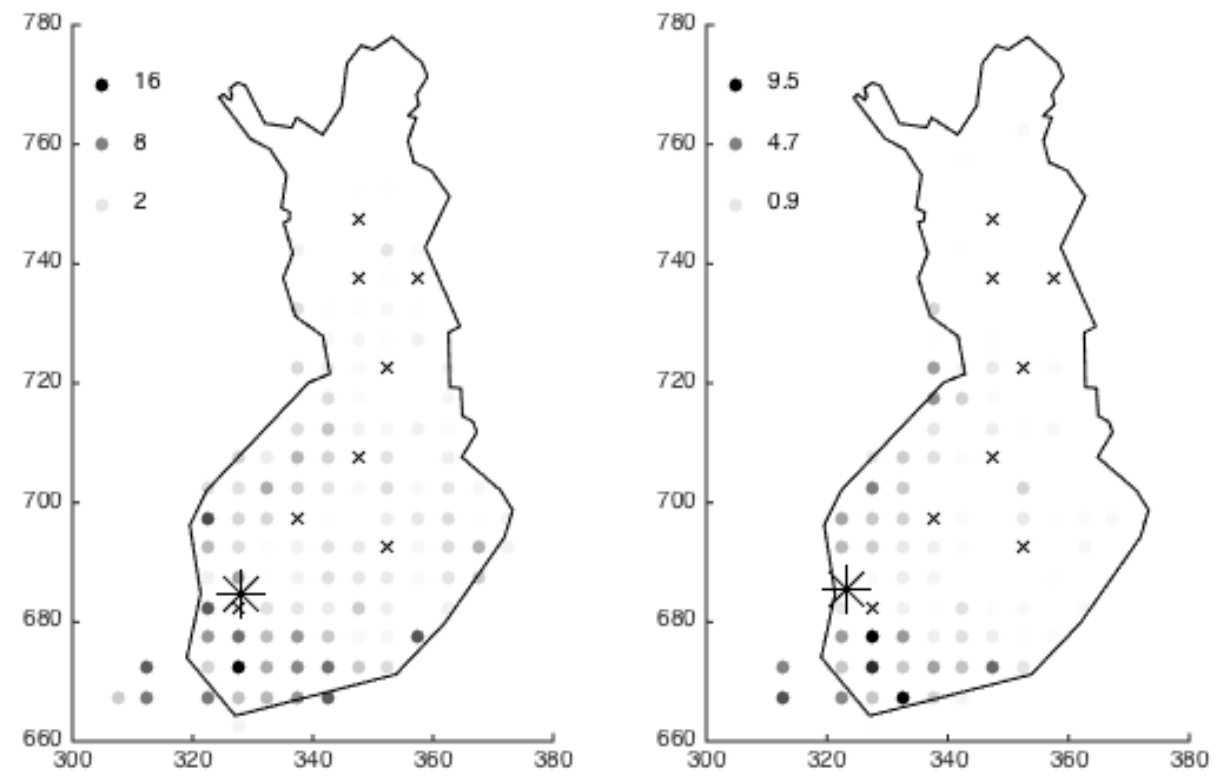

Supplementary fig. 51. Alauda arvensis
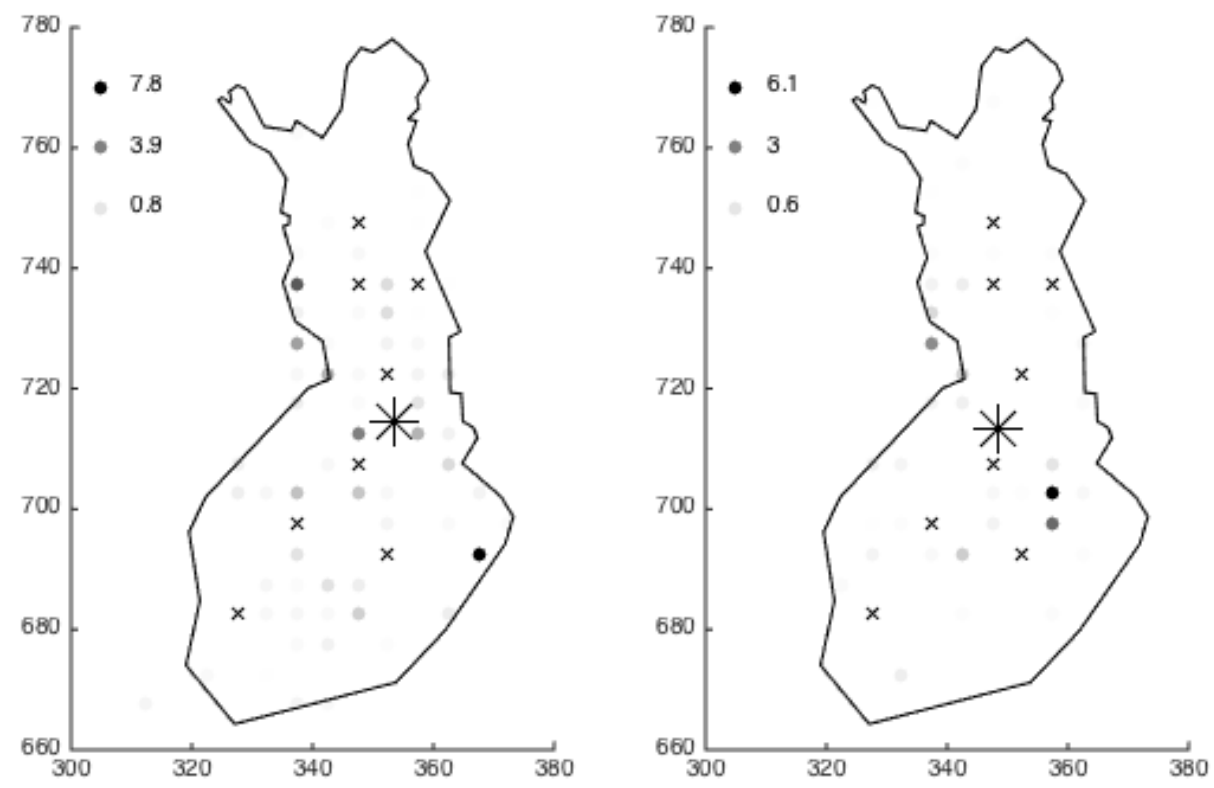

Supplementary fig. 52. Riparia riparia 

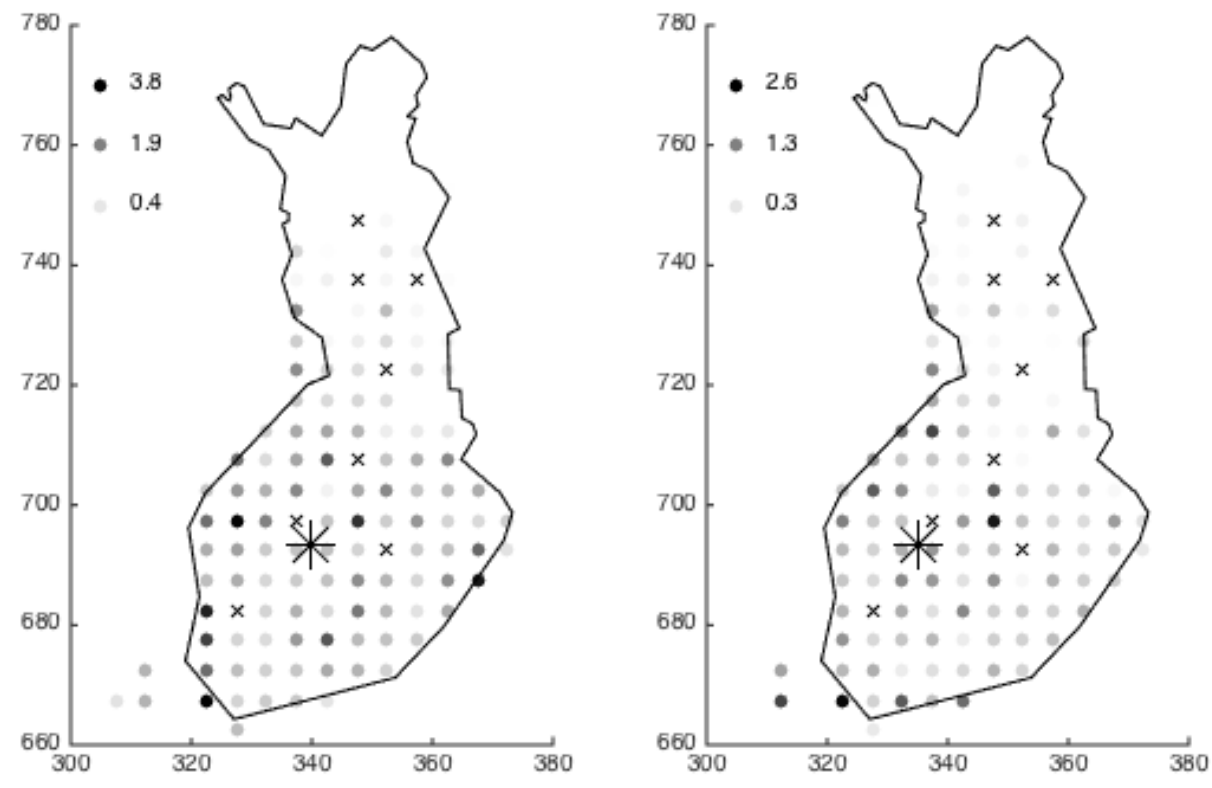

Supplementary fig. 53. Hirundo rustica
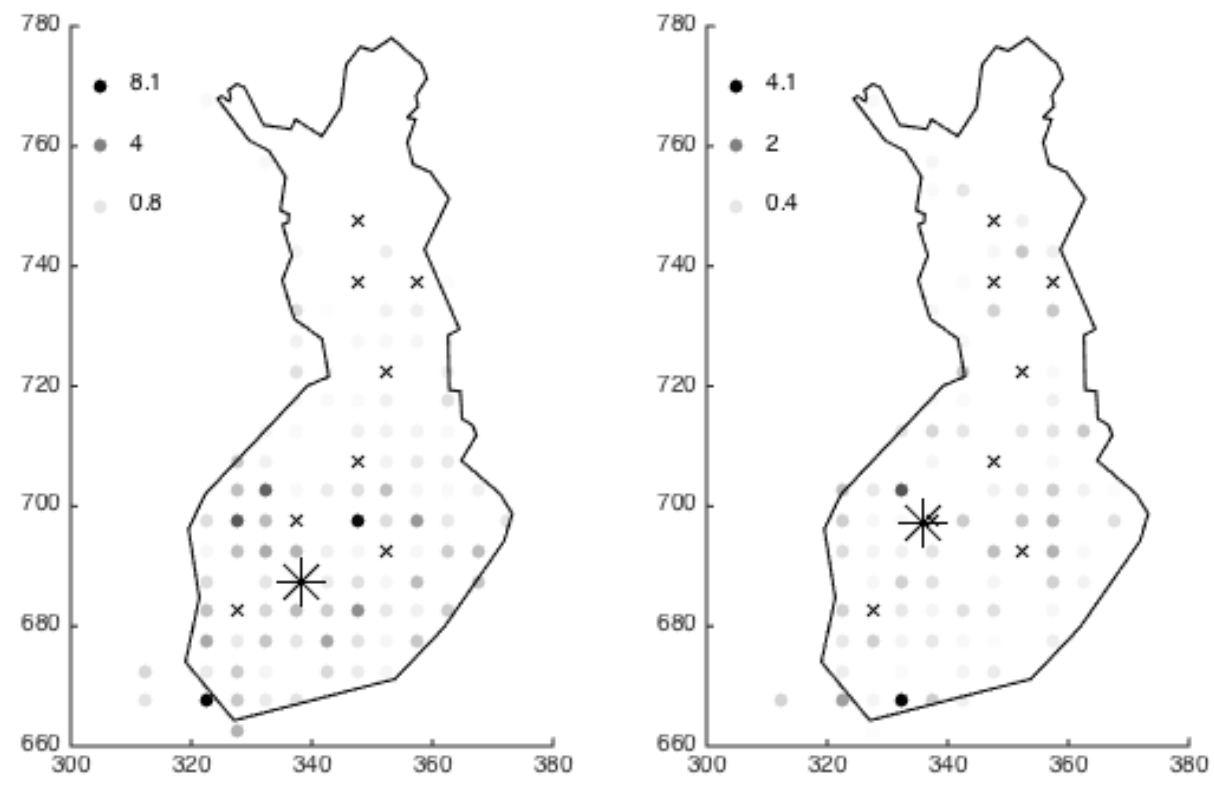

Supplementary fig. 54. Delichon urbicum 

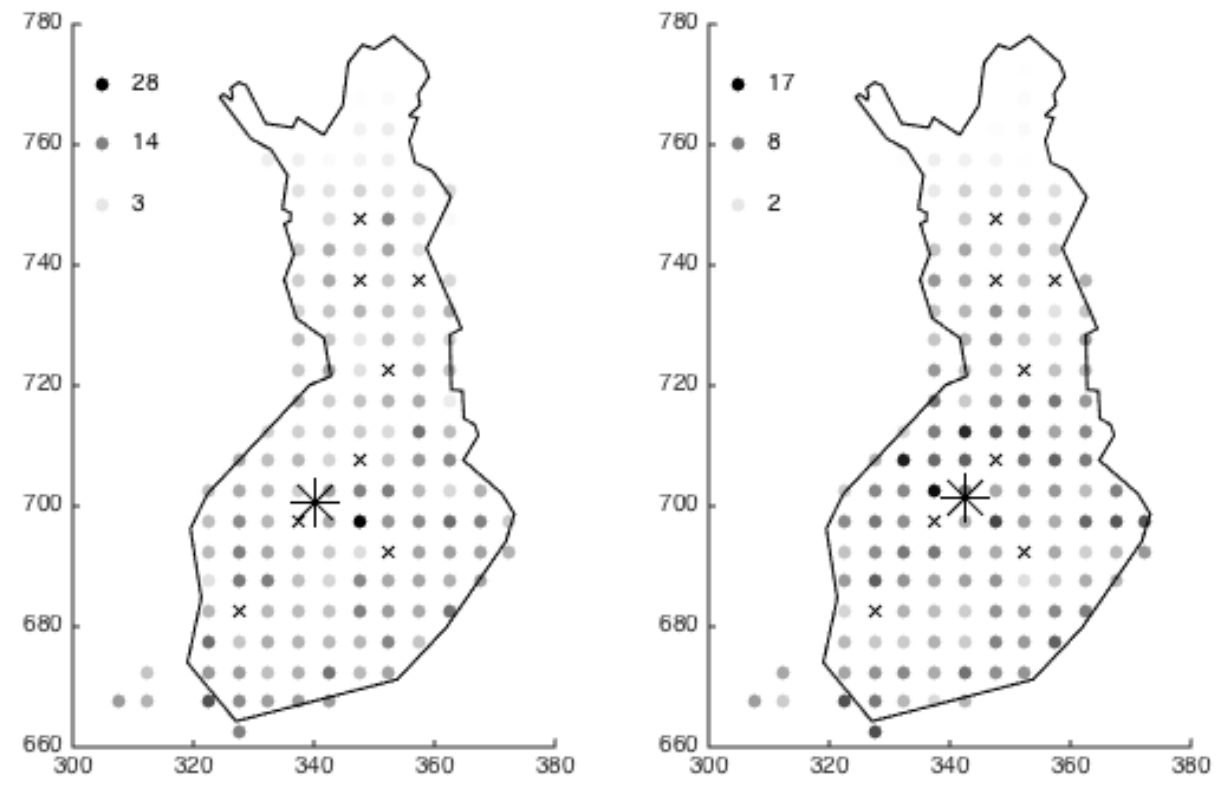

Supplementary fig. 55. Anthus trivialis
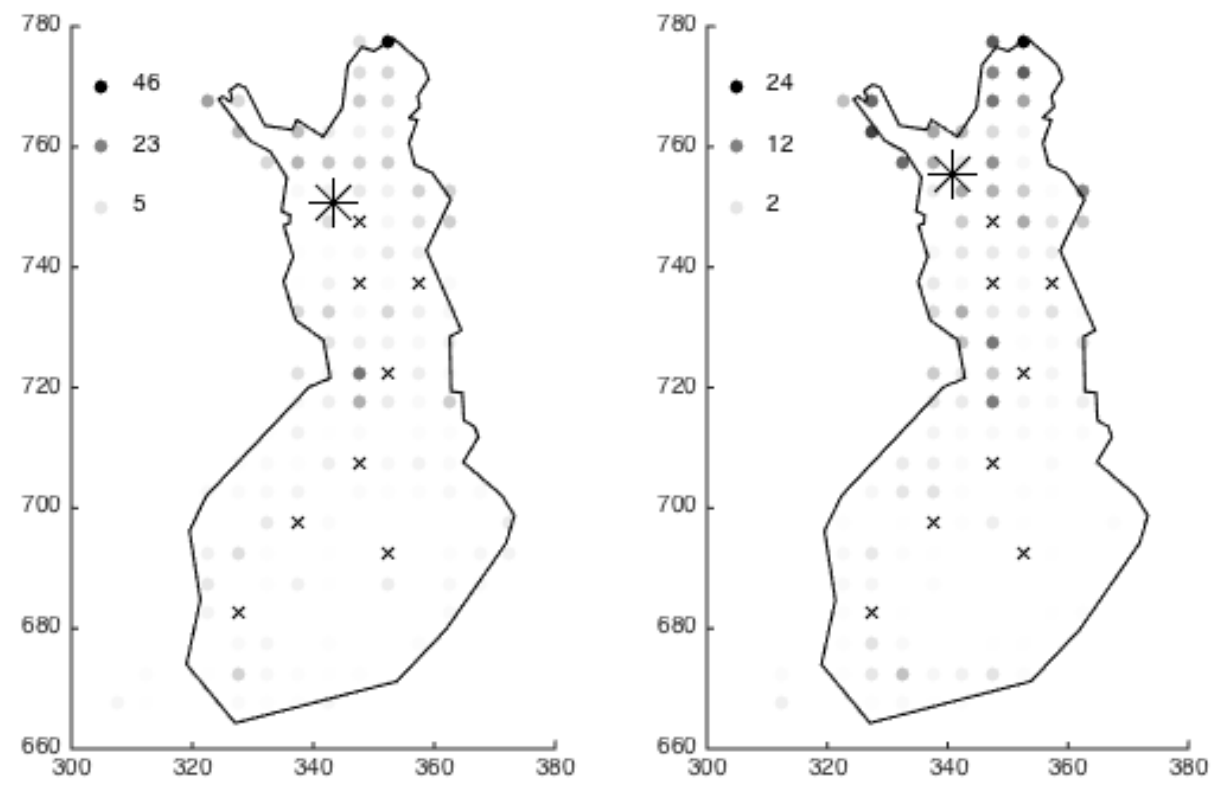

Supplementary fig. 56. Anthus prantensis 

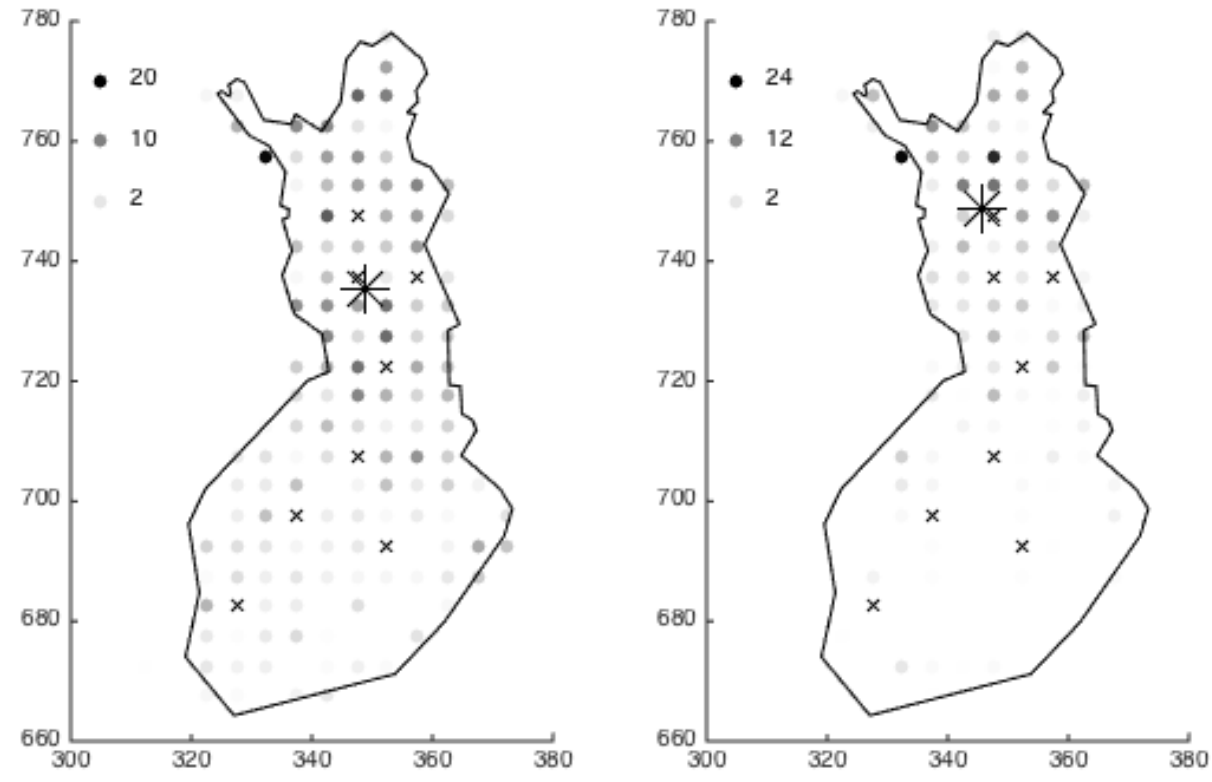

Supplementary fig. 57. Motacilla flava
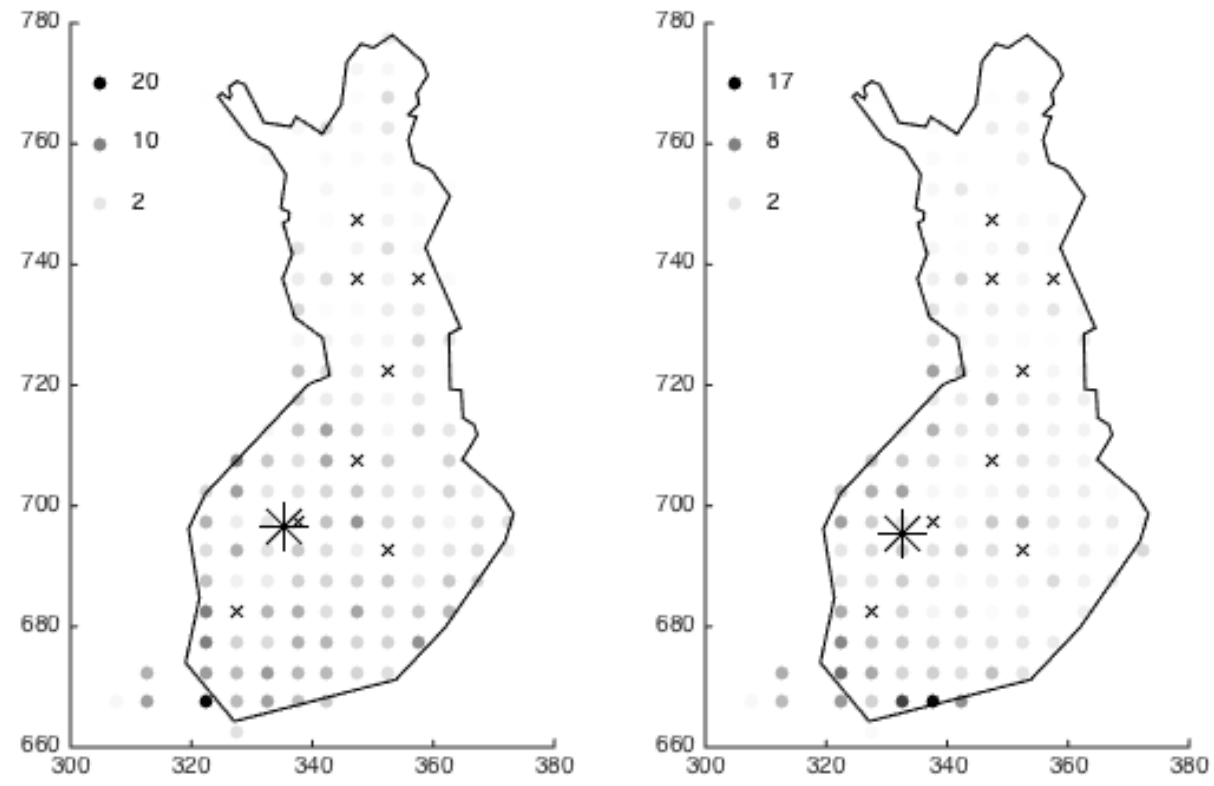

Supplementary fig. 58. Motacilla alba 

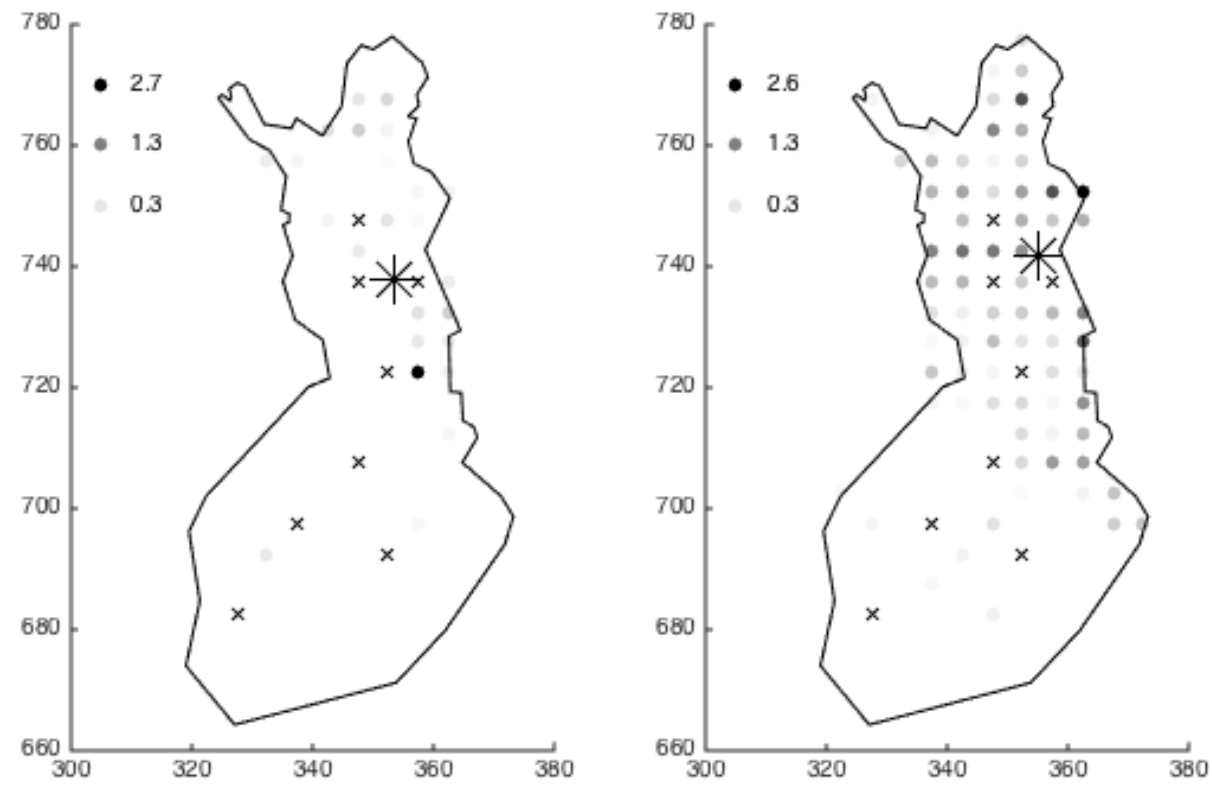

Supplementary fig. 59. Bombycilla garrulus
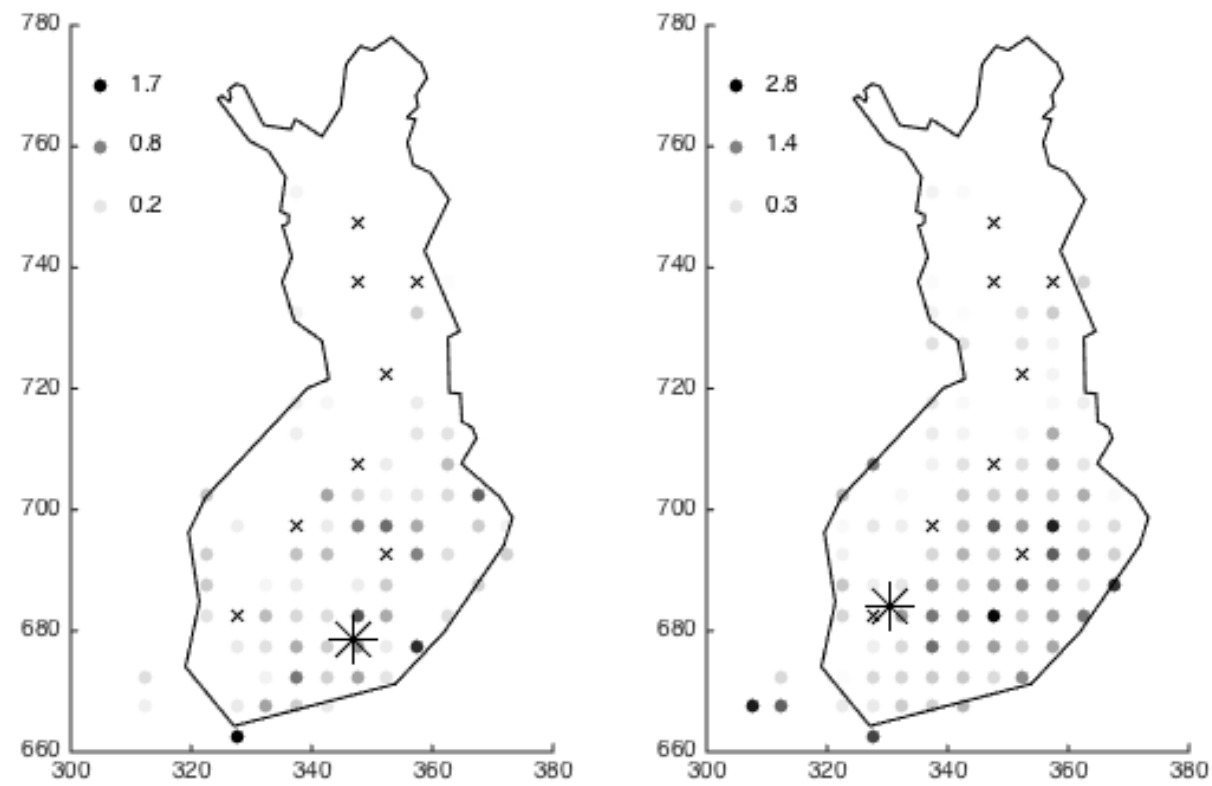

Supplementary fig. 60. Troglodytes troglodytes 

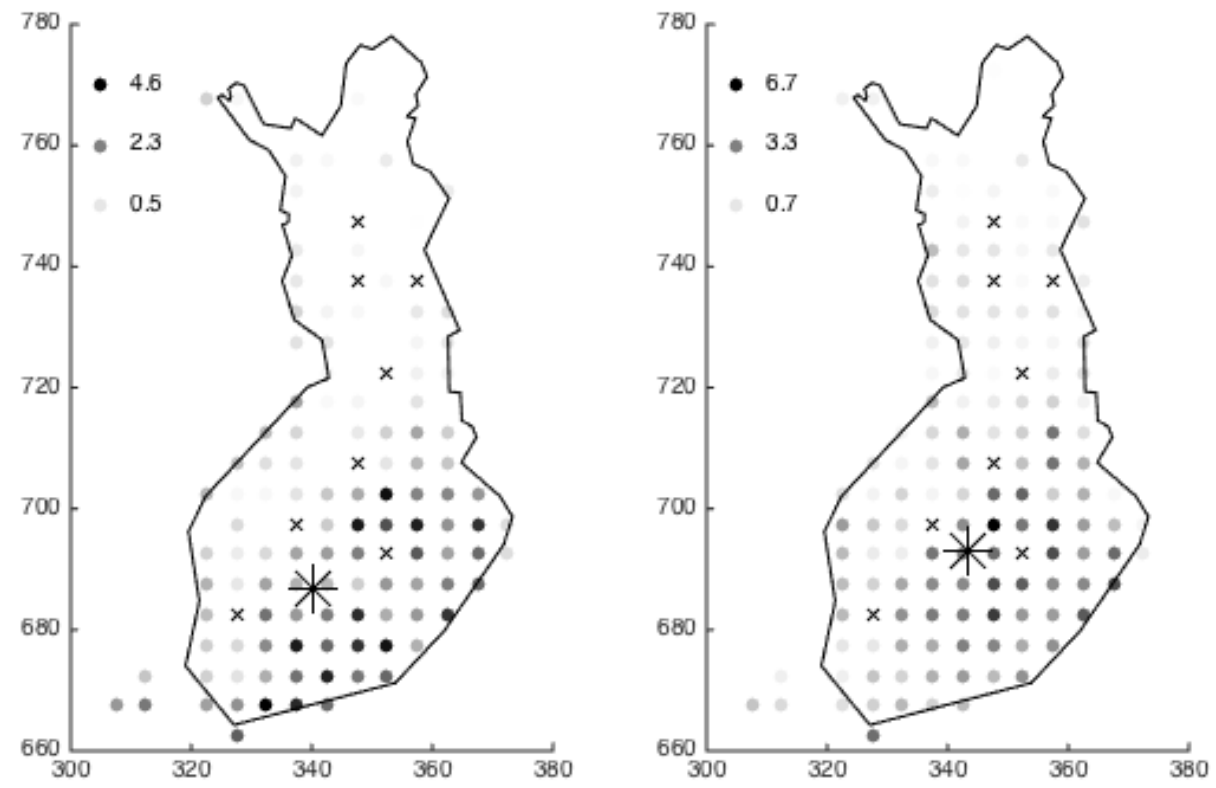

Supplementary fig. 61. Prunella modularis
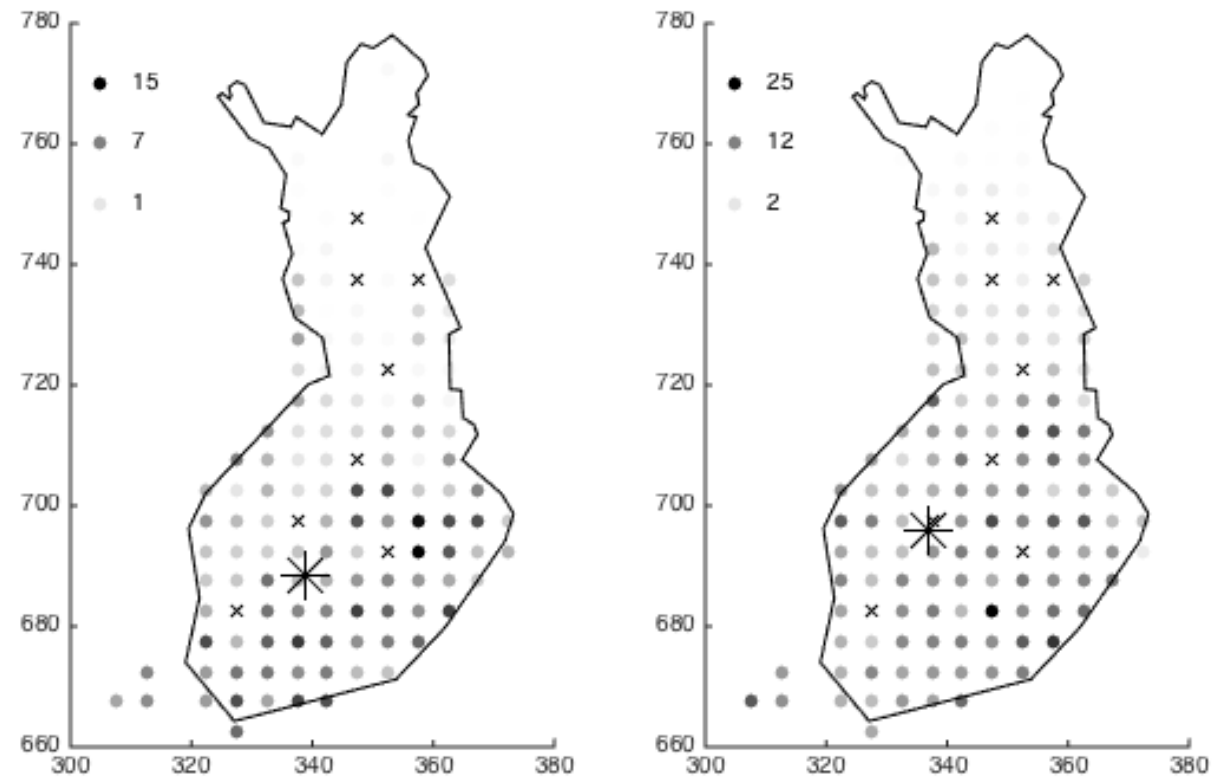

Supplementary fig. 62. Erithacus rubecula 

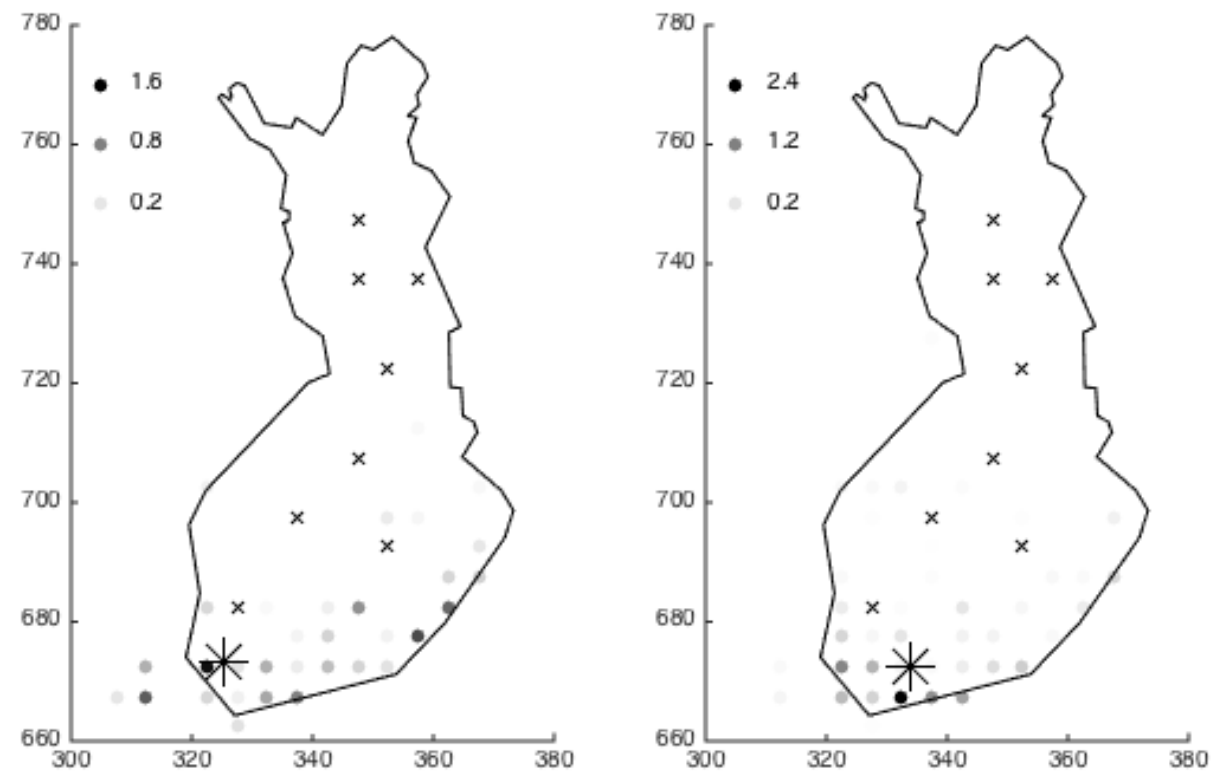

Supplementary fig. 63. Luscinia luscinia
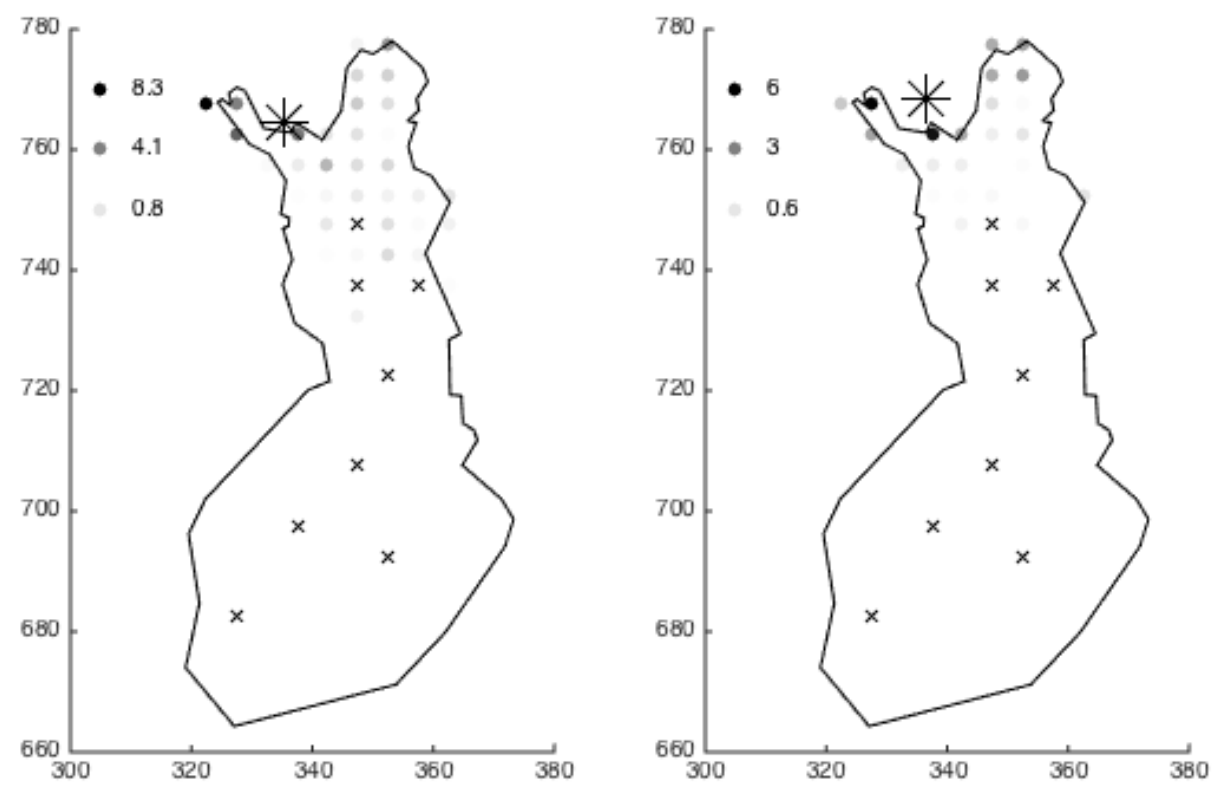

Supplementary fig. 64. Luscinia svecica 

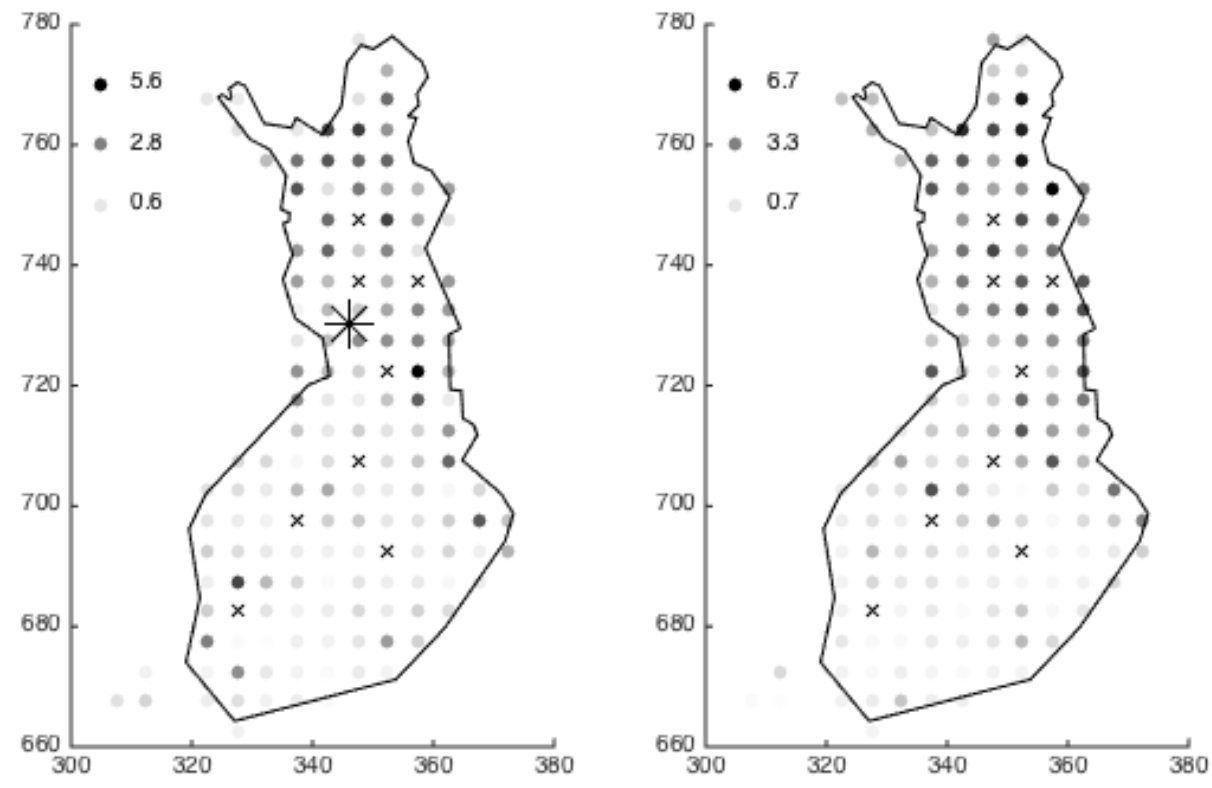

Supplementary fig. 65. Phoenicurus phoenicurus
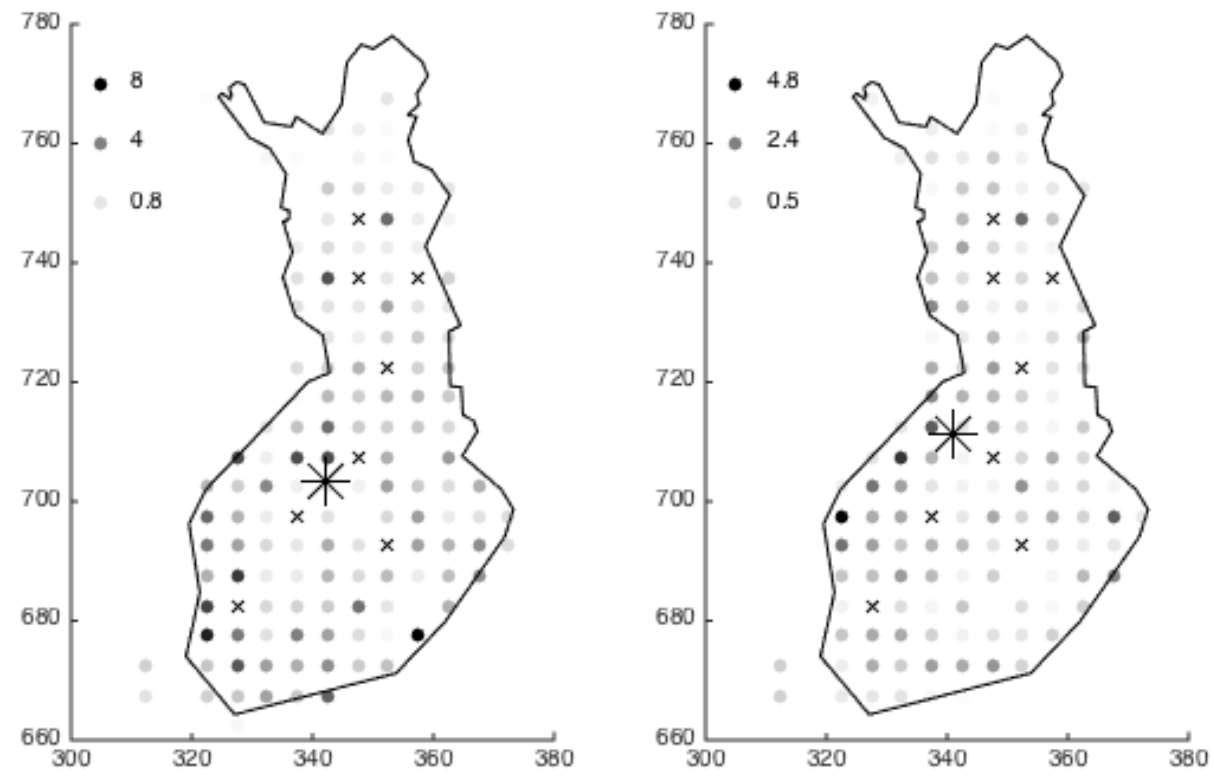

Supplementary fig. 66. Saxicola rubetra 

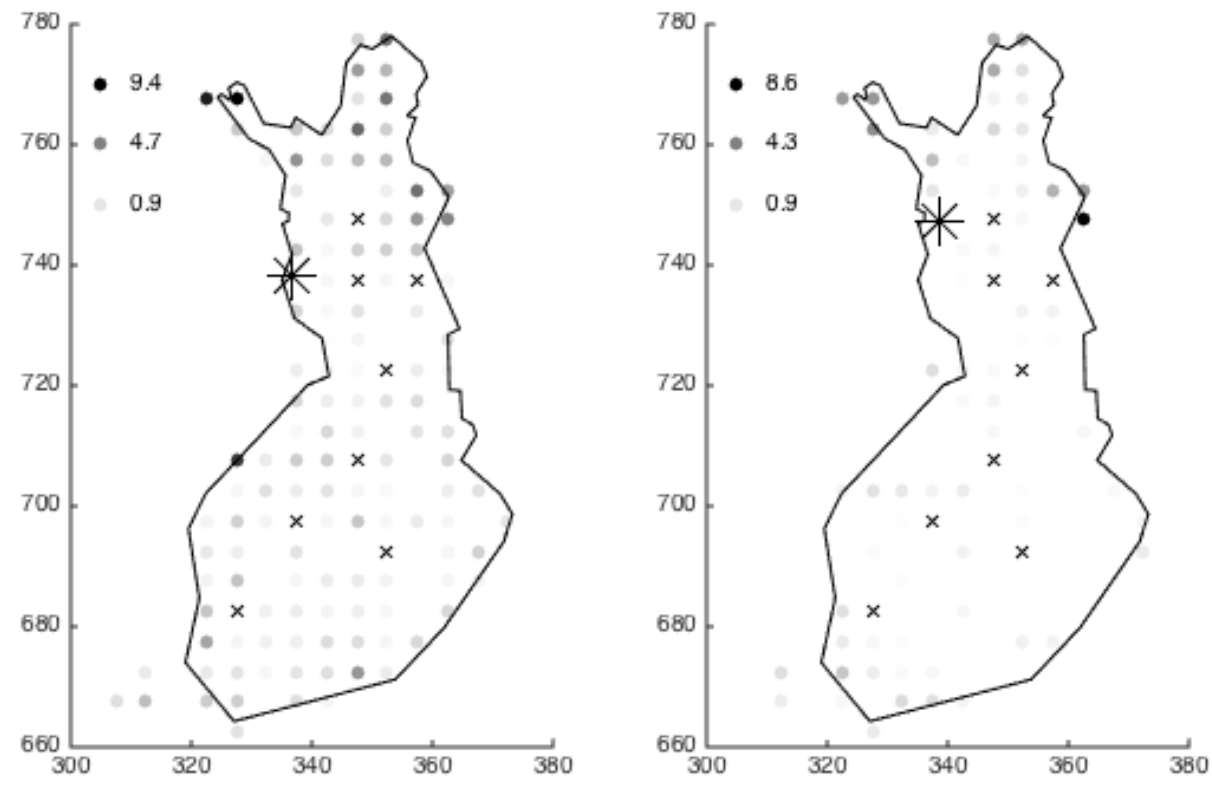

Supplementary fig. 67. Oenanthe oenanthe
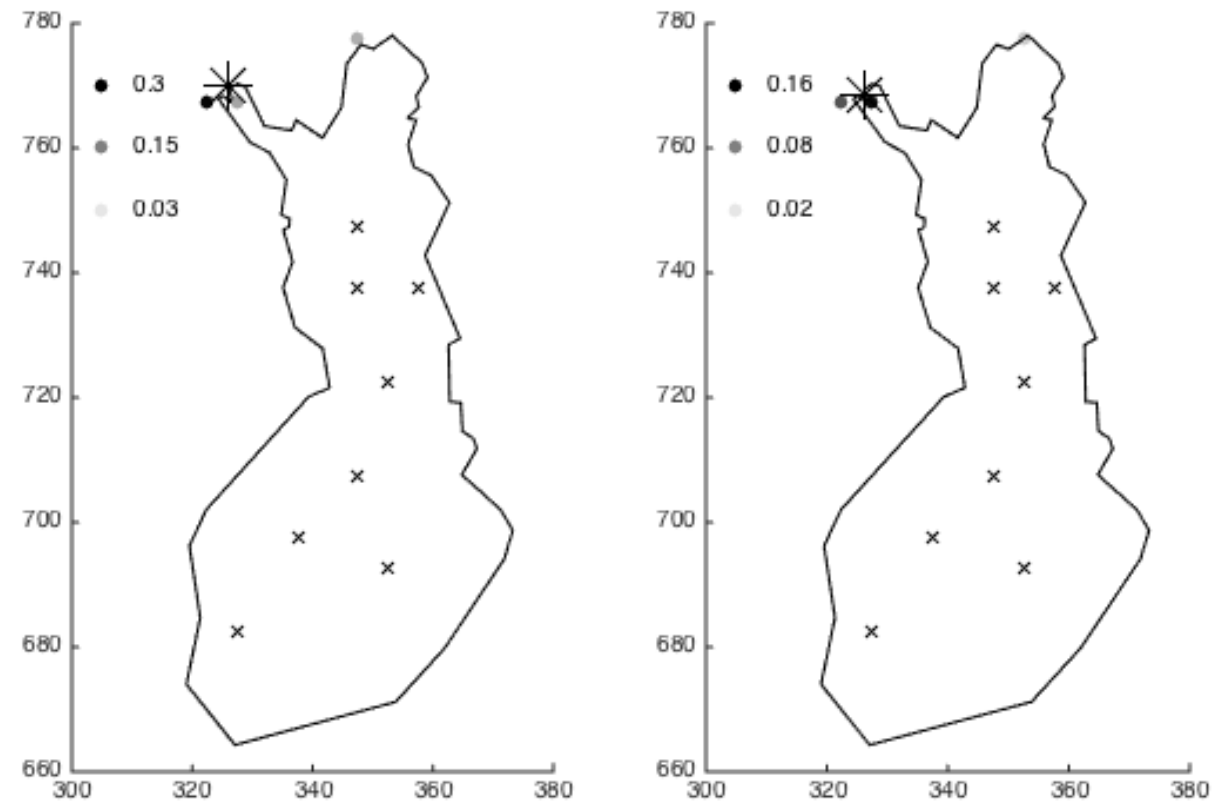

Supplementary fig. 68. Turdus torquatus 

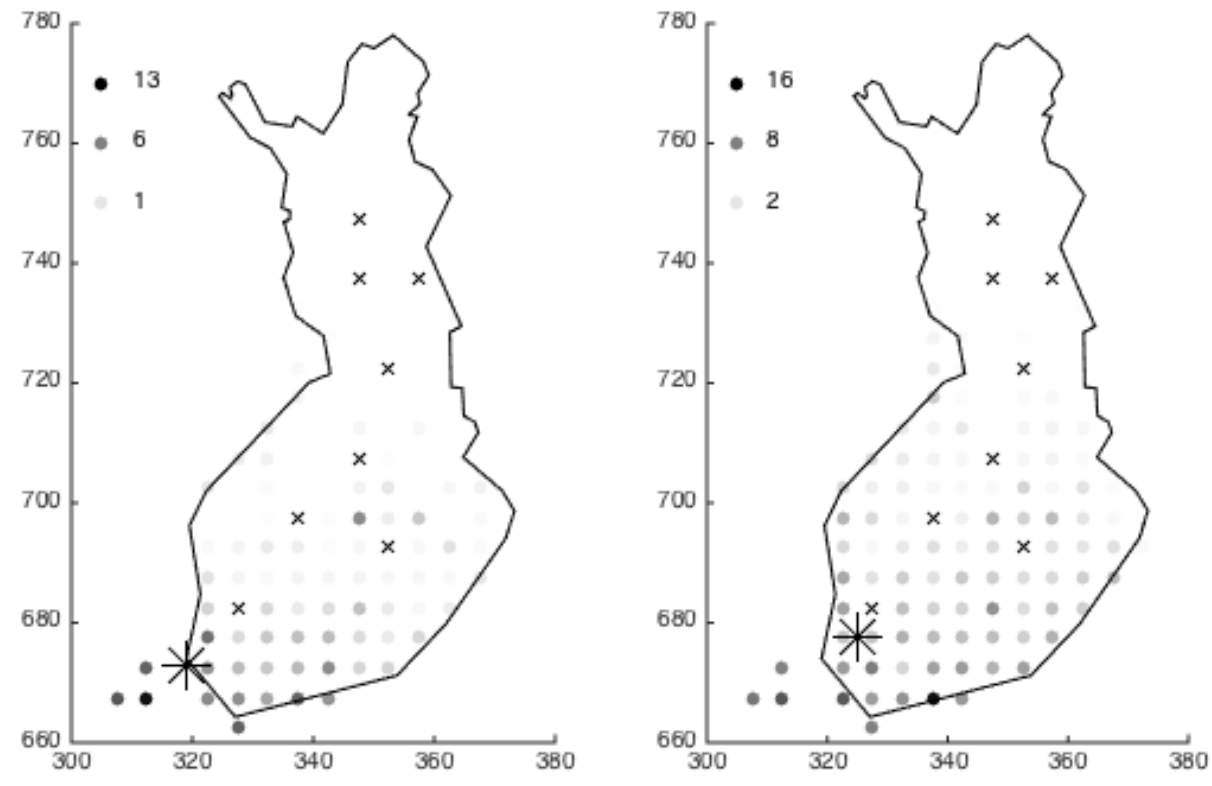

Supplementary fig. 69. Turdus merula
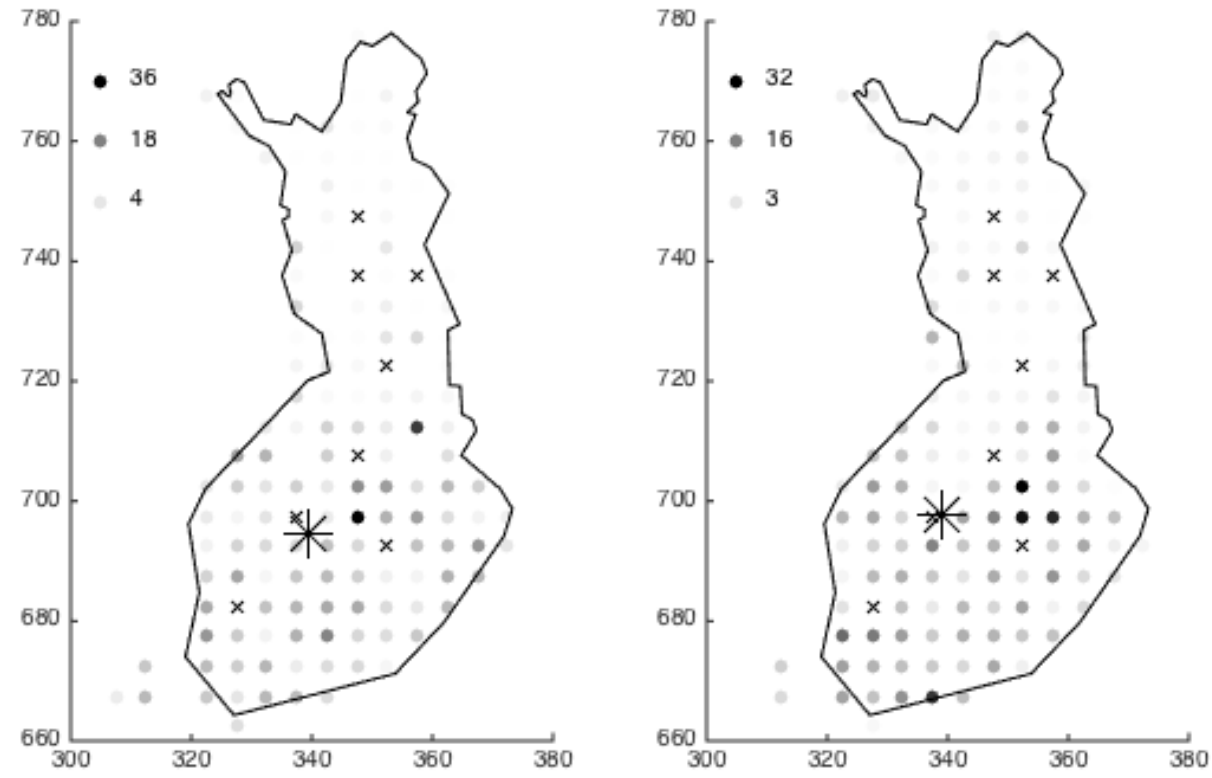

Supplementary fig. 70. Turdus pilaris 

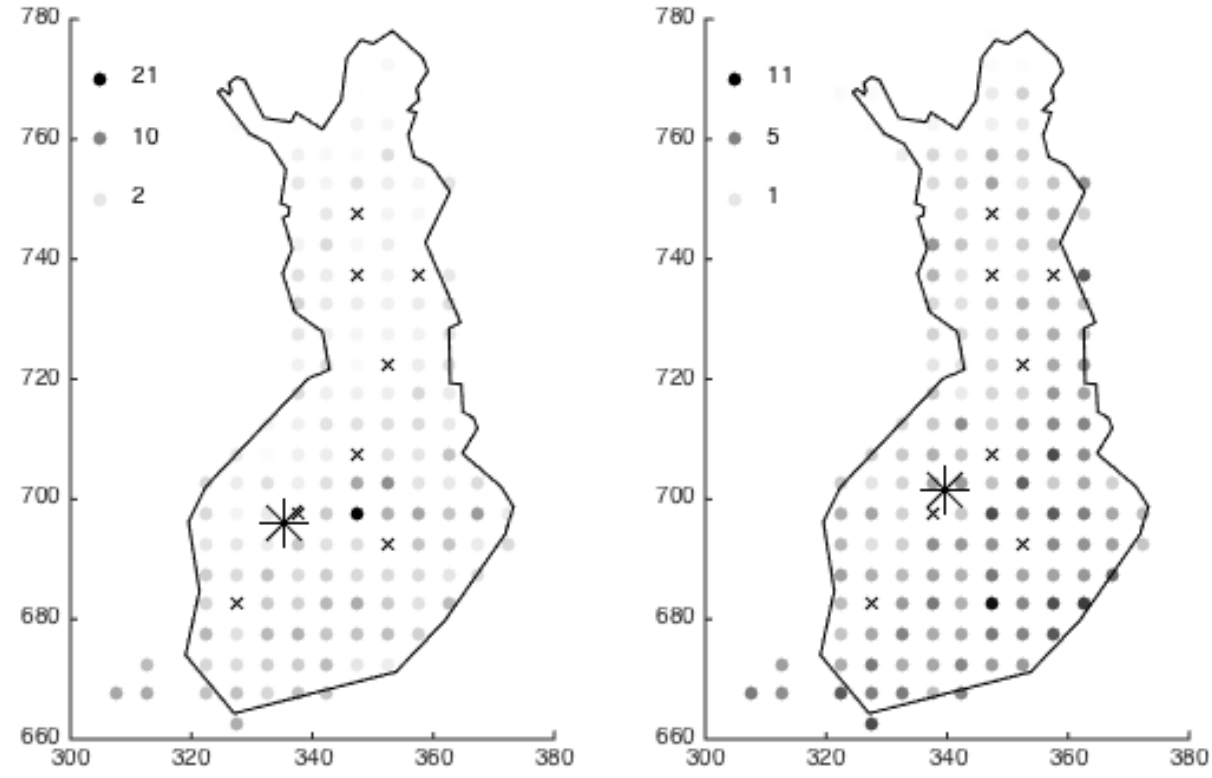

Supplementary fig. 71. Turdus philomelos
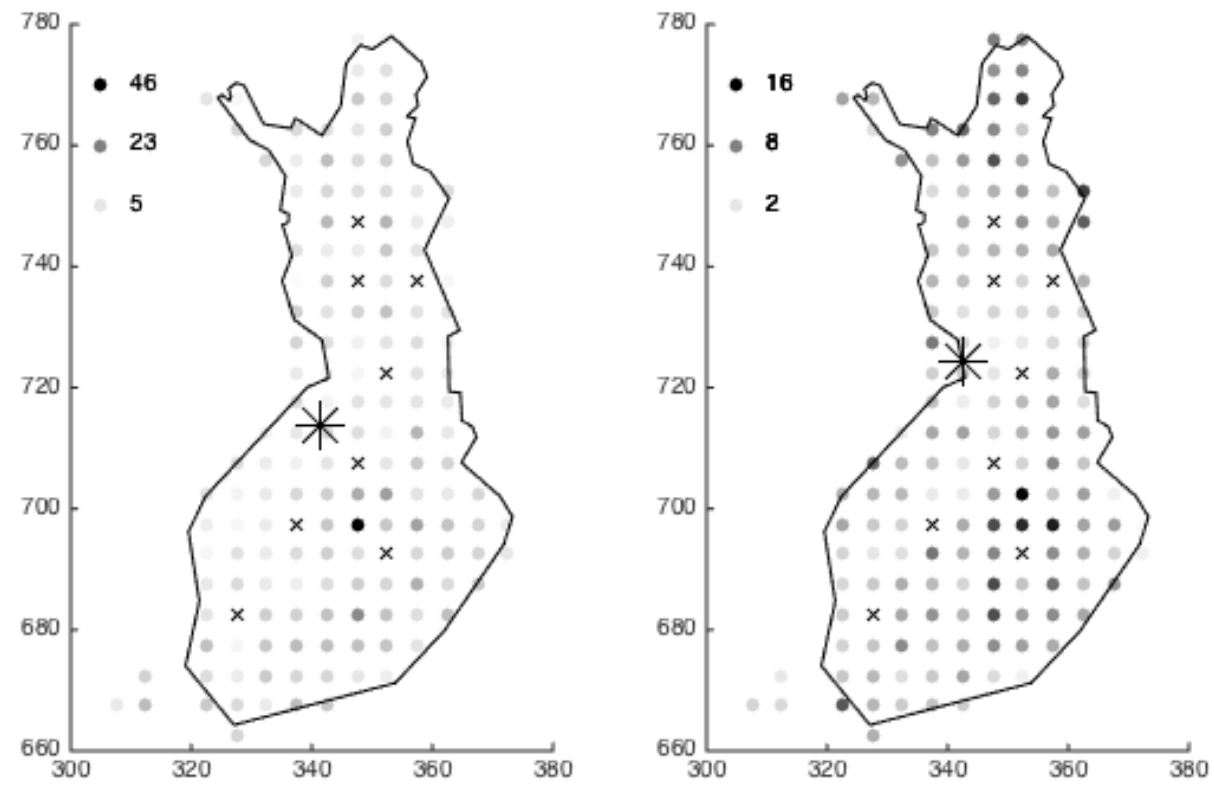

Supplementary fig. 72. Turdus iliacus 

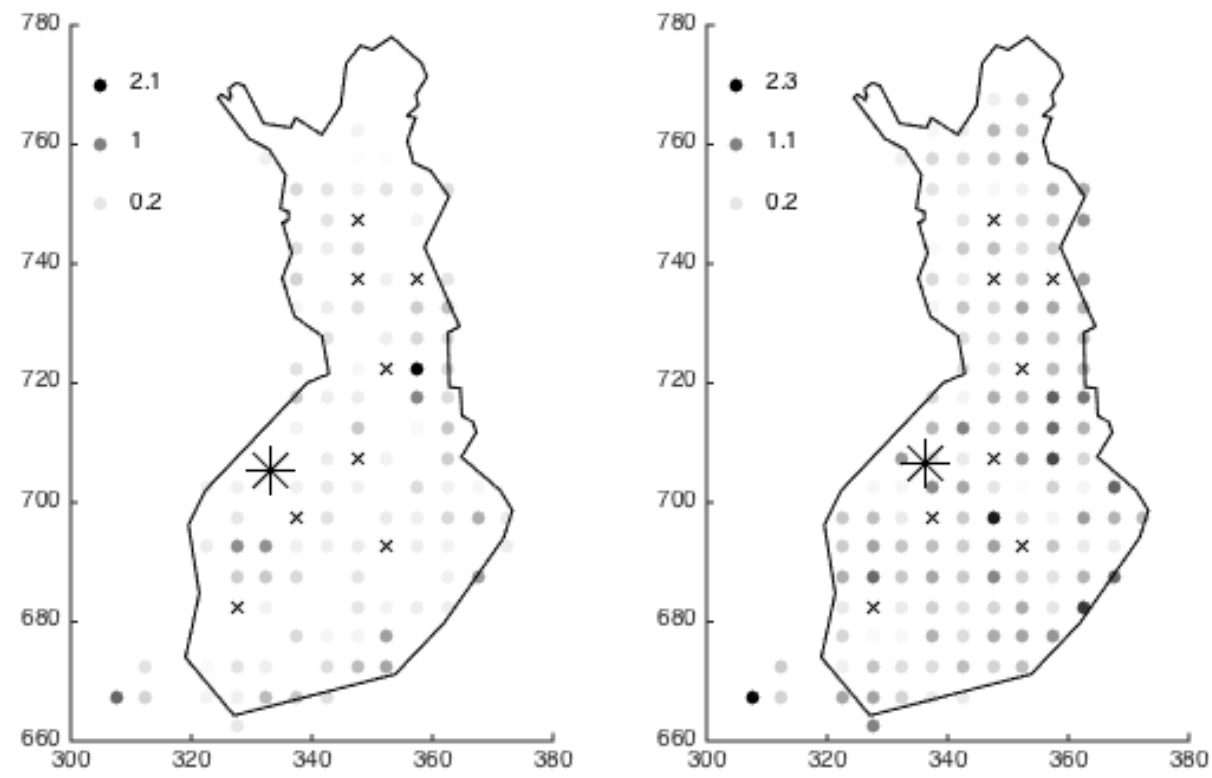

Supplementary fig. 73. Turdus viscivorus
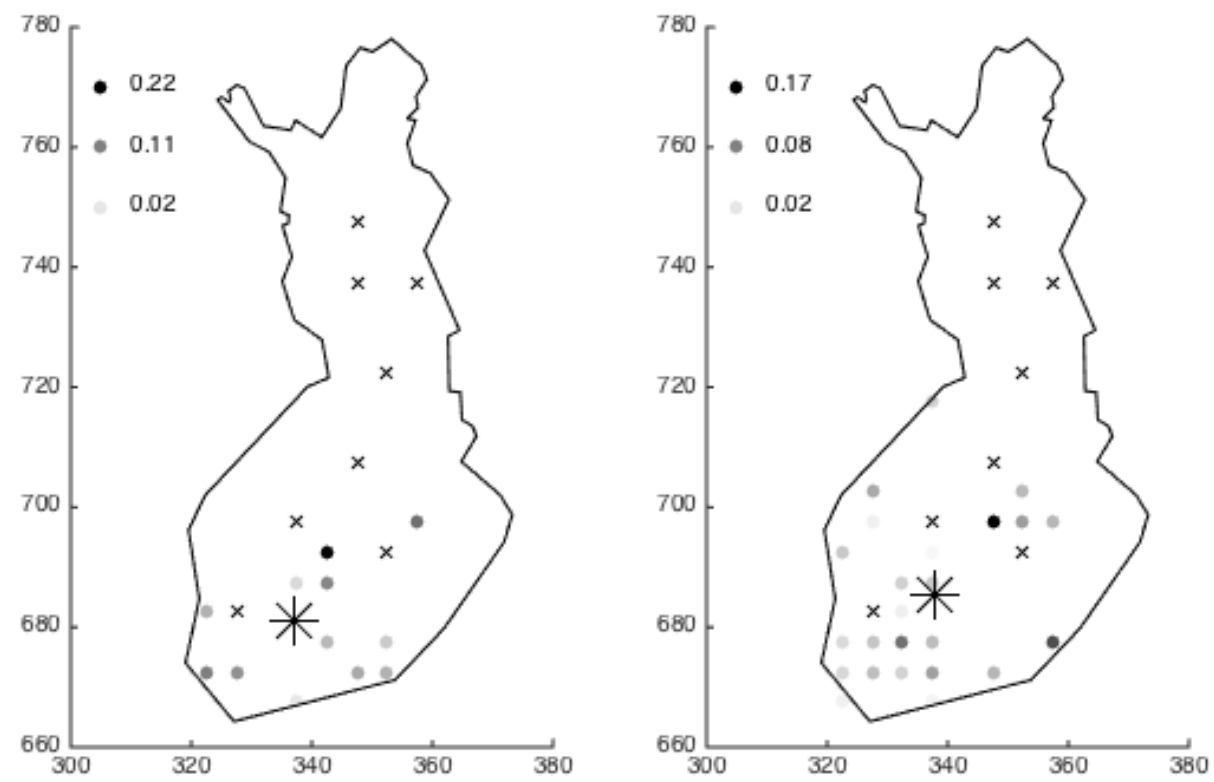

Supplementary fig. 74. Locustella naevia 

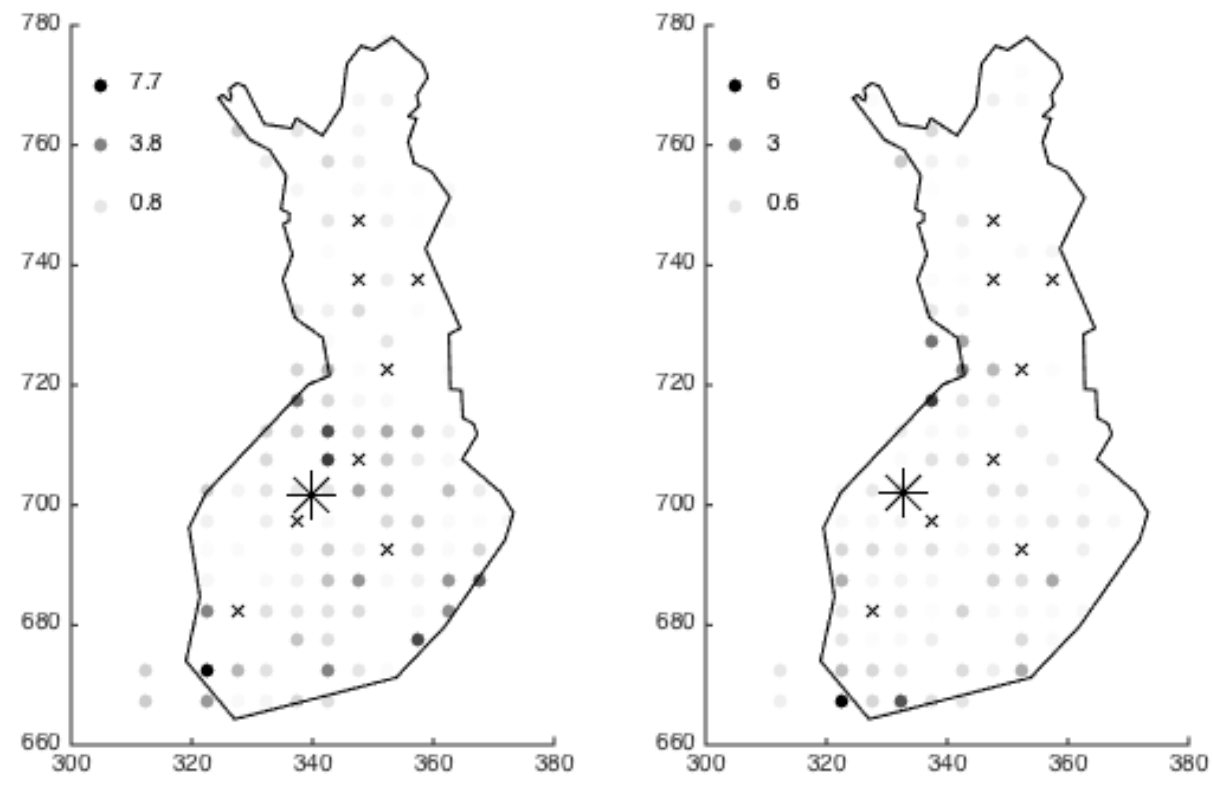

Supplementary fig. 75. Acrocephalus schoenobaenus
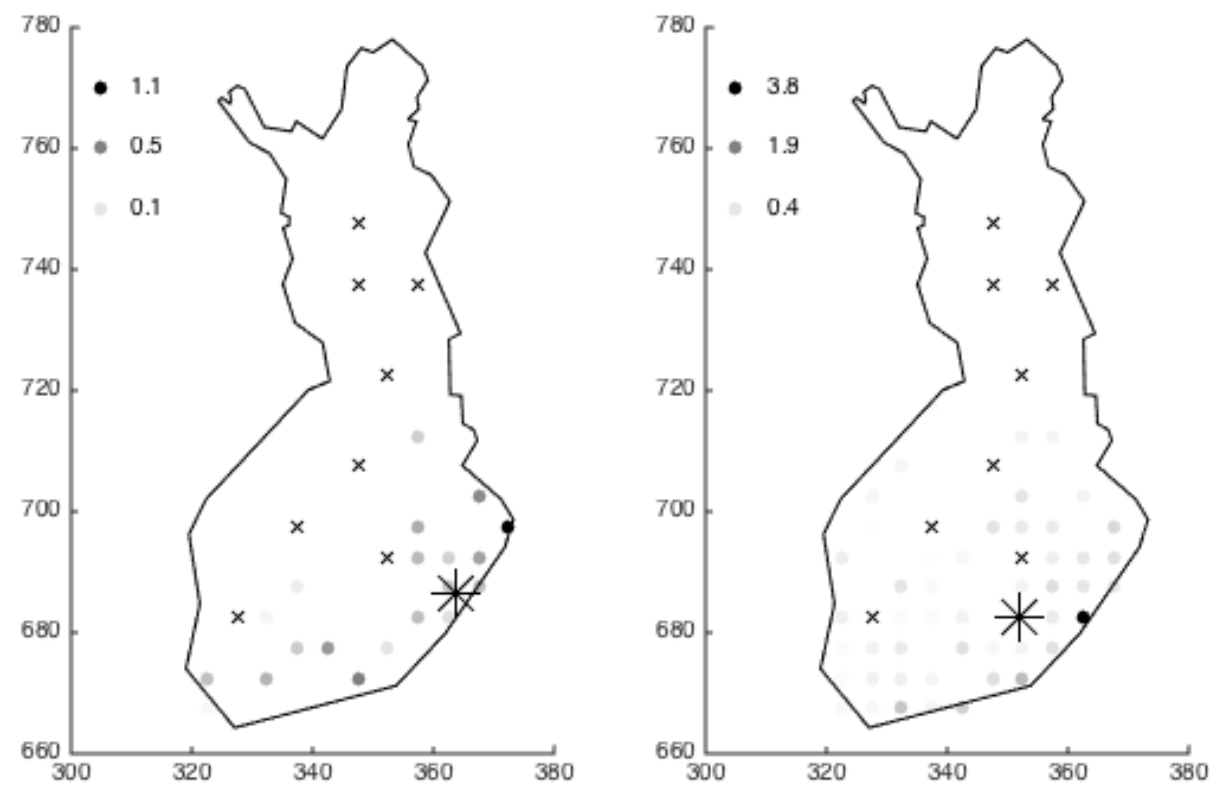

Supplementary fig. 76. Acrocephalus dumetorum 

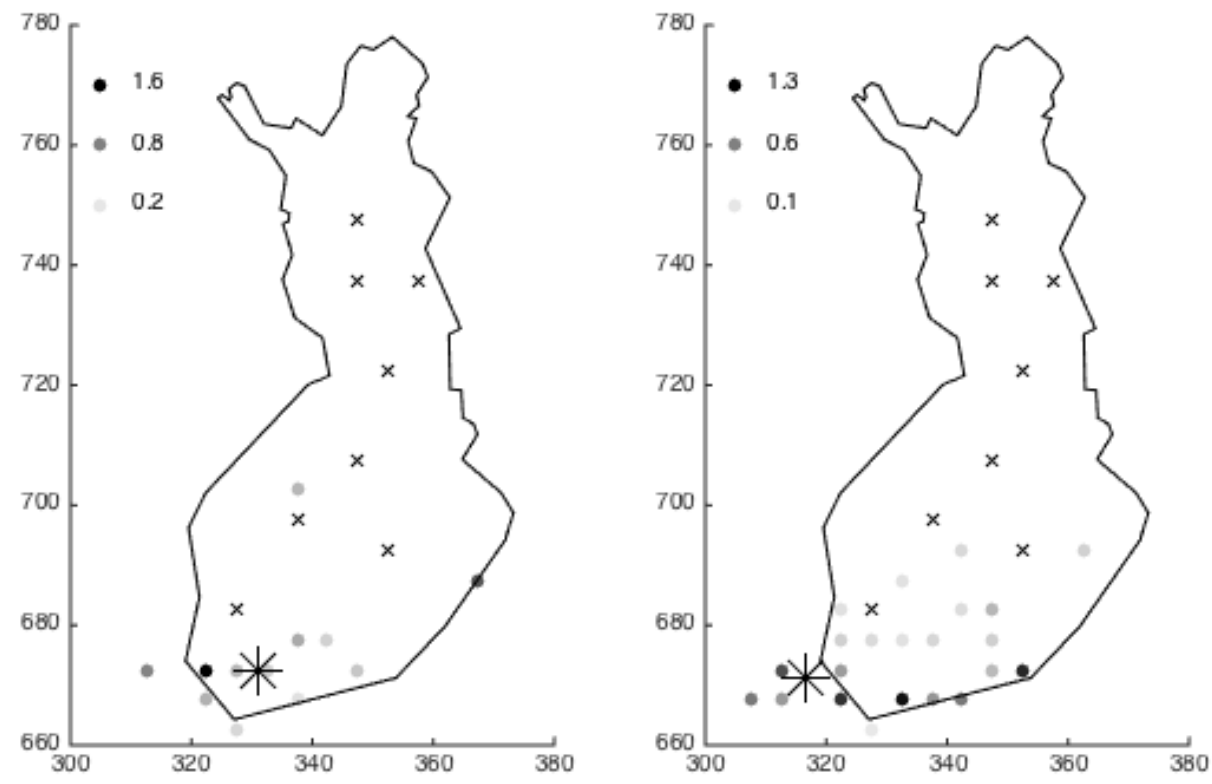

Supplementary fig. 77. Acrocephalus palustris
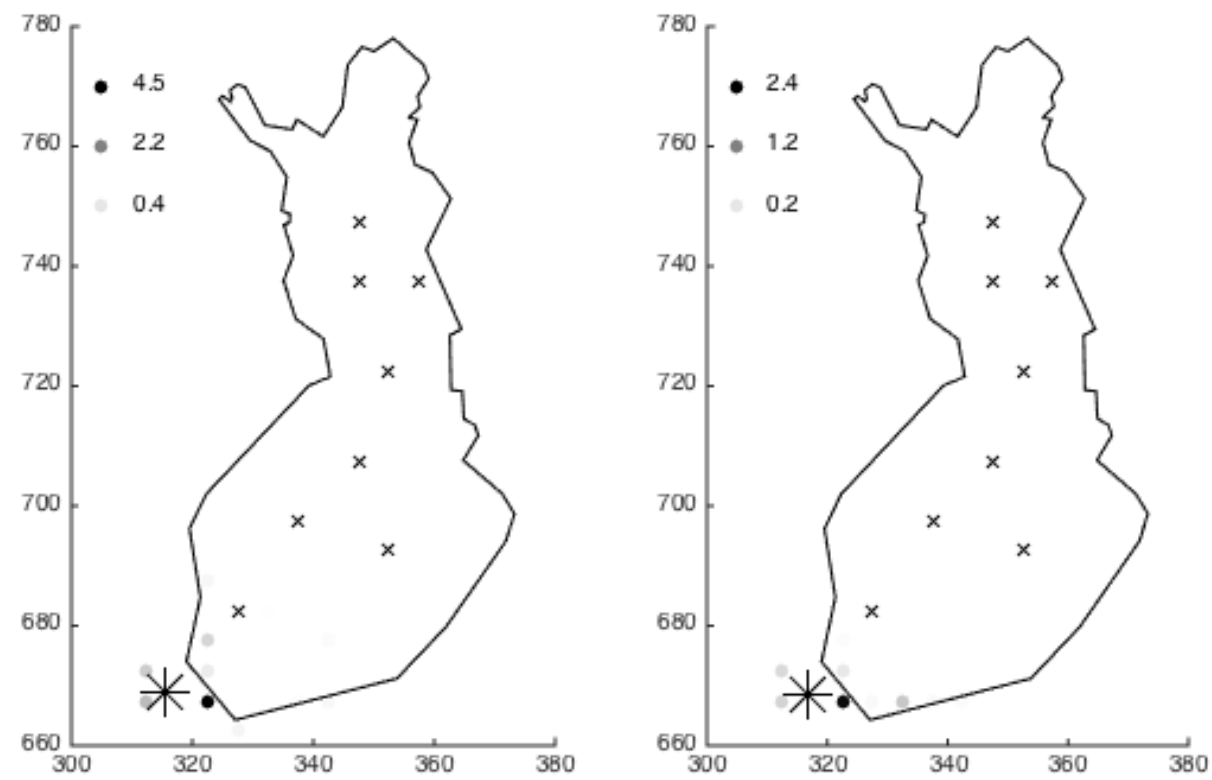

Supplementary fig. 78. Acrocephalus scirpaceus 

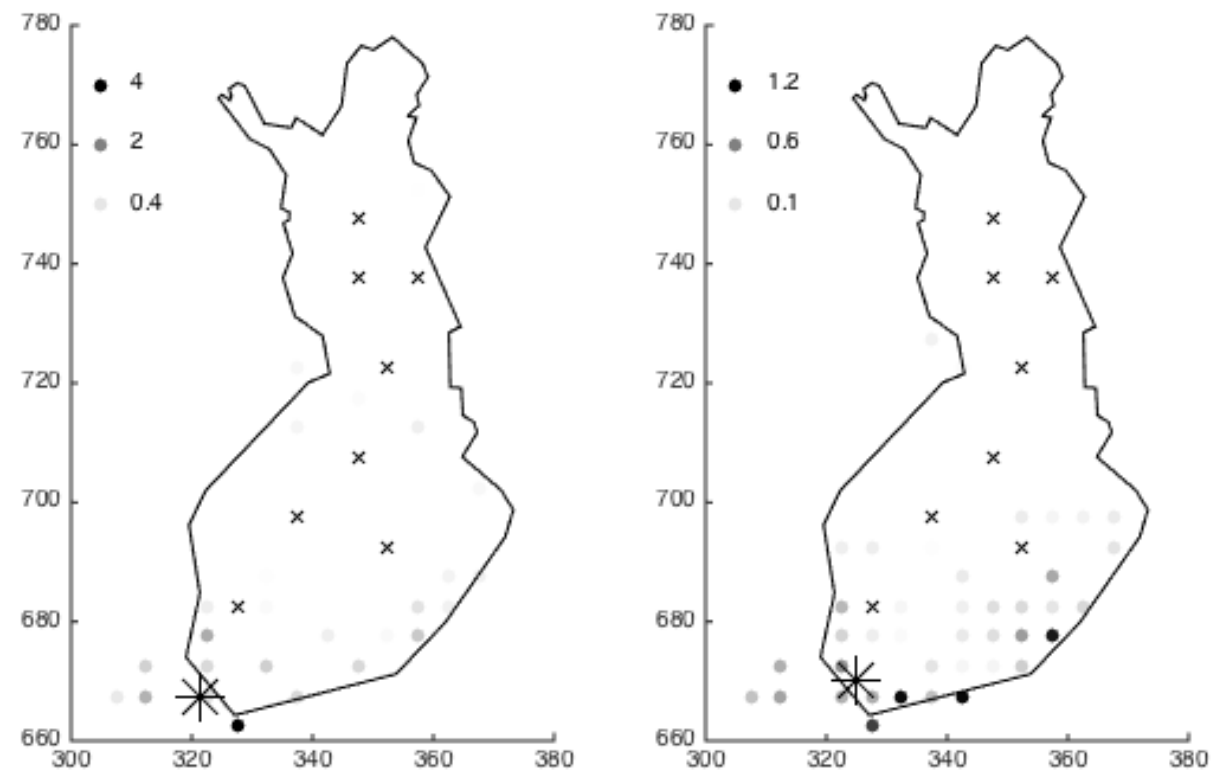

Supplementary fig. 79. Hippolais icterina
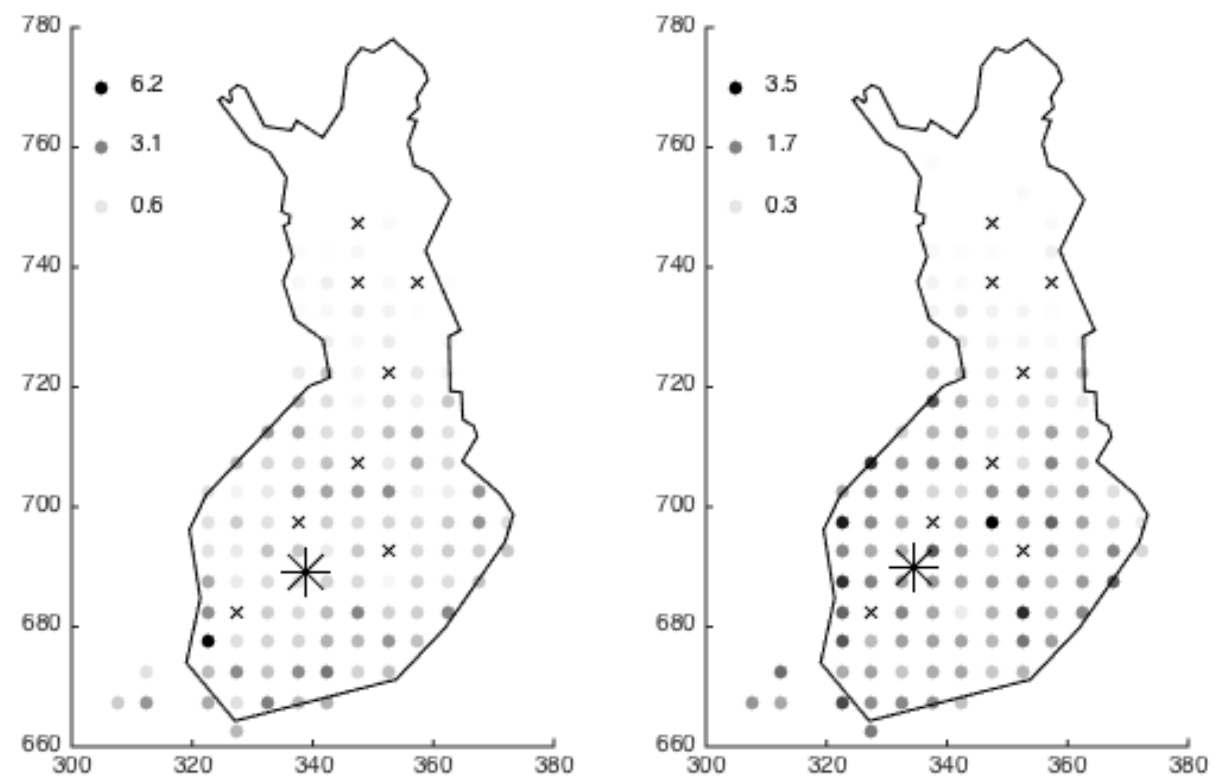

Supplementary fig. 80. Sylvia curruca 

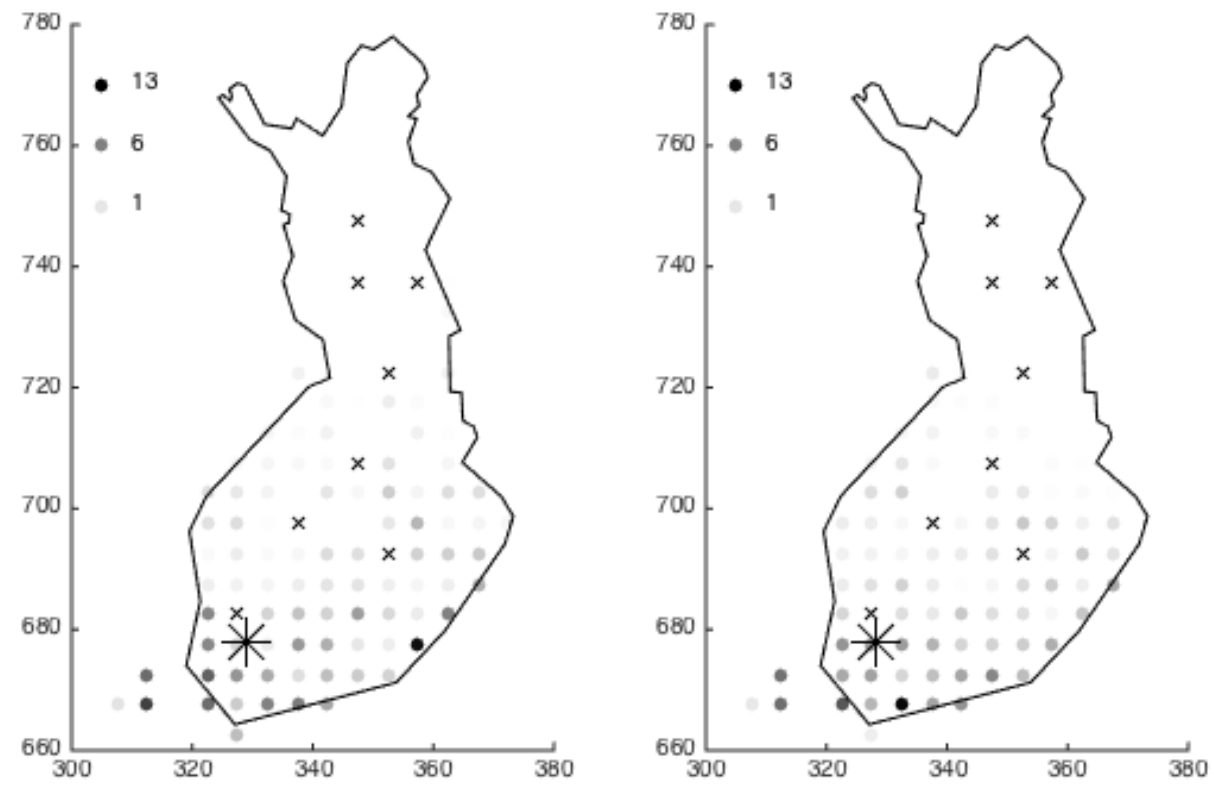

Supplementary fig. 81. Sylvia communis
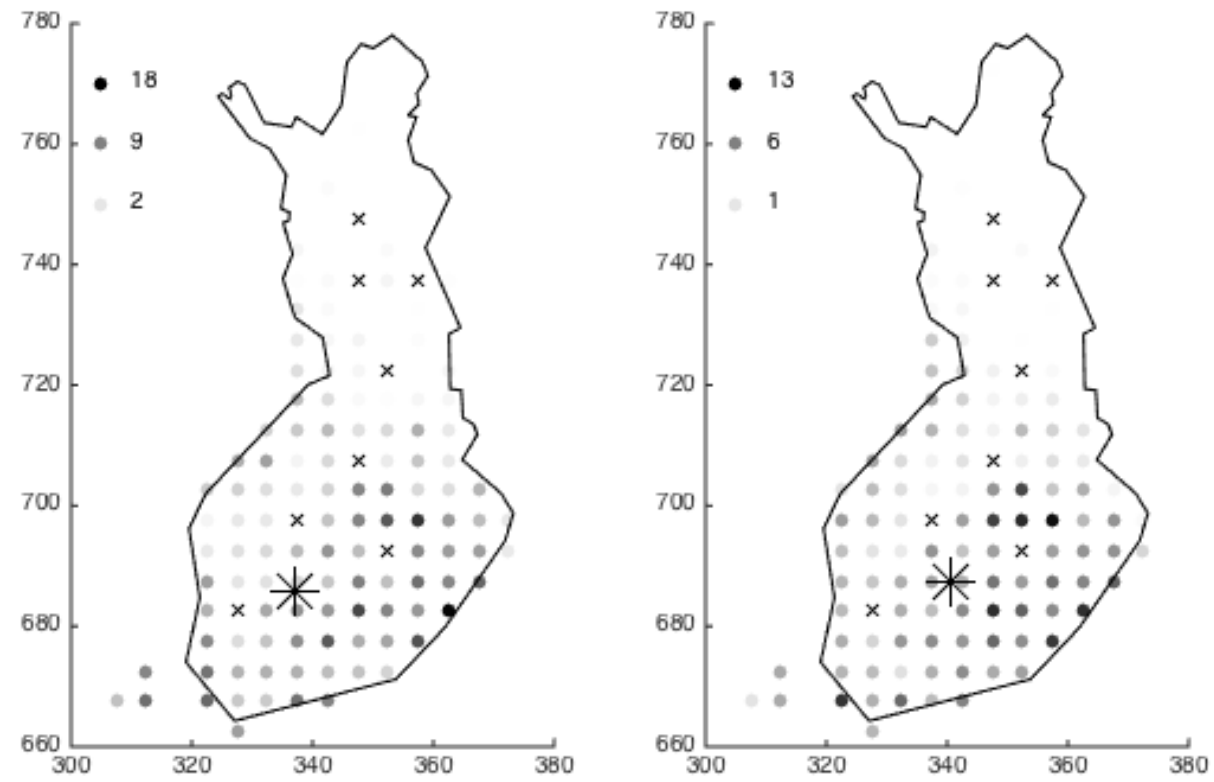

Supplementary fig. 82. Sylvia borin 

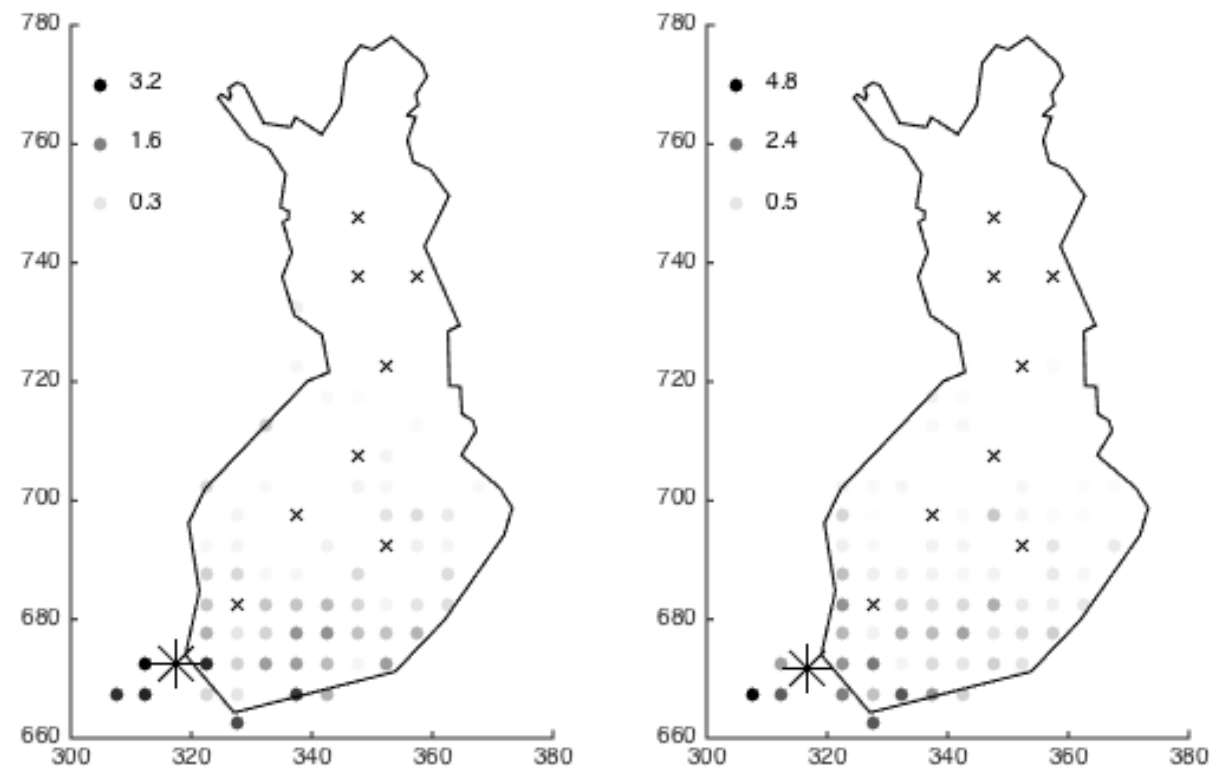

Supplementary fig. 83. Sylvia atricapilla
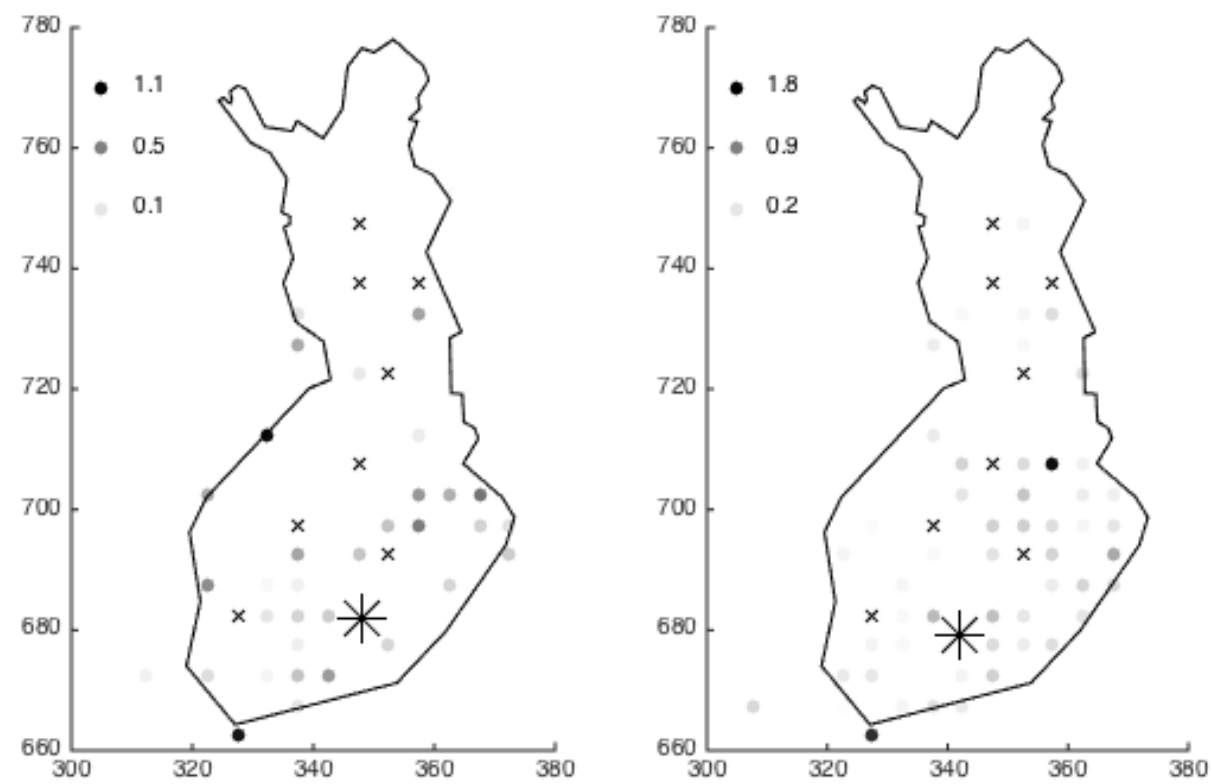

Supplementary fig. 84. Phylloscopus trochiloides 

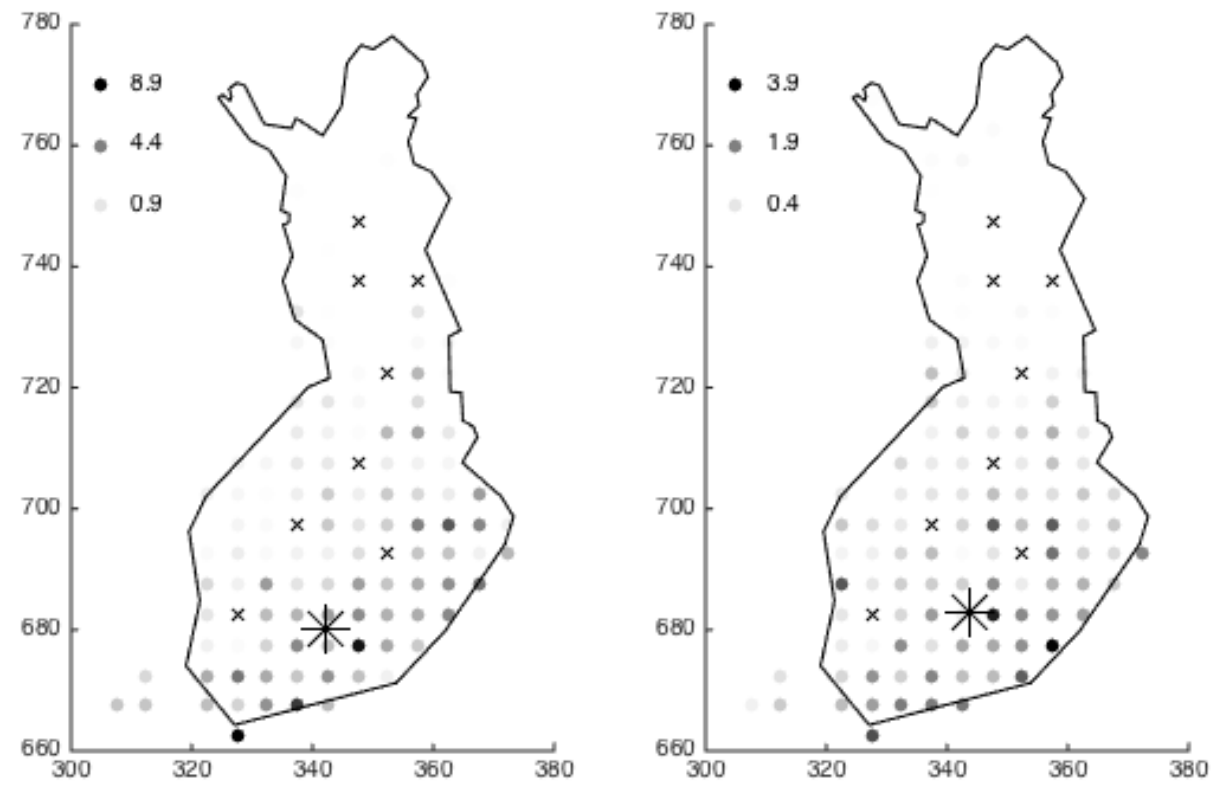

Supplementary fig. 85. Phylloscopus sibilatrix
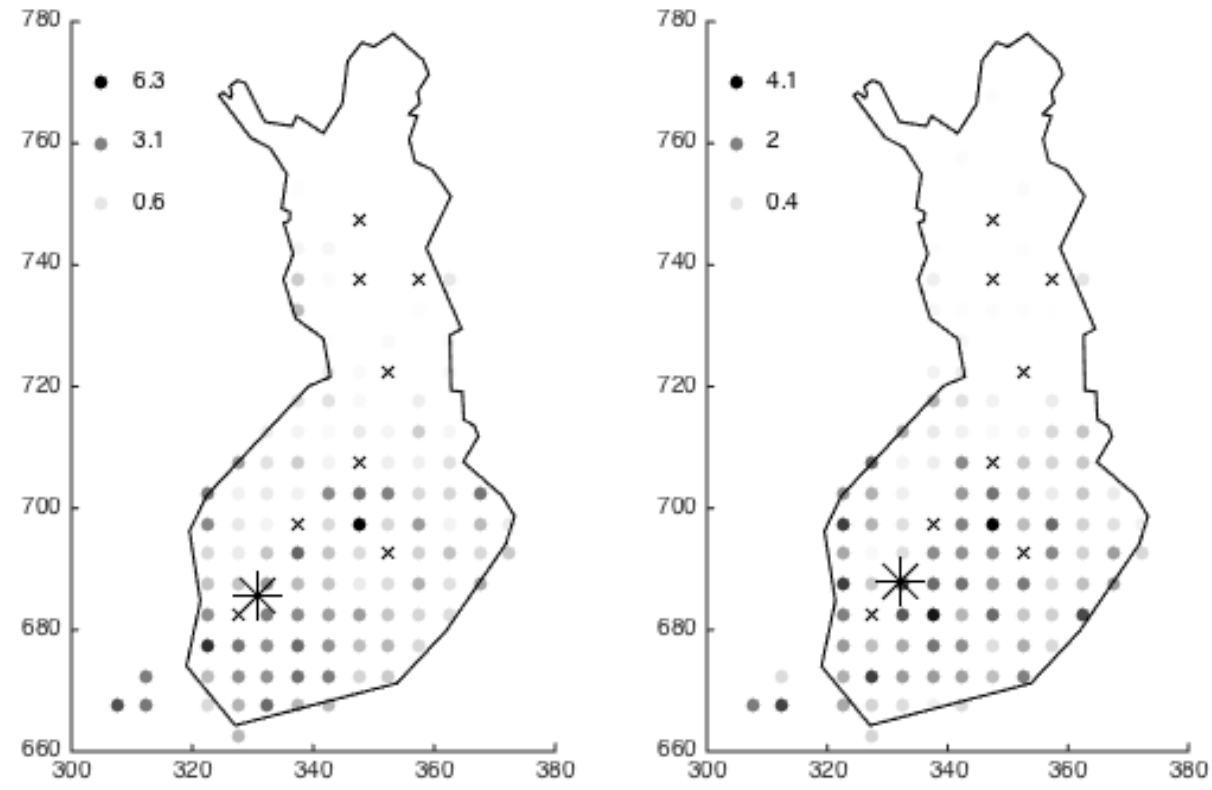

Supplementary fig. 86. Phylloscopus collybita 

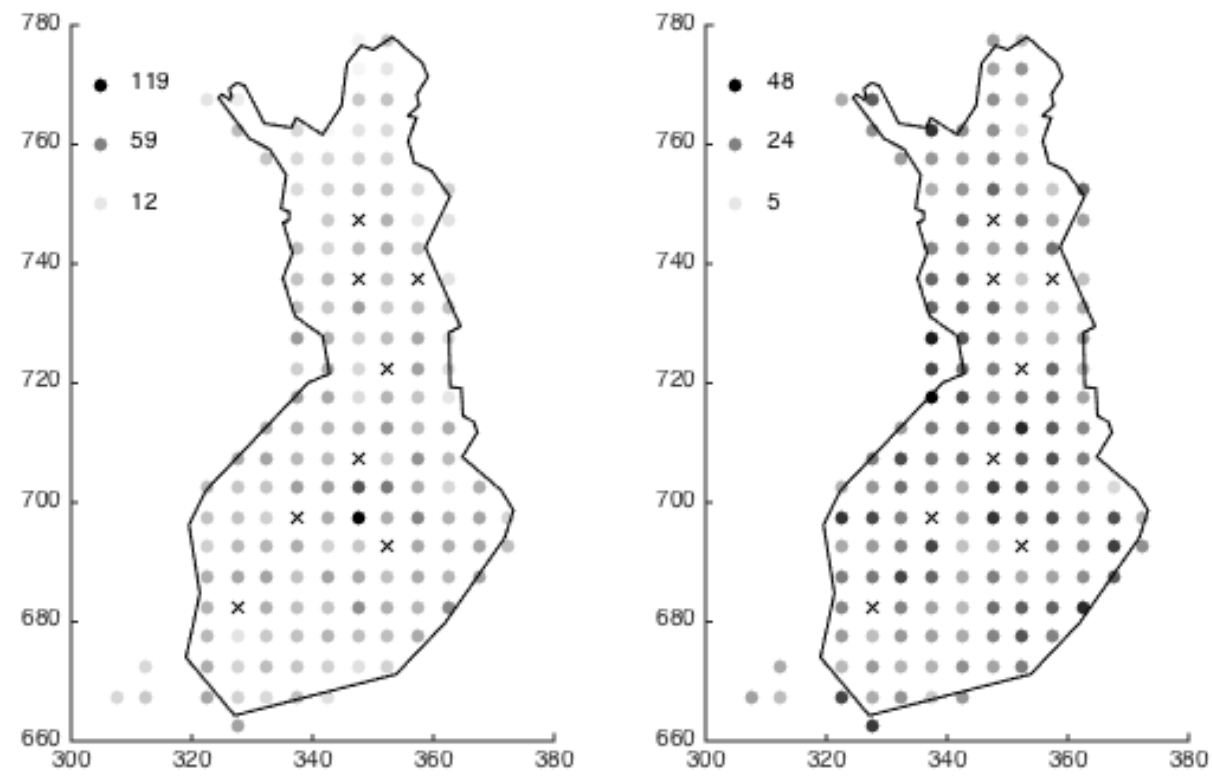

Supplementary fig. 87. Phylloscopus trochilus
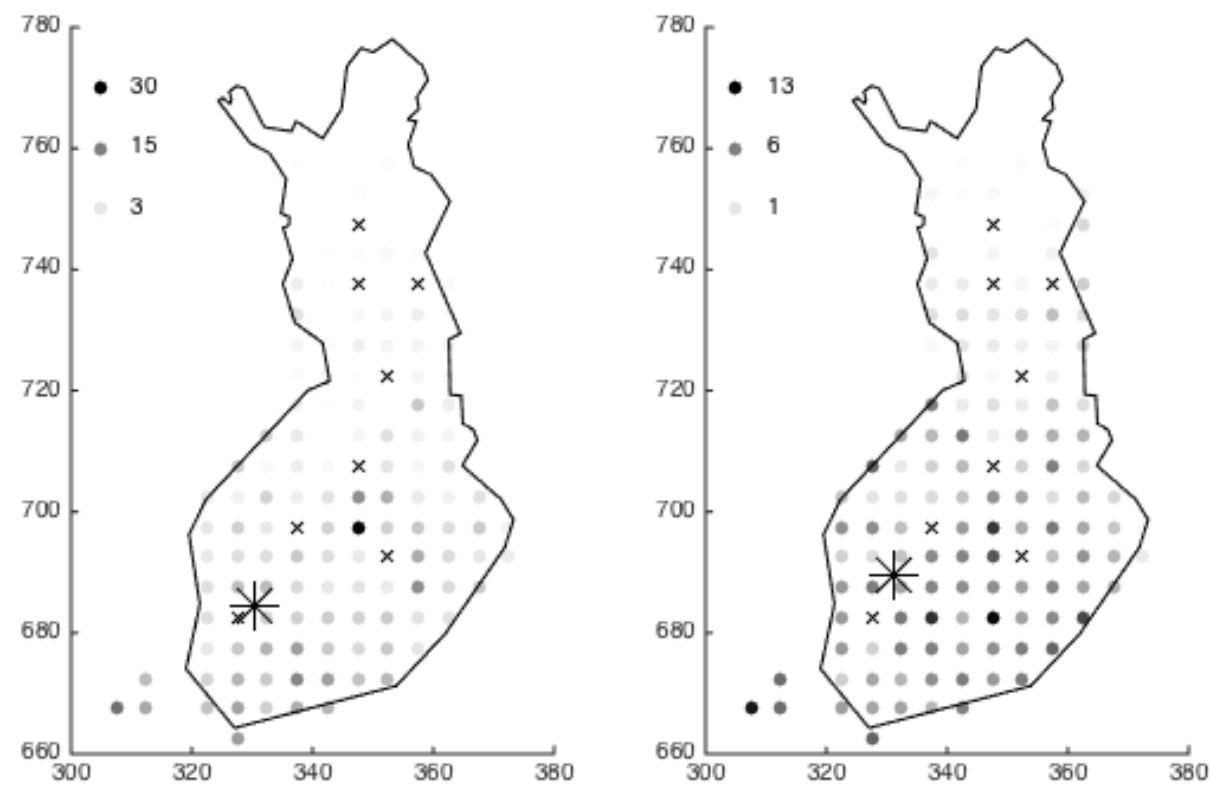

Supplementary fig. 88. Regulus regulus 

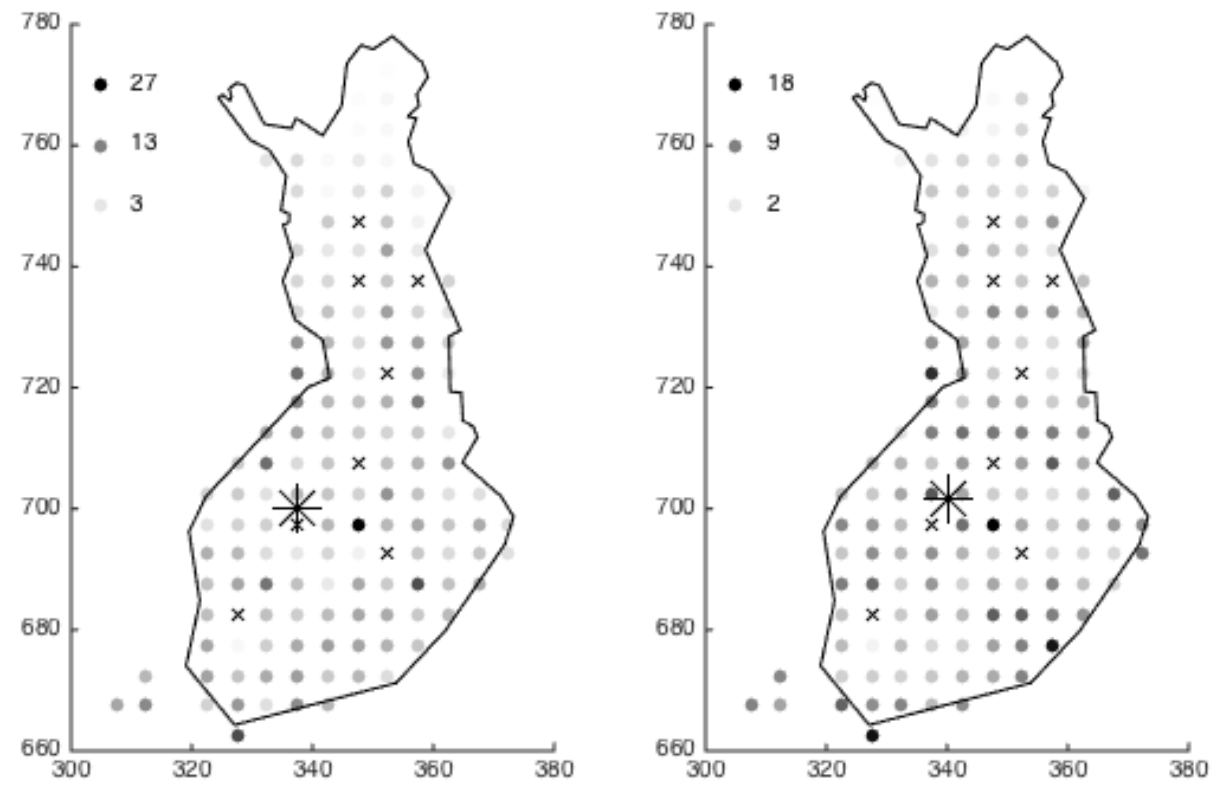

Supplementary fig. 89. Muscicapa striata
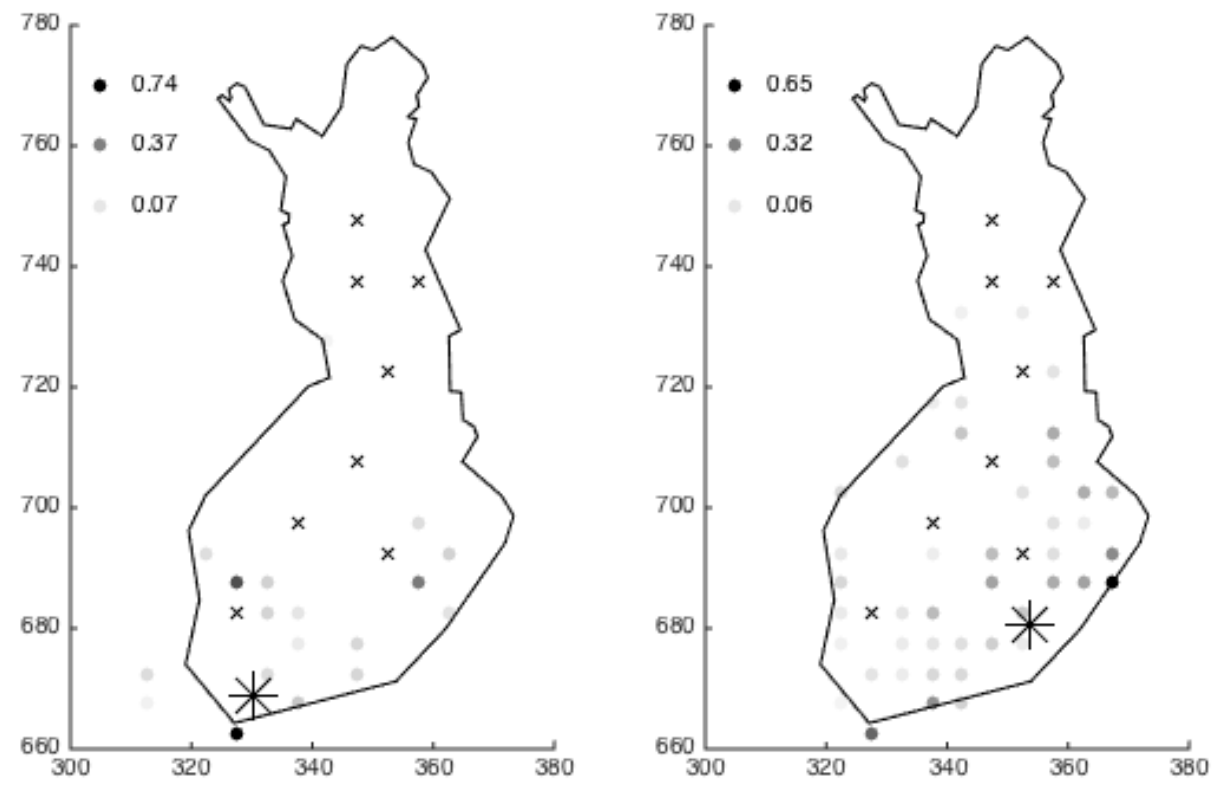

Supplementary fig. 90. Ficedula parva 

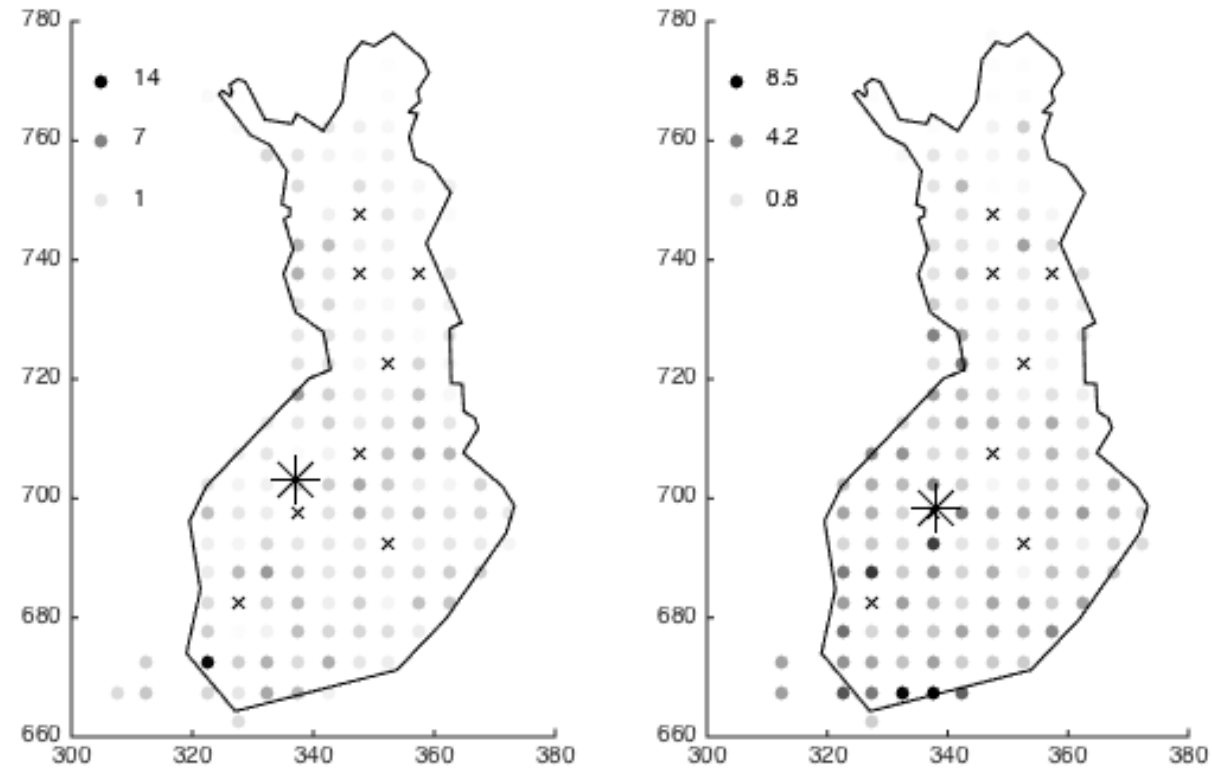

Supplementary fig. 91. Ficedula hypoleuca
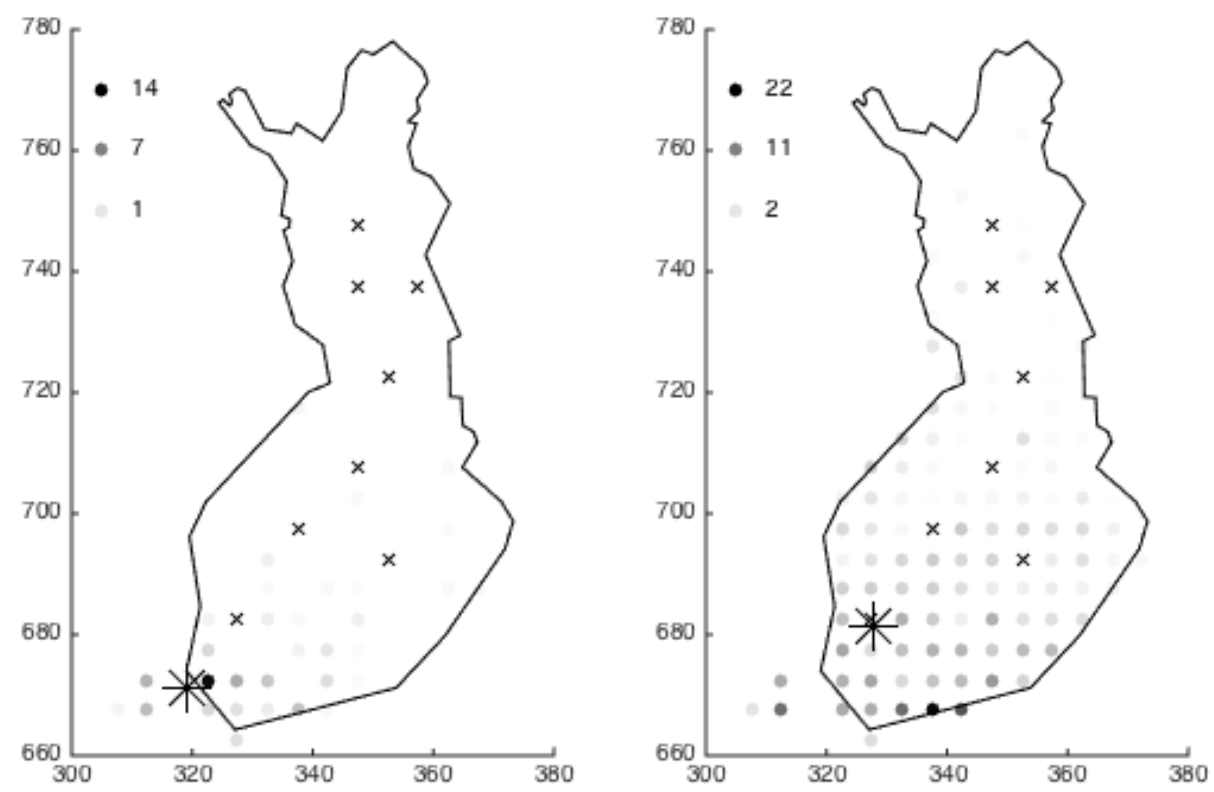

Supplementary fig. 92. Cyanistes caeruleus 

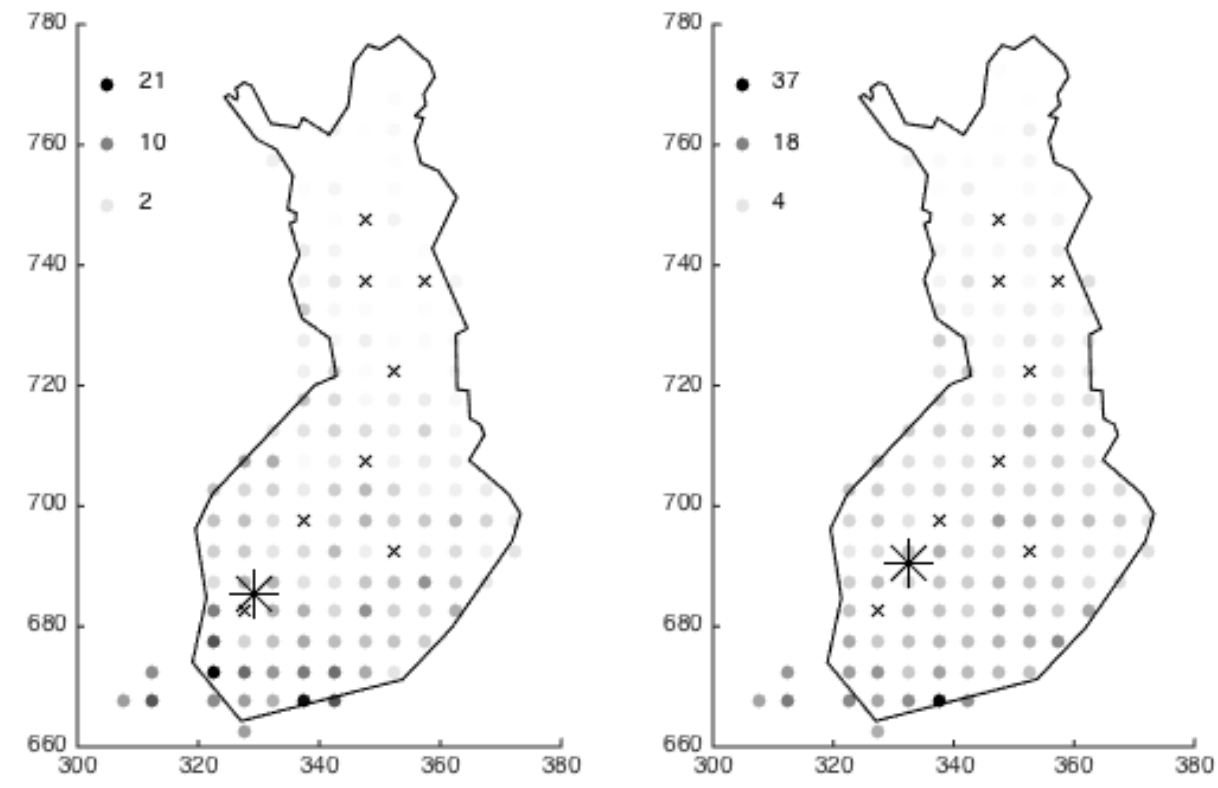

Supplementary fig. 93. Parus major
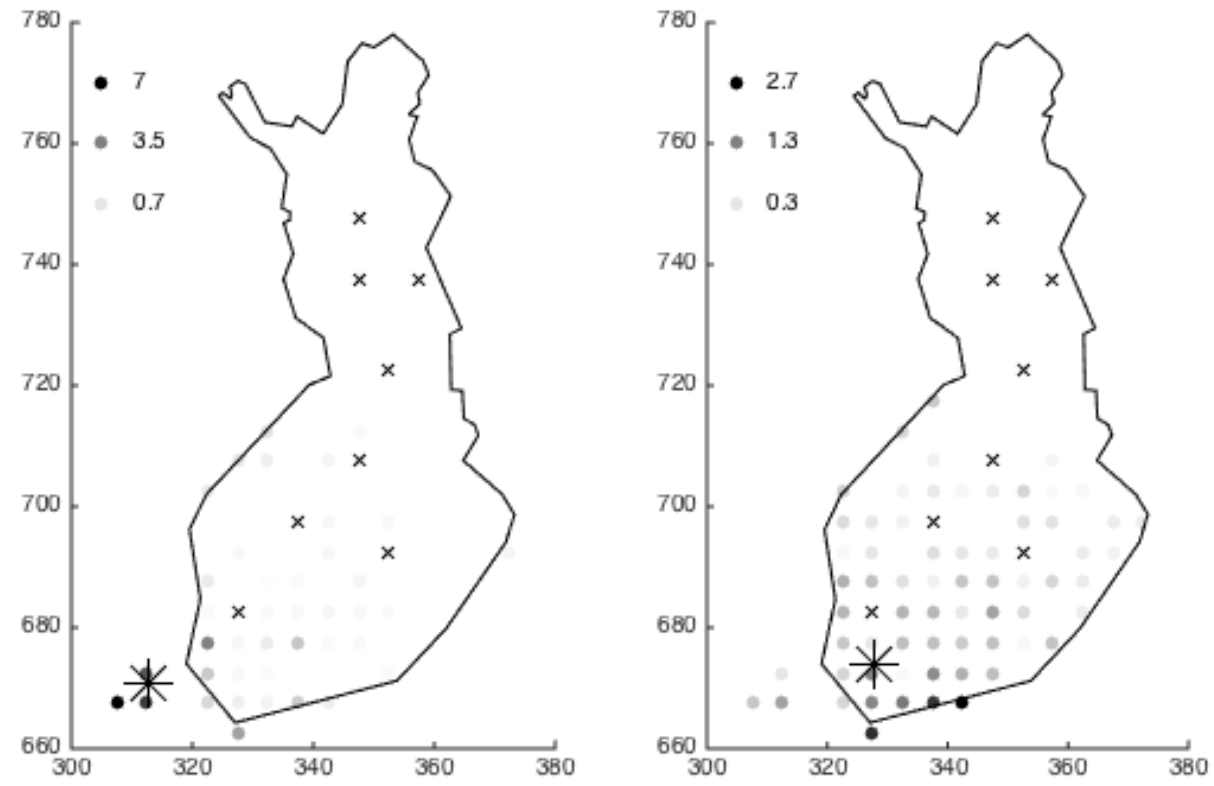

Supplementary fig. 94. Periparus ater 

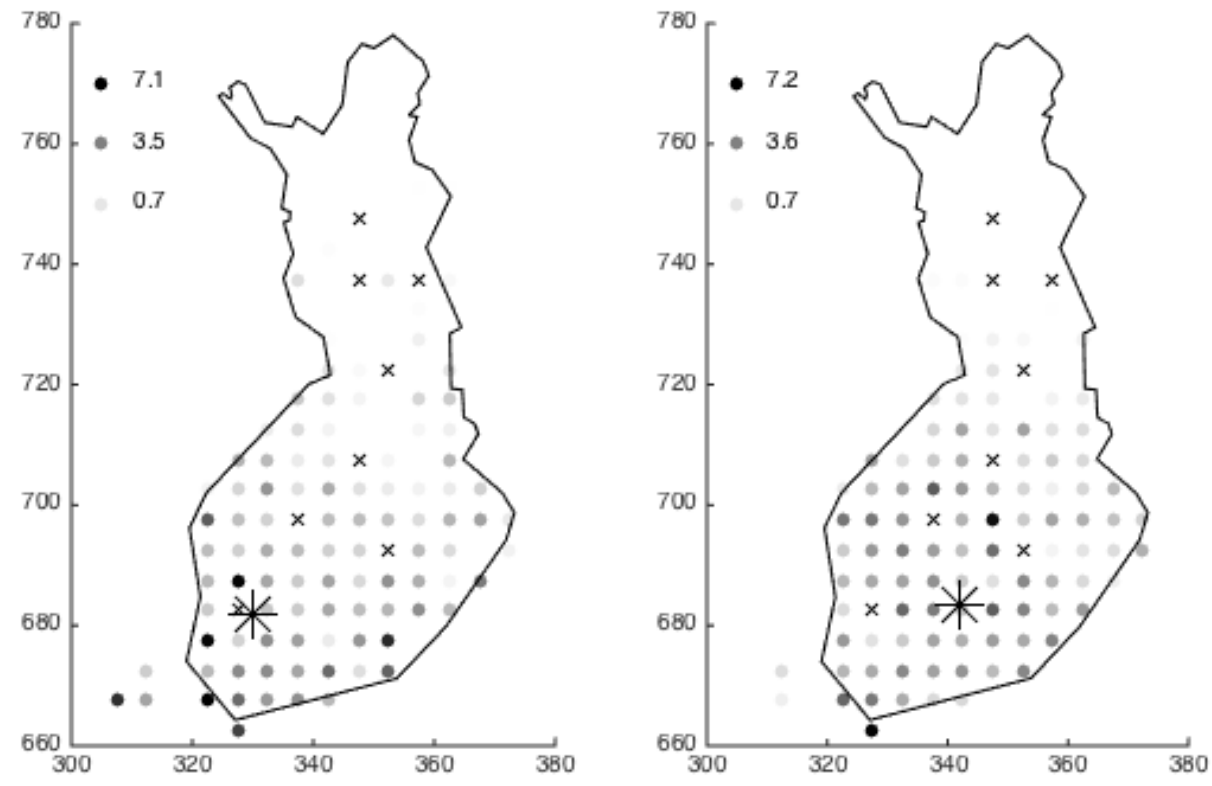

Supplementary fig. 95. Lophophanes cristatus
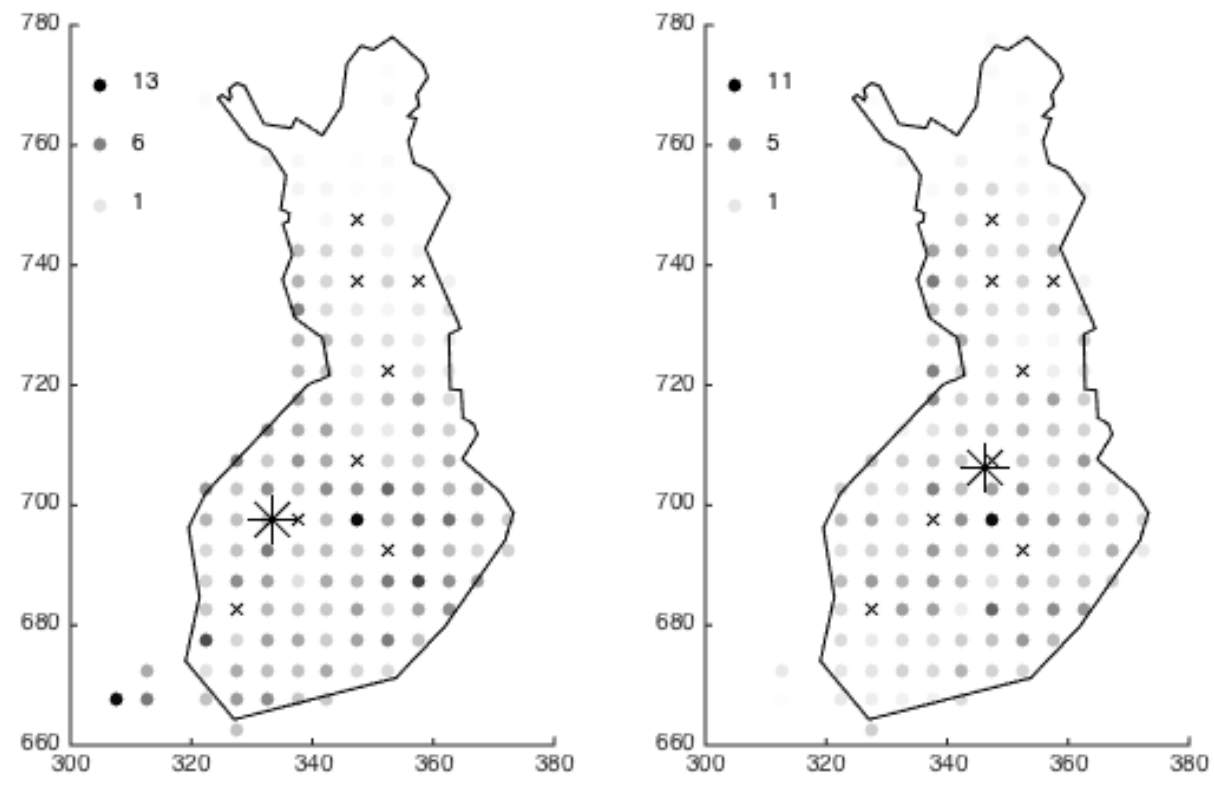

Supplementary fig. 96. Poecile montanus 

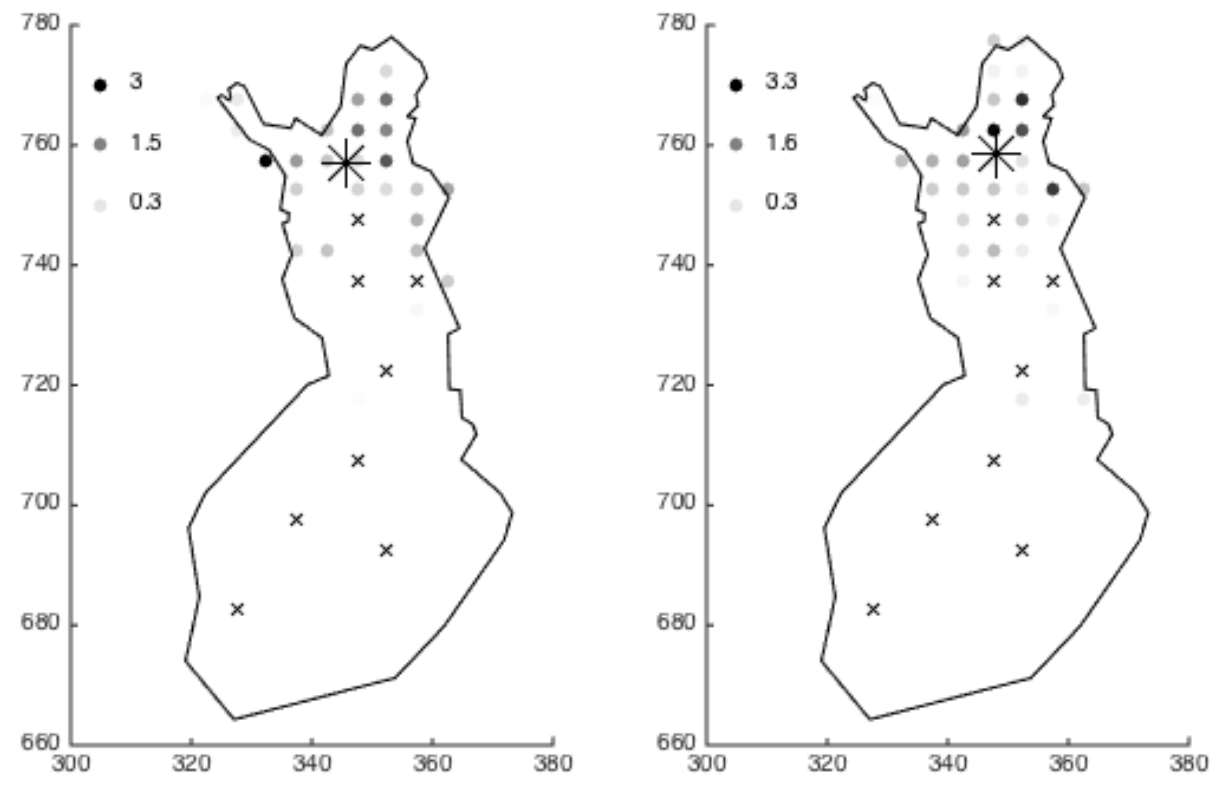

Supplementary fig. 97. Poecile cinctus
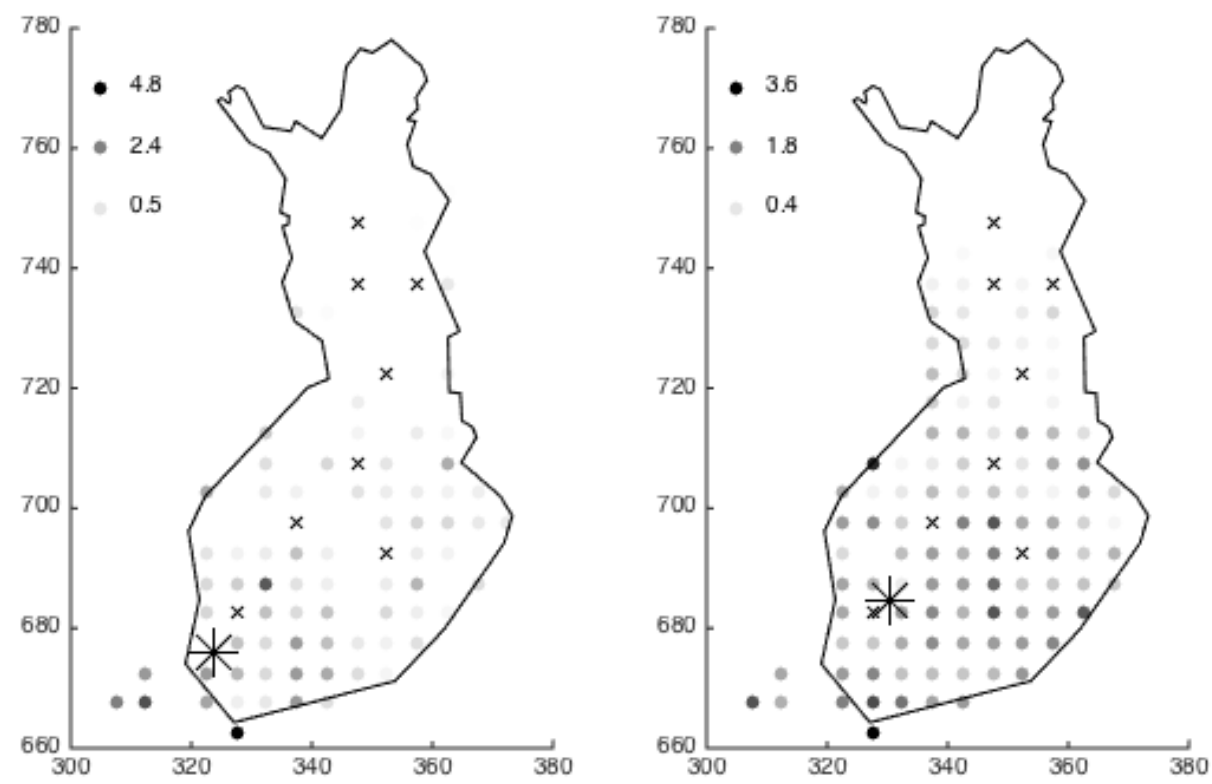

Supplementary fig. 98. Certhia familiaris 

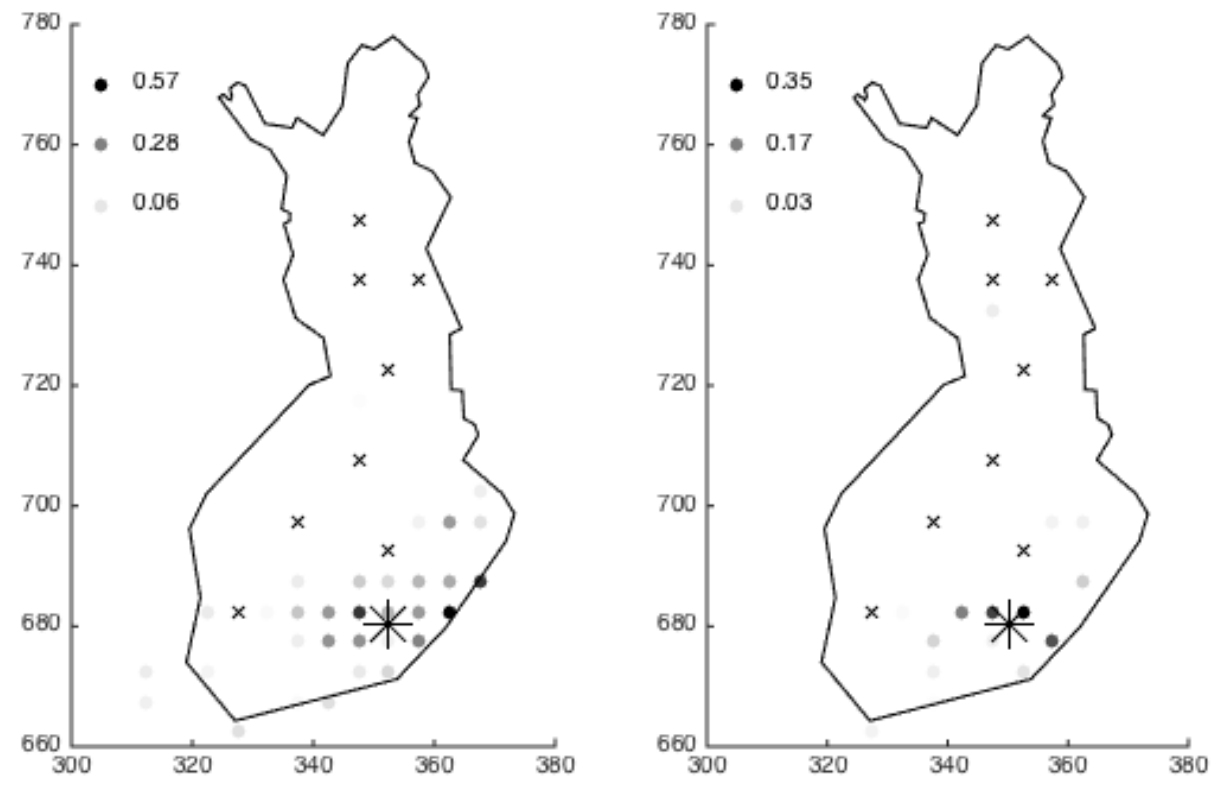

Supplementary fig. 99. Oriolus oriolus
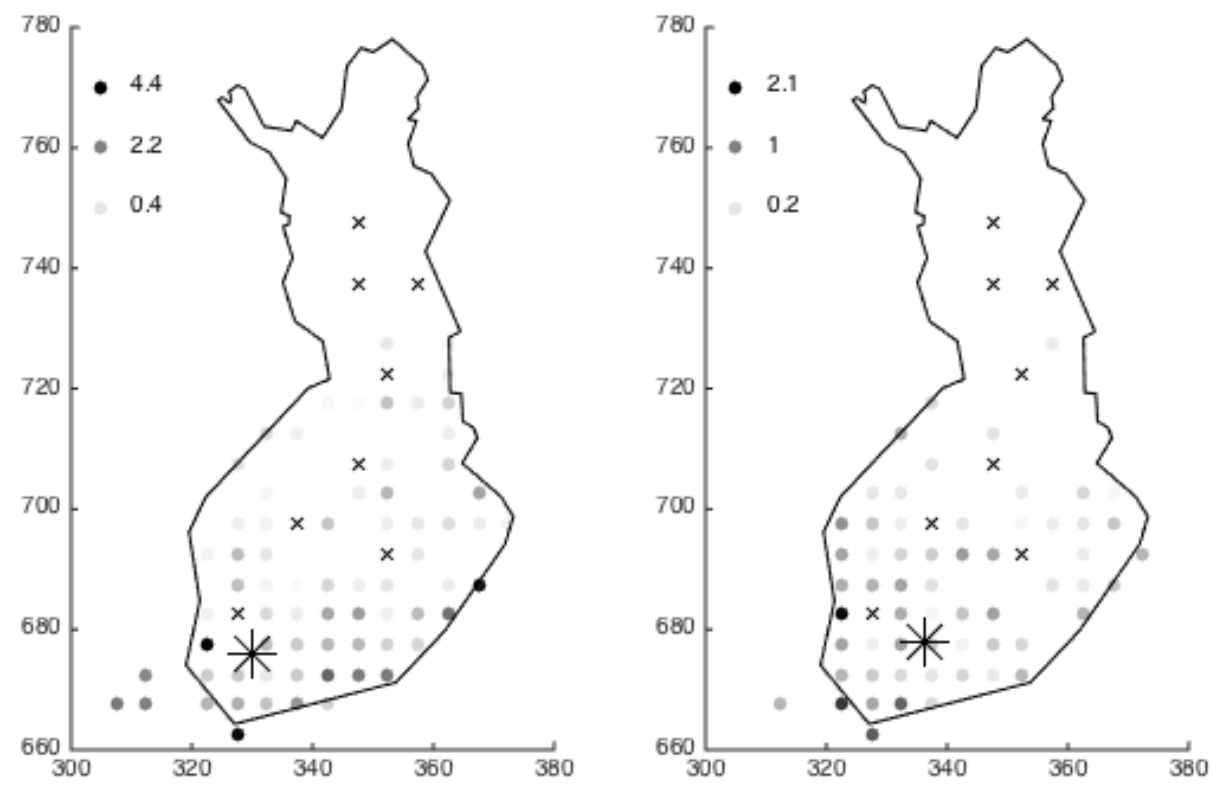

Supplementary fig. 100. Lanius collurio 

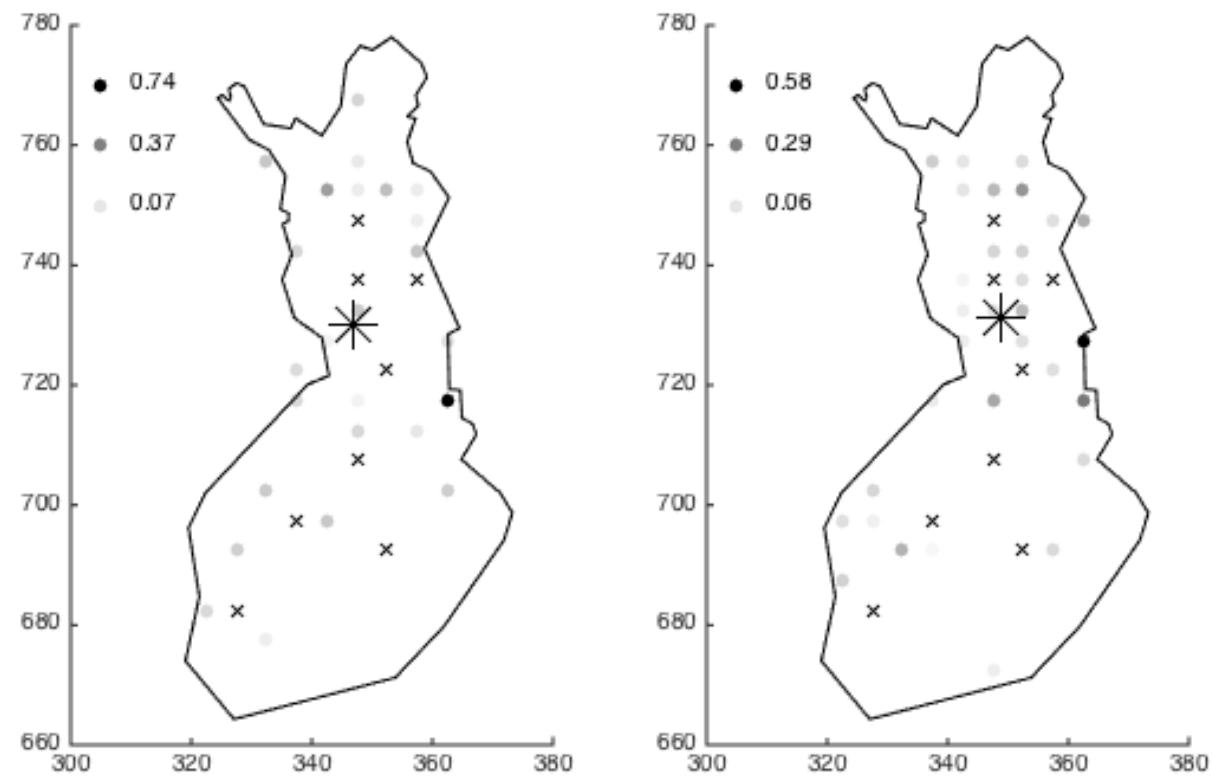

Supplementary fig. 101. Lanius excubitor
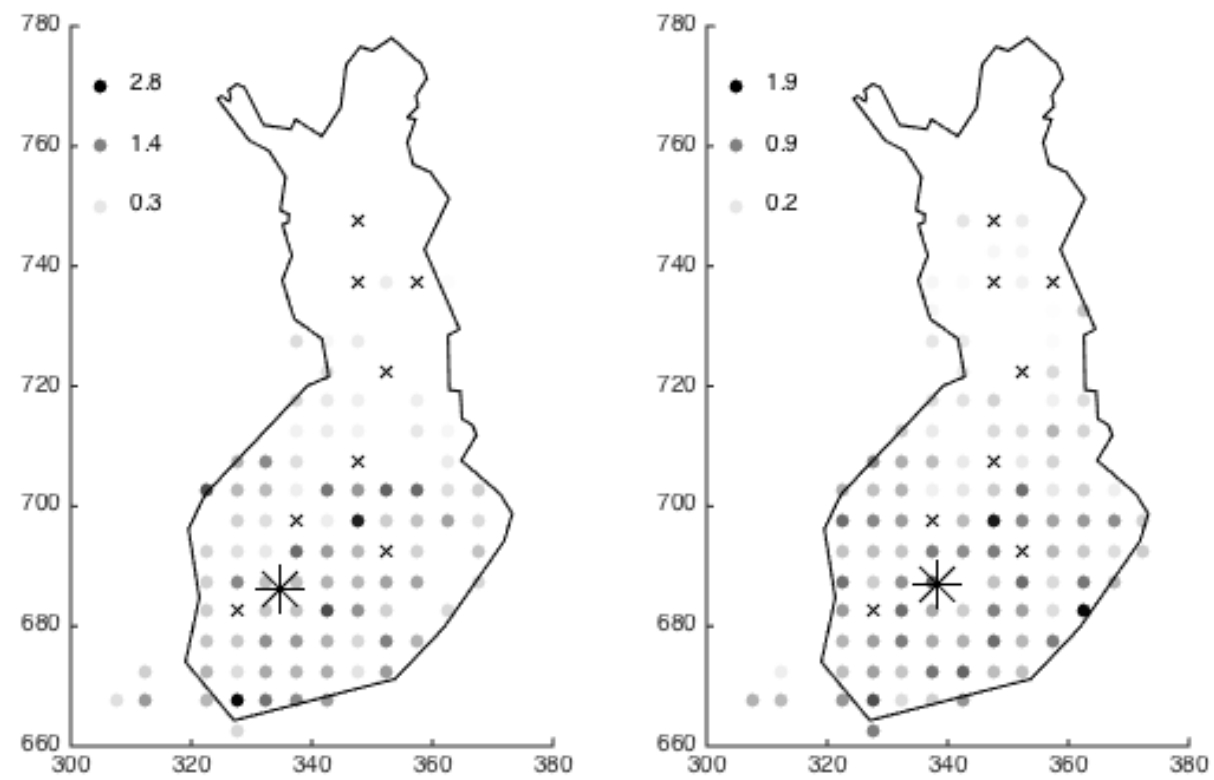

Supplementary fig. 102. Garrulus glandarius 

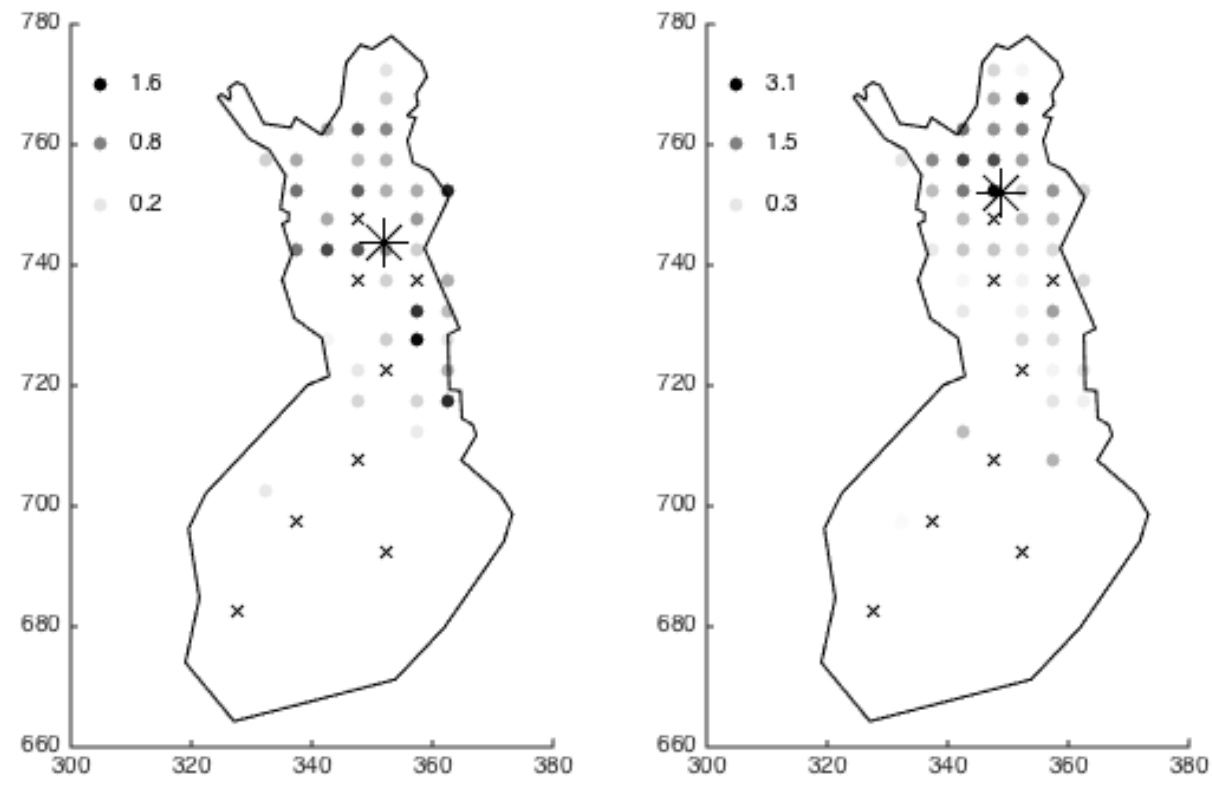

Supplementary fig. 103. Perisoreus infaustus
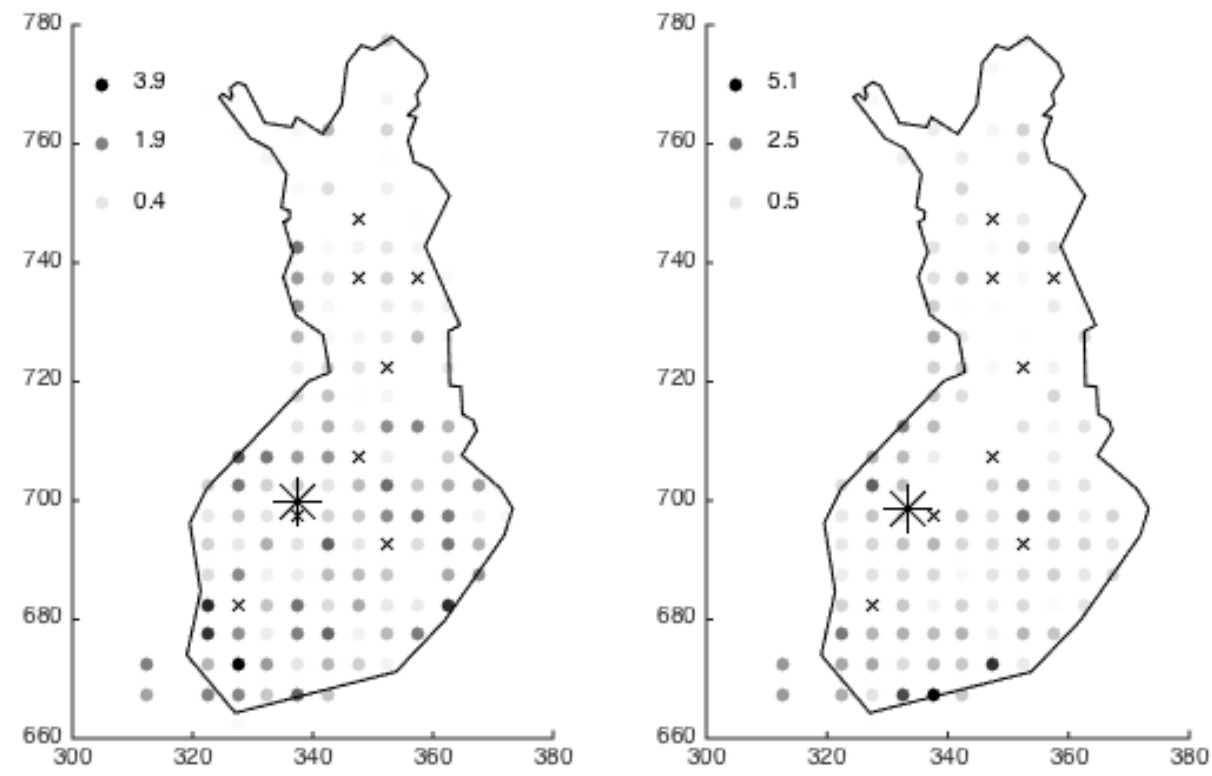

Supplementary fig. 104. Pica pica 

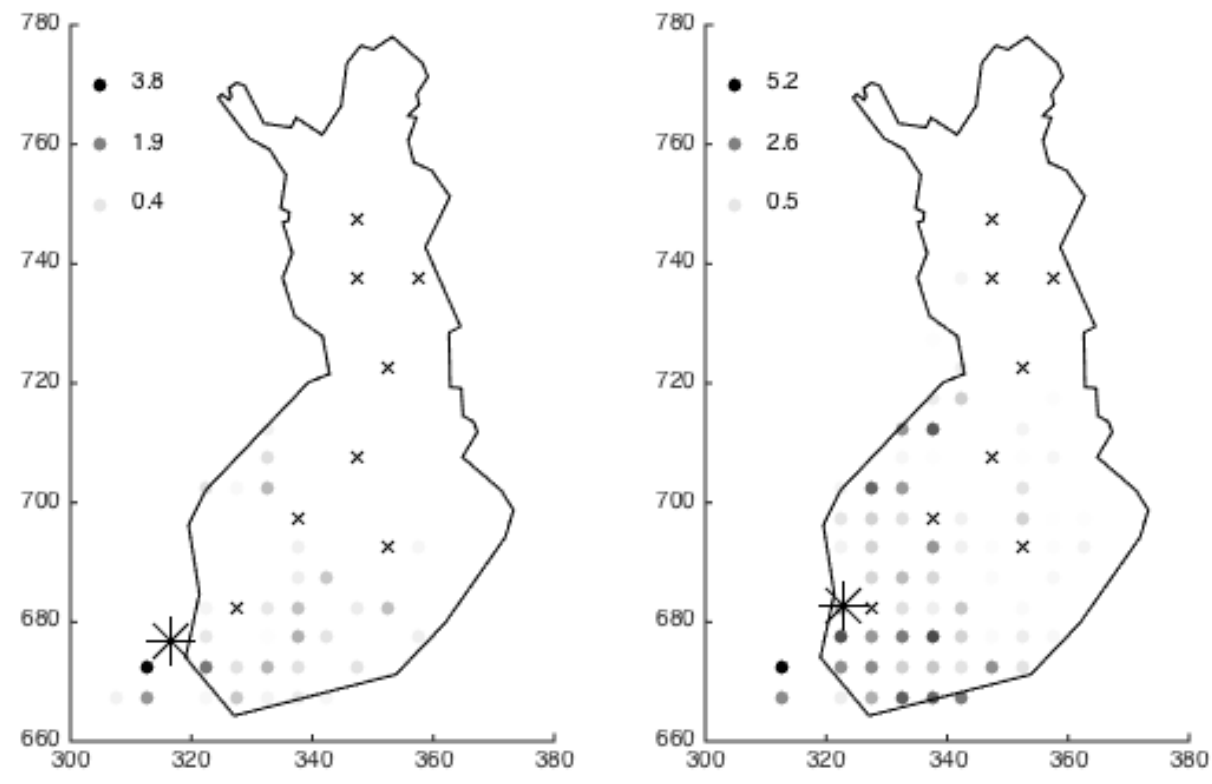

Supplementary fig. 105. Corvus monedula
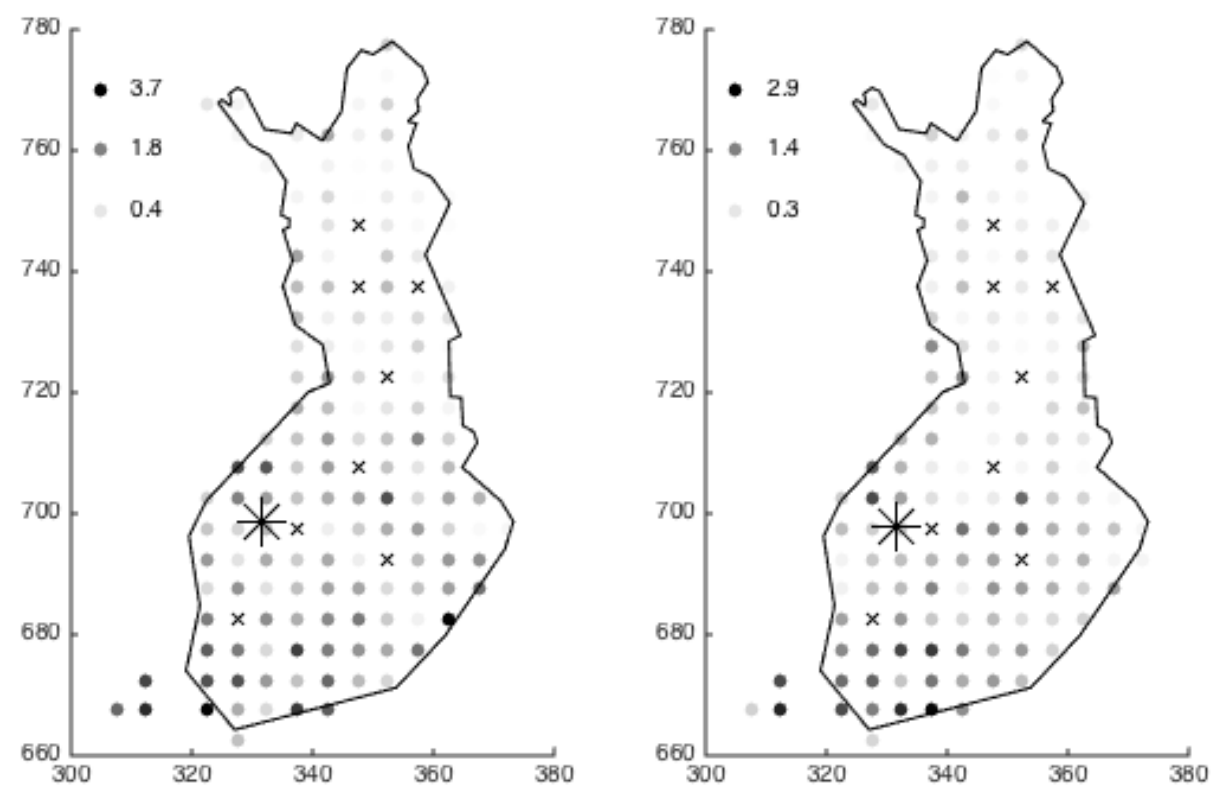

Supplementary fig. 106. Corvus corone 

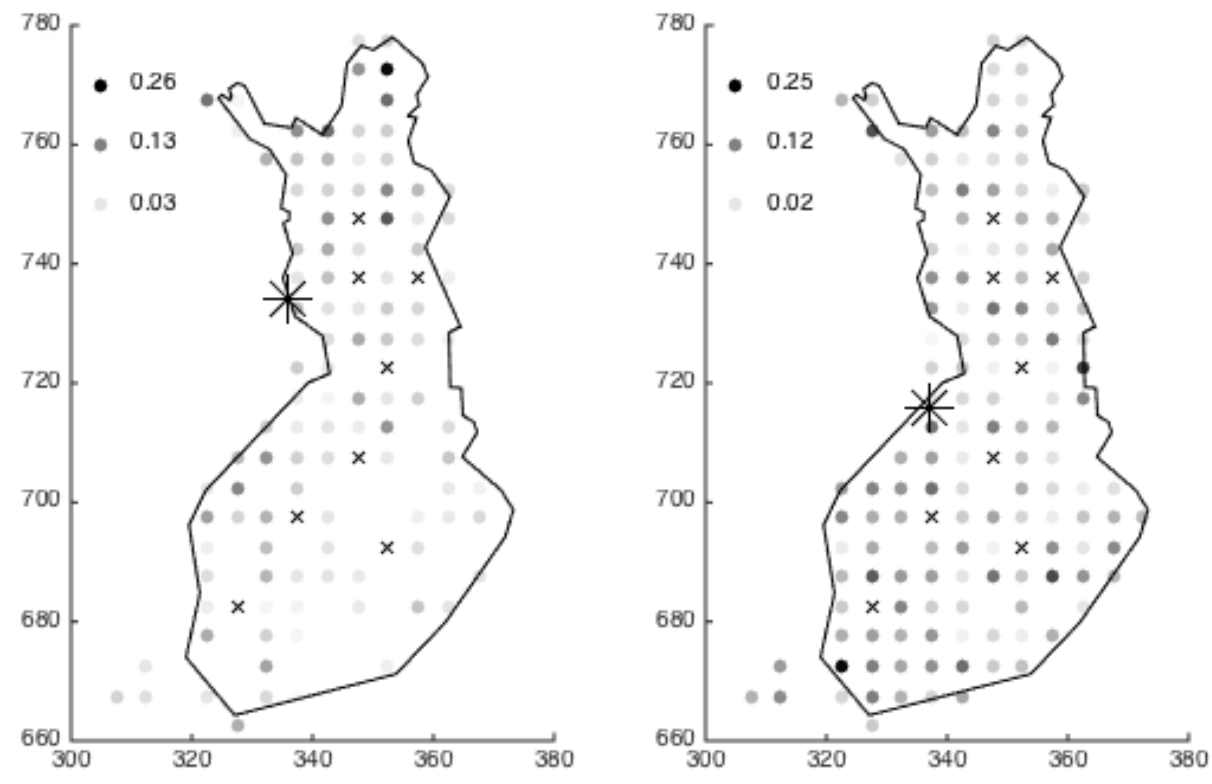

Supplementary fig. 107. Corvus corax
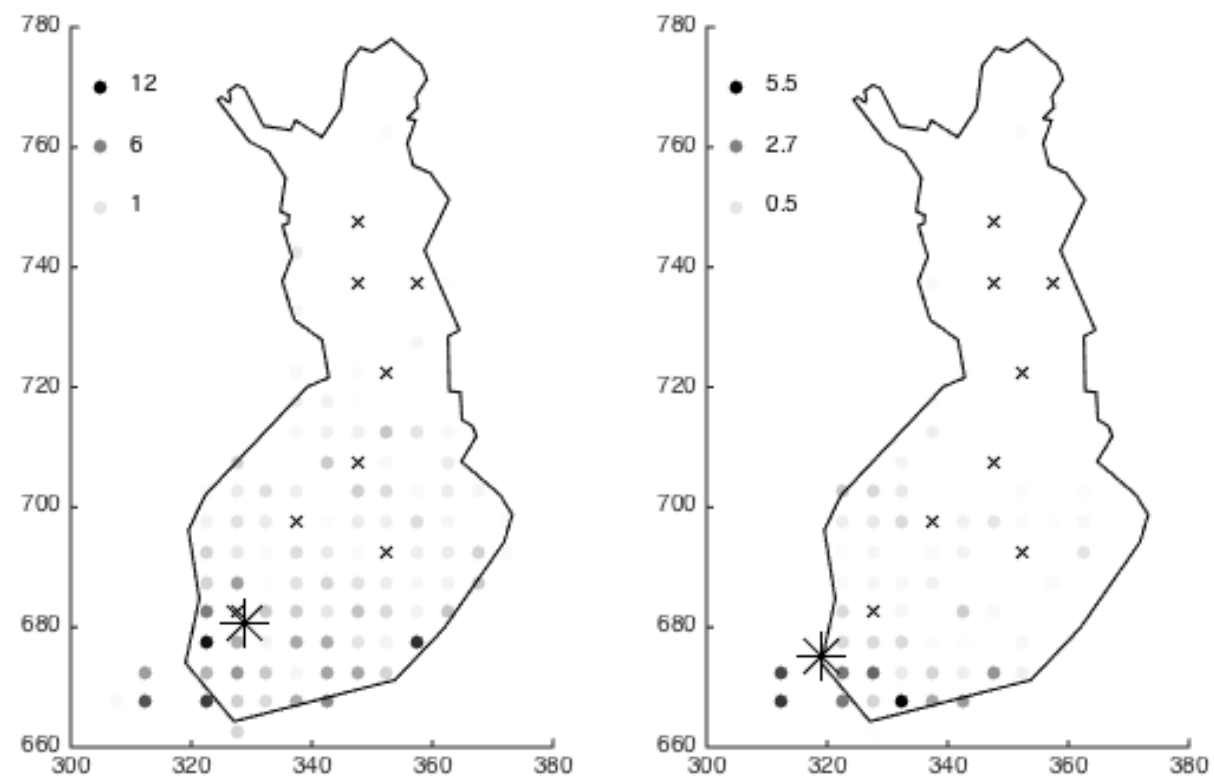

Supplementary fig. 108. Sturnus vulgaris 

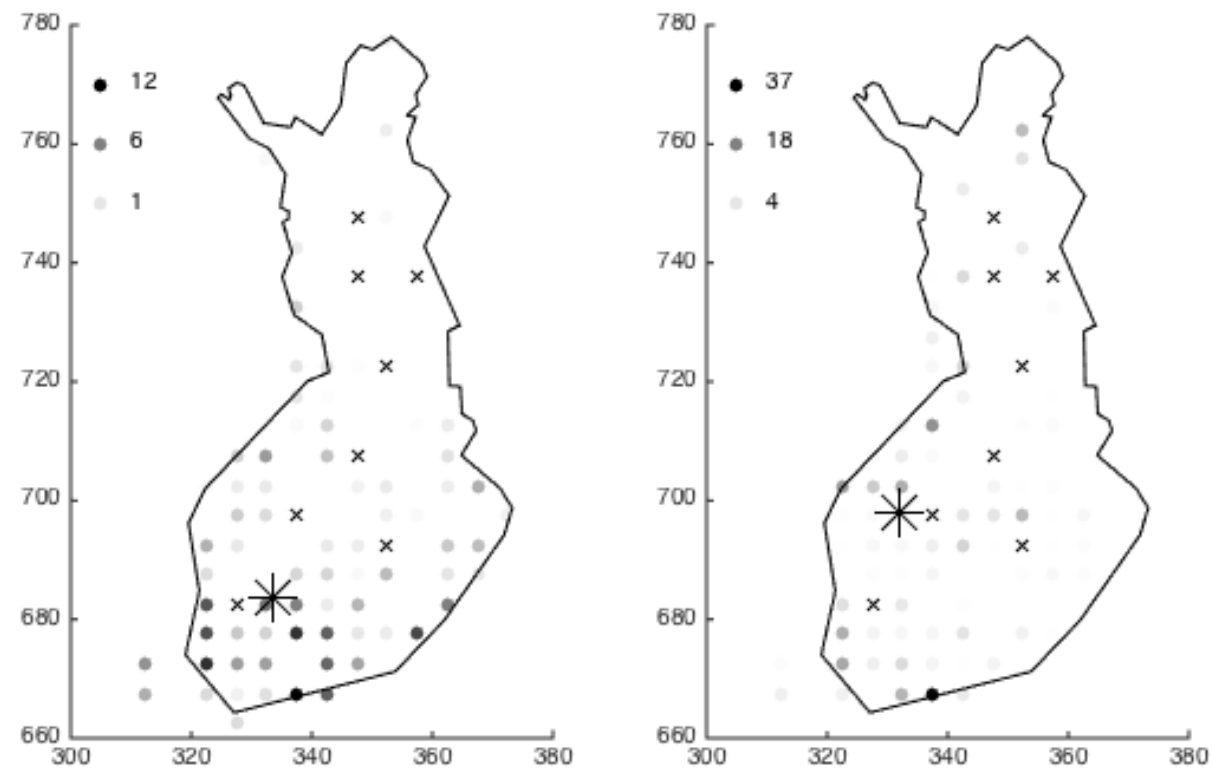

Supplementary fig. 109. Passer domesticus
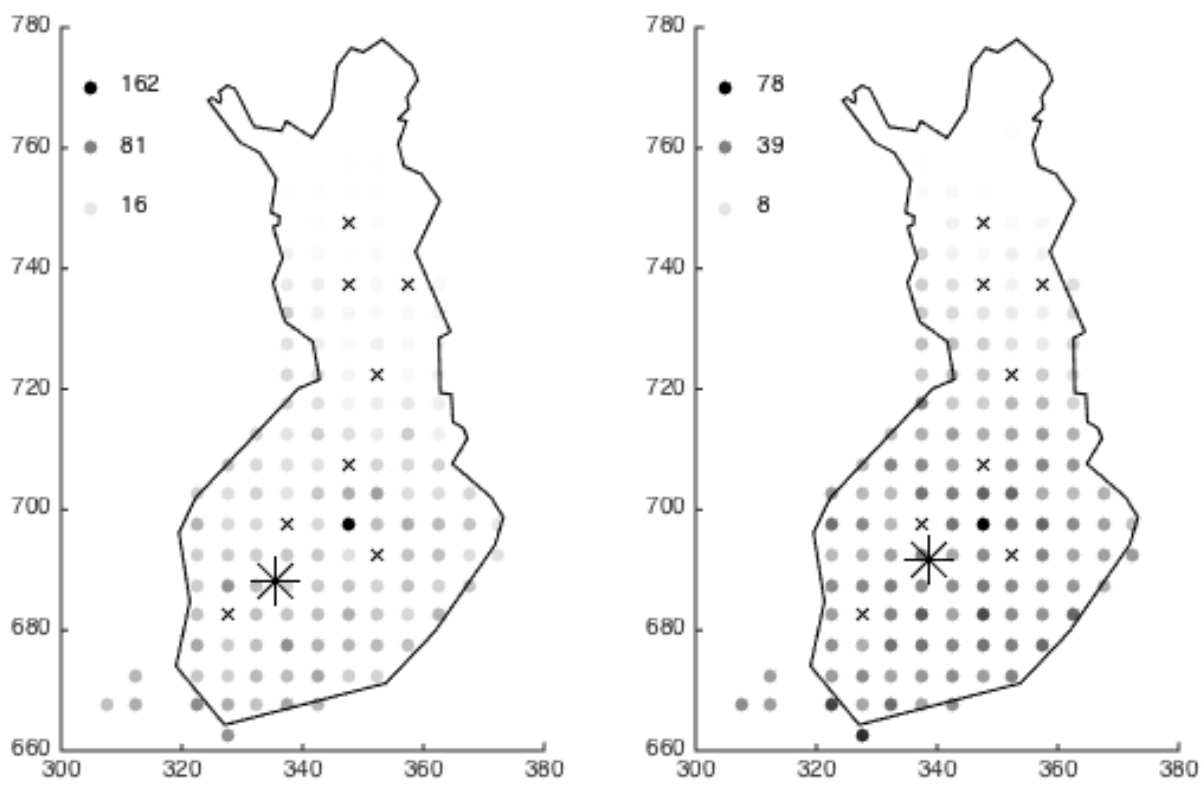

Supplementary fig. 110. Fringilla coelebs 

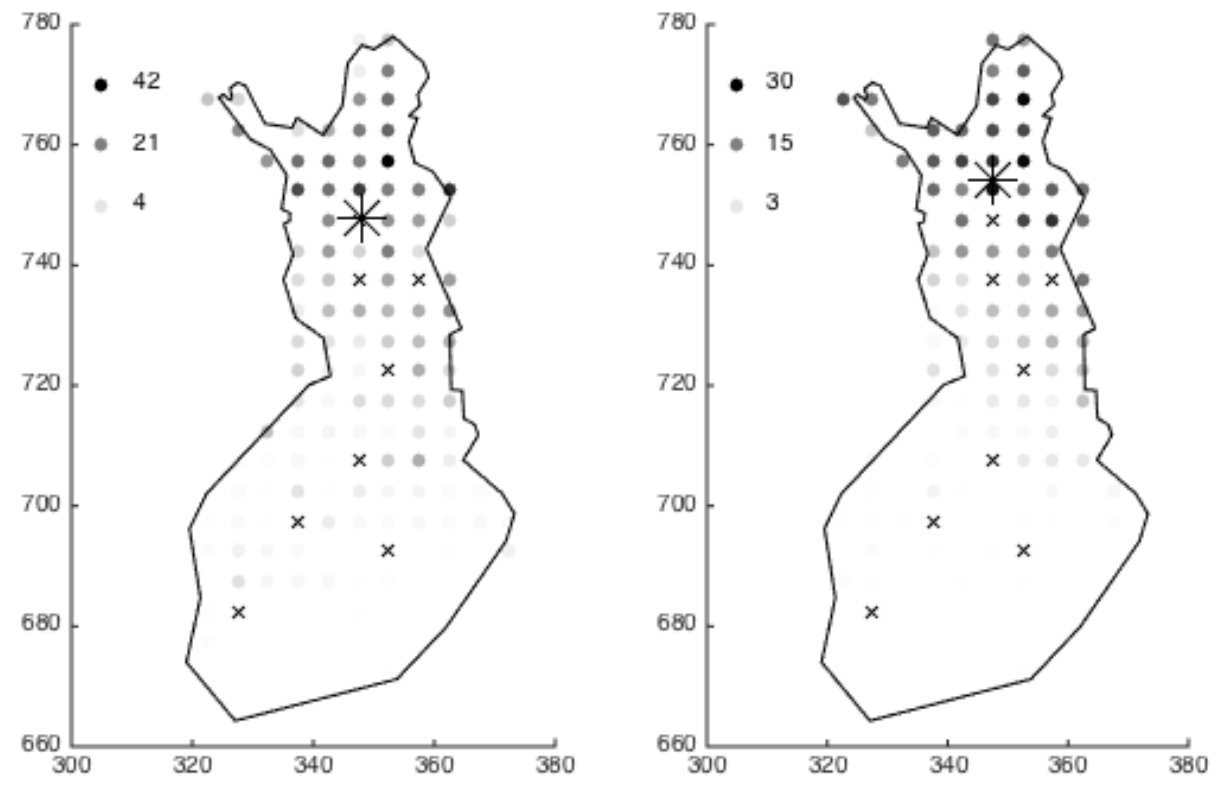

Supplementary fig. 111. Fringilla montifringilla
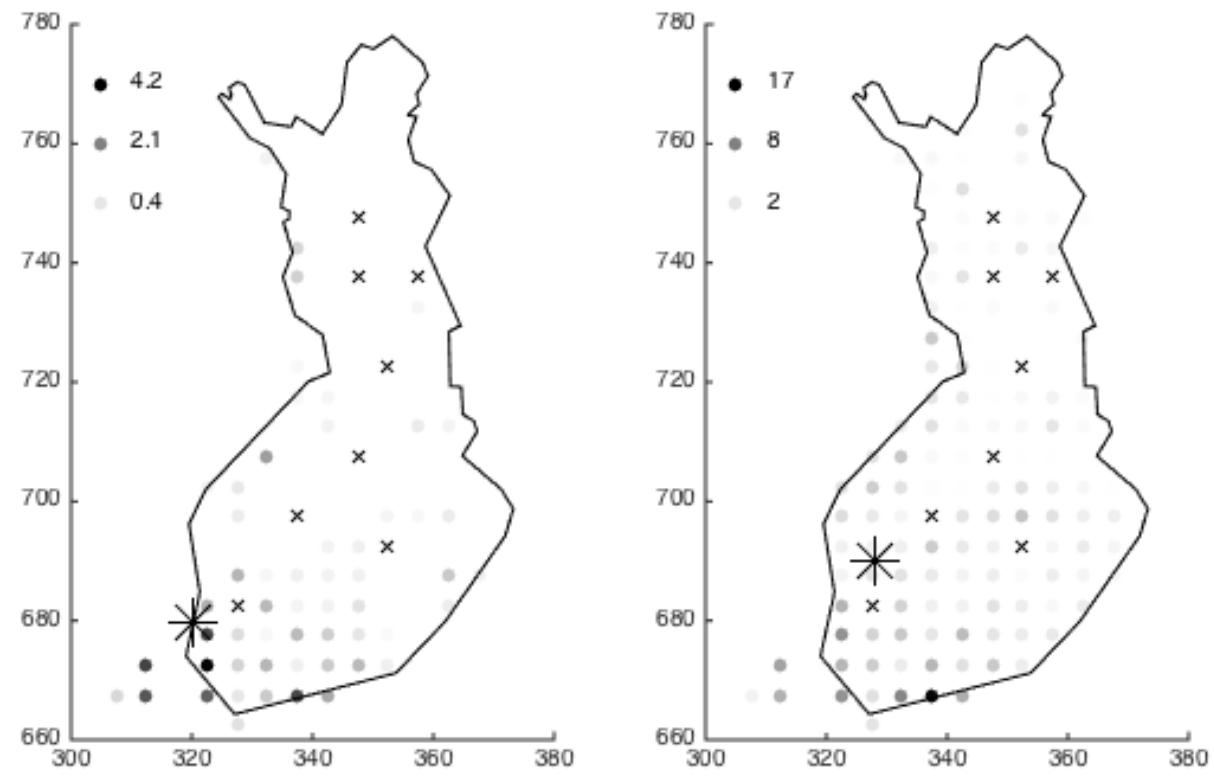

Supplementary fig. 112. Carduelis chloris 

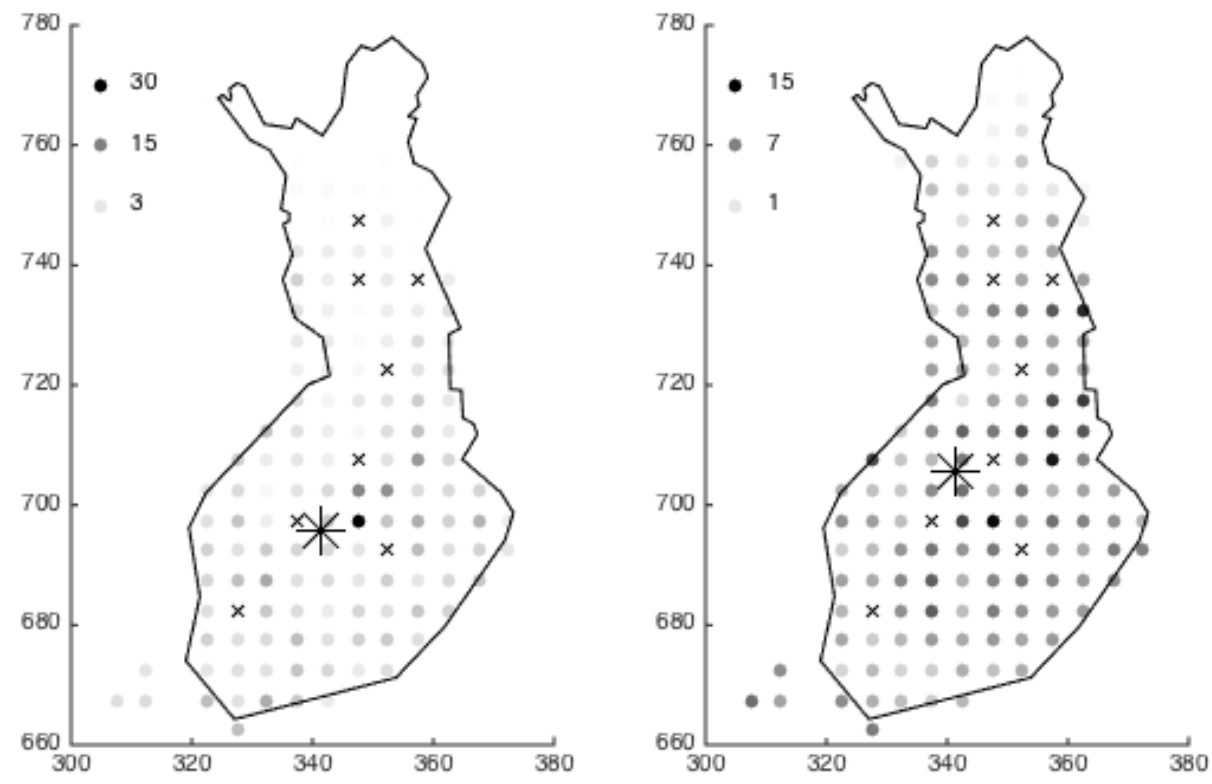

Supplementary fig. 113. Carduelis spinus
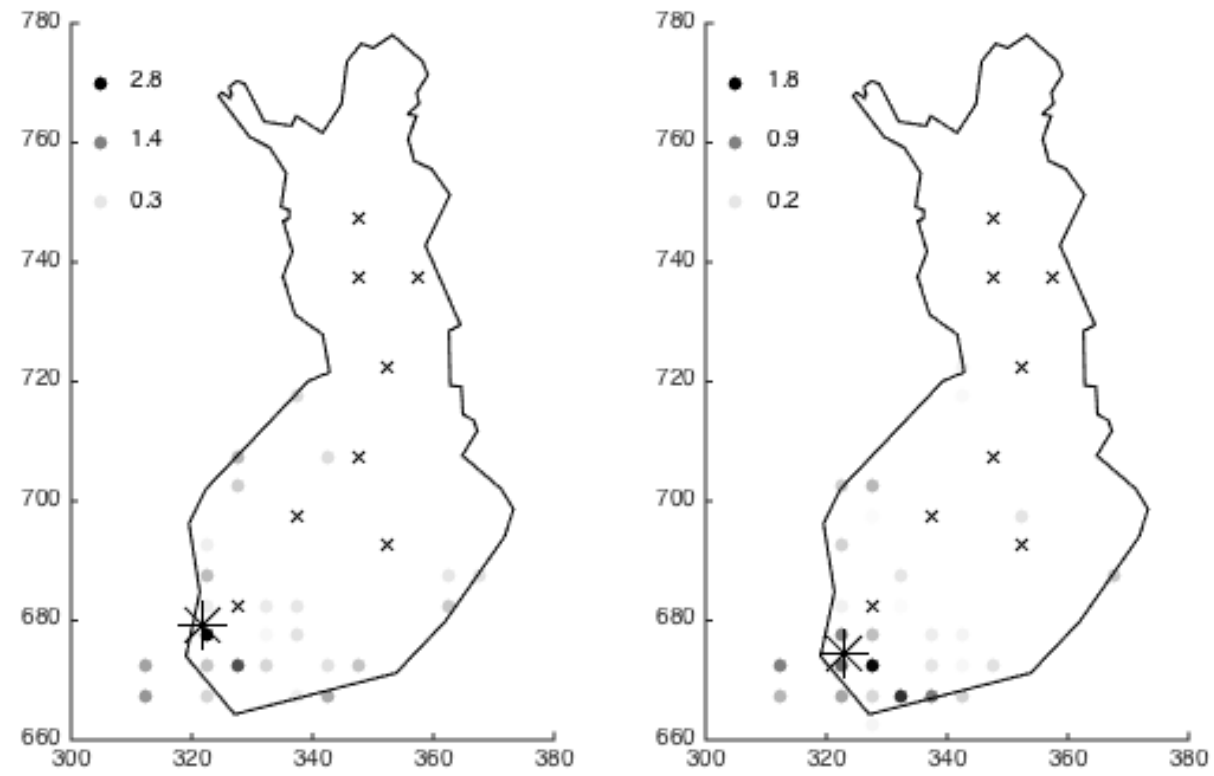

Supplementary fig. 114. Carduelis cannabina 

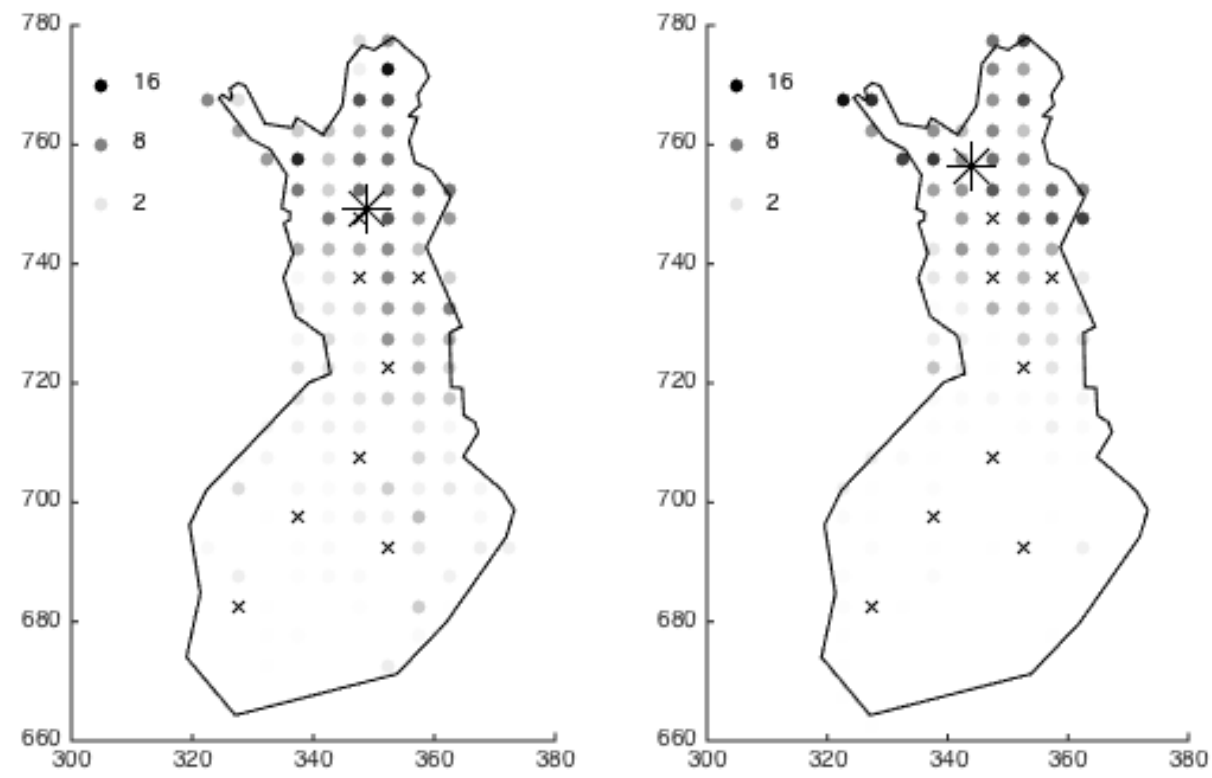

Supplementary fig. 115. Carduelis flammea
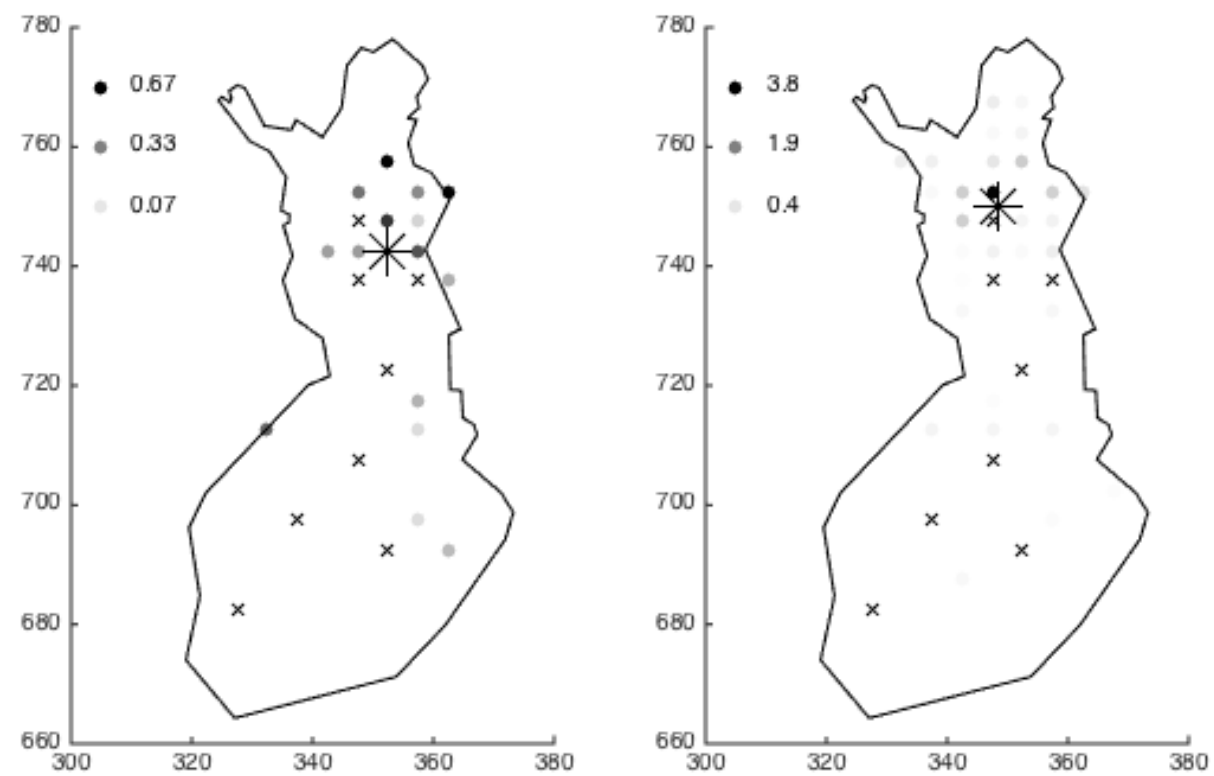

Supplementary fig. 116. Loxia leucoptera 

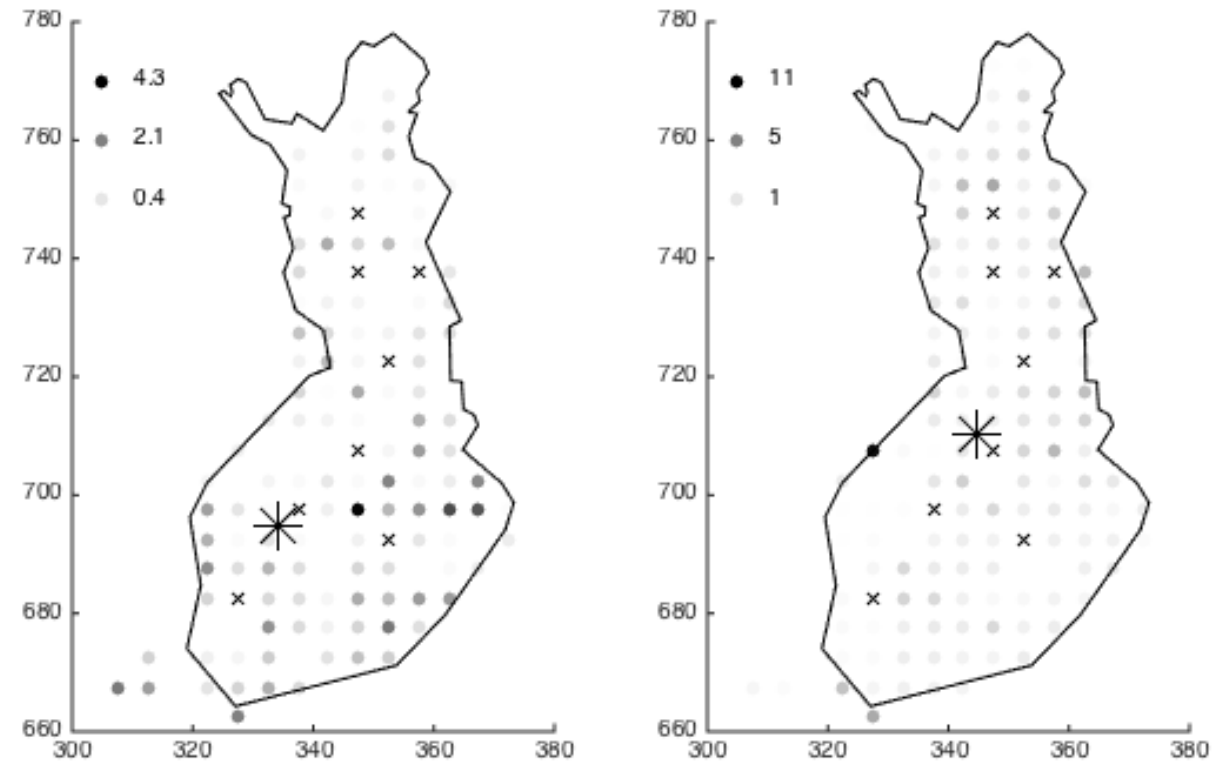

Supplementary fig. 117. Loxia curvirostra
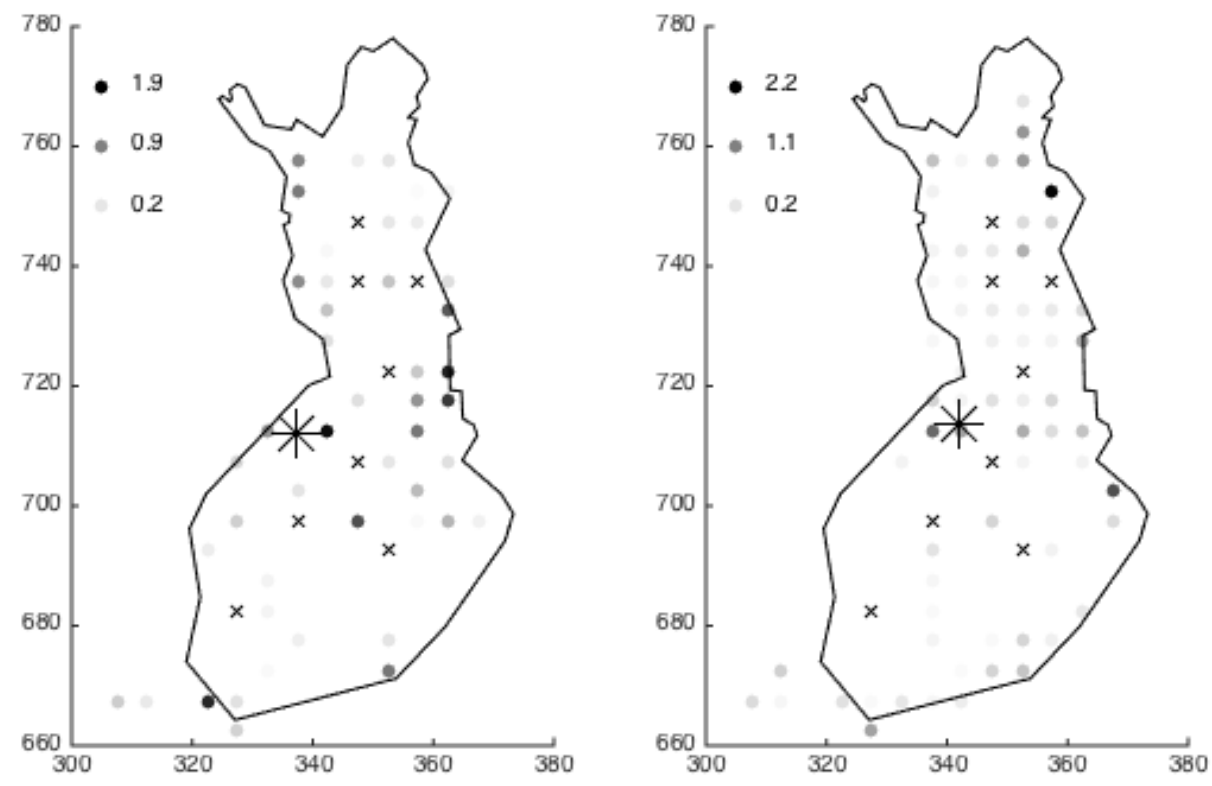

Supplementary fig. 118. Loxia pytyopsittacus 

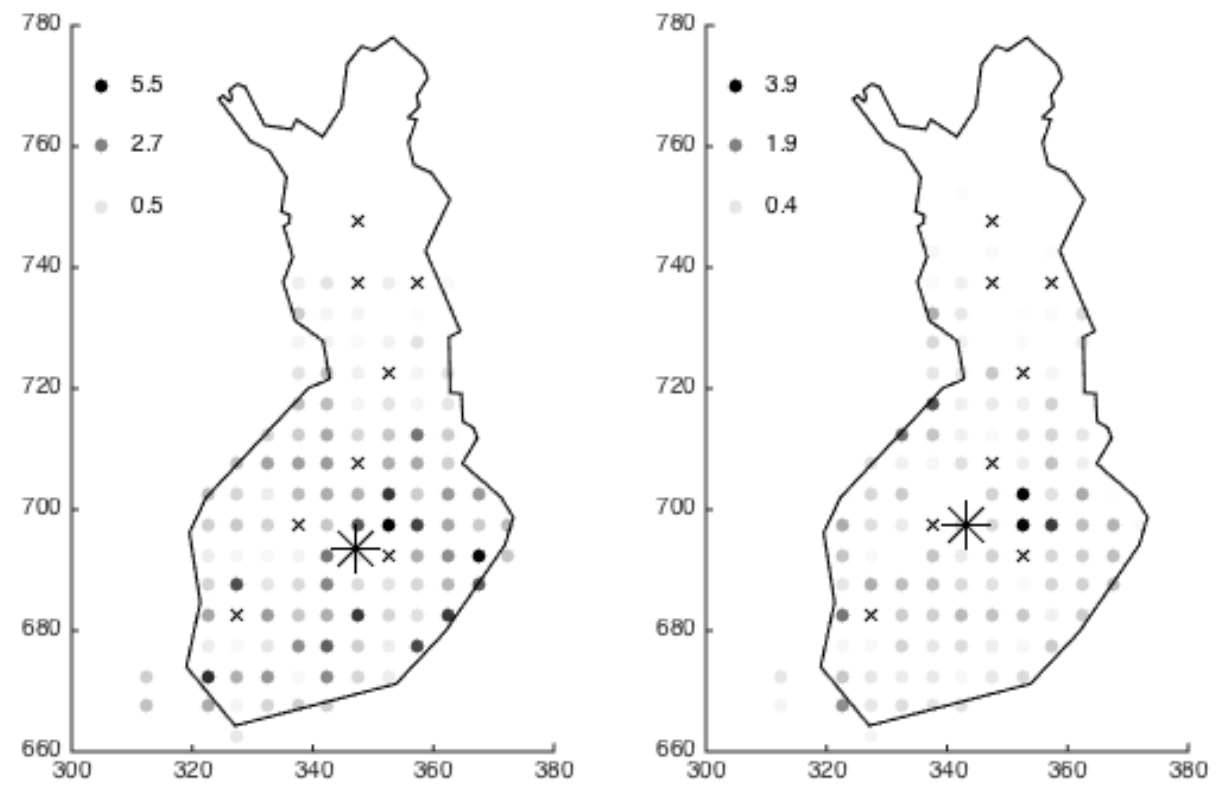

Supplementary fig. 119. Carpodacus erythrinus
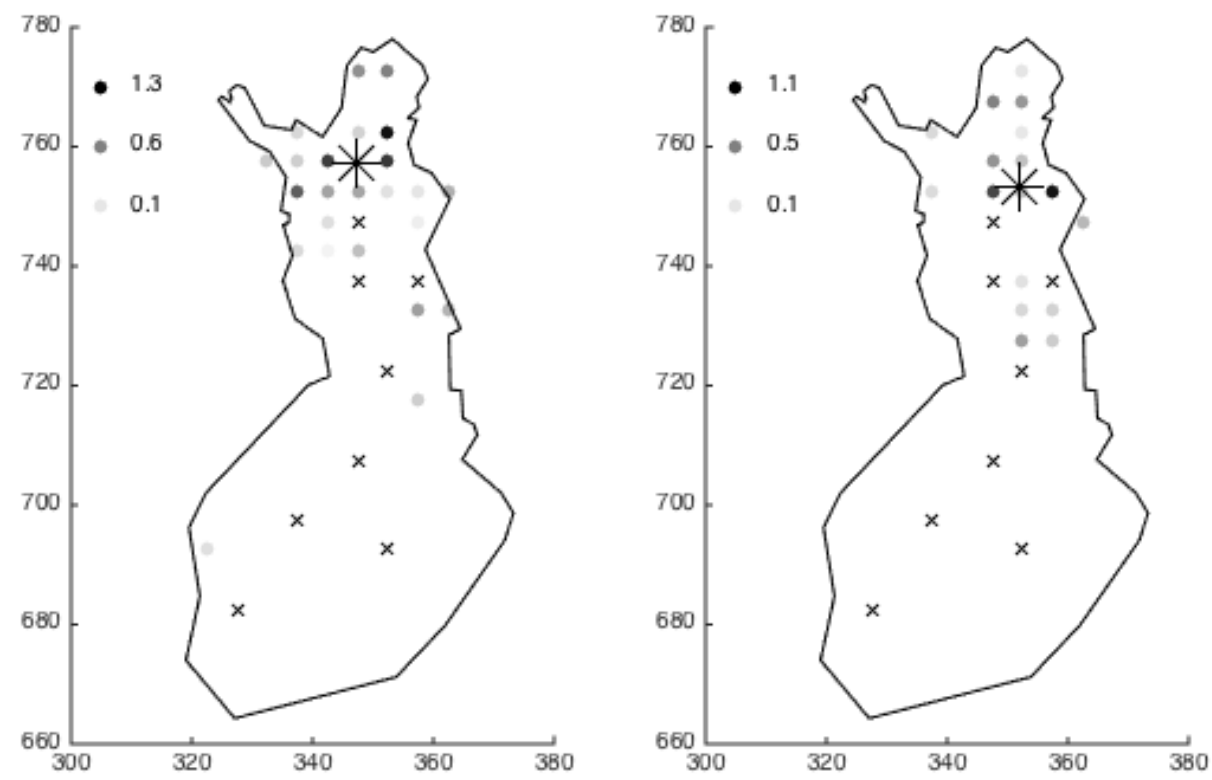

Supplementary fig. 120. Pinicola enucleator 

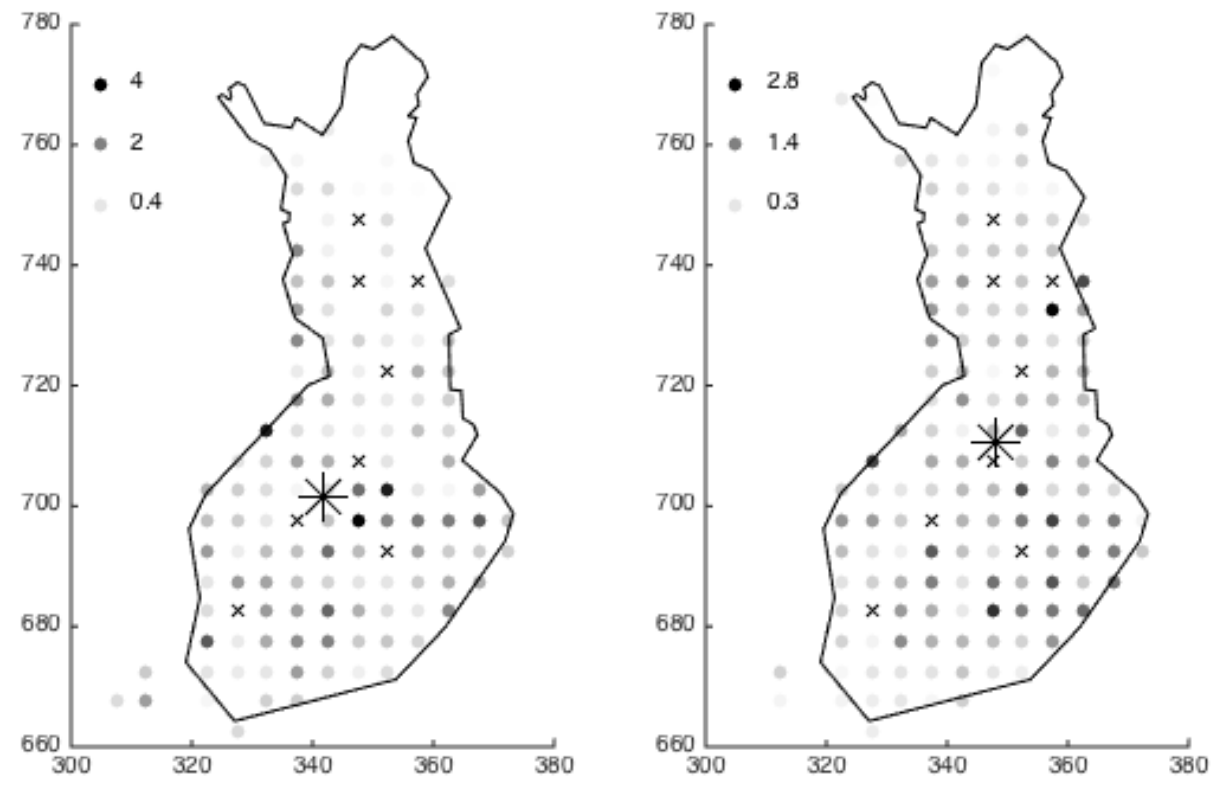

Supplementary fig. 121. Pyrrhula pyrrhula
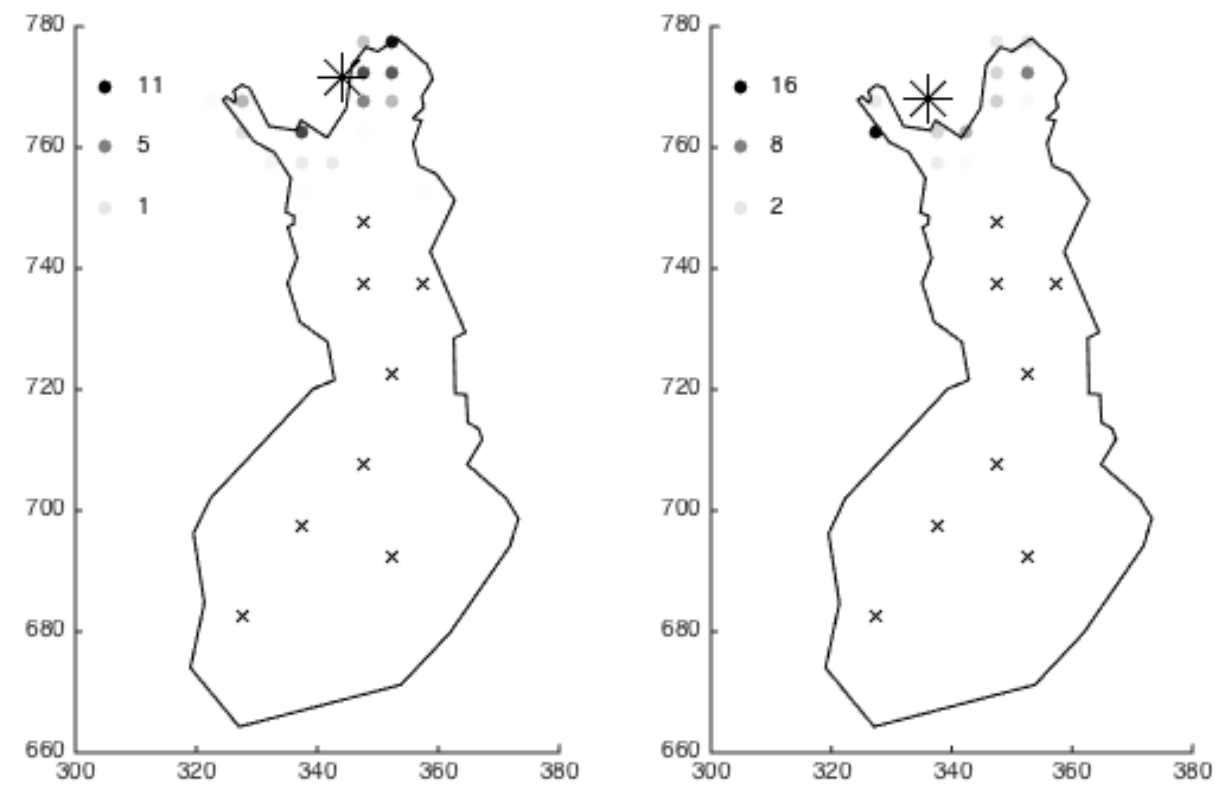

Supplementary fig. 122. Calcarius lapponicus 

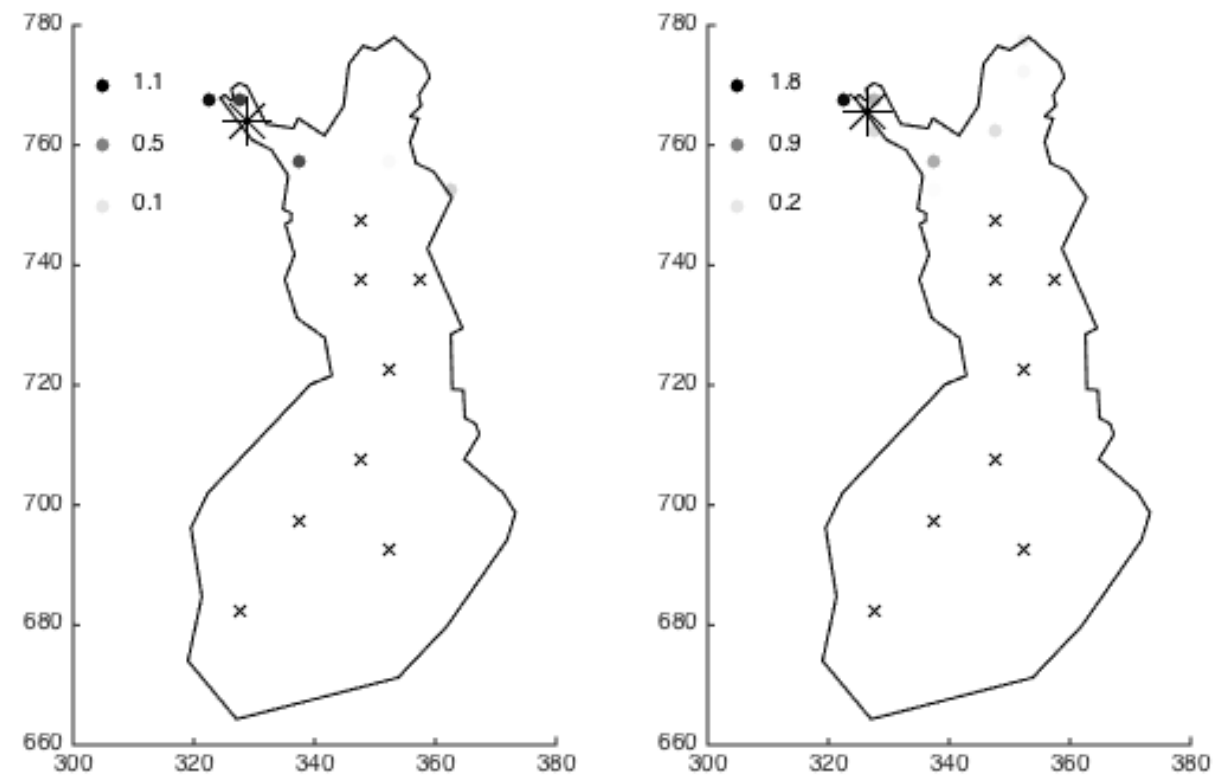

Supplementary fig. 123. Plectrophenax nivalis
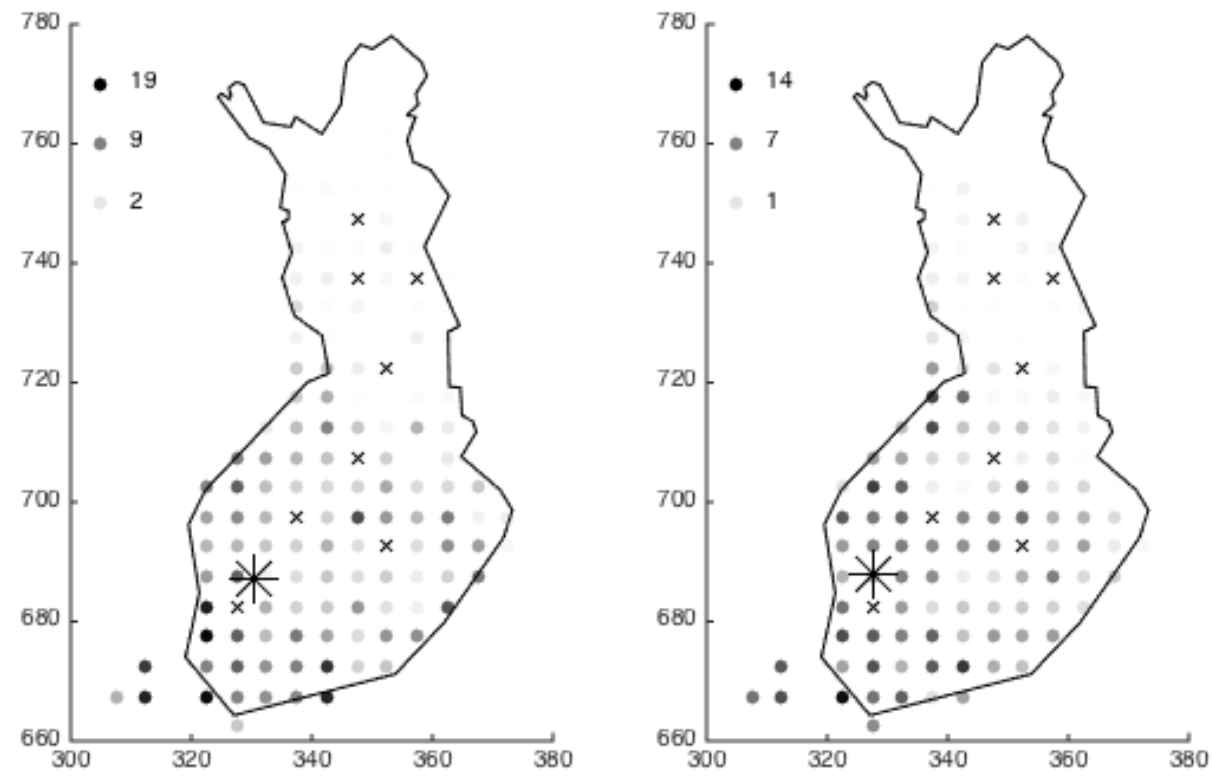

Supplementary fig. 124. Emberiza citrinella 

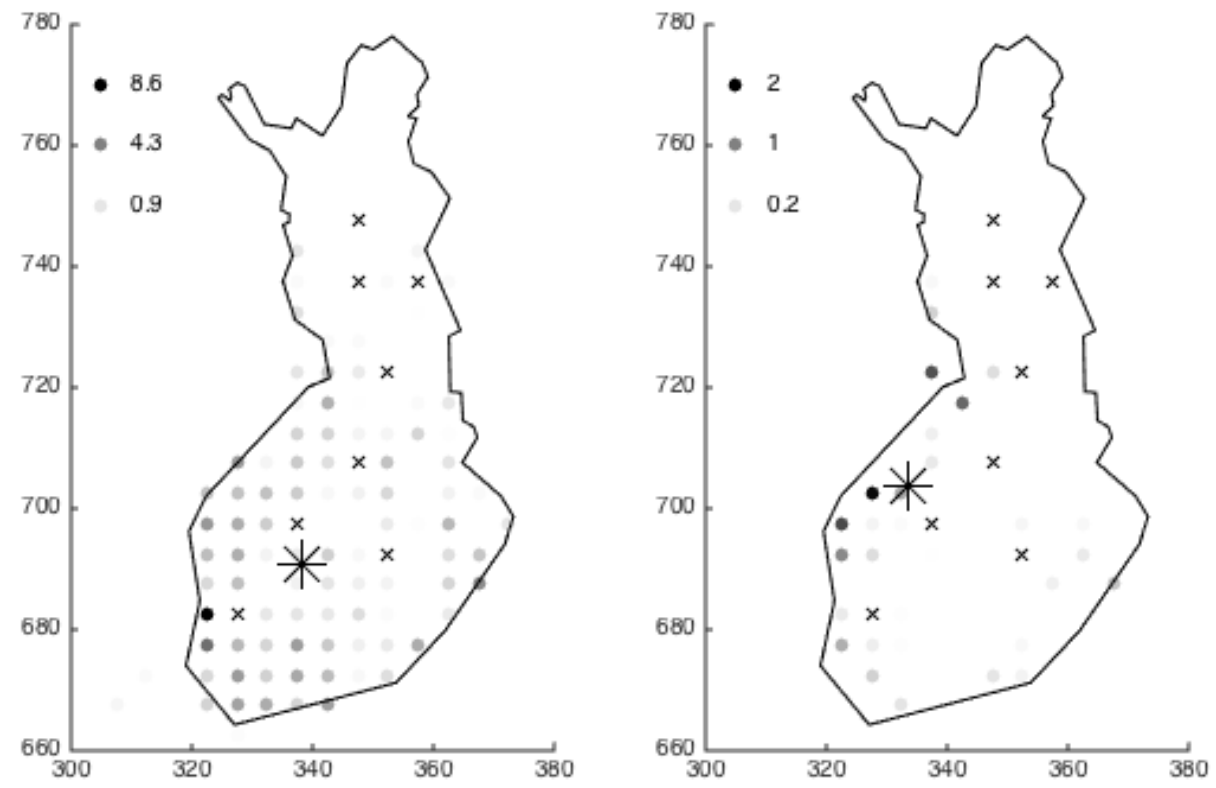

Supplementary fig. 125. Emberiza hortulana
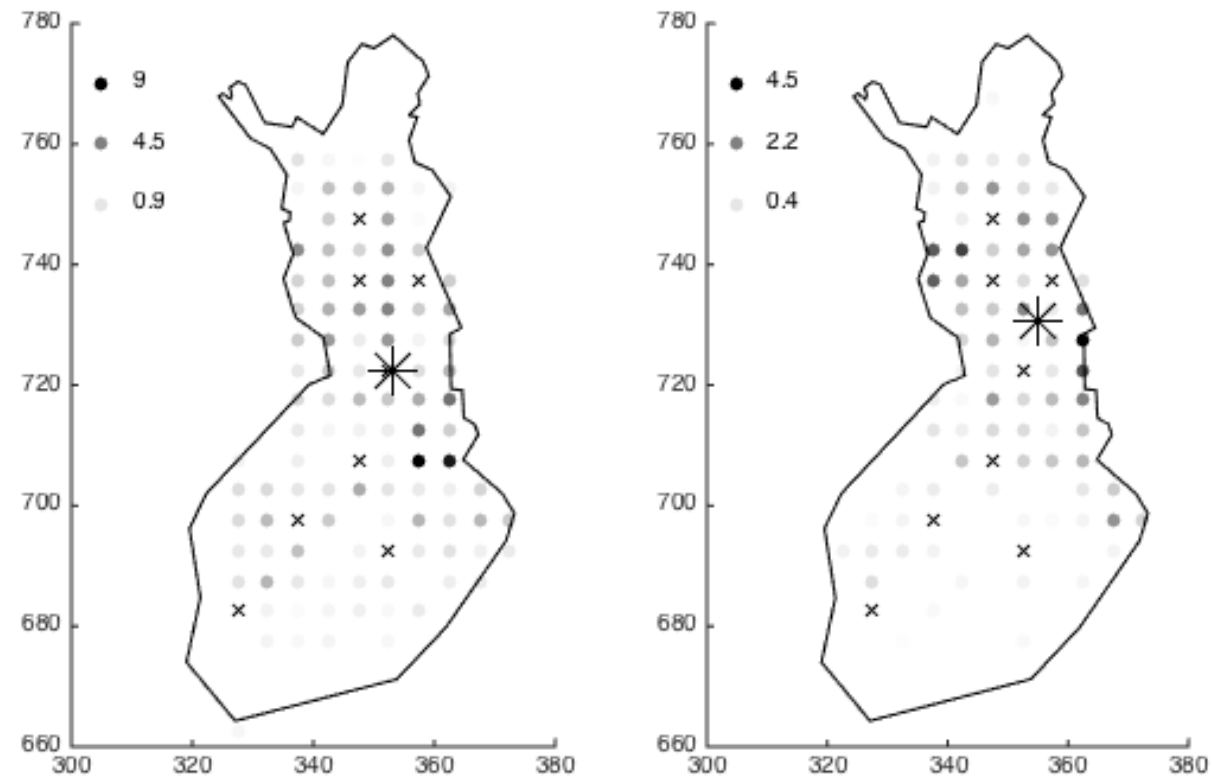

Supplementary fig. 126. Emberiza rustica 

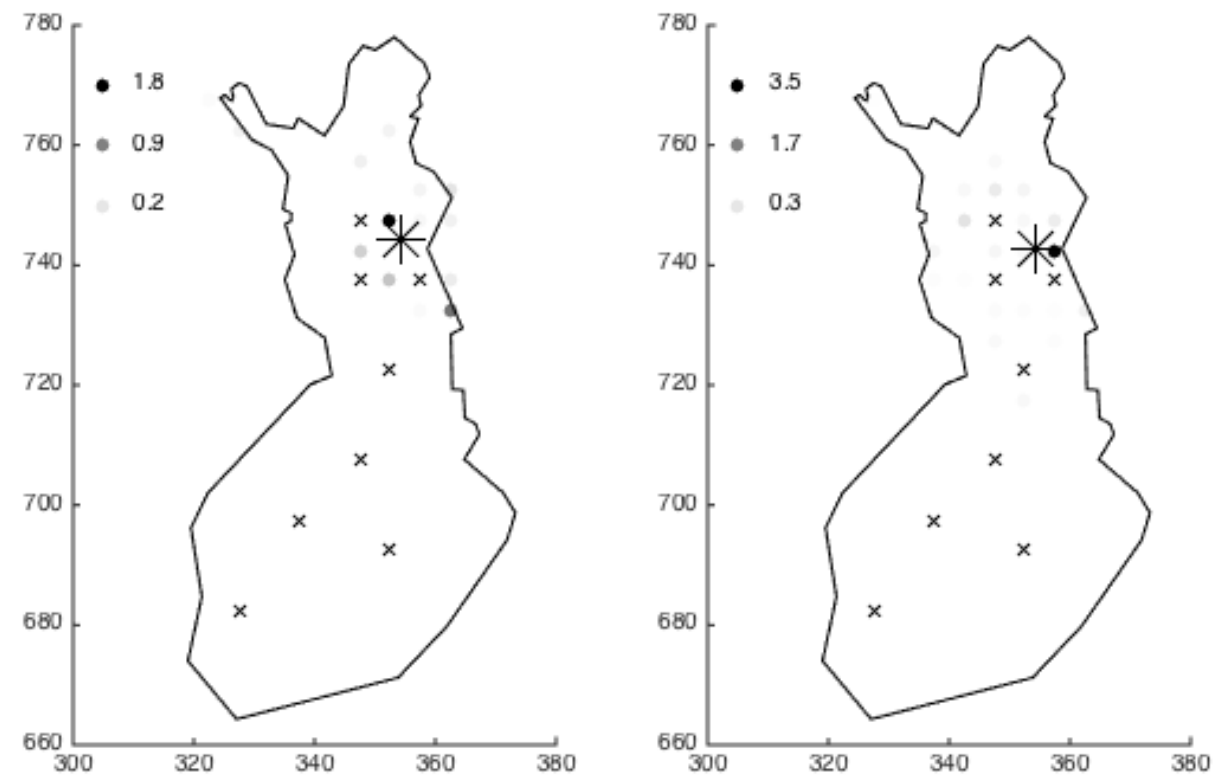

Supplementary fig. 127. Emberiza pusilla
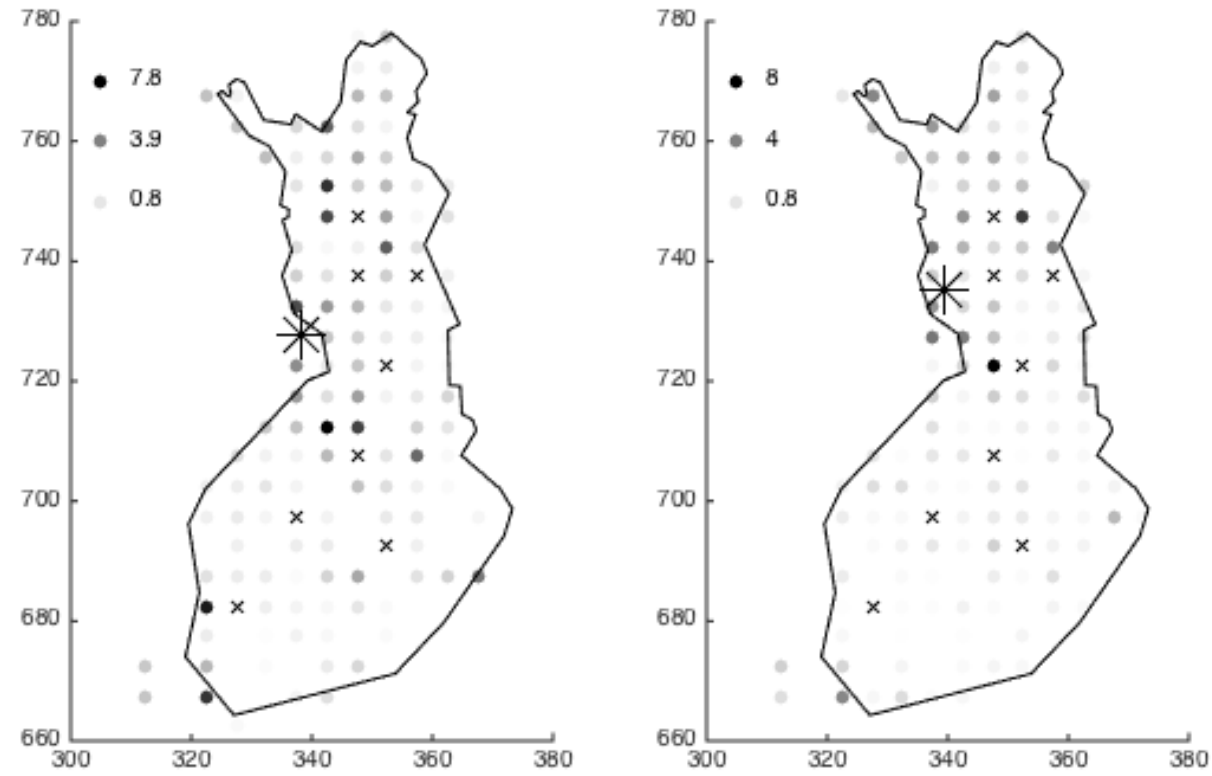

Supplementary fig. 128. Emberiza schoeniclus 


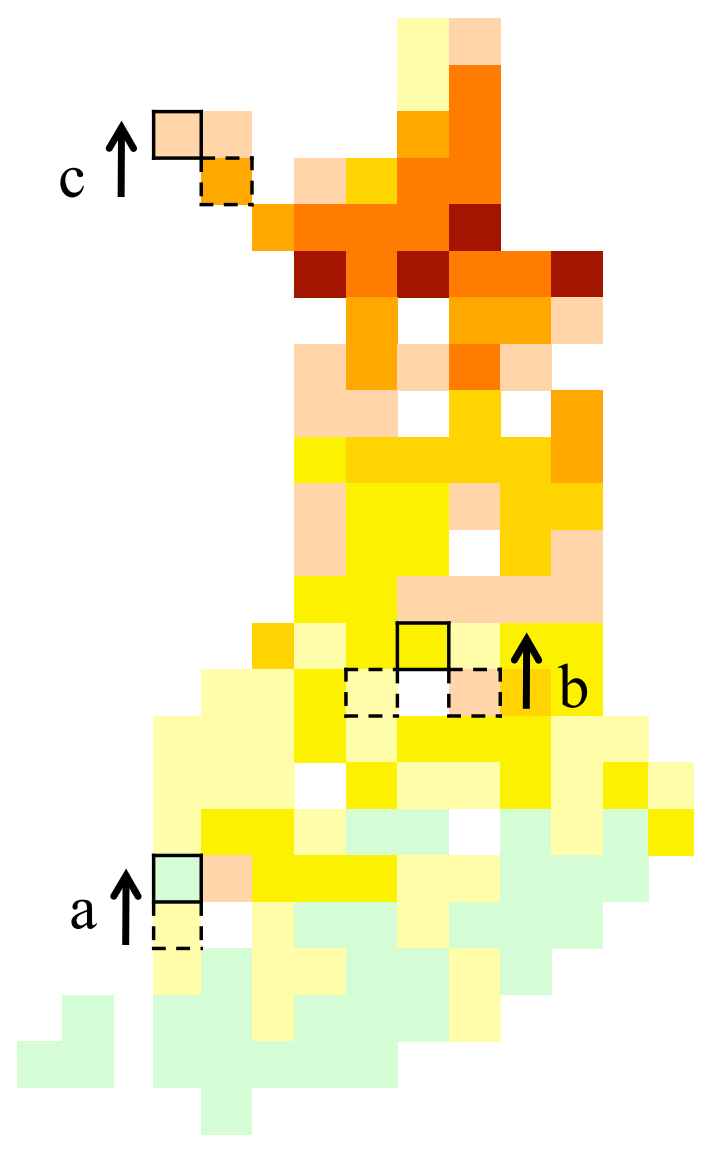

Supplementary Fig. 1. Illustration of how we moved densities of species one grid northwards to estimate the potential effect of shape of the country on the direction of density shifts. In a normal situation (a), the densities were moved one grid northwards. In situations, where the density value was missing from the southern side (b), we used mean of the nearest southwest and southeast grids, or only one of them (c) if both values were not available. The dashed line grids in the figure illustrate the former situation and the solid line grids represents the corresponding grids after the moved densities in Brambling Fringilla montifringilla (see also Supplementary Figs 1-129). In case of examples $b$ and $c$, the densities in the dashed grids were also moved directly northwards like in case a. 

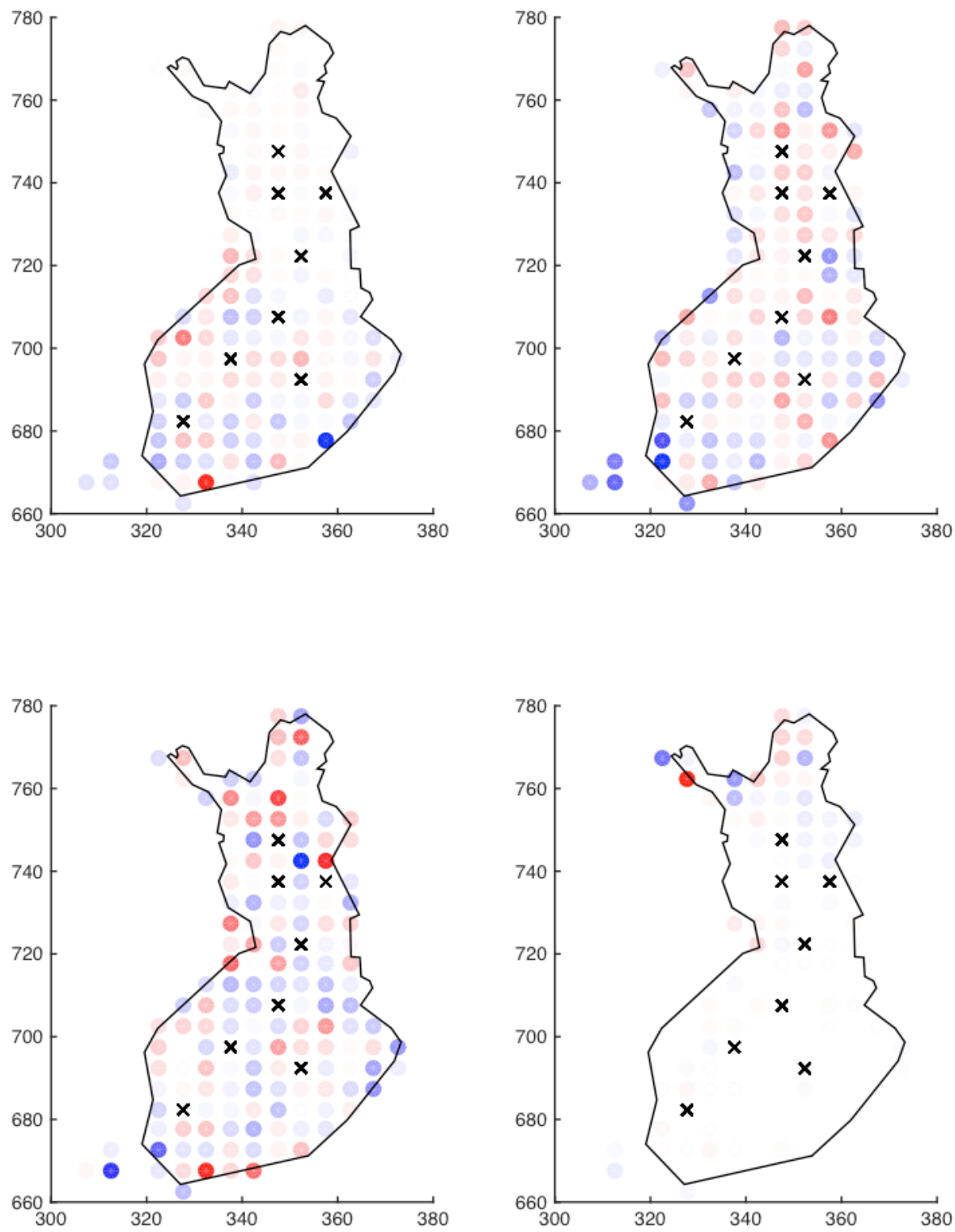

Supplementary Fig. 130. Grid specific changes of relative densities of groups of species classified based on their main habitat type: (a) farmland species, (b) forest species, (c) wetland species and (d) montane species. In graphs the species-specific relative densities have been scaled into the same unit in all species so that all species would have equal impact (in contrast to a situation where the most abundant species would dominate the change) corresponding direction analyses (Fig. 1). These grid specific relative densities of species in the first period were subtracted from the corresponding densities 
of the latter period. These density changes of the same habitat category were combined gridspecifically and are expressed in colours. Red colour means increasing relative densities and blue declining relative densities. The black crosses show grids without data. 

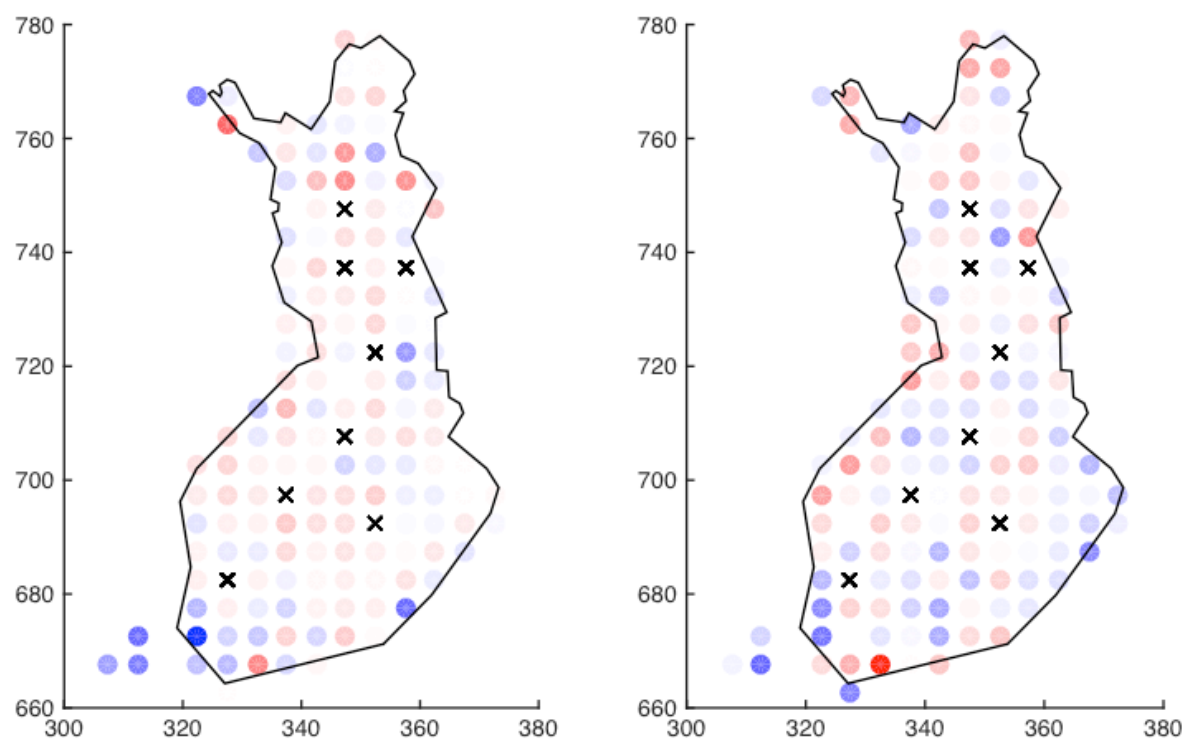

Supplementary Fig. 131. Grid specific changes of relative densities of groups of species classified based on their migration type: (a) residents and partial migrants and (b) short- and long-distance migrants. In graphs the species-specific relative densities have been scaled into the same unit in all species so that all species would have equal impact (in contrast to a situation where the most abundant species would dominate the change) corresponding direction analyses (Fig. 1). These grid-specific relative densities of species in the first period were subtracted from the corresponding densities of the latter period. These density changes of the same migration category were combined grid-specifically 
and are expressed in colours. Red colour means increasing relative densities and blue declining relative densities. The black crosses show grids without data. 
a) Residents

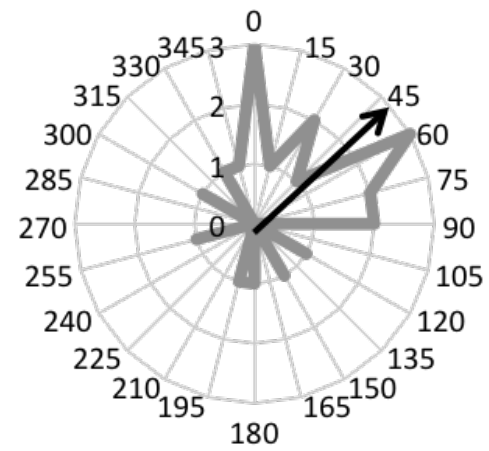

b) Partial migrants

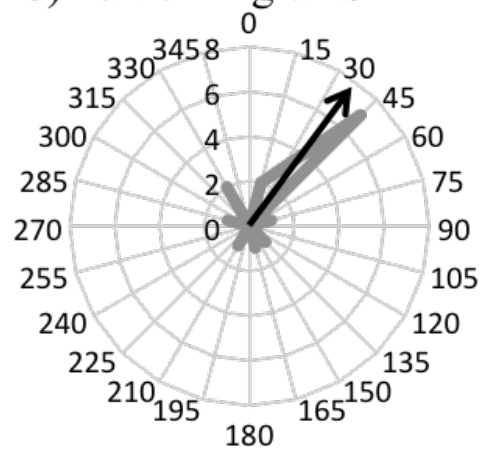

c) Short-distance migrants

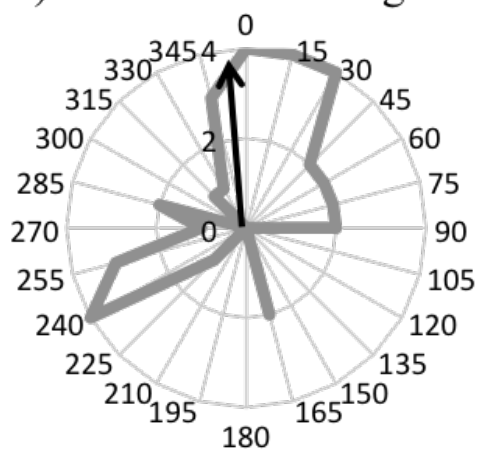

d) Long-distance migrants

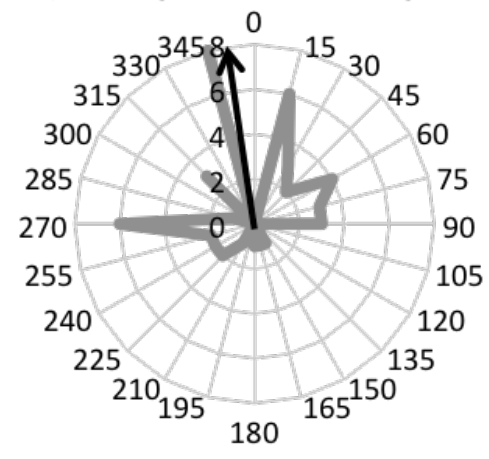

Supplementary Fig. 132. Distribution of directions of changes in densities based on four migration groups (resident: $\alpha=43$, partial: $\alpha=35$, short-distance: $\alpha=359$, and long-distance migrants: $\alpha=357$ ), 
Supplementary Table 1. Species-specific sample sizes (N 70-80, N 2000), habitat (Hab), migration (Mig, Mdir) and distribution (Dist) classifications, central gravity of density expressed as latitudes (La70-80, La00) and longitudes (Lo70-80, La00) during both study periods, direction of the density shift (Dir in degrees), total distance of shift (Dist2), density shift along latitude (Ndist) and longitude (Edist) directions (negative values mean shifts towards south and west, respectively) and direction of the species-specific temperature shift. Bolded values in density shifts along latitude and longitude mean that separate Poisson regression analyses of the particular species

revealed significant shift in latitude or longitude after Bonferroni correction (note that this is different than changes in the mean central gravity, see more accurately in the

\begin{tabular}{|c|c|c|c|c|c|c|c|c|c|c|c|c|c|c|c|}
\hline Species & N 70-80 & N 2000 & $\mathrm{Hab}$ & Mig & Mdir & Dist & La70-80 & La00 & Lo70-80 & Lo00 & Dir (Deg) & Dist2 & Ndist & Edist & Tdir (Deg) \\
\hline Tetrastes bonasia & 462 & 868 & 2 & 0 & 4 & 2 & 692.9 & 701.4 & 342.9 & 347.9 & 30.3 & 99.1 & 85.6 & 50.1 & 25.2 \\
\hline Lagopus lagopus & 267 & 293 & 2 & 0 & 4 & 2 & 751.0 & 756.4 & 343.8 & 343.2 & 353.4 & 54.8 & 54.4 & -6.3 & 350.1 \\
\hline Lagopus muta & 43 & 41 & 4 & 0 & 4 & 3 & 766.2 & 763.5 & 324.9 & 326.1 & 155.6 & 29.7 & -27.0 & 12.3 & 325.9 \\
\hline Tetrao tetris & 1048 & 1916 & 2 & 0 & 4 & 2 & 699.0 & 708.9 & 334.2 & 344.1 & 45.3 & 139.8 & 98.4 & 99.4 & 21.3 \\
\hline Tetrao urogallus & 228 & 418 & 2 & 0 & 4 & 2 & 714.6 & 714.9 & 347.9 & 352.1 & 85.9 & 42.3 & 3.0 & 42.2 & 14.1 \\
\hline Phasianus colchicus & 384 & 515 & 1 & 0 & 4 & 2 & 671.6 & 683.5 & 330.3 & 330.2 & 359.4 & 119.5 & 119.5 & -1.3 & 38.0 \\
\hline Pernis apivorus & 22 & 36 & 2 & 1 & 2 & 2 & 689.9 & 690.8 & 351.4 & 340.9 & 274.6 & 105.9 & 8.6 & -105.5 & 19.4 \\
\hline Circus cyaneus & 45 & 44 & 3 & 1 & 1 & 2 & 725.5 & 713.7 & 350.2 & 341.2 & 217.6 & 148.0 & -117.3 & -90.3 & 9.5 \\
\hline Accipiter gentilis & 60 & 59 & 2 & 0 & 4 & 2 & 699.1 & 702.2 & 334.9 & 335.6 & 11.5 & 31.4 & 30.8 & 6.3 & 30.3 \\
\hline Accipiter nisus & 40 & 70 & 2 & 1 & 1 & 2 & 698.7 & 701.3 & 323.9 & 338.8 & 80.1 & 151.0 & 25.9 & 148.7 & 24.6 \\
\hline Buteo buteo & 98 & 66 & 2 & 1 & 4 & 2 & 698.9 & 684.1 & 348.7 & 334.3 & 224.1 & 206.1 & -148.1 & -143.3 & 22.2 \\
\hline Buteo lagopus & 96 & 66 & 2 & 0 & 3 & 3 & 763.0 & 767.0 & 341.4 & 346.5 & 51.9 & 64.8 & 40.0 & 51.0 & 309.6 \\
\hline Pandion haliaetus & 41 & 54 & 2 & 1 & 2 & 2 & 685.8 & 704.2 & 333.3 & 347.2 & 37.0 & 230.3 & 183.9 & 138.7 & 18.3 \\
\hline Falco tinnunculus & 39 & 121 & 1 & 1 & 1 & 2 & 701.3 & 728.1 & 338.7 & 343.5 & 10.0 & 271.9 & 267.7 & 47.4 & 22.8 \\
\hline Falco columbarius & 21 & 32 & 2 & 1 & 1 & 2 & 745.3 & 763.9 & 333.1 & 339.2 & 18.2 & 195.5 & 185.7 & 61.2 & 333.2 \\
\hline Falco subbuteo & 21 & 52 & 2 & 1 & 2 & 2 & 697.8 & 690.4 & 352.7 & 342.1 & 235.6 & 129.4 & -73.1 & -106.7 & 22.5 \\
\hline Grus grus & 330 & 1696 & 3 & 1 & 2 & 2 & 710.2 & 708.4 & 344.0 & 333.7 & 260.3 & 105.2 & -17.8 & -103.7 & 20.8 \\
\hline Haematopus ostralegus & 31 & 102 & 3 & 1 & 1 & 1 & 674.1 & 689.5 & 312.4 & 317.3 & 17.7 & 161.6 & 153.9 & 49.1 & 33.8 \\
\hline Charadrius hiaticula & 34 & 69 & 4 & 1 & 1 & 2 & 754.8 & 758.8 & 330.2 & 337.5 & 61.1 & 82.9 & 40.0 & 72.6 & 310.7 \\
\hline Pluvialis apricaria & 1139 & 1237 & 4 & 1 & 1 & 2 & 760.6 & 759.5 & 347.8 & 342.5 & 258.8 & 54.3 & -10.6 & -53.3 & 355.1 \\
\hline Vanellus vanellus & 1308 & 2201 & 1 & 1 & 1 & 2 & 691.8 & 691.6 & 338.3 & 331.9 & 267.9 & 64.0 & -2.3 & -64.0 & 25.6 \\
\hline Calidris pugnax & 407 & 156 & 3 & 1 & 1 & 3 & 746.3 & 750.2 & 344.5 & 345.6 & 15.6 & 40.2 & 38.8 & 10.8 & 351.0 \\
\hline Calidris falcinellus & 114 & 206 & 3 & 1 & 3 & 3 & 751.1 & 752.1 & 339.4 & 343.4 & 76.3 & 41.4 & 9.8 & 40.2 & 328.1 \\
\hline Lymnocryptes minumus & 205 & 172 & 3 & 0 & 1 & 3 & 754.1 & 752.6 & 346.5 & 345.7 & 207.8 & 17.0 & -15.0 & -7.9 & 334.4 \\
\hline Gallinago gallinago & 1836 & 2146 & 3 & 1 & 1 & 2 & 723.7 & 729.8 & 338.2 & 342.2 & 33.3 & 72.5 & 60.6 & 39.7 & 12.6 \\
\hline Scolopax rusticola & 158 & 440 & 2 & 1 & 1 & 2 & 690.7 & 691.5 & 327.3 & 334.1 & 83.4 & 67.6 & 7.8 & 67.2 & 28.9 \\
\hline Numenius phaeopus & 1130 & 755 & 3 & 1 & 1 & 2 & 744.7 & 755.3 & 353.9 & 350.1 & 340.2 & 112.5 & 105.9 & -38.2 & 352.0 \\
\hline Numenius arquata & 1734 & 2744 & 1 & 1 & 1 & 2 & 703.5 & 705.6 & 341.4 & 341.5 & 4.1 & 21.1 & 21.0 & 1.5 & 26.5 \\
\hline Tringa erythropus & 222 & 135 & 3 & 1 & 2 & 3 & 758.8 & 756.6 & 345.7 & 347.1 & 148.2 & 26.0 & -22.1 & 13.7 & 332.2 \\
\hline Tringa totanus & 313 & 342 & 3 & 1 & 1 & 2 & 701.5 & 712.6 & 316.0 & 320.9 & 23.5 & 121.3 & 111.3 & 48.4 & 35.6 \\
\hline Tringa nebularia & 737 & 1284 & 3 & 1 & 2 & 2 & 733.1 & 730.1 & 355.1 & 352.8 & 217.3 & 38.8 & -30.8 & -23.5 & 4.0 \\
\hline
\end{tabular}


Tringa ochropus

Tringa glareola

Actitis hypoleucos

Phalaropus lobatus

Stercorarius longicaudus

Columba livia

Columba oenas

Columba palumbus

Cuculus canorus

Surnia ulula

Asio flammeus

Apus apus

Jynx torquilla

Picus canus

Dryocopus martius

Dendrocopos major

Dendrocopos minor

Picoides tridactylus

Lullula arborea

Alauda arvensis

Riparia riparia

Hirundo rustica

Delichon urbicum

Anthus trivialis

Anthus prantensis

Motacilla flava

Motacilla alba

Bombycilla garrulus

Troglodytes troglodytes

Prunella modularis

Erithacus rubecula

Luscinia luscinia

Luscinia svecica

Phoenicurus phoenicurus

Saxicola rubetra

Oenanthe oenanthe

Turdus torquatus

$\begin{array}{rrlll}683 & 2394 & 2 & 1 & 1 \\ 2970 & 3803 & 3 & 1 & 2 \\ 303 & 356 & 3 & 1 & 2 \\ 85 & 34 & 3 & 1 & 3 \\ 33 & 49 & 4 & 1 & 1 \\ 102 & 561 & 1 & 0 & 4 \\ 382 & 302 & 1 & 1 & 1 \\ 3682 & 8195 & 1 & 1 & 1 \\ 4650 & 7760 & 2 & 1 & 2 \\ 27 & 25 & 2 & 0 & 4 \\ 66 & 69 & 3 & 1 & 1 \\ 1231 & 2086 & 1 & 1 & 2 \\ 376 & 206 & 2 & 1 & 1 \\ 29 & 36 & 2 & 0 & 4 \\ 270 & 1043 & 2 & 0 & 4 \\ 1326 & 3648 & 2 & 0 & 4 \\ 30 & 37 & 2 & 0 & 4 \\ 74 & 148 & 2 & 0 & 4 \\ 31 & 101 & 2 & 1 & 1 \\ 3912 & 3581 & 1 & 1 & 1 \\ 341 & 532 & 3 & 1 & 2 \\ 1552 & 1761 & 1 & 1 & 2 \\ 1031 & 758 & 1 & 1 & 2 \\ 15580 & 18958 & 2 & 1 & 2 \\ 5147 & 4754 & 3 & 1 & 1 \\ 4301 & 2805 & 3 & 1 & 1 \\ 2283 & 3315 & 3 & 1 & 2 \\ 73 & 611 & 2 & 0 & 4 \\ 289 & 1371 & 2 & 1 & 1 \\ 2260 & 4949 & 2 & 1 & 1 \\ 5127 & 16046 & 2 & 1 & 1 \\ 288 & 574 & 3 & 1 & 2 \\ 862 & 930 & 4 & 1 & 3 \\ 4109 & 7841 & 2 & 1 & 1 \\ 1687 & 1601 & 1 & 1 & 1 \\ 1467 & 594 & 3 & 1 & 1 \\ 25 & 35 & 4 & 1 & 1 \\ & & & & \end{array}$

$\begin{array}{ll}689.6 & 697.4 \\ 740.9 & 747.5 \\ 707.6 & 722.5 \\ 758.9 & 762.1 \\ 767.2 & 773.4 \\ 674.9 & 687.5 \\ 670.1 & 670.3 \\ 686.7 & 686.4 \\ 710.5 & 711.0 \\ 740.5 & 744.3 \\ 740.4 & 753.8 \\ 684.3 & 688.8 \\ 696.7 & 707.1 \\ 669.1 & 673.7 \\ 688.6 & 694.0 \\ 694.8 & 702.4 \\ 688.9 & 680.8 \\ 735.7 & 730.6 \\ 668.1 & 666.3 \\ 684.8 & 685.5 \\ 714.5 & 713.3 \\ 693.3 & 693.3 \\ 687.2 & 697.1 \\ 700.5 & 701.3 \\ 750.6 & 755.3 \\ 735.2 & 748.7 \\ 696.7 & 695.2 \\ 737.8 & 741.9 \\ 678.4 & 684.0 \\ 686.7 & 693.0 \\ 688.4 & 695.8 \\ 673.3 & 672.3 \\ 764.7 & 768.4 \\ 730.3 & 735.8 \\ 703.4 & 711.2 \\ 738.1 & 747.3 \\ 769.9 & 768.5\end{array}$

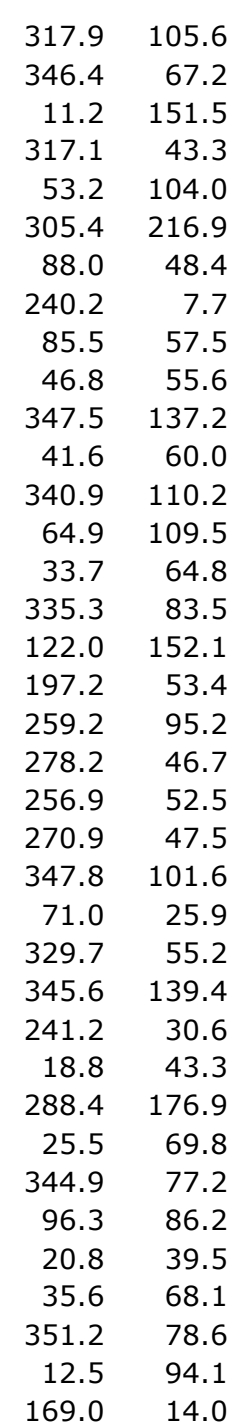

$\begin{array}{llr}\mathbf{7 8 . 3} & -70.8 & 23.2 \\ 65.3 & -15.8\end{array}$

$\begin{array}{lrrr}78.2 & 65.3 & -15.8 & 7.0\end{array}$

$\begin{array}{lllrrrr}336.1 & 339.1 & 11.2 & 151.5 & 148.6 & 29.5 & 16.5\end{array}$

$\begin{array}{lllllll}341.0 & 338.1 & 317.1 & 43.3 & \mathbf{3 1 . 7} & -29.5 & 326.1\end{array}$

$\begin{array}{lllllll}338.6 & 346.9 & 53.2 & 104.0 & \mathbf{6 2 . 3} & 83.3 & 326.4\end{array}$

$\begin{array}{lllllll}347.3 & 329.6 & 305.4 & 216.9 & 125.7 & -176.8 & 20.9\end{array}$

$\begin{array}{rrrrrrr}314.2 & 319.1 & 88.0 & 48.4 & 1.7 & 48.4 & 41.9\end{array}$

$\begin{array}{lllllll}330.9 & 330.2 & 240.2 & 7.7 & \mathbf{- 3 . 8} & \mathbf{- 6 . 7} & 28.2\end{array}$

$\begin{array}{lllllll}339.5 & 345.2 & 85.5 & 57.5 & \mathbf{4 . 5} & \mathbf{5 7 . 4} & 14.0\end{array}$

$\begin{array}{lllllll}345.9 & 349.9 & 46.8 & 55.6 & 38.1 & 40.5 & 327.5\end{array}$

$\begin{array}{lllrrrr}343.5 & 340.6 & 347.5 & 137.2 & \mathbf{1 3 4 . 0} & -29.7 & 357.5\end{array}$

$\begin{array}{lllllll}331.7 & 335.7 & 41.6 & 60.0 & \mathbf{4 4 . 9} & 39.8 & 26.9\end{array}$

$104.1-36.1-17.2$

$\begin{array}{lllllll}317.6 & 327.6 & 64.9 & 109.5 & 46.5 & 99.1 & 38.2\end{array}$

$\begin{array}{lllllll}330.5 & 334.1 & 33.7 & 64.8 & \mathbf{5 3 . 9} & 35.9 & 18.1\end{array}$

$\begin{array}{lllllll}341.8 & 338.3 & 335.3 & 83.5 & \mathbf{7 5 . 8} & -34.9 & 26.1\end{array}$

$\begin{array}{lllllll}321.4 & 334.3 & 122.0 & 152.1 & -80.5 & 129.0 & 27.8\end{array}$

$\begin{array}{lllllll}351.5 & 349.9 & 197.2 & 53.4 & -51.0 & -15.8 & 337.5\end{array}$

$\begin{array}{lllllll}325.4 & 316.1 & 259.2 & 95.2 & -17.8 & \mathbf{- 9 3 . 5} & 34.6\end{array}$

$6.7-46.2$

$\begin{array}{lllllll}353.7 & 348.5 & 256.9 & 52.5 & -11.9 & -51.2 & 16.2\end{array}$

$\begin{array}{llllrrr}339.7 & 334.9 & 270.9 & 47.5 & \mathbf{0 . 7} & -47.5 & 26.9\end{array}$

$\begin{array}{lllllll}338.1 & 336.0 & 347.8 & 101.6 & 99.4 & -21.4 & 26.0\end{array}$

8.424 .4

$\begin{array}{rrrrrrr}343.4 & 340.6 & 329.7 & 55.2 & \mathbf{4 7 . 7} & \mathbf{- 2 7 . 8} & 8.7\end{array}$

$\begin{array}{lllllll}349.0 & 345.5 & 345.6 & 139.4 & \mathbf{1 3 5 . 0} & -34.7 & 12.0\end{array}$

$\begin{array}{lllllll}335.2 & 332.6 & 241.2 & 30.6 & \mathbf{- 1 4 . 7} & \mathbf{- 2 6 . 8} & 16.9\end{array}$

$\begin{array}{rrrrrrr}353.6 & 355.0 & 18.8 & 43.3 & \mathbf{4 1 . 0} & 14.0 & 326.3\end{array}$

$\begin{array}{lllllll}347.0 & 330.3 & 288.4 & 176.9 & \mathbf{5 5 . 9} & -167.8 & 22.5\end{array}$

$\begin{array}{llll}69.8 & \mathbf{6 3 . 0} & \mathbf{3 0 . 1} & 23.2\end{array}$

$\begin{array}{lllllll}338.7 & 336.7 & 344.9 & 77.2 & \mathbf{7 4 . 5} & -20.1 & 23.1\end{array}$

$\begin{array}{lllllll}325.5 & 334.0 & 96.3 & 86.2 & \mathbf{- 9 . 5} & 85.7 & 31.5\end{array}$

$\mathbf{3 6 . 9} \quad 14.0 \quad 312.3$

$\begin{array}{llll}68.1 & \mathbf{5 5 . 4} & 39.6 & 14.1\end{array}$

$\begin{array}{rrrrrrr}336.7 & 338.7 & 12.5 & 94.1 & \mathbf{9 1 . 9} & 20.4 & 12.0\end{array}$

$\begin{array}{lllllll}326.1 & 326.4 & 169.0 & 14.0 & -13.8 & 2.7 & 331.0\end{array}$ 
Turdus merula

Turdus pilaris

Turdus philomelos

Turdus iliacus

Turdus viscivorus

Locustella naevia

Acrocephalus schoenobaenus

Acrocephalus dumetorum

Acrocephalus palustris

Acrocephalus scirpaceus

Hippolais icterina

Sylvia curruca

Sylvia communis

Sylvia borin

Sylvia atricapilla

Phylloscopus trochiloides

Phylloscopus sibilatrix

Phylloscopus collybita

Phylloscopus trochilus

Regulus regulus

Muscicapa striata

Ficedula parva

Ficedula hypoleuca

Poecile montanus

Poecile cinctus

Lophophanes cristatus

Periparus ater

Cyanistes caeruleus

Parus major

Certhia familiaris

Oriolus oriolus

Lanius collurio

Lanius excubitor

Garrulus glandarius

Perisoreus infaustus

Pica pica

Corvus monedula

$\begin{array}{rrrll}2108 & 6764 & 2 & 0 & 1 \\ 5173 & 13779 & 1 & 1 & 1 \\ 6892 & 13336 & 2 & 1 & 1 \\ 12476 & 14609 & 2 & 1 & 1 \\ 448 & 1675 & 2 & 1 & 2 \\ 20 & 39 & 3 & 1 & 1 \\ 1234 & 1691 & 3 & 1 & 2 \\ 51 & 176 & 3 & 1 & 3 \\ 39 & 86 & 3 & 1 & 2 \\ 349 & 265 & 3 & 1 & 1 \\ 164 & 182 & 2 & 1 & 2 \\ 1467 & 2885 & 2 & 1 & 2 \\ 1939 & 3147 & 1 & 1 & 2 \\ 6484 & 9260 & 2 & 1 & 2 \\ 628 & 1334 & 2 & 1 & 2 \\ 88 & 216 & 2 & 1 & 3 \\ 2475 & 1966 & 2 & 1 & 1 \\ 2430 & 3336 & 2 & 1 & 2 \\ 58187 & 76890 & 2 & 1 & 2 \\ 3122 & 5344 & 2 & 0 & 1 \\ 4340 & 6815 & 2 & 1 & 2 \\ 43 & 125 & 2 & 1 & 3 \\ 3157 & 6607 & 2 & 1 & 1 \\ 2744 & 3700 & 2 & 0 & 4 \\ 223 & 152 & 2 & 0 & 4 \\ 1071 & 2169 & 2 & 0 & 4 \\ 398 & 690 & 2 & 0 & 1 \\ 442 & 4257 & 2 & 0 & 1 \\ 3815 & 13145 & 2 & 0 & 1 \\ 523 & 1245 & 2 & 0 & 1 \\ 98 & 37 & 2 & 1 & 2 \\ 352 & 335 & 1 & 1 & 2 \\ 38 & 51 & 2 & 1 & 1 \\ 534 & 936 & 2 & 0 & 4 \\ 264 & 339 & 2 & 0 & 4 \\ 1397 & 2978 & 1 & 0 & 4 \\ 452 & 2663 & 1 & 0 & 1 \\ & & & & \end{array}$

$\begin{array}{rrrr}319.0 & 324.9 & 49.4 & 77.5 \\ 339.4 & 338.9 & 351.6 & 33.5 \\ 335.4 & 339.8 & 38.1 & 70.3 \\ 341.4 & 342.7 & 7.1 & 106.2 \\ 333.2 & 336.4 & 68.6 & 34.5 \\ 337.2 & 337.8 & 8.0 & 43.4 \\ 339.9 & 332.8 & 273.0 & 71.1 \\ 363.6 & 352.0 & 249.8 & 124.2 \\ 331.0 & 316.7 & 265.3 & 144.0 \\ 315.5 & 316.9 & 97.0 & 14.0 \\ 321.2 & 324.9 & 50.8 & 47.7 \\ 338.7 & 334.7 & 283.3 & 41.7 \\ 329.0 & 328.3 & 273.3 & 7.5 \\ 337.2 & 340.5 & 66.6 & 35.5 \\ 317.4 & 316.8 & 229.1 & 7.3 \\ 348.1 & 341.9 & 246.9 & 67.8 \\ 342.1 & 343.9 & 33.0 & 32.1 \\ 330.9 & 332.3 & 34.2 & 25.4 \\ 343.2 & 342.3 & 349.0 & 47.9 \\ 330.2 & 331.0 & 9.0 & 50.7 \\ 337.3 & 340.4 & 65.8 & 33.6 \\ 330.2 & 353.8 & 64.0 & 262.6 \\ 337.1 & 338.2 & 166.7 & 48.6 \\ 333.4 & 346.2 & 55.7 & 155.0 \\ 345.6 & 348.1 & 59.4 & 28.7 \\ 329.8 & 342.0 & 82.8 & 122.6 \\ 312.6 & 327.7 & 79.1 & 154.1 \\ 319.1 & 327.7 & 39.7 & 134.6 \\ 329.0 & 332.6 & 34.5 & 62.2 \\ 323.7 & 330.5 & 39.0 & 109.2 \\ 352.3 & 350.1 & 274.2 & 22.1 \\ 329.9 & 336.3 & 74.6 & 67.0 \\ 346.8 & 348.9 & 60.4 & 23.7 \\ 334.6 & 338.1 & 74.0 & 36.5 \\ 351.8 & 348.8 & 340.0 & 88.3 \\ 337.4 & 333.2 & 252.1 & 43.6 \\ 316.8 & 322.7 & 44.8 & 84.8\end{array}$

$\begin{array}{rrr}\mathbf{5 0 . 5} & \mathbf{5 8 . 8} & 32.2 \\ \mathbf{3 3 . 1} & -4.9 & 16.1 \\ \mathbf{5 5 . 3} & \mathbf{4 3 . 3} & 17.3 \\ 105.4 & 13.2 & 13.7 \\ 12.6 & 32.1 & 16.2 \\ 43.0 & 6.0 & 22.4 \\ 3.8 & -71.0 & 18.5 \\ \mathbf{- 4 2 . 9} & -116.6 & 17.1 \\ \mathbf{- 1 1 . 8} & -143.5 & 19.8 \\ \mathbf{- 1 . 7} & 13.9 & 33.7 \\ \mathbf{3 0 . 1} & 36.9 & 25.9 \\ \mathbf{9 . 6} & -40.6 & 27.4 \\ \mathbf{0 . 4} & -7.5 & 30.1 \\ \mathbf{1 4 . 1} & 32.6 & 26.9 \\ \mathbf{- 4 . 8} & -\mathbf{5 . 5} & 31.6 \\ \mathbf{- 2 6 . 6} & -62.3 & 22.4 \\ \mathbf{2 6 . 9} & 17.4 & 26.7 \\ \mathbf{2 1 . 0} & 14.3 & 29.3 \\ 47.0 & -9.1 & 13.7 \\ \mathbf{5 0 . 1} & 8.0 & 26.0 \\ \mathbf{1 3 . 8} & 30.6 & 16.9 \\ \mathbf{1 1 5 . 2} & 235.9 & 31.4 \\ \mathbf{- 4 7 . 3} & 11.2 & 16.7 \\ \mathbf{8 7 . 4} & 128.0 & 18.7 \\ \mathbf{1 4 . 6} & 24.7 & 316.0 \\ \mathbf{1 5 . 3} & 121.6 & 28.8 \\ \mathbf{2 9 . 0} & 151.3 & 34.5 \\ \mathbf{1 0 3 . 6} & 85.9 & 25.6 \\ \mathbf{5 1 . 2} & 35.2 & 21.1 \\ \mathbf{8 4 . 8} & 68.8 & 25.9 \\ 1.6 & -22.0 & 25.3 \\ \mathbf{1 7 . 8} & \mathbf{6 4 . 6} & 27.9 \\ 11.7 & 20.6 & 359.3 \\ \mathbf{1 0 . 1} & 35.1 & 31.3 \\ \mathbf{8 3 . 0} & -30.1 & 334.6 \\ \mathbf{- 1 3 . 4} & -41.5 & 19.6 \\ \mathbf{6 0 . 2} & \mathbf{5 9 . 7} & 36.6 \\ & & \end{array}$




\begin{tabular}{|c|c|c|c|c|c|c|c|c|c|c|c|c|c|c|c|}
\hline Corvus corone & 4179 & 5956 & 1 & 0 & 1 & 2 & 698.8 & 697.8 & 331.4 & 331.6 & 166.5 & 10.0 & -9.7 & 2.3 & 15.6 \\
\hline Corvus corax & 448 & 1129 & 2 & 0 & 4 & 2 & 734.2 & 715.8 & 336.1 & 336.9 & 177.3 & 184.5 & -184.3 & 8.8 & 11.4 \\
\hline Sturnus vulgaris & 2120 & 1165 & 1 & 1 & 1 & 2 & 680.7 & 675.2 & 328.9 & 319.2 & 240.3 & 111.2 & -55.0 & -96.6 & 29.2 \\
\hline Passer domesticus & 1291 & 3970 & 1 & 0 & 4 & 2 & 683.6 & 697.8 & 333.4 & 331.8 & 353.7 & 142.4 & 141.5 & -15.7 & 25.2 \\
\hline Fringilla coelebs & 40860 & 72779 & 2 & 1 & 1 & 2 & 688.0 & 691.5 & 335.4 & 338.5 & 42.1 & 46.6 & 34.5 & 31.2 & 20.3 \\
\hline Fringilla montifringilla & 17398 & 13105 & 2 & 1 & 1 & 2 & 747.8 & 754.1 & 348.1 & 347.4 & 353.7 & 64.0 & 63.6 & -7.0 & 8.2 \\
\hline Carduelis chloris & 575 & 5110 & 1 & 0 & 1 & 2 & 679.7 & 689.9 & 320.2 & 328.2 & 37.8 & 129.8 & 102.5 & 79.6 & 27.5 \\
\hline Carduelis spinus & 7562 & 20079 & 2 & 1 & 1 & 2 & 695.7 & 705.7 & 341.2 & 341.2 & 359.9 & 100.4 & 100.4 & -0.2 & 19.7 \\
\hline Carduelis cannabina & 101 & 180 & 1 & 1 & 1 & 1 & 679.0 & 674.5 & 321.9 & 323.0 & 166.7 & 47.1 & -45.8 & 10.8 & 33.6 \\
\hline Carduelis flammea & 6215 & 5976 & 2 & 0 & 3 & 2 & 749.3 & 756.5 & 348.8 & 343.9 & 325.5 & 87.0 & 71.7 & -49.2 & 4.4 \\
\hline Loxia leucoptera & 123 & 113 & 2 & 0 & 4 & 3 & 742.5 & 749.8 & 352.5 & 348.5 & 331.8 & 82.8 & 73.0 & -39.2 & 338.5 \\
\hline Loxia curvirostra & 1868 & 4196 & 2 & 0 & 4 & 2 & 694.9 & 710.3 & 334.2 & 344.8 & 34.3 & 186.7 & 154.2 & 105.2 & 17.8 \\
\hline Loxia pytyopsittacus & 213 & 295 & 2 & 0 & 4 & 2 & 712.2 & 713.6 & 337.4 & 342.0 & 72.7 & 47.9 & 14.2 & 45.7 & 13.2 \\
\hline Carpodacus erythrinus & 2177 & 1952 & 3 & 1 & 3 & 2 & 693.6 & 697.4 & 347.0 & 343.0 & 313.5 & 54.8 & 14.2 & 45.7 & 28.9 \\
\hline Pinicola enucleator & 107 & 62 & 2 & 0 & 4 & 3 & 757.1 & 753.1 & 347.3 & 351.8 & 131.5 & 60.8 & 37.7 & -39.7 & 319.5 \\
\hline Pyrrhula pyrrhula & 1169 & 2121 & 2 & 0 & 4 & 2 & 701.7 & 710.7 & 341.9 & 348.1 & 34.8 & 109.4 & -40.3 & 45.5 & 21.0 \\
\hline Calcarius lapponicus & 337 & 497 & 4 & 1 & 3 & 3 & 771.5 & 768.2 & 343.9 & 336.0 & 247.0 & 86.4 & 89.8 & 62.4 & 307.2 \\
\hline Plectrophenax nivalis & 92 & 97 & 4 & 1 & 3 & 3 & 763.8 & 765.6 & 328.8 & 326.6 & 308.9 & 28.5 & -33.8 & -79.5 & 325.9 \\
\hline Emberiza citrinella & 6044 & 9415 & 1 & 0 & 1 & 2 & 687.0 & 687.9 & 330.4 & 327.6 & 286.8 & 30.2 & 17.9 & -22.2 & 21.9 \\
\hline Emberiza hortulana & 1119 & 182 & 1 & 1 & 1 & 2 & 690.8 & 703.6 & 338.3 & 333.7 & 340.1 & 135.6 & 8.7 & -28.9 & 29.2 \\
\hline Emberiza rustica & 916 & 554 & 3 & 1 & 3 & 2 & 722.3 & 730.5 & 353.1 & 354.9 & 12.2 & 84.3 & 127.5 & -46.2 & 12.2 \\
\hline Emberiza pusilla & 77 & 106 & 3 & 1 & 3 & 3 & 744.2 & 742.6 & 354.4 & 354.4 & 180.5 & 16.5 & 82.4 & 17.8 & 319.6 \\
\hline Emberiza schoeniclus & 1907 & 2490 & 3 & 1 & 1 & 2 & 727.8 & 735.2 & 338.2 & 339.5 & 9.6 & 74.8 & -16.5 & -0.1 & 10.3 \\
\hline
\end{tabular}

